\title{
THE GENETICS OF BODY WEIGHT AND FEED EFFICIENCY IN BROILER CHICKENS
}

\section{WOSSENIE SHIBABAW MEBRATIE}

PhD THESIS · SCIENCE AND TECHNOLOGY $\cdot 2019$

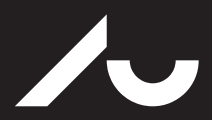

AARHUS UNIVERSITY

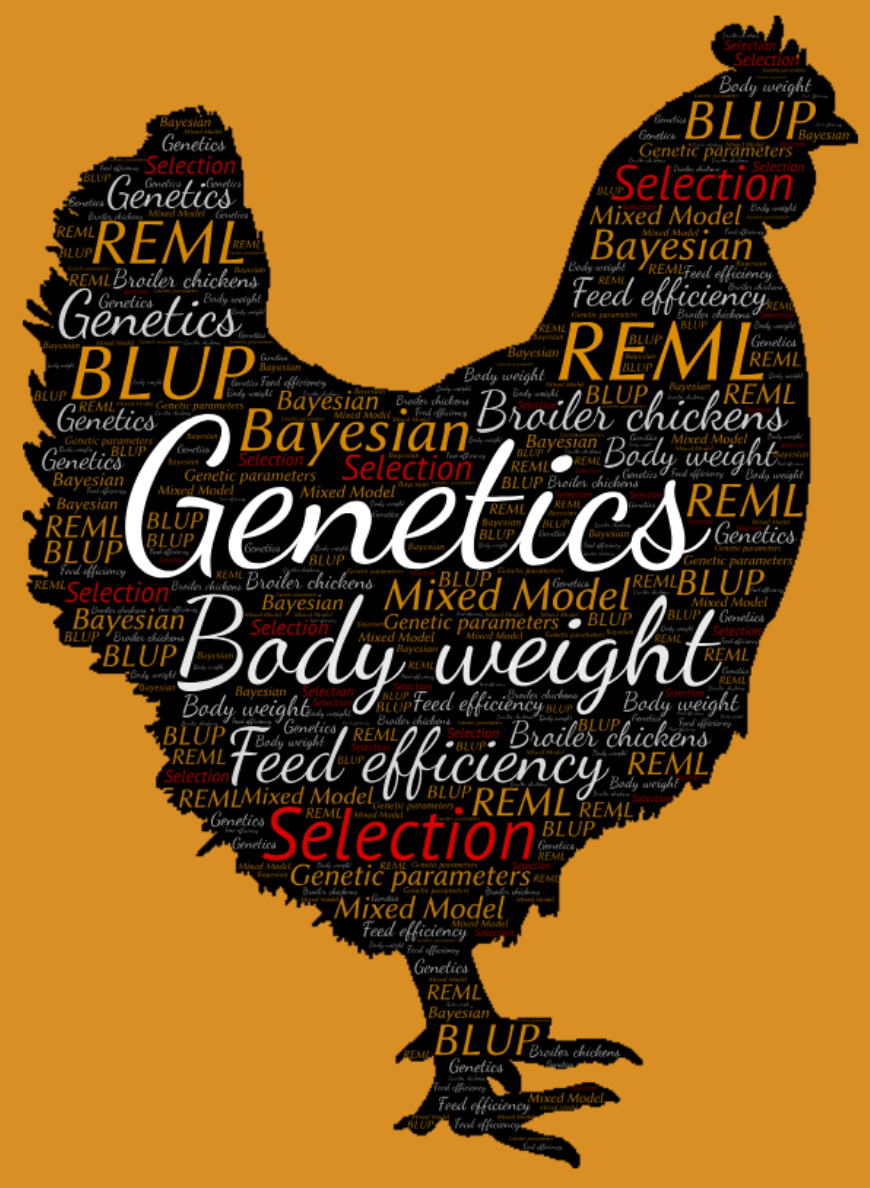




\section{THE GENETICS OF BODY WEIGHT AND FEED EFFICIENCY IN BROILER CHICIENS}

\section{WOSSENIE SHIBABAW MEBRATIE}

PhD THESIS · SCIENCE AND TECHNOLOGY • 2019

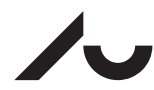

AARHUS UNIVERSITY

Blichers Allé 20

8830 Tjele

Denmark 
The genetics of body weight and feed efficiency in broiler chickens

Wossenie Shibabaw Mebratie 


\section{Supervisors committee in Aarhus University}

\section{Main supervisors}

Prof. Dr Just Jensen

Professor, Center for Quantitative Genetics and Genomics

Aarhus University, Tjele, Denmark

Prof. Dr Henk Bovenhuis

Personal chair at Animal Breeding and Genomics

Wageningen University \& Research, the Netherlands

This research was conducted under the joint auspices of the Graduate School of Science and Technology (GSST), Aarhus University, Denmark and the Graduate School of Wageningen Institute of Animal Sciences (WIAS), the Netherlands as part of the Erasmus Joint Doctorate Program "EGS-ABG". 


\section{Thesis committee Wageningen University}

\section{Promotor}

Prof. Dr Henk Bovenhuis

Personal chair at Animal Breeding and Genomics

Wageningen University \& Research, the Netherlands

\section{Co-promotor}

Prof. Dr Just Jensen

Professor, Center for Quantitative Genetics and Genomics

Aarhus University, Tjele, Denmark

\section{Other members}

Prof. Dr Samuel Aggrey, University of Georgia, USA

Prof. Dr MCM de Jong, Wageningen University \& Research, the Netherlands

Dr Marco Bink, Hendrix Genetics, the Netherlands

Dr Bernt Guldbrandtsen, Aarhus University, Denmark

This research was conducted under the joint auspices of the Graduate School of Science and Technology (GSST), Aarhus University, Denmark and the Graduate school of Wageningen Institute of Animal Sciences (WIAS), the Netherlands as part of the Erasmus Joint Doctorate Program "EGS-ABG". 



\title{
The genetics of body weight and feed efficiency in broiler chickens
}

\author{
Wossenie Shibabaw Mebratie
}

\section{Thesis}

submitted in fulfillment of the requirements for the joint degree of doctor between

\section{Aarhus University}

by the authority of the Head of Graduate School of Science and Technology, and

\section{Wageningen University}

by the authority of the Rector Magnificus

Prof. Dr A.P.J. Mol,

in the presence of the

Thesis Committee appointed by the Head of Graduate School of Science at Aarhus

University and by the Academic board of Wageningen University

to be defended in public

on Monday March 25, 2019

at 1.30 p.m. in Foulum, Aarhus University 
Wossenie Mebratie

The genetics of body weight and feed efficiency in broiler chickens.

PhD thesis, Aarhus University, Denmark and Wageningen University, the Netherlands (2019)

With summaries in English and Danish

ISBN: 978-87-93787-39-1

DOI: https://doi.org/10.18174/472486 


\begin{abstract}
Mebratie W. (2019). The genetics of body weight and feed efficiency in broiler chickens. PhD thesis, Aarhus University, Denmark and Wageningen University, the Netherlands.
\end{abstract}

Tremendous genetic improvement in growth rate and feed efficiency of broiler chickens has been recorded in the past five or more decades due to genetic selection. However, the increasing global human population, increasing demand for affordable animal protein, increase in feed price and the continued global environmental issue still urges the broiler industry to produce broilers that grow fast and efficiently utilize feed. In order to further improve growth rate and feed efficiency of broiler chickens, understanding the genetic background of growth rate (body weight) and feed efficiency in today's broilers is essential. This thesis explored the genetic background of body weight (BW) and feed efficiency (FE) in broiler chickens using different statistical models and methods. Accurate estimation of genetic parameters is the primary pre-requisite to establish an efficient selection program. In this thesis, genetic parameters of BW and FE traits were estimated using different statistical models and methods. It is shown that BW and FE traits are influenced by sex by genotype and age by genotype interaction in addition to direct genetic effects, maternal permanent environmental effects and residual environmental effects. This suggests that genetic evaluation of broiler chickens should take in to account sex and age differences in order to improve accuracy of predicting breeding values and maximize genetic gain. Moreover, by studying the effect of selection on genetic parameters of BW along a selection trajectory, it is shown that the genetic variance of BW did not exhaust/diminish after several generations of selection. This is also supported by genome wide association study (GWAS) in which several quantitative trait loci (QTL) and candidate genes were identified to be associated with BW and FE in a broiler population that was pre-selected for BW and undergone several generations of selection for FE. In addition to identifying QTL regions and candidate genes for BW and FE traits, GWAS using mixed linear model and general linear model approach were compared. The results have shown that GWAS using the two approaches does not necessarily give similar results even if family structure is not a strong concern in the population suggesting that statistical models in GWAS should be carefully chosen. This thesis also explored two definitions of residual feed intake (RFI); phenotypic and genetic RFI. Phenotypic and genetic RFI were derived from a joint Bayesian analysis of body weight, feed intake (FI) and body weight gain (Gain) and genetic parameters of production (BW and Gain) and feed efficiency traits (FI and the two RFI definitions) were estimated. Moreover, genetic relationship 
between production and feed efficiency traits was quantified. Genetic correlations between phenotypic and genetic RFI were close to unity at a younger age and significantly different from unity at an older age suggesting that selection using either of them at that specific younger age results the same genetic response. Overall, the results of this thesis suggest that there exists considerable genetic variation in BW and FE that makes further improvement of the traits possible. The knowledge gained in this thesis will contribute to the understanding of the genetic background of BW and FE in broiler chickens. Furthermore, the statistical models and methods employed and the results reported in this thesis can be extended to other poultry species with little modification since chicken is the prime model for all avian species. 
In memory of my dad, who taught me not to quit no matter what 



\section{Contents}

$7 \quad$ Abstract

$131-$ General introduction

432 - Multi-trait estimation of genetic parameters for body weight in a commercial broiler chicken population

553 - The effect of selection and sex on genetic parameters of body weight at different ages in a commercial broiler chicken population

814 - Genetic parameters of body weight and different definitions of residual feed intake in broiler chickens

1115 - Genome wide association study of body weight and feed efficiency traits in a commercial broiler chicken population, a re-visitation

$1356-$-General discussion

175 Summary

179 Sammendrag

181 Acknowledgement

185 Curriculum vitae

191 Colophon 



\section{1}

General introduction 



\subsection{Broiler production}

Poultry meat production increased nearly 46 million metric tons during the past 15 years from 2003 to 2018 (WATT executive guide to world poultry trends, 2018). US, China and Brazil are the leaders in poultry meat production with forecasted 2018 production of 22.4, 17.8 and 13.7 million metric tons, respectively (WATT executive guide to world poultry trends, 2018). European Union, Russia and Mexico are significant contributors to the world's total poultry meat production in 2018, whereas developing countries continue to drive demand (WATT executive guide to world poultry trends, 2018). Poultry meat production is forecasted to rise from nearly 123 million metric tons in 2018 to 139 million tons in 2027 while its main competitive product pig meat is forecasted to rise from nearly 121 million metric tons to 130.9 million metric tons in 2027 (WATT executive guide to world poultry trends, 2018).

Poultry meat is the main source of animal protein for human beings in the majority of countries worldwide (McKay, 2009). Chickens that are reared exclusively for meat production are called broiler chickens or broilers. In 2010, broiler meat accounted for $88 \%$ of the total poultry meat output worldwide followed by turkey, duck and goose which accounted for 5\%, $4 \%$ and 3\%, respectively (MacLeod et al., 2013). In 2018 broiler meat accounted for $86.9 \%$ of the total poultry production in the US followed by turkey which accounted for $12.1 \%$ of the total production and it is predicted to stay nearly the same in 2019 (USDA, 2018).

Broiler meat production has increased from about 58.7 million tons in 2000 to over 95.6 million tons in 2018 and is forecasted to grow 2 percent in 2019 to a record of 97.8 million tons (USDA, 2018). Since about 1993, the consumption of broiler meat has been higher than any other type of meat each year in the US (Havenstein, 2006). The consumption of chicken meat in the UK ( 23 kilograms per head per year), is greater than that of any other meat and accounts for about a third of all meat consumed (Sheppard, 2004). The human population worldwide is predicted to reach 9.6 billion in 2050 (UN, 2015) and the global demand for chicken meat is forecasted to grow by $61 \%$ between 2005 and 2030 (MacLeod et al., 2013). With the growing human population and consumer demand for affordable meat, chicken meat is predicted soon to become the world's most consumed form of animal protein (OECD/FAO, 2014).

The increased importance of global sustainability in food production is well suited with the progress made in the poultry industry, which has relatively low environmental impact compared to other livestock sectors such as cattle, sheep and 
pig (Williams et al., 2006). Livestock production contributes approximately $18 \%$ of the global greenhouse gas emissions (FAO, 2006) and chicken production attributes the least of the global emissions from livestock production (MacLeod et al., 2014; Williams et al., 2006) which urges the broiler industry to grow even more.

\subsection{Role of broiler breeding programs}

A dramatic transition in poultry genetics has been observed in the last several decades, both in commercial arena of breeding and research (Siegel, 2006). Industrial production has facilitated replacement of dual-purpose chickens with broilers that are specifically bred for meat or layers that are specifically bred for eggs. Today's broiler industry has its origin in the seasonal rearing of cockerels of egg type or dual-purpose breeds for meat. With increasing demand for juvenile chickens, breeds have been selected for rapid growth rate, feed efficiency, and specific carcass parts (Eitan and Soller, 2002).

The broiler industry has shown astonishing change over the past half century. Many factors have contributed to the growth of the industry, but genetics has played the major role (Havenstein, 2006). A number of breeding companies have existed since the late 1940 s to early 1950 s that have specialized in applying quantitative genetics to the selection of chickens that are solely used for meat production (Havenstein et al., 1994a). The genetic progress made since the late 1950s has been the basis of a modern poultry industry, which is a major source of animal protein in most countries of the world (McKay, 2009). Breeding companies have applied different breeding and selection strategies at different periods for the genetic improvement of poultry. Those genetic changes, along with management and nutritional changes, as well as the application and efficiencies of vertical integration led to the development of the modern broiler industry and its ability to produce chicken meat at about the same absolute price today as it was being produced in the early 1950s (Havestein, 2003a). The modern broiler is a chicken that reaches market weight at an early age, has high carcass yield and is highly feed efficient (Siegel, 2014).

Broiler breeding programs mainly select for growth rate, feed efficiency, and breast meat yield, ascites and skeletal abnormalities. Among those traits, growth rate and feed efficiency have received greatest attention in almost all broiler breeding programs mainly due to their economic importance (Arthur and Albers, 2003). Improved growth rate (body weight) has commonly been the principal selection trait over the decades, because it is relatively easy to select, has moderate heritability and has great economic impact for the broiler industry (Arthur and Albers, 2003). The continued effort made by breeding companies enabled the production and 
efficiency of production observed in modern broilers. Havenstein et al. (2003a) compared a representative 2001 broiler strain (Ross 308) reared on a 2001 modern commercial diet with Athens-Canadian random bred control line (ACRBC) established in 1975 and reared on a 1957 type diet and reported that the modern broiler in the year 2001 was nearly five times as large as the 1957 random bred broiler line at 42 and 56 days of age. Moreover, the Ross 308 broiler line with the 2001 feed was estimated to have 1,815 gram body weight and feed conversion ratio of 1.47 at 32 days of age while the ACRBC line with the 1957 feed would not have 1,815 gram body weight and feed conversion ratio of 4.42 before 101 days of age (Havenstein 2003a).

By focusing on economically most important traits, breeding companies succeeded to produce a broiler cross that reach market weight about 1 day earlier each generation (Siegel, 2014). Together with this change, a dramatic reduction in the feed conversion ratio has been recorded. Under good management condition and high-energy diet, modern broilers can reach $2.44 \mathrm{~kg}$ in just 35 days with only $3.66 \mathrm{~kg}$ of feed. Studies have shown that the majority of this tremendous change ( 85 to $90 \%$ ) has been brought by the genetic selection practiced by commercial breeding organizations (Havestein et al., 2003a; Havenstein et al., 1994a; Havenstein et al., 1994b; Sherwood, 1977) while $10-15 \%$ of the change is due to improvements in nutrition and management practices (Havenstein et al., 1994a; Havenstein et al., 1994b).

\subsection{Structure of broiler breeding industry}

A number of broiler breeding companies have existed since the late 1940s and had significant contribution to genetic improvement in broilers over the years. Breeding companies have been successful in populating the production industry with an increasing numbers of efficient stock (Arthur and Albers, 2003).

Until the beginning of the 20 century, breeders were selected based on their phenotypic performance (mass selection). Since then, a number of strategies such as pedigree selection, selection indices, as well as estimation of breeding value of selection candidates using different methods have been implemented (Arthur and Albers, 2003). These selection strategies were applied exclusively on pure breeding lines until 1940s and final broilers were purebreds. After that, all breeding programs for broilers consisted of specialized lines with distinct breeding goals per line and commercial broilers were cross breeds (Arthur and Albers, 2003). Modern commercial broilers are three-way or four-way crosses of specific closed pure 
breeding lines. Between pure breeding lines and final commercial broilers, there are four generations (Arthur and Albers, 2003). To permit the transmission of genetic improvement from the nucleus breeding populations (where all selection takes place) to the billions of crossbred commercial broilers, considerable multiplication is needed through grandparent and parent populations. The structure of all breeding companies is standard. The pure line elite stock, which is relatively small in number, is located at the apex while large number of crossbred broiler stock is located at the base (Pollock, 1999). A typical broiler primary breeder/industry structure is presented in Figure 1. In general, the time lag between selection in the pure breeding lines and gain in the final commercial broilers is about four years (Pollock, 1999).

The purebred line is possessed by the breeding company and undergo full-scale selection program. For each broiler product, three or four purebred lines are used. Individual breeding companies have a range of broiler products; hence, they maintain at least ten purebred lines (Arthur and Albers, 2003). Pedigree selection is intense in the main lines. Individuals at this stage contribute their genetic material to tens of thousands of final broilers (Sigel, 2013).

Great-grandparent stock is owned by the breeding company and undergone limited selection for selected traits. It is mainly used for multiplying the pure lines to at least tens of thousands, which are needed to create the grandparent stock (Arthur and Albers, 2003).

Grandparent stock is the first generation of crossbred stock. In case of a four-way final cross $(A B C D), A$ males, $B$ females, $C$ males and $D$ females produce the grandparent stock (Arthur and Albers, 2003). Grandparents are distributed throughout the world in at least hundreds of thousands to local operations, which may be integrated production companies or local distributors of parent stock (Arthur and Albers, 2003).

Parent stock is the second generation of crossbred stock. In a four-way final cross, $A B$ hybrid males are mated to $C D$ hybrid females. Parent stocks are mainly possessed by companies, which produce final broilers. Finally, broilers are birds that are grown, slaughtered and processed for large-scale chicken meat production (Arthur and Albers, 2003).

The mainline pedigree populations are subjected to genetic selection to improve the major economic traits. For male lines, growth rate, feed conversion ratio and edible carcass yield are the traits that receive priority. These traits are also important for female lines; however, greater emphasis is given to reproductive traits. Traits that received greatest emphasis are improved by intensive selection, which is regenerated from the best families. However, minor traits (e.g. fertility, hatchability, liveability in the male lines) are improved by low intensity selection. This latter 
approach is aimed to maintain performance levels for the minor traits as gain in the major traits accumulate (Pollock, 1999).

\subsection{Selection strategies}

The initial step in any successful breeding program is to establish an appropriate breeding goal (Emmerson, 2003). Breeding goals for producing the modern broiler may vary depending on market demands and related genetic and non-genetic factors (Siegel, 1984). Each breeding program has four fundamental steps. The first step is a clear product profile for each product the breeding company needs to market. The second step is an assessment of the available genepools and their corresponding crosses for best fit to the product profile. The third step is using estimates of variance components to define breeding goals within each genepool for the traits under evaluation. This step also includes designing optimum evaluation procedures and rates of progress for each trait under evaluation. Breeding goals may shift with market changes. The last step is to take the genepools under evaluation and efficiently reproduce, multiply the crosses and deliver the hybrid to customers in a health status that meets the requirement of the modern industry (Collett, 2009).

There are different forms of the modern broiler, each designed to address a specific market, and breeding programs are limited to a small number of groups operating globally. Generations are overlapping rather than discrete, and selection is multistage that is, selections are made at several points during the life of an individual, which may be removed from the population at any time (Siegel, 2014). With the development of a high quality sequence assembly of the chicken genome, genomics can help to complement selection, particularly for traits that are expressed in one sex or later in life or for traits that are difficult to measure (Siegel, 2014). 
Figure 1. A typical broiler primary breeder structure (Figure adopted from Mackay, 2008).

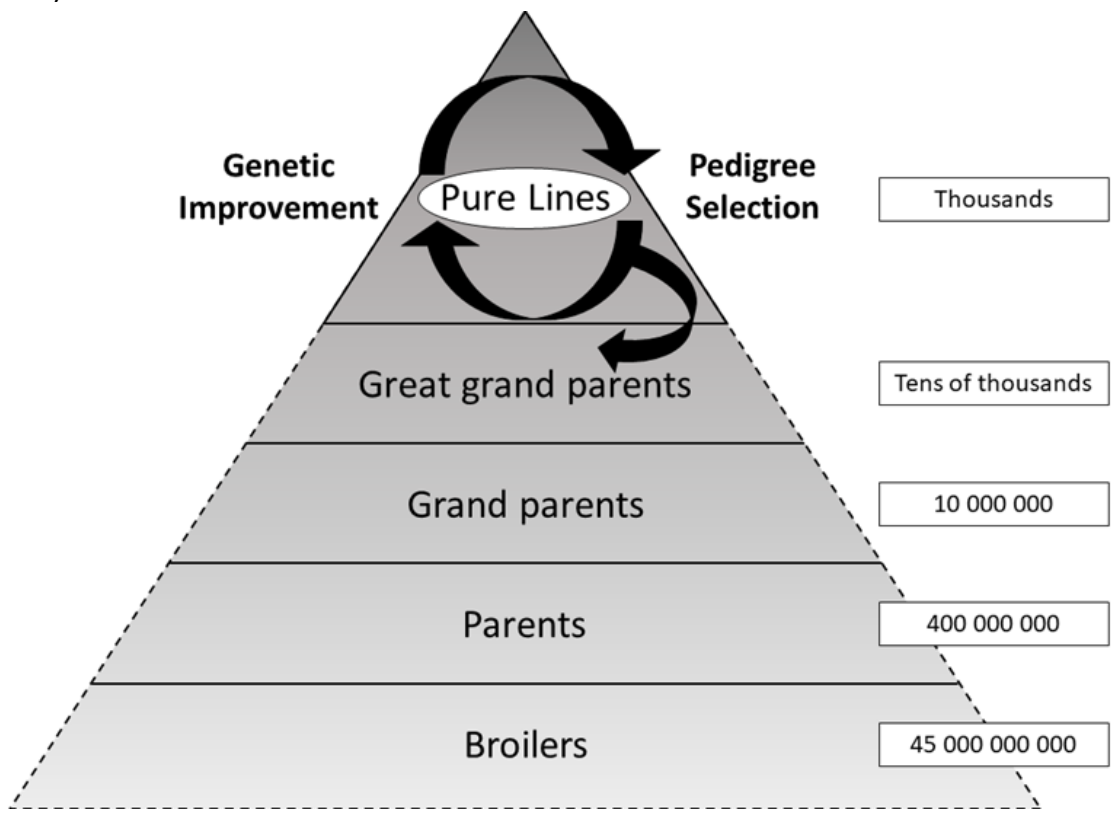

\subsubsection{Selection strategies for growth rate}

Growth rate was the first trait to receive attention in the breeding industry since the start of commercial broiler production due to its economic importance and the relative ease with which it can be improved (Emmerson, 1997). Broiler selection occurs at an earlier point in the growth curve, which gives greatest emphasis to rapid growth and early carcass development (Emmerson, 1997). The primary breeding industry generally follows one of the following three basic approaches in selecting for growth rate (Emmerson, 1997).

Selection at a commercial age: In this approach, pure lines are selected at an age that matches market age. This has the advantage of not being complicated by the weight difference between male and female lines. In this approach, candidates are pre-selected at a relatively immature stage prior to final selection at a commercial environment. This pre-selection is commonly practiced especially in lines under extreme selection for growth rate (Emmerson, 1997).

Selection at a commercial weight: In this approach, pure lines are selected at a weight that matches market weight and the age at selection decreases with time as 
growth rate increases. This approach takes into account the fact that male lines are 30-40\% heavier than female lines and that growth rates are significantly greater in a structured pedigree program than would be observed under field conditions due to genotype by environment interaction (Emmerson, 1997). Thus, primary selection might occur at a much younger age than typical market age but at a weight and developmental maturity that corresponds with the ultimate breeding objective. Although requirements are changing rapidly, selection at a commercial weight is the most common strategy employed in industrial broiler breeding programs (Emmerson, 2003) as a result broiler products generally fall within a relatively narrow weight ranges. Broilers that deviate from the prescribed weight ranges result in processing inefficiencies and associated economic loss (Emmerson, 1997).

Multi-stage selection: It accommodates selection at a commercial age and selection at a commercial weight. Multi-stage selection is appropriate for development of multi-purpose products that perform over a relatively large range of market weights or in cases where there is a secondary breeding objective (Emmerson, 2003). Selection environments range from a simulated commercial environment to an optimal environment that allows full expression of genetic potential for growth. Mass selection is common, although many industries are currently utilizing more advanced statistical methods for breeding value estimation, including family selection, single and multi-trait indices and best linear unbiased prediction (Emmerson, 1997).

\subsubsection{Selection strategies for feed efficiency}

Improvement in feed efficiency is historically achieved mainly through improvement in growth rate. This indirect approach in improvement of feed efficiency is associated with negative traits such as increased feed intake and carcass fatness (Emmerson, 1997). Direct selection for feed efficiency was started in the 1970 s to select for components of feed efficiency that were lowly or negatively associated with growth rate (Emmerson, 1997). There is difference in industrial approaches to feed conversion selection. The most common approach involves individual testing of male candidates that have been pre-selected for body weight and other physical traits such as conformation in individual cages. Feed conversion is evaluated in a relatively short period in relation to the life span of the bird, which lasts between 1 to 3 week period starting between 3 and 8 weeks of age. The data generated is measured in a cumulative form giving a total feed intake and weight gain over the test period. Feed conversion results are generally corrected for body size using different statistical 
procedures or standardized based on energy requirements for maintenance. Males that are highly feed efficient are selected through mass selection, sib selection, or index and in a few cases, females are selected based on the performance of their male sibs (Emmerson, 1997).

\subsection{Challenges in the broiler industry}

In broilers, combined selection for growth rate, feed efficiency, body composition, and livability delivers 2-3\% improvement per year in the efficiency of meat production (McKay, 2009). Traits such as disease resistance, robustness, and absence of metabolic defects have also contributed to this improvement (McKay, 2009). However, one of the challenges in modern broiler breeding programs is the high negative genetic correlation of economically important production and feed efficiency traits with health related traits and welfare (Dawkins and Layton, 2012; Knowles et al., 2008 ; Renema et al., 2007) as well as reproductive traits (Schmidt et al., 1998; Schmidt et al., 1994). Studies have shown that selection for growth rate results in decreased heart and lung size relative to the rest of the body (Druyan et al., 2009; Ducuypere et al., 2000) and skeletal abnormalities that influence the gait of broilers (Julian, 2005; Corr et al., 2003; Bradshaw et al., 2002). Moreover, chickens that are highly feed efficient have low oxygen consumption and lower metabolic rate, which makes them susceptible to ascites and heart failure (Julian, 2005; Decuypere et al., 2000) which also contributes to decreased welfare, increased mortality and disease in modern broilers (Havenstein et al., 2003a; Havenstein et al., 2003b). Hence, genetic selection for growth rate and feed efficiency in broiler chickens has unintended consequences that compromise the health and welfare of broiler chickens, which in turn limits further progress in growth rate and feed efficiency. In the future more complications may arise which urges further selective breeding to give due consideration for alleviating correlated side effects in addition to improving production and production efficiency by extending or modifying selection goals (Decuypere et al., 2003).

Another challenge in broiler breeding programs is genotype by environment interaction $(G \times E)$. Genes that are expressed in one environment may not be expressed or may be expressed differently in another environment (Dawkins and Layton, 2012). Significant $G \times E$ interactions may be caused not only by specifically differentiated genotypes, such as breeds or lines, but also by single major gene effects (Mathur, 2003). There is evidence of significant $G \times E$ interactions in broilers, especially with respect to environmental conditions such as heat stress and nutrition. One component of $\mathrm{G} \times \mathrm{E}$ interaction in broilers is that breeders (parents) are tested 
in controlled environment referred to as bio-secure environment while their progeny are expected to perform in a less controlled commercial farms. For example, until recently the parent and grandparent broiler breeders have been selected in disease free environments, which is different from the commercial farms (de Jong and Guémené, 2011). Different studies have compared broilers raised in different environments and reported a significant genotype by environment interaction (Kapell et al., 2012; N’Dri et al., 2007; Pakdel et al., 2005; Mathur et al., 2003). For example, N'Dri et al. (2007) noted that growth traits show $G \times E$ interactions between selection and production environments, which may suggest that estimation of breeding values of selection candidates, should include data from production environments. On the other hand, commercial environments may avoid disease but allow evaluation of response to stocking density, climate, social stress and other physiological stresses (Emmerson, 1997) which might not be the case in bio-secured environments.

Commercial broiler production is growing worldwide while broiler breeding is increasingly becoming centralized. Genetic products developed in limited range of environments are expected to meet the requirements of diverse markets, environments, and husbandry practices worldwide (Emmerson, 1997). Prior estimates of heritability and trait correlations, based on a narrow range of genotypes kept in a restricted range of environments, may be highly quantitative but also may lead to pessimistic views of the likely success of such breeding programs (Dawkins and Layton, 2012). Even though, there are many industry examples of $G \times E$ interactions under field conditions, considerable emphasis is not given to develop genetic solutions to these environment and husbandry induced production problems (Emmerson, 1997). There is a need to estimate the magnitude of the interactions to evaluate their biological significance and role in selection programs (Mathur, 2003). Statistically significant interactions may or may not be biologically relevant, e.g. if they do not affect the ranking order of specific breeds or lines from one environment to the other. However, they can be relevant if superior individuals such as sires in one environment cannot maintain superiority in a different environment (Mathur, 2003). The phenomenon of $G \times E$ interactions requires additional effort in the choice of breeding stocks, which are adaptable to a wide range of environment (Mathur, 2003). Appropriate use of this phenomenon can be useful for production of genotypes that are well adapted and genetically superior for the given environmental conditions (Mathur, 2003).

In addition to the above-mentioned challenges, sustainable poultry production is increasingly becoming an issue. The shift towards long-term sustainability of poultry production based on being economically profitable, ecologically friendly and socially 
acceptable has received much attention recently (Soisontes, 2017). In developed countries, consumers are increasingly concerned about sustainable food, particularly food safety, animal welfare and environmental issues (Windhorst, 2015b) where as in low to middle income countries poultry production is an important source of income and a top priority for feeding a growing human population in the future (Soisontes, 2015a). Priotization of sustainable issues are different across regions; differences in agro-ecological and socio-economic circumstances as well as public policies in various regions have an impact on the sustainability of poultry production, especially between high income and low to middle-income countries (Soisontes, 2017). Overall, the issue of sustainable poultry production is expected to increasingly become a challenge to the broiler industry in the foreseeable future.

\subsection{Genetic variation in body weight and feed efficiency traits}

Despite the considerable historical improvement that has been observed in growth rate and feed efficiency, there exists considerable variation in growth rate and feed efficiency within and between commercial broiler strains (Emmerson, 1997). Different studies have reported heritability estimates for body weight in broiler chickens at different ages to be in the range from 0.20-0.64 (Mebratie et al., 2017; Begli et al., 2016; Adeyinka et al., 2006; Prado-Gonzalez et al., 2003; MignonGrasteau et al., 1999; Le Bihan-Duval et al., 1998). The variability of the estimates is due to a number of reasons including genetic groups (lines, strains), sex, age, diet, rearing environment, and estimation methods. The reported moderate to high heritability estimates suggest that genetic selection for body weight will result considerable response, which is consistent with the success of selection in improving the trait in the broiler breeding industry.

Body weight in broiler chickens is not only influenced by direct animal genetic effects but also by genetic and non-genetic maternal effects (Liu et al., 1993). Different authors have reported estimates of maternal genetic and maternal environmental effects on body weight in broilers and it seems that maternal genetic effects as well as genetic correlations between direct and maternal genetic effects are difficult to estimate accurately. Koerhuis and Thompson (1997) reported low maternal heritability (0.02-0.13) with negative genetic correlation $(-0.11$ to -0.92$)$ between direct and maternal genetic effects while Mignon-Grasteau (1999) reported a relatively higher (0.08-0.24) maternal genetic effect in broilers. Furthermore, reported genetic correlation estimates between direct and maternal genetic effects 
are often negative (Larivière et al., 2009; Prado-Gonzalez et al., 2003; Cheverud, 2003; Koerhuis and Thompson, 1997; Meyer, 1997) mainly due to ignoring environmental covariance between dam and offspring records in the statistical analyses (Koerhuis and Thompson, 1997) and also not fitting more detailed fixed effects in the statistical model (Meyer, 1997). Thus, accounting for the direct and maternal environmental covariance and fitting detailed fixed effects in statistical models is suggested to give better estimates of the direct and maternal genetic correlation (Bijma, 2007). In addition, different authors have reported that maternal environmental effects account only small proportion of the total phenotypic variance (Begli et al., 2016; Aslam et al., 2011; Koerhuis and Thompson, 1997; Towne et al., 1997).

Residual feed intake (RFI) which is defined as the difference between actual feed intake and expected feed intake based on production and maintenance requirements and feed conversion ratio (FCR) which is defined as the ratio of feed intake to body weight gain are the two popular measures of feed efficiency in poultry. Different authors have reported genetic variability of RFI and FCR in poultry (Willems et al. 2013). The heritability estimate of RFI is reported to be in the range from 0.14 - 0.45 (Begli et al., 2016; Verdal et al., 2011; Aggrey et al., 2014; Aggrey et al., 2010; Gaya et al., 2006; Melo et al., 2006; N'Dri et al., 2006; Pakdel et al., 2005). On the other hand, the heritability estimate of FCR is reported to be in the range from 0.10 to 0.49 (Aggrey et al., 2014; Howie et al., 2011; Verdal et al., 2011; Aggrey et al., 2010; N'Dri et al., 2006; Gaya et al., 2006; Mignon-Grasteau et al., 2004) suggesting that considerable genetic gain can be achieved by selecting for feed efficiency using these traits. Indeed significant improvements in feed efficiency have been recorded through direct selection (Flock, 1998).

Population genetics theory states that genetic variation diminishes as a result of long-term genetic selection (Emmerson, 1997). However, long-term selection experiments do not provide strong evidence that selection limits are reached and they suggest limits are only temporary when they do occur (Marks, 1991). To this end, commercial breeding companies utilize relatively large populations and have additional tools available to recapture variation, such as outcrossing and development of synthetic lines (Emmerson, 1997).

\subsection{Non-genetic factors that contribute to variation in body weight and feed efficiency traits}


The astonishing genetic improvement in broilers for growth rate and feed efficiency has been discussed above. As shown in Havestein et al. (2003a; 2003b; 1994a; 1994b) $85-90 \%$ of the improvement in body weight and feed efficiency in today's broilers is due to genetics and the remaining $10-15 \%$ is due to differences in nutrition and management practices (Havestein et al., 1994a; Havestein et al., 1994b). Furthermore, the expression of genetic differences in growth rate and feed efficiency of broiler chickens can be manipulated by non-genetic factors such as nutrition, stocking density, heat stress, lighting and other husbandry practices. Although it is hard to strictly attribute a particular factor to genetic, non-genetic (environmental) factor and their interaction, the main non-genetic factors that influence growth rate and feed efficiency in broiler chickens are discussed below.

1.7.1. Nutrition: dietary nutrient and energy levels, feed forms, pellet quality and other components of nutrition influence growth rate and feed efficiency in broiler chickens. Broilers that fed high protein and energy diets show faster growth rate than their counterparts that fed diets with less protein and energy. The genotype of broilers may influence their nutrient requirements. However under normal conditions broilers should take $22 \%, 20 \%$, and $18 \%$ of crude protein in the starter, grower, and finisher periods, respectively, and $3200 \mathrm{kcal}$ ME kg diet (NRC, 1994). Studies have shown that broilers that fed less protein diet than the average requirement show reduced growth rate and feed efficiency. Plavnik and Hurwitz (1990) reported that broilers fed a 9.4\% crude protein diet ad libitum from 8 to 14 days have shown $57 \%$ and $41 \%$ reduction in feed intake and weight gain, respectively compared to broilers that fed the recommended requirement. Havenstein et al. (2003b) compared feed conversion ratio (FCR) of a random bred ACRBC line fed a 1957 diet and a 2001 diet. The ACRBC male at 56 days had a FCR of 2.23 with the 2001 diet and FCR of 2.37 with the 1957 diet. Diets from 2001 had more energy, protein, lysine, methionine and total sulfur amino acids. On the other hand, 2001 diets were crumbled and pelleted while 1957 diets were mash.

Feed forms such as pellet, mash and crumble also influence broiler growth and development (Jones et al., 1995; Reece et al., 1986). Broilers that fed crumble pellet diets have shown improved feed intake, weight gain and feed conversion ratio compared to their counterparts that fed mash (Jones et al., 1995; Hamilton and Proudfoot, 1995; Calet, 1965). The improved feed intake, weight gain and feed efficiency of broilers that fed pelleted diets may be due to greater digestibility of carbohydrates together with increased daily nutrient intake (Hamilton and Proudfoot, 1995), better nutrient availability (Nir et al., 1995), and/ or less feed wastage (Savory, 1974; Calet, 1965). 
1.7.2. Stocking density: Stocking density has an impact on growth rate and feed efficiency of broiler chickens. Current recommendations for stocking density in broilers differ widely by country and organization (Bessie, 2006). However, there is a documented reduction in feed intake and growth rate when stocking density exceeds about $30 \mathrm{~kg} / \mathrm{m} 2$ for broilers reared on deep litter conditions (Bessie, 2006). It was reported that the negative effect of stocking density reduced when broilers were kept in cages or on perforated floors combined with under floor ventilation (Bessie, 2006). Moreover, the negative effect of stocking density on growth rate is reported to decrease by increasing ventilation rates (Grashorn and Kutritz, 1991) which leads to the assumption that the main factor for the decrease in growth rate might be related to problems of dissipating the metabolic heat (Bessie, 2006). Hence, the influence of stocking density on growth rate of broilers is mainly related to heat stress than physical restriction of the broilers space for movement (Bessie, 2006). However, there is no consistent trend of stocking density on feed efficiency (Bessie, 2006).

1.7.3. Heat stress: Heat stress causes reduced growth rate and increased mortality of broilers, which in turn results significant economic loss for the industry particularly in tropical countries (Geraert et al., 1996a). Heat exposure weakens the performance of broilers, especially during growing and finishing periods, as their ability to dissipate heat decreases according to body growth (Rosa et al., 2007). The main consequence of heat exposure is reduction in feed intake (Geraert et al., 1996a). This decreased feed intake leads to decreased growth, which is a physiological response in order to decrease metabolic heat production and maintain body homeostasis (Koh \& Macleod, 1999). However, the reduction in feed intake is often less than the reduction in growth, resulting in higher feed conversion ratio (Howlider \& Rose, 1987).

The negative effect of heat stress on broiler performance is higher in fast growing lines than slow growing lines. Metabolic heat production is highly associated with protein accretion (Macleod, 1997). Hence, under high environmental temperature, maintaining body homeostasis may be more difficult for fast growing broilers than their slow growing counterparts. Thus, the performance of slow-growing broilers under heat stress is not as impaired as that of the fast growing ones (Leenstra \& Cahaner, 1992).

1.7.4. Lighting: In most broiler production industries, broiler chickens are raised under 23 hour light per day, as continuous light regime allow the birds to feed continuously throughout the day and in turn increases growth rate. Different studies have shown that growth rate and feed efficiency of broilers were better under continuous light than under a natural day-night regime (Morris, 1967; Schutze, 
1960). However, recent studies reported that reducing the lighting hours or developing intermittent lighting schedule improves feed utilization by lowering cumulative feed intake while maintaining the same market weight at a given age (Apeldoorn et al., 1999; Buys et al., 1998; Buyes et al., 1996). For example, Buyes et al. (1994) studied the effect of intermittent and continuous lighting on the performance of female broilers and reported lower cumulative feed intake and considerable improvement in feed efficiency of the broilers under an intermittent program (1 hour light: 3 hours dark from 8 to 49 days) compared to those under a continuous lighting schedule. Buyes et al. (1996) also reported improved feed efficiency and compensatory growth in male broiler chickens at 41 days with a light schedule of 1 hour light: 3 hours darkness from day 7 and repeating this light schedule six times a day.

Other than the above mentioned non-genetic factors, management practices such as vaccination against disease influences the immune responsiveness of broilers to pathogens and in turn influence growth rate (Emara et al., 2002) and feed efficiency. Moreover, management practices related to housing conditions (ambient temperature, humidity, ventilation, litter quality, flooring system) influence growth rate and feed efficiency of broiler chickens which might be associated with the modification of the energy and amino acid requirements of birds, and could potentially affect feed intake, growth and feed efficiency (Tallentire et al., 2016).

\subsection{Genome wide association study of body weight and feed efficiency traits}

Genome wide association study (GWAS) is an ideal technique to discover the major genes for complex traits and is a novel approach to study the genetic mechanism of complex traits (Zhang et al., 2012). GWAS has revealed many important findings associated with production traits, disease resistance, and morphological characteristics in chickens (Zhang et al., 2012). Furthermore, GWAS has gained popularity in mapping Quantitative trait locus (QTL) to economically important traits like body weight (BW) and feed efficiency (FE) in chickens. A number of SNPs and QTLs associated with BW and FE traits are reported in the chicken QTL database (http://www.animalgenome.org/cgi-bin/QTLdb) and the reported QTLs are distributed throughout the genome. The chicken QTLdb allows for easy search and comparison of QTL results from different studies and facilitates a narrowing of possible chromosomal regions from overlapping QTL results of different studies, which will speed up positional searches for underlying genes (Hu et al., 2005). 
Although a number of GWA studies reported SNPs and QTL regions associated with body weight to be distributed randomly across the genome, various studies have found chromosome 1 (Liu et al., 2013; Sheng et al., 2013; Xie et al., 2012; Gu et al., 2011; Wahlberg et al., 2009; Gao et al., 2006; Pinto et al., 2006; Carlborg et al., 2003; Van Kaam et al., 1998) or/and chromosome 4 (Wang et al., 2016; Gu et al., 2011; Wahlberg et al., 2009; Tsudzuki et al., 2007; Rowe et al., 2006; Schreiweis et al., 2005; Sasaki et al., 2004; Sewalem et al., 2002; Tuiskula-Haavisto et al., 2002) to be strongly associated with body weight at different ages in various breeds of chickens.

With ever advancing technology and better knowledge of genetic mechanisms using GWAS, we are a step closer to the understanding of complex traits. However, along with the success stories, there are differences in the identified QTL regions and candidate genes among GWAS reports for the same trait. This might mainly be attributed to aspects such as population size, density of the markers (SNPs), not properly accounting for population structure, as well as choice of statistical models (Sharma et al., 2015; Zhang et al., 2012). If statistical models are carefully chosen in a way that can account for population stratification, family structure and cryptic relatedness, they can help to minimize the chances of spurious associations and type I error (Sharma et al., 2015).

\subsection{Variance components}

Estimation of variance components is a method often used in population genetics and applied in animal breeding (Mašata and Rasch, 2006) and quantitative genetics (Robinson, 1987). In animal breeding knowledge of variance components of traits of interest is the primary pre-requisite to establish a selection program. Variance components enable animal breeders to better understand the genetic architecture of a trait of interest. Moreover, variance components are essential for prediction of breeding values and expected response to selection in breeding programs (Robinson, 1987). Variance components of a population are useful to understand the nature of the population through genetic and environmental components of a phenotypic variance (Falconer and Mackay, 1996).

A general phenotypic model contains the contributions from the genotype, the environment and their interactions (Falconer and Mackay, 1996). The environmental factor and the genotype by environmental interaction can be combined as nongenetic sources of variation so that the phenotypic model would be a simpler model that contains the genetic and non genetic sources of variation. The genetic effects can be partitioned in to additive, dominance, and epistatic effects (Falconer and 
Mackay, 1996). The additive genetic variance is an important genetic parameter in animal breeding since most quantitative traits are mainly influenced by additive genetic effects and it is the main contributor to response to selection for a trait of interest. The environmental effects can also be partitioned in to common environmental effects, a general environmental effect and a specific environmental effect, which is unique to each individual (Falconer and Mackay, 1996). The possible sources of the common environmental effects could also be partitioned in to shared environmental effects, temporary nutritional or climatic changes and maternal effects, which are related to pre-natal and post-natal nutrition. Except the pre-natal maternal effect, the other components of the environmental variance can often be partly controlled by suitable experimental design (Falconer and Mackay, 1996).

Since genotypes of a population must be manipulated through their corresponding phenotypes, it is important to calculate the change in the additive component of a genotype per unit change in phenotype, which is defined as heritability in the narrow sense or heritability (Lush, 1947). In animal breeding, heritability is the central parameter of a population that explains the proportion of variation among individuals in a population, which is due to variation in the additive genetic values (Falconer and Mackay, 1996). Heritability is formally defined as a ratio of variances, specifically as the proportion of total variance in a population for a particular measurement, taken at a particular time or age that is attributable to variation in additive genetic genetic values (Visscher et al., 2008). Different heritability estimates may be found for the same trait in different populations or in the same population at different times because the additive genetic variance may be reduced due to selection or/and the phenotypic variance may be altered due to environmental change (Falconer and Mackay, 1996). Moreover, considerable changes may have occurred in a population due to inclusion of external genetic material other than errors in estimating genetic and non-genetic parameters. Therefore, variance components should be estimated in every population regularly and updated overtime using sufficient amount of data. If sufficient amount of data is not available, the information in literature for the same population is in many cases even better than estimations based on small data set because in such situations heritabilities cannot be estimated with great precision and may result large standard errors.

Phenotypic values of different traits may be correlated due to genetic or/and environmental factors. Similar to the phenotypic variance, the phenotypic covariance can be partitioned in to genetic and non-genetic (environmental) correlations (Lynch and Walsh, 1998). Genetic correlation is defined as the correlation between the additive genetic values of traits. Genetic correlation between traits mainly arise from pleiotropy; property of a gene whereby it influences 
two or more traits (Falconer and Mackay, 1996. In animal breeding, knowledge of genetic correlation between traits of interest is important because it may enable improvement of traits through indirect selection. Moreover, knowledge of genetic correlation helps to predict correlated response to genetic selection, determine the extent of genotype by environment interaction, understand evolutionary processes of traits as well as to develop selection indices for multiple trait selection. The environmental correlation may arise from shared cages/housing and common maternal effects (Falconer and Mackay, 1996).

\section{This thesis}

In the above sections, the success of the broiler industry in terms of improving growth rate (body weight) and feed efficiency has been discussed. However, further improvement of the traits is needed to accommodate the rising feed cost, growing human population, the increasing demand for cheap source of animal protein and the global issue of sustainable food production with a minimal environmental footprint. Thus, further understanding of the genetic background of body weight (BW) and feed efficiency (FE) traits of today's broilers is essential.

The overall objective of this thesis is therefore to study the genetic background of BW and FE traits in male and female broiler chickens at different ages using different statistical models and methods. Hence, genetic parameters of BW and FE traits were estimated using commercial broiler chicken population. Sex by genotype interaction, age by genotype interaction, the effect of selection on genetic parameters of BW, phenotypic and genetic definitions of residual feed intake and direct and correlated superiority of a group selected on phenotypic and genetic residual feed intake were studied. Furthermore, GWAS was conducted to study association between BW and FE traits with SNP markers. The knowledge gained in this thesis will contribute to the understanding of genetic background of the most economically important traits in the broiler industry. Moreover, the methods used and the results found in this thesis can be extended to other poultry species with little modification since chicken is the prime model for all avian species.

In chapter 2, multivariate restricted maximum likelihood (REML) analysis was conducted for BW in male and female broiler chickens measured at three different ages and sex by genotype interaction as well as age by genotype interaction were investigated for the broiler population under study. In chapter 3, the same data set as in chapter 2 was used to study the development in genetic variance for BW after 
several generations of selection using random regression model (RRM). Moreover, the multivariate REML results obtained in chapter 2 were confirmed using Bayesian RRM. In chapter 4, BW, feed intake and body weight gain in broiler chickens were simultaneously analyzed from a multivariate Bayesian analysis and phenotypic and genetic residual feed intake ( $\mathrm{RFI}$ ) were derived. Moreover, genetic parameters were estimated for BW and FE traits along with the two derived RFI traits. Finally, direct and correlated superiority of a selected group on phenotypic and genetic RFI were investigated. In chapter 5, GWAS was conducted to identify quantitative trait loci and candidate genes associated with BW and FE traits. In addition, GWAS using general linear model and mixed linear model approach were compared. In chapter 6 , the main findings of the four papers of this thesis are summarized and integrated and the different statistical models and methods used in the papers are discussed relative to other possible models and methods. Moreover, the available information on literature about unintended consequences of improved growth rate and feed efficiency in broiler chickens are highlighted. Finally, areas that should be exploited to enhance further improvement in BW and FE traits as well as to alleviate the unintended consequences of improved growth rate and feed efficiency are explored.

\section{References}

Adeyinka IA, Oni OO, Nwagu BI, and Adeyinka FD. 2006. Genetic Parameter Estimates of Body Weights of Naked Neck Broiler Chickens. International Journal of Poultry Science. 5 (6): 589-592.

Aggrey SE, Arthur BK, Sebastian B, Anthony NB. 2010. Genetic properties of feed efficiency parameters in meat-type chickens. Genetics Selection Evolution 42: 25.

Apeldoorn EJ, Scharama JW, Machaly MM, Parmentier HK. 1999. Effect of melatonin and lighting schedule on energy metabolism in broiler chickens. Poult. Sci. 78: 223-229.

Arthur JA and Albers GAA. 2003. Industrial perspective on problems and issues associated with poultry breeding, in: MUIR, W.M \& AGGREY, S.E. (Eds) Poultry Genetics, Breeding and Biotechnology, pp.1-12 (CABI Publishing, CAB International, Wallingford, UK).

Aslam ML, Bastiaansen, JW, Crooijmans, RP, Ducro, BJ, Groenen, MA, Vereijken, A. 2011. Genetic variances, heritabilities and maternal effects on body weight, breast meat yield, meat quality traits and the shape of the growth curve in turkey birds. BMC. Genet. 12: 14. 
Bessie W. 2006. Welfare of broilers, a review. World's Poultry Science Journal. 62(03):455 - 466.

Begli H, Vaez Torshizi R, Masoudi AA, Ehsani A. 2016. Longitudinal analysis of body weight, feed intake and residual feed intake in F2 chickens. Livest. Sci. 184: 28-34.

Bijma P. 2007. Estimating maternal genetic effects in livestock. J. Anim. Sci. 2006. 84: 800-806.

Bradshaw RH, Kirkden RD, Broom DM. 2002. A review of the aetiology and pathology of leg weakness in broilers in relation to welfare. Avian Poult. Biol. Rev. 13: 45-103.

Buss EG. 1990. Genetics of growth and meat production in turkeys, in: CRAWFORD, RD. 145 (Ed.). Poultry Breeding and Genetics Amsterdam, Elsevier; pp. 645675.

Buys N, Buyse J, Hassanzadeh-Ladmakhi M, Decuypere E. 1998. Intermittent lighting reduces the incidence of ascites in broilers: an interaction with protein content of feed on performance and the endocrine system. Poult. Sci. 77:5461.

Buyse J, Decuypere E, Michels H. 1994. Intermittent lighting and broiler production. 1. Effect on female broiler performance. Archive fur Geflugelkunde. 58: 6974.

Buyse J, Kuhn R, Decuypere E. 1996. The use of intermittent lighting in broiler raising. 1. Effect on broiler performance and efficiency of nitrogen retention. Poult Sci. 75(5):589-594.

Calet C. 1965 . The relative value of pellets versus mash and grain in poultry nutrition. World Poult. Sci.J. 21: 23-52.

Carlborg Ö, Kerje S, Schutz K, Jacobsson L, Jensen P and Andersson L. 2003. A global search reveals epistatic interaction between QTL for early growth in the chicken. Genome Research. 13: 413-421.

Cheverud JM. 2003. Evolution in a genetically heritable social environment. Proc. Natl. Acad. Sci. USA 100:4357-4359.

Collett SR. 2009. Managing current disease challenges in breeders. Biology of poultry breeding. (ed. P.M. Hocking), pp.414-433.

Corr SA, Gentle MJ, McCorquodale CC and Bennett D. 2003. The effect of morphology on walking ability in the modern broiler: a gait analysis study. Animal Welfare. 12: 159-171.

Dawkins MS, Cook PA, Whittingham MJ, Mansell KA, Harper AE. 2003. What makes free-range broiler chickens range? In situ measurement of habitat preference. Animal Behaviour. 65:01-10. 
Dawkins MS and Layton R. 2012. Breeding for better welfare: genetic goals for broiler chickens and their parents. Animal Welfare. 21: 147-155.

Decuypere E, Buyse J and Buys N. 2000. Ascites in broiler chickens: exogenous and endogenous structural and functional causal factors. World's Poultry Science Journal 56: 367-377.

Decuypere E, Bruggeman V, Barbato GF and Buyse J. 2003. Growth and Reproduction Problems Associated with Selection for Increased Broiler Meat Production. Poultry genetics pp 13-28.

de Jong IC and Guémené D. 2011. Major welfare issues of broiler breeders. World's Poultry Science Journal 67: 73-81.

Druyan S, Shinder D, Shlosberg A, Cahaner A, Yahav S. 2009. Physiological parameters in broiler lines divergently selected for incidence of ascites. Poult. Sci. 88:1984-90

Eitan $Y$ and Soller M. 2002. Associated effects of sixty years of commercial selection for juvenile growth rate in broiler chickens: Endo/exophysiological, or genetic? Proc. $7^{\text {th }}$ World Congress on Genetics Applied to Livestock Production, Montpellier, France, August 19-23.

Emara MG, Lapierre RR, Greene GM, Knieriem M, Rosenberger JK. 2002. Phenotypic Variation Among Three Broiler Pure Lines for Marek's Disease, Coccidiosis, and Antibody Response to Sheep Red Blood. 81:642-648.

Emmerson, DA. 1997. Commercial Approaches to Genetic Selection for Growth and Feed Conversion in Domestic Poultry. Poultry Science. 76:1121-1125.

Emmerson D. 2003. Breeding objectives and selection strategies for broiler production, in: MUIR, W.M \& AGGREY, S.E. (Eds) Poultry Genetics, Breeding and Biotechnology, pp. 133-136 (CABI Publishing, CAB International, Wallingford, UK).

Falconer DS \& Mackay TFC. 1996. Introduction to quantitative genetics. Harlow: Longman.

FAO. 2006. Livestocks' Long Shadow. Environmental issues and options.

Flock DK. 1998. Genetic economic aspects of feed efficiency in laying hens. World's Poultry Science Journal 54: 225-239.

Gao Y, Hu XX, Du ZQ, Deng XM, Huang YH, Fei J, Feng JD, Liu ZL, Da Y and Li N. 2006. A genome scan for quantitative trait loci associated with body weight at different developmental stages in chickens. Animal Genetics. 37: 276-278.

Gaya, LG, Ferraz JBS, Rezende FM, Mourão GB, Mattos EC, Eler JP, Michelan Filho T. 2006. Heritability and genetic correlations estimates for performance, carcass and body composition traits in a male broiler line. Poultry Science. 85: 837-843. 
Geraert PA, Guillaumin S, Leclercq B. 1993. Are genetically lean broilers more resistant to hot climate? British Poultry Science. 34: 643-653.

Geraert PA, Padilha JCF, Guillaumin S. 1996a. Metabolic and endocrine changes induced by chronic heat exposure in broiler chickens: growth performance, body composition and energy retention. British Journal of Nutrition. 75:195204.

Grashorn M, Bessei W, Thiele HA and Seemann G. 1998. Inheritance of Troponin T levels in meat-type chicken. Archiv für Geflügelkunde. 62: 283-286.

Gu X, Feng C, Ma L, Song C, Wang Y, Da Y, Li H, Chen K, Ye S, Ge C, Hu X, and Li N. 2011. Genome-wide association study of body weight in chicken $F 2$ resource population. PLoS One 6(7):e21872.

Hamilton RMG, Proudfoot FG.1995. Ingredient particle size and feed texture: effects on the performance of broiler chickens. Anim. Feed Sci. Technol. 51: 203 210.

Havenstein GB, Ferket PR, Scheideler SE, and Larson BT.1994a. Growth, Livability, and Feed Conversion of 1957 vs 1991 broilers when fed "typical" 1957 and 1991 broiler diets. Poultry Sci.73:1785-1794.

Havenstein, G. B., P. R. Ferket, S. E. Scheideler, and D. R. Rives. 1994b. Carcass composition and yield of 1991 vs 1957 broilers when fed "typical" 1957 and 1991 broiler diets. Poultry Sci. 73:1795-1804.

Havenstein, GB, Ferket PR, and Qureshi MA. 2003a. Growth, Livability and Feed Conversion of1957 vs 2001 Broilers When Fed representative 1957 and 2001 Broiler diets1 Poultry Sci. 82: 1500-1508.

Havenstein GB, Ferket PR, and Qureshi MA.2003b. Carcass composition and yield of 1957 vs 2001 broilers when fed representative 1957 and 2001 broiler diets. Poultry Sci. 82: 1509-1518.

Havenstein GB. 2006. Performance changes in poultry and livestock following 50 years of genetic selection. Lohman information. 41: 30-41.

Howie JA, Avendano S, Tolkamp BJ, Kyriazakis I. 2011. Genetic parameters of feeding behavior traits and their relationship with live performance traits in modern broiler lines. Poultry Science. 90: 1197-1205.

Howlider MAR \& Rose SP. 1987. Temperature and growth in broilers. World's Poultry Science Journal. 43: 228-237.

Hu Z-L, Dracheva S, Jang W-H, Maglott D, Bastiaansen J, Rothschild MF, Reecy JM. 2005. A QTL resource and comparison tool for pigs: Pig QTLDB. Mamm. Genome. 16:792-800.

Jones FT, Anderson KE, Ferket PR. 1995. Effect of extrusion on feed characteristics and broiler chicken performance. J. Appl. Poult. Res. 4:300-309. 
Julian RJ. 2005. Production and growth related disorders and other metabolic diseases of poultry: a review. Veterinary Journal. 169: 350-369.

Kapell DN, Hill WG, Neeteson AM, McAdam J, Koerhuis AN, Avendaño S. 2012. Genetic parameters of footpad dermatitis and body weight in purebred broiler lines in 2 contrasting environments. Poultry Sci. 91:565-574.

Knowles, TG, Kestin SC, Haslam SM, Brown SN, Green LE, Butterworth A, Pope SJ, Pfeiffer D, and Nicol CJ. 2008. Leg disorders in broiler chickens: prevalence, risk factors and prevention. PLoS ONE 3:e1545.

Koerhuis ANM and Thompson R. 1997. Models to estimate maternal effects for juvenile body weight in broiler chickens. Genetics Selection Evolution. 29: 225-249.

Koh K \& Macleod MG. 1999. Effects of ambient temperature on heat increment of feeding and energy retention in growing broilers maintained at different food intakes. British Poultry Science. 40: 511-516.

Larivière JM, Michaux C, Verleyen V and Leroy P. 2009. Heritability Estimate and Response to Selection for Body Weight in the Ardennaise Chicken Breed. International Journal of Poultry Science. 8 (10): 952-956.

Le Bihan-DuvaL E, Mignon-Grasteau S, Millet N \& Beaumont C. 1998. Genetic analysis of a selection experiment on increased body weight and breast muscle weight as well as on limited abdominal fat weight, British Poultry Science. 39: 346-353.

Leenstra F \& Cahaner A. 1992. Effects of low, normal, and high temperatures on slaughter yield of broilers from lines selected for high weight gain, favorable feed conversion, and high or low fat content. Poultry Science. 71: 19942006.

Liu G, Dunnington EA and Siegel PB. 1993. Maternal effects and heterosis for growth in reciprocal cross populations of chickens. Journal of Animal Breeding and Genetics 110: 423-428.

Liu R Sun Y, Zhao G, Wang F, Wu D, Zheng M, Chen J, Zhang L, Hu Y, and Wen J. 2013. Genome-wide association study identifies loci and candidate genes for body composition and meat quality traits in Beijing-You chickens. PLoS One 8(4):e61172.

Lush JL. 1947. Family merit and individual merit as bases for selection. Part I. Amer. Naturalist. 81: 442-450.

Lynch M \& Walsh B. 1998. Genetic analysis of quantitative traits. Sinauer Associates, Sunderland. 
Macleod MG. 1997. Effects of amino acid balance and energy: protein ratio on energy and nitrogen metabolism in male broiler chickens. British Poultry Science. 38: 405-411.

MacLeod M, Gerber P, Mottet A, Tempio G, Falcucci A, Opio C, Vellinga T, Henderson B \& Steinfeld H. 2013. Greenhouse gas emissions from pig and chicken supply chains - A global life cycle assessment. Food and Agriculture Organization of the United Nations (FAO), Rome.

Marks HL. 1991. Eight-five generations of selection for high four-week body weight in Japanese quail. Pages 113-132 in: Proceedings of the Fortieth Annual National Poultry Breeders Roundtable, St. Louis, MO.

Mathur PK. 2003. Genotype-Environment Interactions: Problems Associated with Selection for Increased Production. in: MUIR, W.M \& AGGREY, S.E. (Eds) Poultry Genetics, Breeding and Biotechnology, pp. 83-99 (CABI Publishing, CAB International, Wallingford, UK).

McKay JC. 2008. The genetics of modern commercial poultry. Proceedings of the 23rd World's Poultry Congress, Brisbane, Australia, July 2008. CD-ROM.

McKay JC. 2009. Biology of breeding poultry. 2009. The genetics of modern commercial poultry. Book chapter pp. 3-9; Conference paper 29th in the Poultry Science Symposium Series, Edinburgh, UK, 23-25 July 2007.

Mašata $O$ and Rasch D. 2006. Methods of variance component estimation. Czech J. Anim. Sci. 51 (6): 227-235.

Melo JE, Romano E, Canet Z, Miquel MC. 2006. Genetic parameters of growth and feed efficiency in a free-range broiler stock. In Proceedings of the $8^{\text {th }}$ World Congr Genet Appl Livest Prod Minas Gerais Brazil 7-13.

Meyer K, Carrick MJ, and Donnelly BJP. 1994. Genetic parameters for milk production of Australian beef cows and weaning weight of their calves. J. Anim. Sci. 72:1155-1165.

Mignon-Grasteau, Beaumont S, Le Bihan-Duval E, Poivey JP, Rochambeau HDE and Ricard, FH. 1999. Genetic parameters of growth curve parameters in male and female chickens. British Poultry Science. 40: 44-51.

Morris TR. 1967. Light requirement of the fowl. In: T.C. Carter: Environmental control in poultry production, Edinburgh and London: Oliver \& Boyd Ltd.: 15-39.

N'Dri AL, Sellier N, Tixier-Boichard M, Beaumont C and Mignon-Grasteau S. 2007. Genotype by environment interactions in relation to growth traits in slow growing chickens. Genetics Selection Evolution. 39: 513-528.

Nir I, Hillel R, Ptichi I, Shefet G.1995. Effect of particle size on performance. 3. Grinding pelleting interactions. Poult. Sci. 74: 771-78. 
NRC. 1994. Nutrient Requirements of Poultry. $9^{\text {th }}$ Revised edition, National Academy Press, Washington, DC.

OECD/FAO, 2014. OECD-FAO Agricultural Outlook 2014-2023.

Pakdel A, Van Arendonk, JAM, Vereijken AL, Bovenhuis H. 2005. Genetic parameters of ascites-related traits in broilers: correlations with feed efficiency and carcass traits. Br. Poult. Sci. 46: 43-53.

Pinto LFB, Packer IU, Ledur MC, Campos RLR, Nones K and Ruy DC, Coutinho LL. 2006. Multi-trait analysis for QTL mapping in chicken. Proc. 8th World Congress on Genetics Applied to Livestock Production, Belo Horizonte, MG, Brasil, August 13-18.

Plavnik I, Hurwitz S. 1990. Performance of broiler chickens and turkeys poults subjected to feed restriction or to feeding of low sodium diets at an early age. Pout. Sci. 69(4): 945-952.

Pollock DL. 1999. A geneticist's perspective from within a broiler primary breeder company. Poultry Science 78: 414-418.

Prado-Gonzalez EA, Ramirez-Avila L, Segura-Correa JC, 2003. Genetic parameters for body weights of Creole chickens from Southeastern Mexicou singan animal model. Livest. Res.Rural.Dev. 15: 1-7.

Reece FN, Lolt BD, Deaton JW, Branbn SL. 1986. Meal feeding and broiler performance. Poult. Sci. 65:1497-1501. REDDY, C.V. (2000) Maintaining growth and production. Poult. Inter. 39(2): 36- 40.

Renema RA, Rustad ME and Robinson FE. 2007. Implications of changes to commercial broiler and broiler breeder body weight targets over the past 30 years. World's Poultry Science Journal 63: 457-472.

Rosa PS, Faria Filho DE, Dahlke F, Vieira BS, Macari M and Furlan RL. 2007. Brazilian Journal of Poultry Science. 9: 181-186

Robinson DL. 1987. Estimation and use of variance components. The Statistician. 36 : 3-14.

Rowe SJ, Windsor D, Haley CS, Burt DW, Hocking PM, Griffin H, Vincent J. and De koning DJ. 2006. QTL analysis of body weight and conformation score in commercial broiler chickens using variance component and half-sib analyses. Animal Genetics. 37: 269-272.

Sasaki O, Odawara S, Takahashi H, Nirasawa K, Oyamada Y, Yamamoto R. Ishii K, NagaminE Y, Takeda H, Kobayashi E. and Furukawa T. 2004. Genetic mapping of quantitative trait loci affecting body weight, egg character and egg production in F2 intercross chickens. Animal Genetics. 35: 188-194.

Savory CJ. 1974. Growth and behavior of chickens fed on pellets or mash. Br. Poult. Sci. 15:281-286. 
Schmidt GS. Figueiredo EAP, Ledur MC and Fairfull R.W.1994. Selection for reproductive traits in a white egg stock breeding programme. Proc. $5^{\text {th }}$ World Congress on Genetics Applied to Livestock Production, University of Gulph.

Schmidt GS, Figueiredo EAP, Ledur MC and Munari DP. 1998. Correlated response on reproductive traits when broiler lines are selected for body weight. Proc. $6^{\text {th }}$ World Congress on Genetics applied to Livestock production, Armidale, Australia, January 11-16.

Schreiweis MA, Hester PY and Moody DE. 2005. Identification of quantitative trait loci associated with bone traits and body weight in an F2 resource population of chickens. Genetics Selection Evoluton. 37: 677-698.

Schutze JV, Jensen LS, Carver JS and Matson WE.1960. Influence of various lighting regimes on the performance of growing chickens. Washington Agric. Exp. Stn. Techn. Bull 36

Sewalem A, Morrice DM, Law, A, Windsor D, Haley CS, Ikeobi CON, Burt DW and Hocking PM. 2002. Mapping of quantitative trait loci for body weight at three, six, and nine weeks of age in a broiler layer cross. Poultry Science 81: 1775-1781.

Sharma A, Leea JS, Dang CG, Sudrajad P, Kim HC, Yeon SH, Kang HS and Lee S. 2015. Genome Wide Association Studies in Livestock - A Review. Asian Australas. J. Anim. Sci. 28(10): 1371-1379.

Sheng Z, Pettersson ME, Hu X, Luo C, Qu H, Shu D, Shen X, Carlborg O. and Li N. 2013. Genetic dissection of growth traits in a Chinese indigenous $\mathrm{x}$ commercial broiler chicken cross. BMC Genomics 14: 151-162.

Sherwood, DH. 1977. Modern broiler feeds and strains: What two decades of improvement have done. Feedstuffs 49:70.

Sheppard A. 2004. The structure and economics of broiler production in England. Special studies in agricultural economics. No. 59

Siegel PB. 1984. The role of behavior in poultry production: a review of research. Appl. Anim. Ethol. 11: 299-316.

Siegel PB, Dodgson JB, Andersson L. 2006. Progress from chicken genetics to the chicken genome. Poult. Sci. 85:2050-60.

Siegel PB. 2014. Evolution of the Modern Broiler and Feed Efficiency. Annu. Rev. Anim. Biosci. 2014. 2:375-85.

Soisontes S. 2015a. Sustainability in poultry production: a comparative study between Germany and Thailand. Ph.D. Thesis, University of Vechta. 
Soisontes S. 2017. Concerns about sustainability in the poultry industry: a comparative Delphi study in Germany and Thailand. World's Poultry Science Journal, Vol. 73: 886-903.

Tallentire CW, Leinonen I and Kyriazakis I. 2016. Breeding for efficiency in the broiler chicken: A review Agron. Sustain. Dev. 36:66. DOI 10.1007/s13593-0160398-2.

Thompson WA, JR. 1962. The problem of negative estimates of variance components. Ann. Math. Statist. 33: 273-289.

Thompson R, Brotherstone S, and White IMS. 2005. Estimation of quantitative genetic parameters. Phil. Trans. R. Soc. B. 360: 1469-1477.

Towne B, Seirvogel RM and Blangero J. 1997. Effects of genotype by sex interaction on quantitative trait linkage analysis. Genet. Epidemiol. 14: 1053- 1058.

Tsudzuki M, Onitsuka S, Akiyama R, Iwamizu M, Goto N, Nishibori M, Takahashi H and Ishikawa A. 2007. Identification of quantitative trait loci affecting shank length, body weight and carcass weight from the Japanese cockfighting chicken breed, Oh-Shamo (Japanese Large Game). Cytogenetic Genome Research. 117: 288-295.

Tuiskula-haavisto M, Honkatukia M, Vilkki J, De koning DJ, Schulman NF and Makitanila A. 2002. Mapping of quantitative trait loci affecting quality and production traits in egg layers. Poultry Science 81: 919-927.

UN (United Nations). 2015. World population projected to reach 9.7 billion by 2050 http://www.un.org/en/development/desa/news/population/2015 report.html. Accessed on 28-11-2018.

USDA. 2018. http://www.usda.gov/nass/pubs/agr05/05ch8.PDF. Accessed on 1911- 2018.

Van kaam JBCMH, Van Arendonk JAM, Groenen MAM, Bovenhuis H, Vereijken, ALJ, Crooijmans R, Van der poel JJ and Veenendaal A. 1998. Whole genome scan for quantitative trait loci affecting body weight in chickens using a three generation design. Livestock Production Science. 54: 133-150.

Verdal H, Narcy A, Bastianelli D, Chapui H, Même N, Urvoix S, Le Bihan Duval E, Mignon-Grasteau, S. 2011. Improving the efficiency of feed utilization in poultry by selection. 2. Genetic parameters of excretion traits and correlations with anatomy of the gastro-intestinal tract and digestive efficiency. BMC Genetics. 12:71.

Visscher PM, Hill WG and Wray NR. 2008. Heritability in the genomics era-concepts and misconceptions. Nat. Rev. Genet. 9:255-266.

Wahlberg P, Carlborg Ö, Foglio M, Tordoir X, Syvänen AC, Lathrop M, Gut IG, Siegel PB and Andersson L. 2009. Genetic analysis of an F2 intercross between two 
chicken lines divergently selected for body-weight. BMC Genomics 10: 248261.

Wang W, Zhang T, Wan J, Zhang G, Wang Y, Zhang Y, Zhang J, Li G, Xue Q, Han K, Zhao $X$ and Zheng H. 2016. Genome-wide association study of 8 carcass traits in Jinghai Yellow chickens using specific-locus amplified fragment sequencing technology. Poultry Science. 95: 500-506.

WATT executive guide to world poultry trends. The statistical reference for poultry executives. 2018. http://www.poultrytrends.com/201811/ Accessed on 1511-2018.

Williams AG, Audsley E \& Sandars DL. 2006. Determining the environmental burdens and resource use in the production of agricultural and horticultural commodities. Main Report, Defra Research Project ISO205, Bedford, Cranfield University and Defra, available on www.silsoe.cranfield.ac.uk, and www.defra.gov.uk.

Willems OW, Miller SP, Wood BJ. 2013. Aspects of selection for feed efficiency in meat producing poultry. World's Poultry Science Journal. 69: 77-87.

Windhorst, H.W. 2015b. Housing systems in laying hen husbandry. Development, present situation and perspectives (London, IEC).

Xie L, Luo C, Zhang C, Zhang R, Tang J, Nie Q, Ma L, Hu X, Li N, Da Y and Zhang X. 2012. Genome-wide association study identified a narrow chromosome 1 region associated with chicken growth traits. PLoS One 7: e30910.

Zhang H, Wang Z, Wang S, Li H. 2012. Progress of genome wide association study in domestic animals. J Anim. Sci. Biotechnol. 3:26. 



\section{2}

\section{Multi-trait estimation of genetic parameters for body weight in a commercial broiler chicken population.}

\footnotetext{
W. Mebratie ${ }^{1}$, P. Madsen ${ }^{1}$, R. Hawken ${ }^{2}$, and J. Jensen ${ }^{1}$

${ }^{1}$ Center for Quantitative Genetics and Genomics, Department of Molecular Biology and Genetics, Aarhus University, 8830 Tjele, Denmark. ${ }^{2}$ Cobb-Vantress Inc. Siloam Springs, Arkansas, USA 72761-1030.
}

Livestock Science (2018) 217:15-18 


\begin{abstract}
Data from 54 selection rounds (SRs) for growth rate in a commercial broiler chicken line were used for analysis to estimate genetic parameters for body weight (BW) in males and females at three different ages. BW was measured at three different ages in different animals ( $t-7, t-4$ and $t$ days) of both sexes. First BW was recorded at $t$ days of age for 39 SRs, however, as selection continued the birds start to grow faster and attain desired body weight earlier, therefore, the weighing age was changed and BW was recorded at $t-4$ and $t-7$ days of age for 7 and 8 SRs, respectively. Multivariate animal model was used to estimate genetic parameters for BW in males and females with REML analysis using DMU software package. In males, heritability estimates of BW were found to be $0.37,0.33$ and 0.29 at $t-7, t-4$ and $t$ days of age, respectively, while, in females, heritability estimates of BW at $t-7, t-4$ and $t$ days of age were found to be $0.40,0.38$ and 0.38 , respectively. The genetic correlations of BW between males and females at $t-7, t-4$ and $t$ days of age were found to be $0.94,0.89$ and 0.89 , respectively, which is significantly different from unity. Also, the genetic correlations of BW between ages were significantly different from unity. The heritability and genetic correlation estimates in this study suggest that BW in males and females should be considered as two different traits. Moreover, BW in the three ages should be considered as three different traits.
\end{abstract}

Key words: Heritability; genetic variance; genetic correlation; body weight. 


\subsection{Introduction}

Breeding programs for broilers select for body weight (BW) as the most important part of the breeding goal to produce chickens that have high growth rate and high market body weight, while minimizing cost of production (Aslam et al., 2011). In this context, estimation of genetic parameters is a required condition in defining, guiding and evaluating the efficiency of a selection program used in generations that make up a particular line (Grosso et al., 2010) and is needed in genetic ranking of potential parents of new generations.

Different authors have estimated genetic parameters for BW in poultry and found heritability estimates in the range from 0.20 to 0.77 (Aslam et al., 2011; Adeyinka et al., 2006; Chapuis et al., 1996; Buss, 1990). Furthermore, substantial variation in genetic parameter estimates of BW in males and females has been reported in poultry (Nestor et al., 2008; Chapuis et al., 1996). Other than the sex differences, genetic parameters of BW might vary with age (Aslam et al., 2011; Adeyinka et al., 2006; Chapuis et al., 1996). In this regard, the significance of the differences in genetic parameters for BW in males and females across different ages in poultry should be quantified by computing standard errors for the estimated genetic parameters and corresponding decisions about the significance of the differences in estimates across sexes and ages should be properly addressed in genetic evaluation models to increase accuracy of the predicted breeding values and reduce bias.

In this study, we have used multivariate analysis to estimate genetic parameters for BW in male and female broiler chickens measured at three different ages. The data used in this study is the same as the data used in chapter 3 (Mebratie et al., 2017). However, Mebratie et al. (2017) used bivariate random regression model mainly to study the development in genetic variance for BW over several generations of selection whereas in this study multivariate animal model was used to investigate whether BW in males and females as well as BW at the three different ages should be considered as same trait or separate traits. The results of this study were used as prior information in chapter 3 (Mebratie et al., 2017) and therefore were briefly mentioned in the materials and methods part of the paper. However, this paper gives details of the statistical model with the results of the multivariate animal model and provides clear insight to multi-trait estimation of BW in male and female broiler chickens measured at three different ages with the subsequent conclusions. Thus, this study aims at estimating genetic parameters for BW in male and female broiler 
chicken population measured at three different ages using multivariate REML analysis.

Table 2.1. Descriptive statistics of the data.

\begin{tabular}{lllll}
\hline Age (days) & Sex & $\mathrm{N}$ & Mean BW(kg) & SD \\
\hline$t$ & Male & 215066 & $2.50^{\mathrm{a}}$ & 0.46 \\
& Female & 226703 & $2.15^{\mathrm{b}}$ & 0.48 \\
$t-4$ & Male & 41121 & $2.38^{\mathrm{a}}$ & 0.20 \\
& Female & 41882 & $2.10^{\mathrm{b}}$ & 0.20 \\
$t-7$ & Male & 61118 & $2.05^{\mathrm{a}}$ & 0.25 \\
& Female & 60813 & $1.81^{\mathrm{b}}$ & 0.25 \\
\hline
\end{tabular}

a-b: Least square means with different superscript letters at the same age are significantly different from each other. Summary of the data is the same as Mebratie et al. (2017).

\subsection{Material and Methods}

\subsubsection{Data}

Data from 54 selection rounds (SRs) for growth rate in a selection line from CobbVantress chicken breeding company was used for analysis. BW was measured in males and females at three different ages ( $t, t-4$ and $t-7$ days). For the first 39 SRs BW was recorded at $t$ days of age, however, as selection continued the birds reached desired BW earlier and the weighing age was changed to $t$-4 days for 7 SRs and then changed again to $t-7$ days for the last 8 SRs (Table 2.1). In total 646, 703 broiler chickens with BW records were used and pedigree information were available for 649,483 broilers. The data summary is presented in Table 2.1 and it is the same as the data used in chapter 3 (Mebratie et al., 2017).

\subsubsection{Statistical model}

Selection round hatch ( $\mathrm{SRH}$ ), which is an interaction of selection round and hatch batch of the individual chicken, were included as fixed effect in the statistical model after testing significance of the effect using PROC GLM of SAS. Direct genetic effect of the animal $(a)$, maternal permanent environmental effect of the dam (pe) and residual environmental effect $(e)$ were included as random effects in the model. 
Variance components were estimated with REML animal model using DMU software package (Madsen and Jensen, 2013). Multivariate analysis was used to estimate variance components by regarding BW at the three ages in males and females as different traits. This results a six trait analysis and the following model was used for each of the BW traits.

$$
\begin{aligned}
& \mathrm{y}_{\mathrm{BWm}(\mathrm{t})}=\mathrm{Xb}_{\mathrm{BWm}(\mathrm{t})}+\mathrm{Z}_{1} \mathrm{a}_{\mathrm{BWm}(\mathrm{t})}+\mathrm{Z}_{2} \mathrm{pe}_{\mathrm{BWm}(\mathrm{t})}+\mathrm{e}_{\mathrm{BWm}(\mathrm{t}),} \\
& \mathrm{y}_{\mathrm{BWf}(\mathrm{t})}=\mathrm{Xb}_{\mathrm{BWf}(\mathrm{t})}+\mathrm{Z}_{1} \mathrm{a}_{\mathrm{BWf}(\mathrm{t})}+\mathrm{Z}_{2} \mathrm{pe}_{\mathrm{BWf}(\mathrm{t})}+\mathrm{e}_{\mathrm{BWf}(\mathrm{t}),} \\
& \mathrm{y}_{\mathrm{BWm}(\mathrm{t}-4)}=\mathrm{Xb}_{\mathrm{BWm}(\mathrm{t}-4)}+\mathrm{Z}_{1} \mathrm{a}_{\mathrm{BWm}(\mathrm{t}-4)}+\mathrm{Z}_{2} \mathrm{pe}_{\mathrm{BWm}(\mathrm{t}-4)}+\mathrm{e}_{\mathrm{BWm}(\mathrm{t}-4),}, \\
& \mathrm{y}_{\mathrm{BWf}(\mathrm{t}-4)}=\mathrm{Xb}_{\mathrm{BWf}(\mathrm{t}-4)}+\mathrm{Z}_{1} \mathrm{a}_{\mathrm{BWf}(\mathrm{t}-4)}+\mathrm{Z}_{2} \mathrm{pe}_{\mathrm{BWf}(\mathrm{t}-4)}+\mathrm{e}_{\mathrm{BWf}(\mathrm{t}-4),} \\
& \mathrm{y}_{\mathrm{BWm}(\mathrm{t}-7)}=\mathrm{Xb}_{\mathrm{BWm}(\mathrm{t}-7)}+\mathrm{Z}_{1} \mathrm{a}_{\mathrm{BWm}(\mathrm{t}-7)}+\mathrm{Z}_{2} \mathrm{pe}_{\mathrm{BWm}(\mathrm{t}-7)}+\mathrm{e}_{\mathrm{BWm}(\mathrm{t}-7),} \\
& \mathrm{y}_{\mathrm{BWf}(\mathrm{t}-7)}=\mathrm{Xb}_{\mathrm{BWf}(\mathrm{t}-7)}+\mathrm{Z}_{1} \mathrm{a}_{\mathrm{BWf}(\mathrm{t}-7)}+\mathrm{Z}_{2} \mathrm{pe}_{\mathrm{BWf}(\mathrm{t}-7)}+\mathrm{e}_{\mathrm{BWf}(\mathrm{t}-7)}
\end{aligned}
$$

Where $y_{B W m(t)}, \quad y_{B W f(t)}, \quad y_{B W m(t-4)}, \quad y_{B W f(t-4)}, y_{B W m(t-7)}$ and $y_{B W f(t-7)}$ are phenotypic vectors of records for BW in males at $t$ days of age, BW in females at $t$ days of age, BW in males at $t-4$ days of age, BW in females at $t-4$ days of age, BW in males at $t-7$ days of age and BW in females at $t-7$ days of age, respectively. Vectors $b_{B W m(t)}, b_{B W f(t)}, b_{B W m(t-4)}, b_{B W f(t-4)}, b_{B W m(t-7)}$ and $b_{B W f(t-7)}$ contain "fixed" effects of SRH for traits $\mathrm{BW}_{\mathrm{m}(\mathrm{t})}, \mathrm{BW}_{\mathrm{f}(\mathrm{t})}, \mathrm{BW}_{\mathrm{m}(\mathrm{t}-4)}, \mathrm{BW}_{\mathrm{f}(\mathrm{t}-4)}, \mathrm{BW}_{\mathrm{m}(\mathrm{t}-7)}$ and $\mathrm{BW}_{\mathrm{f}(\mathrm{t}-7)}$,

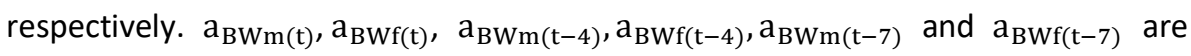
vectors of animal additive genetic effects for traits $\mathrm{BW}_{\mathrm{m}(\mathrm{t})}, \mathrm{BW}_{\mathrm{f}(\mathrm{t})}, \mathrm{BW}_{\mathrm{m}(\mathrm{t}-4)}, \mathrm{BW}_{\mathrm{f}(\mathrm{t}-4)}, \mathrm{BW}_{\mathrm{m}(\mathrm{t}-7)}$ and $\mathrm{BW}_{\mathrm{f}(\mathrm{t}-7)}, \quad$ respectively. Vectors, $\mathrm{pe}_{\mathrm{BWm}(\mathrm{t})}, \mathrm{pe}_{\mathrm{BWf}(\mathrm{t})}, \mathrm{pe}_{\mathrm{BWm}(\mathrm{t}-4)}, \mathrm{pe}_{\mathrm{BWf}(\mathrm{t}-4)}, \mathrm{pe}_{\mathrm{BWm}(\mathrm{t}-7)}$ and $\mathrm{pe}_{\mathrm{BWf}(\mathrm{t}-7)}$ are maternal permanent environmental effects for traits $B W_{m(t)}, B W_{f(t)}, B W_{m(t-4)}$, $\mathrm{BW}_{\mathrm{f}(\mathrm{t}-4)}, \mathrm{BW}_{\mathrm{m}(\mathrm{t}-7)}$ and $\mathrm{BW}_{\mathrm{f}(\mathrm{t}-7)}$, respectively. $\mathbf{X}, \mathbf{Z 1}$ and $\mathbf{Z 2}$ are the corresponding design matrices for the fixed effect $\mathrm{SRH}$, the random effects additive genetic effect of the animal and permanent environmental effect of the dam for the 6 traits, respectively. Random effects $a, p e$ and $e$ are assumed to be normally distributed and independent to each other with the following assumptions: $a \sim N(0, A \otimes G)$, $p e \sim N(0, \mathrm{I} \otimes \mathrm{K}), e \sim N(0, I \otimes R)$, where $\mathrm{A}$ is the numerator relationship matrix, $\mathrm{G}$ is the co (variance) matrix for direct animal additive genetic effects of dimension $6, \mathrm{I}$ is identity matrix, $\mathrm{K}$ is the co (variance) matrix for maternal permanent environmental effects of dimension $6, \mathrm{R}$ is residual co (variance) matrices of dimension 6 which was 
assumed to be heterogeneous with different variance for each of the six BW traits. Residual covariance between the six traits were assumed to be zero since BW was measured at different birds in males and females at all the three ages. Symbol $\otimes$ denotes Kronecker (direct) product.

\subsection{Results}

The heritability estimates of BW in females $(0.40,0.38$ and 0.38$)$ at $t-7, t-4$ and $t$ days, respectively, were found to be higher than that of males $(0.37,0.33$, and 0.29$)$ at the same age (Table 2.2). The genetic correlations of BW between males and females at the same age were found to be $0.94,0.89$ and 0.89 at $t-7, t-4$ and $t$ days, respectively, which is different from unity and higher at earlier age than later ages (Table 2.2). Genetic correlations of BW within males at different age combinations $(t-7, t-4),(t-$ $4, t)$ and $(t, t-7)$ days were found to be $0.97,0.90$ and 0.86 , respectively (Table 2.3), while the genetic correlation of BW within females were found to be $0.95,0.87$ and 0.81 at $(t-7, t-4),(t-4, t)$ and $(t, t-7)$ days, respectively (Table 2.3$)$. This shows that the genetic correlation of BW between the three ages is different from unity and decreased as the distance between BW measurements (ages) increased. 
Table 2.2. Genetic parameters of body weight in males and females at the three ages.

\begin{tabular}{|c|c|c|c|c|c|c|c|c|c|}
\hline \multirow[t]{2}{*}{ Age (days) } & \multirow[t]{2}{*}{ Sex } & \multirow[t]{2}{*}{$h^{2}$} & \multirow[t]{2}{*}{ SE } & \multicolumn{4}{|c|}{ Variance components $\left(\mathrm{Kg}^{2}\right)$} & \multirow[t]{2}{*}{ Genetic Correlation } & \multirow[t]{2}{*}{ SE } \\
\hline & & & & Genetic & Residual & $\begin{array}{l}\text { Permanent } \\
\text { environment }\end{array}$ & Phenotypic & & \\
\hline \multirow[t]{2}{*}{$t-7$} & Males & 0.37 & 0.02 & 0.0129 & 0.0206 & 0.0011 & 0.0345 & $* 0.94$ & 0.01 \\
\hline & Females & 0.40 & 0.02 & 0.0081 & 0.0114 & 0.0006 & 0.0202 & & \\
\hline \multirow[t]{2}{*}{$t-4$} & Males & 0.33 & 0.02 & 0.0136 & 0.0265 & 0.0010 & 0.0412 & $* * 0.89$ & 0.01 \\
\hline & Females & 0.38 & 0.02 & 0.0086 & 0.0137 & 0.0005 & 0.0228 & & \\
\hline \multirow[t]{2}{*}{$t$} & Males & 0.29 & 0.01 & 0.0139 & 0.0328 & 0.0020 & 0.0488 & $* * * 0.89$ & 0.01 \\
\hline & Females & 0.38 & 0.01 & 0.0111 & 0.0170 & 0.0009 & 0.0289 & & \\
\hline
\end{tabular}

* Genetic correlation of body weight between males and females at $t-7$ days.

** Genetic correlation of body weight between males and females at $t-4$ days.

${ }^{* * *}$ Genetic correlation of body weight between males and females at $t$ days. 
Table 2.3. Genetic correlation of body weight with standard errors within males (upper diagonal) and within females (lower diagonal) at different ages.

\begin{tabular}{llll}
\hline Age (days) & $t-7$ & $t-4$ & $t$ \\
$t-7$ & & $0.97(0.01)$ & $0.86(0.05)$ \\
$t-4$ & $0.95(0.02)$ & & $0.90(0.01)$ \\
$t$ & $0.81(0.05)$ & $0.87(0.03)$ & \\
\hline
\end{tabular}

\subsection{Discussion}

\subsubsection{Genetic parameters of BW in male and female broilers}

Body weight in males is significantly different from that of females; males having higher mean body weight than females in all the three ages (Table 2.1). This is in line with, Singh (1989) who reported that male chickens have $15-20 \%$ higher BW than females at the same stage of growth. Higher heritability estimates of BW were observed in females than males in all the three ages (Table 2.2). This is in agreement with Chapuis et al. (1996) who reported higher heritability estimates in females than males in turkey birds. The genetic variance estimates of males are higher than that of females at all the three ages. However, females have higher heritability estimates than males in all the three ages due to the observed higher residual variance in males than in females. The maternal permanent environmental variance estimates in this study explain a very small proportion of the total phenotypic variance in both sexes (Table 2.2). This is in line with Aslam et al. (2011) who reported that the proportion of variance explained by the maternal permanent environment in turkeys was high at hatch and its effect decreased with age and becomes negligible after 60 days of age.

In the present study, estimated genetic correlations of BW between males and females at the same age were significantly lower than unity. The effect was more pronounced at later ages of $t$ or $t-4$ days than $t-7$ days of age (Table 2.2). Chapuis et al. (1996) also reported a genetic correlation less than one between BW in male and female turkeys. This might be due to different hormonal regulations between males and females, which is sex by genotype interaction; genes interacting differently in male and female physiological environments as explained by Towne et al. (1997) and the difference in hormonal regulations might even be more distinct with age. In agreement with this, Mignon-Grasteau et al. (1998) reported that male and female 
chickens might have different physiological age at a given age. The observed decrease in genetic correlation of BW between males and females with age indicates that the hormonal differences become more significant as the birds age towards sexual maturity, as sexual hormones might probably have significant role for the genes controlling BW in the two sexes. Using random regression model, Mebratie et al. (2017) have also reported genetic correlation of BW between males and females which is significantly different from unity for the same broiler line. The significantly different heritability estimates of BW in males and females, and the significantly lower genetic correlations than unity between BW in males and females at the same age suggest that the genetic background of BW in males and females in this broiler chicken population might be partly different and genetic evaluation models should take this sex differences in to account to increase accuracy of selection.

\subsubsection{Genetic parameters of BW at the three different ages}

The heritability estimates of body weight at $t-7$ days $(0.37,0.40), t-4$ days $(0.33,0.38)$ and, $t$ days $(0.29,0.38)$ in males and females, respectively were found to be moderate (Table 2.2). The estimates are in agreement with different authors who reported heritability estimates of BW in males and females at different ages in the range from 0.20 - 0.48 in different poultry species (Mebratie et al., 2017; Aslam et al., 2011; Adeyinka et al., 2006). The heritability estimates in this study decreased with age. In line with this study, Adeyinka et al. (2006) observed a decreasing heritability with age in broiler chickens. In the current study, both genetic and residual variance increased with age, however, the residual variance increased in a relatively larger proportion than the genetic variance, which explains the decrease in heritability estimates with age.

The genetic correlation of BW between the three ages decreased as the distance between the ages increased; genetic correlations were higher between measurements taken closer in age than measurements that were taken far apart. Aslam et al. (2011) also reported a decrease in genetic correlation between BW at different ages as the distance between recording ages increased in turkeys. This suggests that there might be physiological changes of birds with age, which might be related to genes that "turn on" and "turn off" as an animal ages, resulting in changes in physiology and performance as stated by Schaeffer (2011). Moreover, the genetic correlations of BW at the three different ages suggest that BW in the three ages might be partially controlled by different genes.

The significantly different heritability estimates of BW in the three ages, and the significantly lower genetic correlations than unity between BW in the three ages 
within sexes suggest that the genetic background of BW in the three ages might be different in this broiler line and genetic evaluation models should take this age differences in to account to increase accuracy of the predicted breeding values. In general, the significantly different heritability estimates of BW in males and females as well as genetic correlations of BW between males and females, which is significantly different from unity, suggest that BW in males and females should be considered as separate traits in the subsequent analysis. Similarly, the significantly different heritability estimates of BW in the three ages and genetic correlations of BW between ages, which are significantly different from unity, suggest that BW at the three different ages should be considered as separate traits in the subsequent analysis.

The above conclusion led us to the bivariate random regression model in chapter 3 (Mebratie et al., 2017). In the bivariate RRM model, males and females were treated as different traits and random regression coefficients (co-variables) were fitted to the random effects in the three ages (periods) to allow individual variation across the selection trajectory (54 selection rounds). By doing so, we have verified the results of the multivariate REML analysis in the current study with an additional objective of studying the development in genetic variance for BW over several generations of selection.

\subsection{Conclusions}

The present study showed that the heritability estimates of BW significantly varied with sex and the genetic correlations of BW between sexes significantly differed from unity. Therefore, BW in males and females should be treated as two different traits in genetic evaluation and optimization of broiler breeding programs. Furthermore, the heritability estimates of BW at $t-7, t-4$ and $t$ days of age were significantly different and genetic correlations of BW between the three ages were significantly different from unity suggesting that BW in the three ages should be regarded as three different traits underlining the importance of recording body weight at the target slaughtering age. In general, the result of this study suggest that genetic evaluation models for body weight should take sex and age differences in to account to increase accuracy of selection rather than assuming a genetic correlation of unity between males and females as well as different recording ages. 


\section{Acknowledgements}

The authors would like to thank Cobb-Vantress for providing the data and the European graduate school in animal breeding and genetics ("EGS-ABG"), which is funded by the European Union, for providing scholarship for the first Author.

\section{References}

Adeyinka IA, Oni OO, Nwagu BI, and Adeyinka FD. 2006. Genetic parameters estimate of body weight of nacked neck broiler chickens. International journal of poultry science. 5(6) 589-592.

Aslam ML, Bastiaansen JW, Crooijmans RPMA, Ducro BJ, Groenen MA, Vereijken A. 2011. Genetic variances, heritabilities and maternal effects on body weight, breast meat yield, meat quality traits and the shape of the growth curve in turkey birds. BMC. Genet. 12, 14.

Buss EG. 1990. Genetics of growth and meat production in turkeys, in: Crawford, r.d. (ED.) Poultry breeding and Genetics Amsterdam, Elsevier. 645-675.

Chapuis H, Delabrosse Y, Ducroc V, Tixer-Boichard M. 1996. Multivariate restricted maximum likelihood estimation of genetic parameters for production traits in three selected turkey strains. Genet. Sel. Evol. 28, 299-317.

Grosso JLBM, Balieiro JCC, Eler JP, Ferraz JBS, Mattos EC, and Michelan Filho T. 2010. Comparison of different models to estimate genetic parameters for carcass traits in a commercial broiler line. Genet. Mol. Res. 9 (2): 908-918.

Madsen P and Jensen J. 2013. A User's guide to DMU, A Package for analyzing multivariate Mixed Models. Ver. 6, Rel 5.2. http://dmu.agrsci.dk/DMU/Doc/Current/dmuv6_guide.5.2.pdf

Mebratie W, Shirali M, Sapp RL, Madsen P. Hawken R, Jensen J. 2017. The effect of selection and sex on genetic parameters of body weight in a commercial broiler chicken population. Livestock scie. 204, 78-87.

Nestor KE, Anderson JW, Patterson RA, Velleman SG. 2008. Genetics of growth and reproduction in turkey. Poult. Sci. 87, 1971-1979.

Mignon-Grasteau S, Beaumont C, Poivey J, Hubert DR. 1998. Estimation of the genetic parameters of sexual dimorphism of body weight in 'label' chickens and Muscovy ducks. Genet. Sel. Evol. 30, 481-491.

Schaeffer LR. 2011. Animal Breeding Methods course notes, Random regression models, pp. 1-9. Access http://www.aps.uoguelph.ca/ Irs/ (Accessed 05.08.2015). 
Singh SS, Verma SK, Khan AG, Shrivastava AK. 1989. Studies in genetic variability in juvenile body weight and sexual dimorphism in layer type chickens, Indian J. Poult. Scie.24 (4), 308-310.

Towne B, Seirvogel RM, and Blangero J. 1997. Effects of genotype by sex interaction on quantitative trait linkage analysis. Genet. Epidemiol.14, 1053- 1058. 


\section{The effect of selection and sex on genetic}

parameters of body weight at different ages in a commercial broiler chicken population

W. Mebratie ${ }^{1}$, M. Shirali ${ }^{1}$, P. Madsen ${ }^{1}$, R.L. Sapp ${ }^{2}$, R. Hawken ${ }^{2}$, and J. Jensen ${ }^{1}$

${ }^{1}$ Center for Quantitative Genetics and Genomics, Department of Molecular Biology and Genetics, Aarhus University 8830 Tjele, Denmark. ${ }^{2}$ Cobb-Vantress Inc. Siloam Springs, Arkansas, USA 72761-1030.

Livestock science (2017) 204: 78-87 


\section{Abstract}

Data from 54 selection rounds (SRs) for growth rate in a selection line from CobbVantress was used for analysis with the objective to investigate the extent of sex by genotype interaction for body weight (BW) in a commercial broiler chicken population, estimate genetic parameters of BW at three different ages, and study the development in genetic variance for BW over several generations of selection. BW was measured at three different ages ( $t, t-4$ and $t-7$ days) in different birds of both sexes. For the first $39 \mathrm{SRs}$, BW was recorded at $t$ days of age, however, as selection continued the birds reached desired BW earlier and the weighing age was changed to $t-4$ days for $7 \mathrm{SRs}$ and then to $t-7$ days for the last $8 \mathrm{SRs}$. A bivariate random regression model regarding $\mathrm{BW}$ in each sex as different traits using segmented linear splines and heterogeneous residual variance was used to estimate genetic parameters of BW across the selection trajectory. The genetic variance and the heritability estimates of BW in males and females were found to be different at all the three ages. The genetic correlation between BW measured in males and females was less than unity and decreased further as the weighing age increased. This illustrated that BW in the two sexes should be considered as different but correlated traits and models for BW should account for a decreasing genetic correlation as the distance between weighing ages increased. An increased genetic variance of BW along the selection trajectory in the first period was observed and genetic correlations between BW measured in different SRs gradually decreased as the distance between SRs increased. Genetic correlations lower than unity between BW at early and late SRs in the first period indicated that the genetic background of BW gradually changed along the selection trajectory. This change probably contributes significantly to maintaining large levels of genetic variance in highly selected broiler populations.

Key words: random regression; linear splines; heritability; genetic variance; genetic correlation. 


\subsection{Introduction}

In broilers body weight (BW) and carcass quality traits have been under intensive selection for more than half a century, and are considered the most important economic traits in broiler breeding programs (Nassar et al., 2012). Production traits in broilers are influenced not only by the genotype of the individual but also by maternal effects (Szwaczkowski, 2010). Considerable variation is found in the literature concerning estimates of heritabilities and genetic correlations for growth traits in broilers (Prado-González, 2003) due to differences in recording systems and age at recording. Nestor et al. (2008) regarded BW in male and female turkeys as different traits with a genetic correlation different from unity. This is the same as sex by genotype interaction and this interaction has been reported to be related to different hormonal regulations in males and females (Towne et al., 1997). Chapuis et al. (1996) reported higher genetic correlation for BW in turkey birds between males and females at early ages than later ages which is consistent with increased differentiation between the sexes as the birds get older. Therefore, models used for estimation of genetic parameters of BW in poultry need careful consideration of sex differences and different recording ages.

Selection, generally, reduces the genetic variability of a trait due to change in gene frequencies in response to selection. The reduction in genetic variance is likely to be small during the first few generations because gene frequencies change slowly unless there are genes with large effects (Falconer and Mackay, 1996). The outcome of selection over a long period is however unpredictable because the outcome depends on the properties of the individual genes contributing to the response and also due to new variation caused by mutation (Falconer and Mackay, 1996). Sørensen (1986) observed that the genetic variance for growth rate in broiler chickens were not significantly reduced after several generations of selection which was explained to be due to generation of new genetic variation as a result of mutuation and epistatic effects.

Random regression models (RRMs) are reported to be more accurate than multiple trait models (MTM) in estimating genetic parameters especially when the data set is large. Meyer (2004) reported RRMs to be up to 9.5\% more accurate than MTMs. Bohmanova et al. (2005) also reported the accuracy of RRMs over MTMs. According to their report MTMs and RRMs have similar accuracy when records occur at standard points (ages). However, MTMs lose accuracy while RRMs maintain accuracy when records occur at non-standard points (outside the pre-adjusted age intervals). The authors also reported an increased accuracy of RRMs when additional records are incorporated. 
BW growth is a longitudinal process and random regression models (RRMs) are useful for the analysis of longitudinal data (Schaeffer, 2004). RRMs can also be used to study changes in genetic parameters over time (Schaeffer, 2004). The right way to model traits that are measured over a trajectory is to fit a set of random coefficients of time or weight for each animal to allow for individual variation in the course of the trajectory (Meyer, 1998). Cognizant of this facts, RRMs should also be a model of choice to study development in genetic variance (genetic parameters) of a trait over several generations of selection. RRMs using Legendre polynomials have been widely used following Kirkpatrick et al. (1990) and Meyer (2005). Legendre polynomials are able to model a variety of curves along a trajectory but they may have undesirable properties such as poor fit at the extremes of the trajectory and at points of the trajectory with few records (Misztal et al., 2000). However, poor fits in splines are more visible than with Legendre polynomials and they can be better controlled by changing the number and position of knots. Such models usually have good fit at the knots but may have poorer fit between the knots (Misztal, 2006). In addition RRMs with splines are reported to have better numerical properties than Legendre polynomials since each coefficient in splines affect only a portion of the trajectory and only co-variables associated with two adjacent knots are non-zero while in Legendre polynomials of order $\mathrm{n}$ all co-variables are generally non-zero (Robbins et al., 2005). Splines are also advantageous in offering greater flexibility than the functions typically used in RRMs and are often used for smoothing data (Jensen, 2001).

Thus, the objectives of the present study were to (i) investigate the extent of sex by genotype interaction for BW in a commercial broiler chicken population (ii) estimate genetic parameters of BW at three different ages and (iii) study the development in genetic variance for BW over several generations of selection.

\subsection{Material and Methods}

\subsubsection{Simulation study}

A small simulation study was performed to test if the complex random regression model we have used for the real body weight data can handle a continuous change in variance over time. Data on 30,000 birds were generated, so that each bird had 3 observations recorded at different ages according to the following model.

$y_{i j k}=\mu+a_{o i}+a_{1 i}\left(L_{1 j}\right)+a_{2 i}\left(L_{2 k}\right)+e_{i j k}$ 
Where, $y_{i j k}$ is the trait of interest for bird i recorded at time point $\mathrm{j}$ and age k. $a_{0 i}$ is the intercept, $a_{1 i}$ and $a_{2 i}$ are breeding values of bird $i$ for intercept, time effects and age effects, respectively. $L_{1}$ and $L_{2}$ are co (variables) for across bird time effects and within bird age effects, respectively, and $e_{i j k}$ is the random residual. Co (variables) $L_{1}$ and $L_{2}$ were generated as follows: $L_{1 i}=I D_{i} / n a$, where $I D_{i}$ is the individual bird and $n a$ is the total number of birds. The ID of individual birds were ordered by time $t$ and this means that time effects gradually change over from the first bird to the

last bird. $L_{2 k}=j_{k} / n_{j}$, where $j_{k}$ is the $k^{\text {th }}$ record number (age) and $n_{j}$ is the total number of records (ages). I.e. these effects gradually change with age of the birds. The birds were assumed to be independent and breeding values were assumed to be trivariate normal, with a $3 \times 3$ identity matrix as co (variance) matrix. Normal distribution and unit variance were assumed for the residuals. After the generation of the data, co (variance) components were estimated using the same model as used for simulation. Estimation of variance components were carried out using DMU software package (Madsen and Jensen, 2010). The simulation was replicated 150 times and the mean, standard deviation (SD) and standard error of the mean (SEM) of all co (variance) components estimated are reported.

\subsubsection{Data}

Data from 54 selection rounds (SRs) for growth rate in a selection line from Cobb broiler breeding company was used for analysis. The number of broilers with BW and pedigree data were 646,703 and 649,483 , respectively, and the pedigree covers about 8 generations back from the youngest animals. BW was measured at three different ages ( $t, t-4$ and $t-7$ days) in different animals of both sexes. For the first 39 SRs BW was recorded at $t$ days of age, however, as selection continued the birds reached desired BW earlier and the weighing age was changed to $t-4$ days for 7 SRs and then changed again to $t-7$ days for the last 8 SRs. Descriptive statistics of the data can be referred in chapter 2 , Table 2.1 .

\subsubsection{Statistical model}

The results of the multivariate analysis in chapter 2 (Mebratie et al., 2018) showed different heritability estimates of BW in the two sexes and genetic correlations of BW between the two sexes to be different from unity. The results also showed that BW in the three weighing ages have different heritability estimates and genetic correlations of BW between the three different ages are different from unity with 
decreased genetic correlation as the distance between the ages increased. Therefore, the initial model illustrated that BW in the two sexes as well as BW in the three different ages should not be considered as same trait in the subsequent analysis.

Thus, a bivariate random regression model with piece-wise (segmented) linear splines which are not continuous across segments were used to estimate genetic parameters of BW along the trajectory of SRs using Gibbs sampling. Such a model can accommodate different parameters for each sex and different parameters for each age at measuring BW and finally can estimate gradual changes in genetic parameters over the selection trajectory. The bivariate RRM in scalar notation used for both males and females was:

$y_{i j l t=} S R H_{j}+\sum_{k=1}^{4} \emptyset_{k}(t) a_{i k}+\sum_{k=1}^{4} \emptyset_{k}(t) p e_{l k}+e_{i j l t}$

Where $\boldsymbol{y}_{\boldsymbol{i j} l \boldsymbol{t}}$ is the BW of animal $\mathrm{i}$ hatched in selection round hatch batch $\mathrm{j}$ from dam I and recorded in SR, t. The selection round and hatch batch interaction (SRH) were considered fixed and the random part of the model was fitted using segmented linear spline functions which were not continuous over segments, with knots at SR 1 and 39 for the first period where BW was measured at $t$ days of age, and one knot with constant (linear spline) regression coefficient for all the 7 and 8 SRs in the second and third period, where BW were recorded at $t-4$ and $t-7$ days of age respectively. Thus, $\boldsymbol{a}_{\boldsymbol{i} \boldsymbol{k}}$ and $\boldsymbol{p} \boldsymbol{e}_{\boldsymbol{l} \boldsymbol{k}}$ represent the random regression coefficients for the splines describing the additive genetic effect of animal $i$ and the maternal permanent environmental effect of dam I, respectively and $\boldsymbol{e}_{\boldsymbol{i} j \boldsymbol{t} \boldsymbol{t}}$ represents the residual effect of animal $\mathrm{i}$ in SR, t. $\emptyset_{\boldsymbol{k}}(\boldsymbol{t})$ represents the value of the $\mathrm{k}^{\text {th }}$ covariate at time $t(\mathrm{SR})$. These covariates were computed as described by Misztal (2006). In the first period, the covariates were computed as: $\frac{(t-1)}{(39-1)}$ and $1-\frac{(t-1)}{(39-1)}$, where 1 and 39 are the first and last knots in the first period, respectively. In the second and third period, constant (1) intercept was used due to the small number of SRs in the two periods, which were not enough to estimate a clear pattern in change in variance along the selection trajectory. The same functions were used for the direct genetic effect of the animal and maternal permanent environmental effects. Therefore, a total of four knots and three segments were used in the bivariate RRM with two knots in the first period and a single knot in each segment of the second and third period.

The random effects direct genetic effect, maternal permanent environment and residual variance were assumed to be normally distributed with the following 
assumptions: $\boldsymbol{a} \sim \mathrm{N}\left(0, \mathbf{A} \otimes \mathbf{k}_{\mathbf{0 a}}\right), \mathbf{p e} \sim \mathrm{N}\left(0, \mathrm{I} \otimes \mathbf{k}_{\mathbf{0 p e}}\right), \mathbf{e} \sim \mathrm{N}\left(0, \sum_{1}^{54} \bigoplus \mathbf{I} \boldsymbol{\sigma}_{\text {et }}^{2}\right)$. Where $\mathbf{A}$ is the numerator relationship matrix, $\mathbf{k}_{\mathbf{0 a}}$ is the co (variance) matrix for direct additive genetic effects of dimension eight (four variance components for each sex), and $\mathbf{I}$ is identity matrix, $\mathbf{k}_{\mathbf{0 p e}}$ is the co (variance) matrix for maternal permanent environmental effect also of dimension eight, and $\mathbf{I} \boldsymbol{\sigma}_{\boldsymbol{e} t}^{2}$ is the residual variance for males and females separately in SR, $t$, i.e. residual variance were assumed to be heterogeneous with different variance for each sex in each SR. Thus, the model included 54 residual variances for each sex, one for each SR. Residual covariance between sexes were assumed to be zero. Symbol $\otimes$ denotes Kronecker (direct) product and symbol $\oplus$ denotes direct sum.

A Bayesian procedure using Gibbs sampling was used to estimate (co) variances between random regression coefficients and estimates of residual variance for each SR-sex sub group. Flat priors were assumed for all "fixed" effects and variance components. Marginal posterior distributions were obtained for all parameters in the model using the RJMC module in the DMU software package (Madsen and Jensen, 2013). A total of 1,000,000 samples were obtained from the Gibbs sampler and out of these, the first 250,000 were discarded as burn in and from the remaining samples every $200^{\text {th }}$ were saved for post Gibbs analysis. Means of the marginal posterior distributions of (co)variance components and breeding values were computed as averages of samples after the burn-in period. Convergence of the Gibbs chain was monitored by using the BOA program (Smith, 2007).

\subsection{Results}

The results of the small simulation study are shown in Table 3.1. The results of the study have shown that the means of the estimates of the diagonal and off diagonal elements of the co (variance) components are very close to the true value. The means of the estimates of the diagonals are close to 1 (identity) and the means of the estimates of the off diagonals are close to 0 with small standard error of the means which meets the expectation of the model. The SD of the estimates show that the variance components for intercept and age effects are quite accurately estimated with SD of 0.086 and 0.061 , respectively. However, for the time effect where each individual is measured at its own specific time different from other individuals, have a SD of 0.257 . I.e. The accuracy of estimating the change in variance over time is lower compared with the effects associated with each animal. 
Table 3.1. Means of co (variance) components for trait y from the simulation study.

\begin{tabular}{llllll}
\hline $\begin{array}{l}\text { Parameter } \\
\text { number }\end{array}$ & Co (variance) & $\begin{array}{l}\text { Mean of } \\
\text { estimates }\end{array}$ & SD & SEM & True value \\
\hline 1 & $1-1$ & 1.001 & 0.086 & 0.007 & 1.000 \\
2 & $1-2$ & 0.005 & 0.012 & 0.001 & 0.000 \\
3 & $1-3$ & 0.000 & 0.061 & 0.005 & 0.000 \\
4 & $2-2$ & 0.987 & 0.257 & 0.021 & 1.000 \\
5 & $2-3$ & 0.003 & 0.123 & 0.010 & 0.000 \\
6 & $3-3$ & 1.009 & 0.061 & 0.005 & 1.000 \\
7 & $4-4$ & 1.000 & 0.012 & 0.001 & 1.000 \\
\hline
\end{tabular}

N.B. Parameters 1-6 are values for the random effect animal and parameter 7 is value for the random residual variance. SD is standard deviation. SEM is the standard error of the mean of the estimates across the replicates.

Descriptive statistics of the data is presented in Table 2.1. Body weight in males is significantly different from that of females; males having higher mean BW than females at all the three weighing ages. Mean BW decreased in both sexes as the weighing age decreased (Table 2.1). The posterior means of genetic variance for BW in males and females is presented in Figure 1 as a function of time (SR). The genetic variance of BW in the first period showed an overall increasing trend from 0.0103 to $0.0268 \mathrm{~kg}^{2}$ in males and from 0.0074 to $0.0197 \mathrm{~kg}^{2}$ in females along the selection trajectory from SR 1 to 39. However, the genetic variance in the second period dropped from 0.0268 to 0.0124 in males and from 0.0197 to 0.0084 in females at the SR where the weighing age was changed from $t$ to $t-4$ days. Similarly, it dropped slightly in the third period at the SR where the weighing age was changed from $t-4$ to $t-7$ days, from 0.0124 to 0.0116 in males and from 0.0084 to 0.0076 in females (Figure 3.1). 

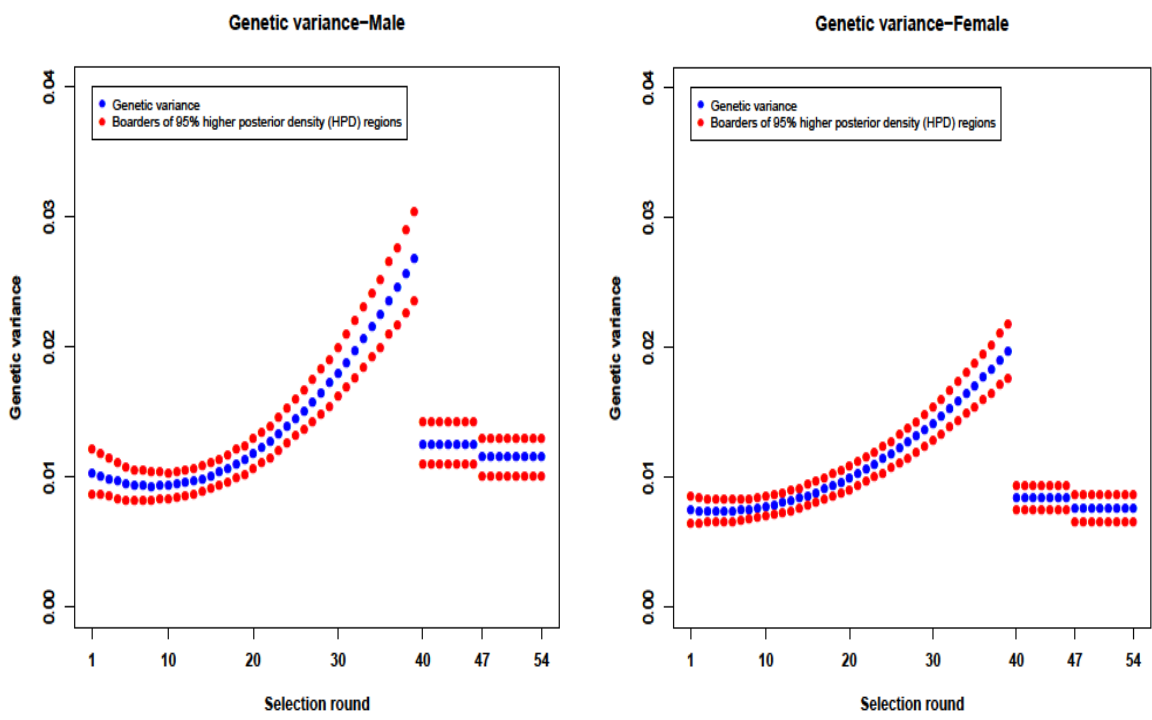

Figure 3.1. Posterior means of genetic variance of body weight (BW) in males and females along the selection trajectory.

The posterior means of maternal permanent environmental variance of $\mathrm{BW}$ in males and females is presented in Figure 3.2 as a function of SR (time). In males the maternal permanent environmental variance showed an increasing trend in the first period, from 0.0016 to 0.0026 and then dropped to 0.0015 in the second period at the SR where the weighing age was changed from $t$ to $t-4$ days. Similarly, a drop in maternal permanent environmental variance of BW was observed in males in the third period from 0.0015 to 0.0013 at the SR where the weighing age was changed from $t-4$ to $t-7$ days. However, in females the change in permanent environmental variance over SRs was not significant since all higher posterior density regions (HPD) were overlapping (Figure 3.2). 

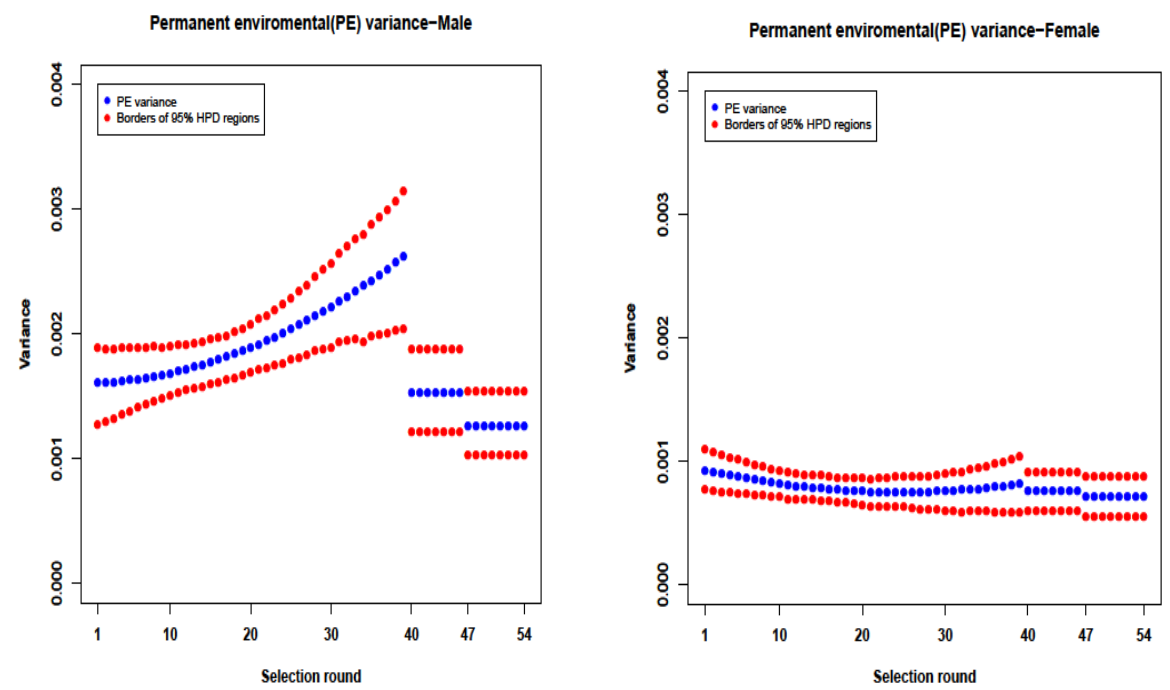

Figure 3.2. Posterior means of maternal permanent environmental variance of $B W$ in males and females along the selection trajectory.

The residual variance of $\mathrm{BW}$ showed an overall increasing trend in the first period from 0.0220 to 0.0344 in males and from 0.0129 to 0.0163 in females but with considerable fluctuation from one SR to another reflecting seasonal variation. The residual variance dropped slightly in the second period from 0.0344 to 0.0252 in males and from 0.0163 to 0.0127 in females at the SR where the weighing age was changed from $t$ to $t-4$ days. Similarly, the residual variance of BW showed a clear drop in the third period from 0.0273 to 0.0216 in males and dropped slightly from 0.0143 to 0.0125 in females at the SR where the weighing age was changed from $t-4$ to $t-7$ days. However, clear pattern in change in residual variance along the selection trajectory was not observed in the second and third period in both sexes probably due to the small number of SRs included in the two periods (Figure 3.3). 

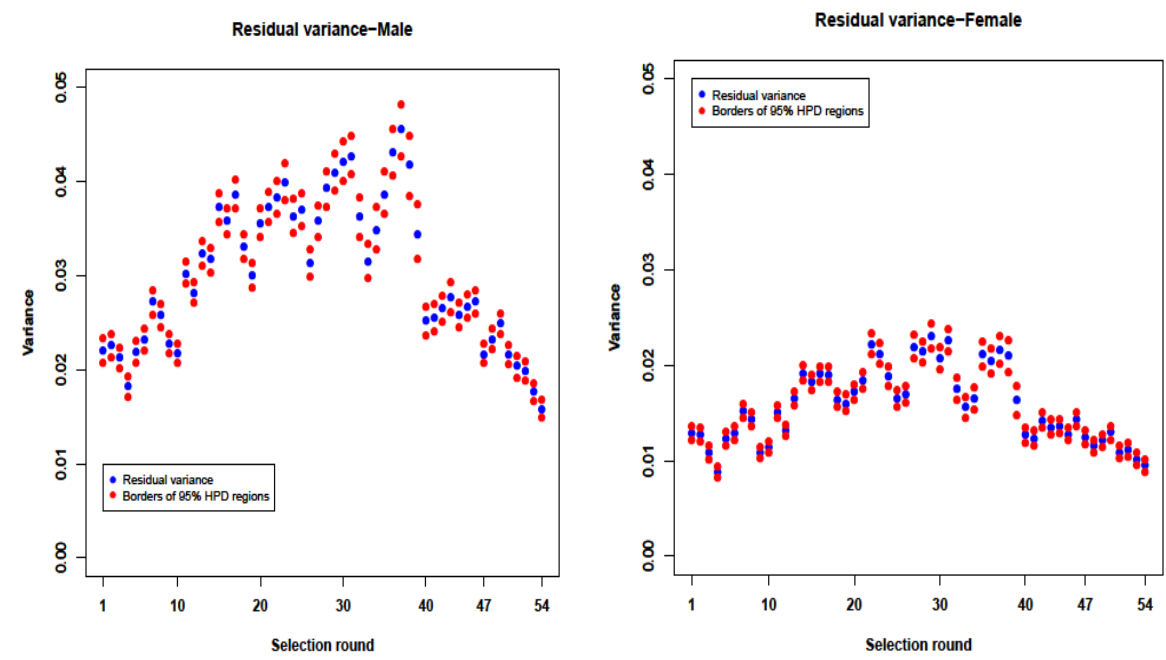

Figure 3.3. Posterior means of residual variance of BW in males and females along the selection trajectory.

The phenotypic variance of BW showed a clear increase in the first period from 0.0339 to 0.0638 in males and from 0.0212 to 0.0368 in females with fluctuation from one SR to another within the period mainly due to the observed fluctuation in the residual variance. However, phenotypic variance dropped in the second period from 0.0638 to 0.0392 in males and from 0.0368 to 0.0219 in females at the SR where the weighing age was changed from $t$ to $t-4$ days. Similarly phenotypic variance showed a clear drop in the third period from 0.0413 to 0.0344 in males and a slight drop from 0.0234 to 0.0208 in females at the SR where the weighing age was changed from $t$ - 4 days to $t-7$ days and then kept fluctuating from one $S R$ to another in the second and third period in both sexes (Figure 3.4). 

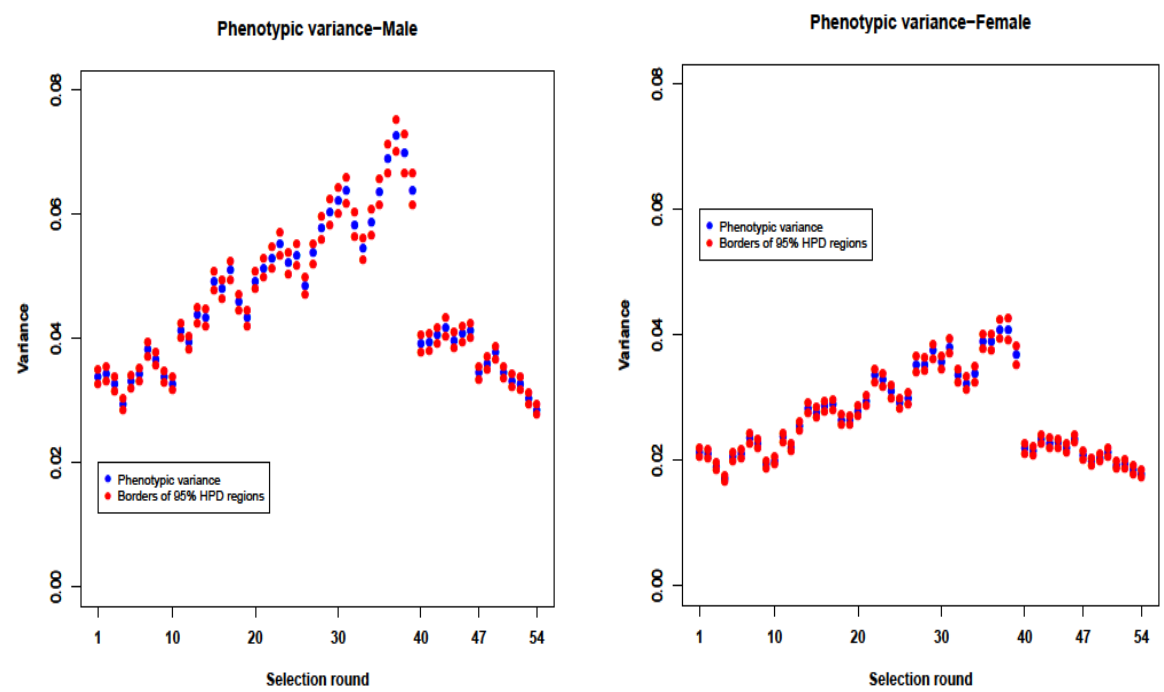

Figure 3.4. Posterior means of phenotypic variance of BW in males and females along the selection trajectory.

The heritability estimates in the first period showed an overall increase from 0.3040 to 0.4194 in males and from 0.3504 to 0.5345 in females but with fluctuation from one SR to another along the selection trajectory due to the heterogeneous residual variance (Figure 3.5). In males a clear drop in heritability from 0.4194 to 0.3172 was observed in the second period at the SR where the weighing age was changed from $t$ to $t-4$ days. Similarly a clear drop in heritability was observed in females from 0.5345 in the first period to 0.3860 in the second period at the SR where the weighing age was changed from $t$ days to $t-4$ days. However, a slight increase was observed in the third period with SR 47-54 from 0.3013 to 0.3358 in males and from 0.3598 to 0.3654 in females at the SR where the weighing age was changed from $t-4$ days to $t$ 7 days. The heritability estimates in the second and third period did not show any clear pattern along the selection trajectory within the individual periods due to the observed fluctuation in the residual variance in the two later periods. In males the heritability estimates ranged from 0.2987 to 0.3172 in the second period with 7 SRs and from 0.3065 to 0.4043 in the third period with 8 SRs, while in females it ranged from 0.3598 to 0.3926 in the second period and from 0.3573 to 0.4259 in the third period with fluctuation from one SR to another within the individual periods (Figure 3.5). The heritability estimates of BW ranged from 0.2056 to 0.4194 and 0.2962 to 0.5345 in males and females, respectively considering the estimates in all the three periods. In males the mean heritability estimates of BW over SRs in each individual 
period were found to be $0.2835,0.3083$ and 0.3480 while in females it was found to be $0.3804,0.3851$ and 0.4372 at $t, t-4$ and $t-7$ days of age, respectively with increasing heritability as the weighing age decreased.
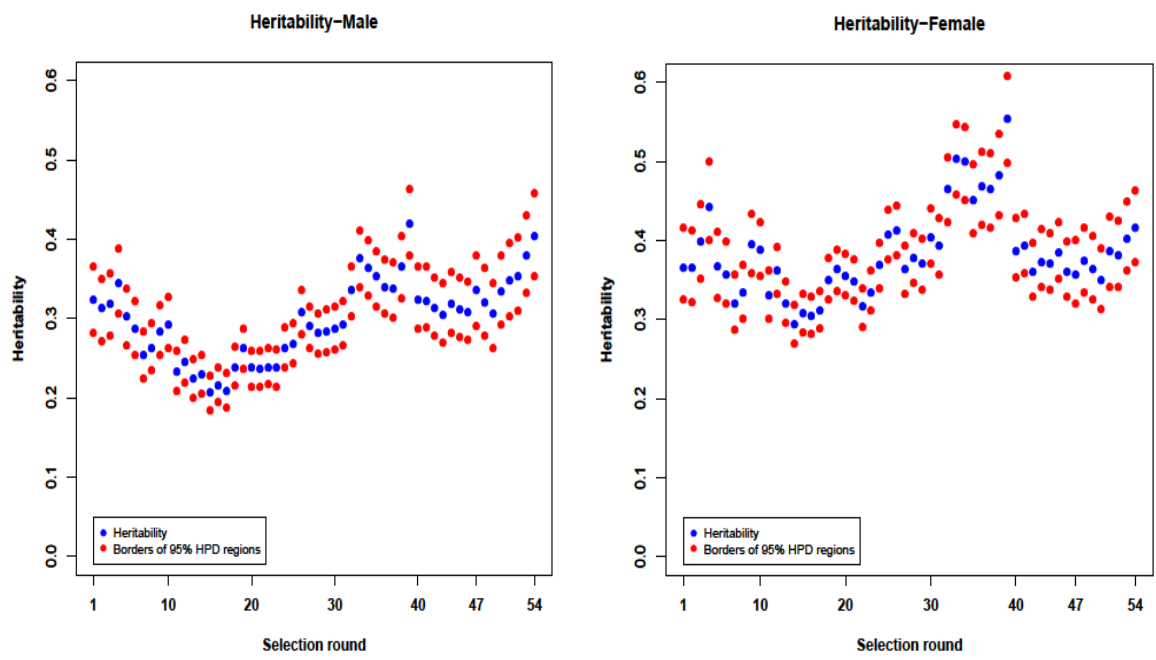

Figure 3.5. Posterior means of heritability of BW in males and females along the selection trajectory.

The genetic correlation of BW measured at different SRs depends on the SR and the distance between the SRs. Correlation plots from longitudinal models are three dimensional plots that are difficult to grasp. Therefore only selected subsets of correlations are shown. In Figure 3.6 the genetic correlation between BW at SR 20 and all other SRs are presented for males and females, respectively. The genetic correlation between BW expressed in different SRs decreased in both sexes as the distance between the SRs increased and was found to be different from unity while the genetic correlation of BW between adjacent SRs within sexes was found to be high and close to one (Figure 3.6). The genetic correlation of BW between SR 20 and all the SRs in the second period was constant within sexes, due to model asumptions, i.e. a constant genetic variance in all the SRs within the two last periods were assumed. However, the genetic correlation of BW between different SRs in the first period and BW expressed in the second or third period would change gradually with SR since BW expressed in different SRs in the first period have gradually changing variance and covariance while in the second and third period all SRs were defined as having a constant genetic variance. 
The genetic correlation of BW between the three periods was found to be different from unity with decreased genetic correlation as the distance between the periods increased (Figures 3.6-3.8). Figure 3.6 shows the genetic correlation of BW between SR 20 in the first period with SRs (1-54) for each sex. The genetic correlation of BW between the first and second period was found to be higher than the genetic correlation of BW between first and third period (Figure 3.6). The genetic correlation of BW between first and second period was found to be 0.8357 and 0.8324 within males and females, respectively, while the genetic correlation of BW between period one and three was found to be 0.7766 and 0.7029 within males and females, respectively (Figure 3.6).
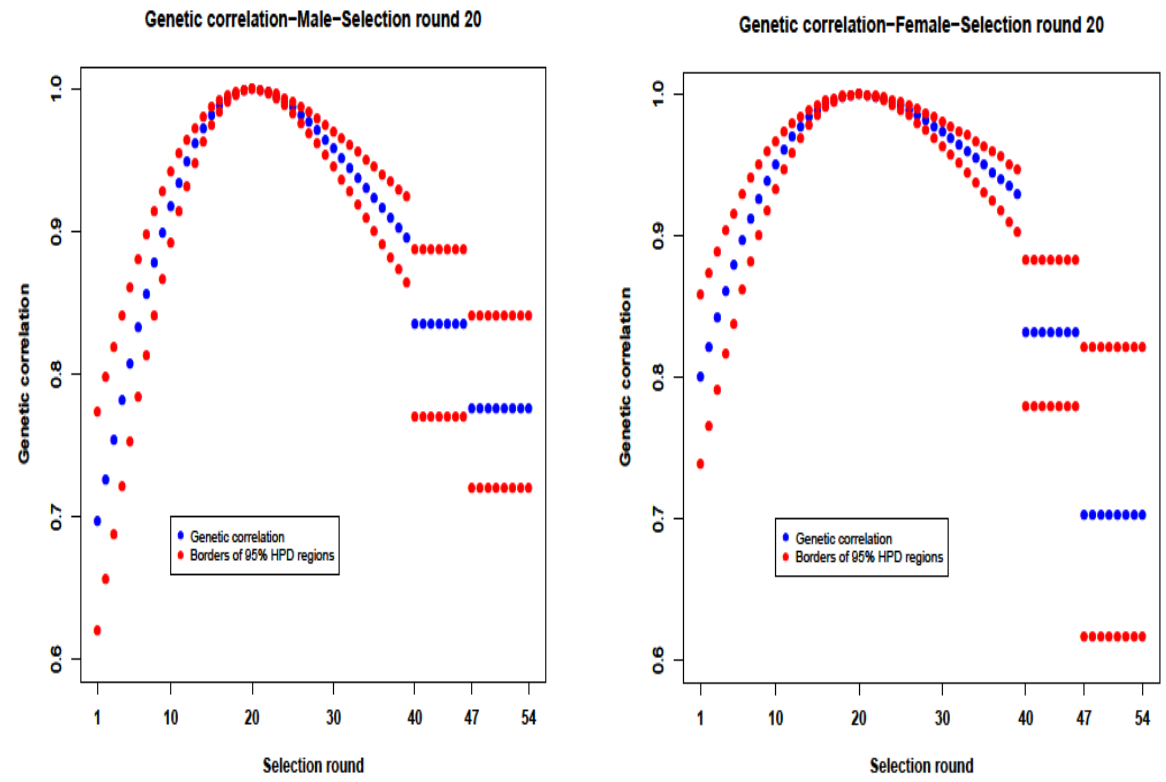

Figure 3.6. Posterior means of genetic correlations between BW in selection round (SR) 20 (first period) and all other SRs in males and females along the selection trajectory.

Figure 3.7 shows the genetic correlation of BW between SR 40 in the second period with SRs (1-54) within sexes. The Figure shows the genetic correlation of BW between the second and third period with weighing age $t-4$ and $t-7$ days, respectively to be higher than the genetic correlation of BW between the first and second period with weighing age $t$ and $t-4$ days, respectively. The genetic correlations of BW between period two and three were found to be 0.9398 and 0.9232 within males and females, respectively both significantly different from unity (Figure 3.7). 

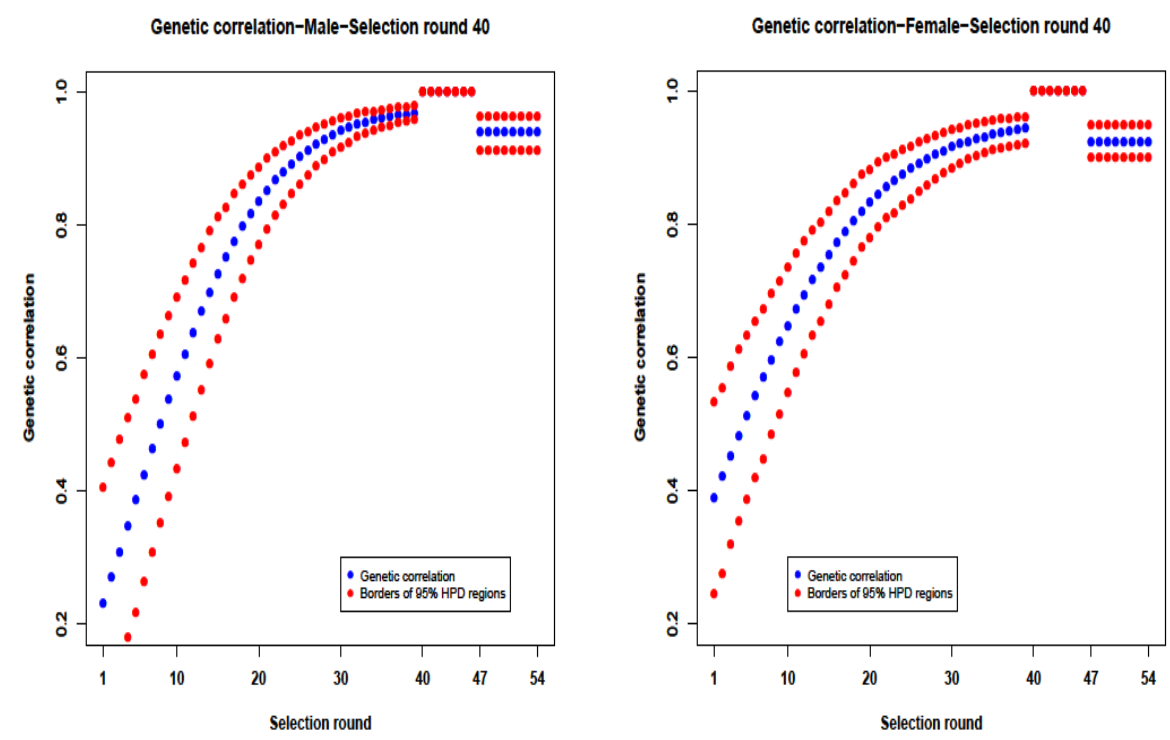

Figure 3.7. Posterior means of genetic correlations between BW in SR 40 (second period) and all other SRs in males and females along the selection trajectory.

Figure 3.8 shows the genetic correlation of BW between SR 47 in the third period with SRs 1-54 within sexes. The genetic correlation of BW between the second and third period was found to be higher than the genetic correlation of BW between first and third period while the genetic correlation of BW between SR 47 and all the SRs in the third period (47-54) within sexes was one due to the constant genetic variance in all the SRs within the individual periods (Figure 3.8). 

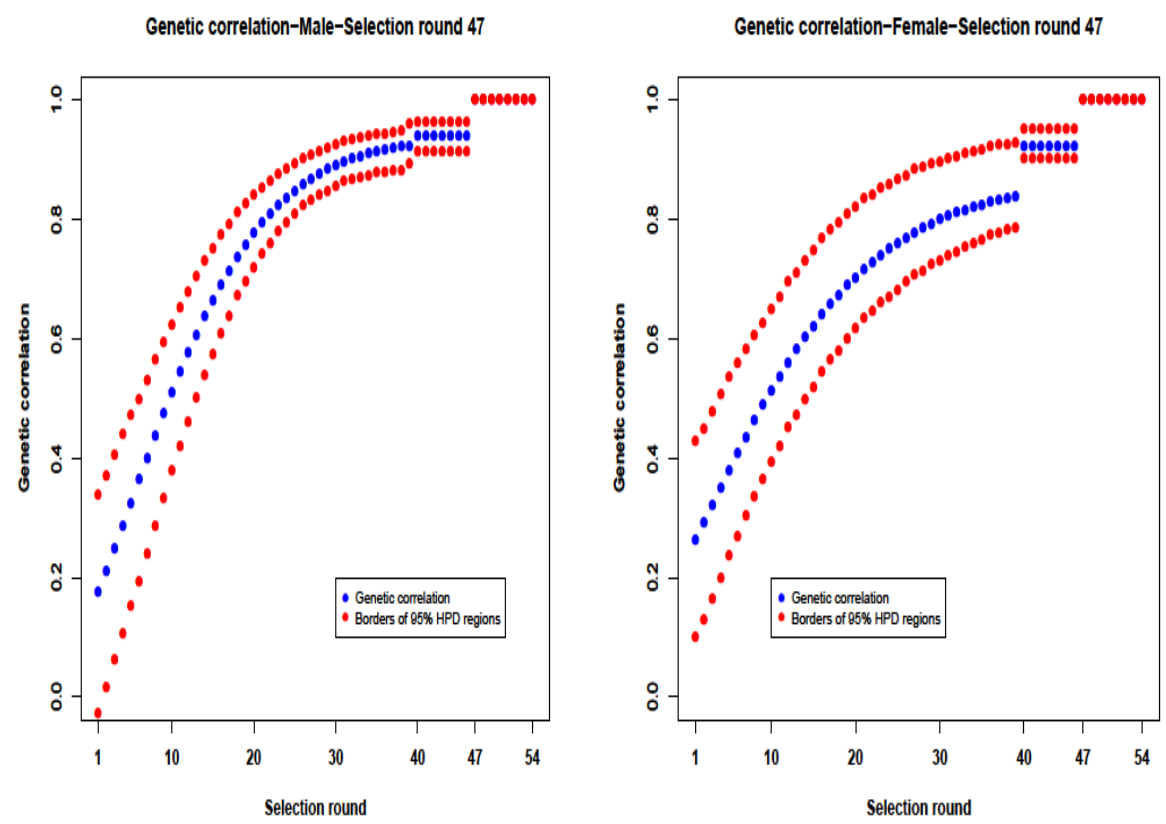

Figure 3.8. Posterior means of genetic correlations between BW in SR 47 (third period) and all other SRs in males and females along the selection trajectory.

Figures 3.9 show the genetic correlation of BW between males and females within the three different periods at the same weighing age. The first plot shows genetic correlation of BW between males and females within the first period (1-39 SR) and the second plot shows genetic correlation of BW between males and females within the second period (40-46 SR) while the third plot shows the genetic correlation of BW between males and females within the third period (47-54 SR). The genetic correlation of BW between males at SR 20 and females at all SRs in the first period (taking mean of genetic correlations of all the 39 SRs) was found to be 0.8479 and the genetic correlation of BW between males and females at the second period was found to be 0.8962 while the genetic correlation of BW between males and females at the third period was found to be 0.9298 (Figure 3.9). The above Figures clearly illustrate that the genetic correlation of BW between males and females increased as the weighing age decreased from $t$ days in the first period to $t-4$ and $t-7$ days in the second and third period, respectively. 

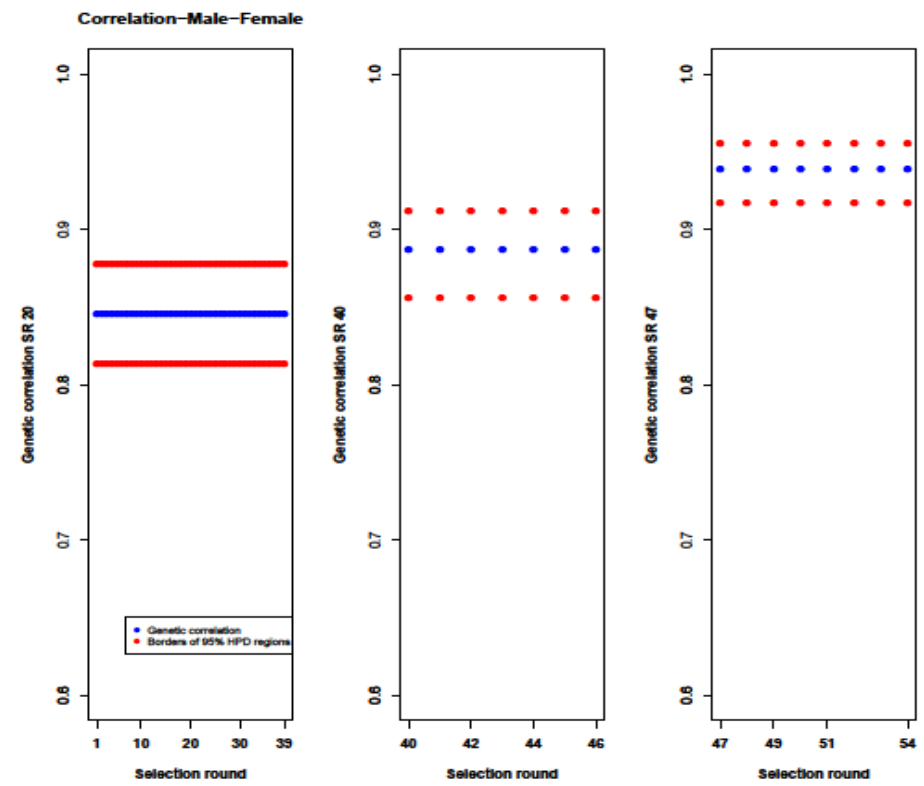

Figure 3.9. Posterior means of genetic correlations of BW between males and females at the three different periods.

\subsection{Discussion}

A bivariate random regression model was used to estimate genetic parameters of BW in each sex and at varying age of measuring BW in order to investigate the amount of sex by genotype interaction and estimate genetic parameters of BW at three different ages. In addition, the model was used to study the development in genetic variance of BW over several generations of selection. Selection for increased BW has increased all variance components partly due to scale effects. Heritability was not strongly affected by selection. However, the genetic correlation between BW measured in different SRs was less than unity with a decreasing correlation as the number of SRs between BW measurements increased. Genetic correlations between BW measured at different ages were considerably less than unity. Heritability of BW measured in males and females were different, the genetic variance were different in the two sexes and the genetic correlation between BW in males and females were significantly less than unity and further decreased as the age at measuring BW were increased. 


\subsubsection{Simulation results}

The results of the small simulation study have shown that the random regression model, which is used in the real body weight data, can be used to estimate a gradual change in variance over time, even in models that also include age effects for each bird. In the simulation, only one bird were recorded at each time point. Therefore, estimating gradual change in variance is less accurate than estimating effects relative to individual birds such as intercept or age effects. This means that large data sets are needed for such analysis such as the case in this study. I.e. The model can be used to study the change in variance over time within and across animals.

\subsubsection{Sex by genotype interaction for BW at three ages}

The higher heritability estimate of BW in females than males in this study was due to the observed higher residual variance in males compared to females (Figure 3.5). Genetic correlations were significantly lower than unity between BW in males and females at all three recording ages, suggesting that BW in the two sexes should be considered as different but correlated traits. This sex by genotype interaction is due to genes affecting BW differently in male or female physiological "environments" as explained by Towne et al. (1997). In agreement with this study, Merritt (1966) and Morton (1973) have regarded BW in male and female chickens as separate traits with a genetic correlation different from unity. Similarly, Chapuis et al. (1996) analyzed BW in male and female turkeys at 12 and 16 weeks of age and noted the largest genetic correlation of BW between males and females at 12 weeks of age than at 16 weeks of age.

The decreasing genetic correlation of BW between sexes as the weighing age increased suggests that the amount of sex by genotype interaction increases with age probably due to physiological differentiation during growth (Towne et al., 1997). In general, the different heritability estimates of BW in males and females in all the three ages, different variances and a genetic correlation of BW between males and females lower than unity suggest that BW in males and females should be considered as different but correlated traits. I.e. there is a clear sex by genotype interaction for BW in this broiler population. Accounting for these effects in models for genetic evaluation will increase accuracy of selection compared to currently used models that assume an average heritability and a genetic correlation of unity between BW expressed in males and females. In addition, the different residual variances in the two sexes needs to be taken in to account since male records have a considerably 
larger residual environmental variance than female records, i.e. female records are more informative than male records.

\subsubsection{Genetic parameters of $\mathrm{BW}$ at three different ages}

The variance components estimated in third period decreased for both sexes compared with estimates from period one and two where the age at recording BW were higher. This is primarily due to scale effects since both the mean BW and the variance of BW decreased as the weighing age decreased (Table 2). This conforms to the theory explained by Falconer and Mackay (1996) which states that the variance of a trait is not independent on the mean because when the mean changes under selection, the variance also changes. I.e. when the mean increases, the variance increases and vice versa. The maternal permanent environmental variances of BW in all the three periods explained only a small proportion of the total phenotypic variance in both sexes. The observed fluctuations in the residual variance within the first period were due to seasonal variation. The phenotypic variance of BW in this study showed exactly the same pattern as the residual variance since the highest proportion of the phenotypic variance is the residual variance.

Reducing the age at weighing reduces all components of variance considerably. Since birds were only weighed once and weighing age changes with SR, a direct comparison is difficult. However, the changes are in line with the results of Begli et al. (2016) who analysed records from chickens that were weighed weekly and noted an increase in variance of BW by factors of 1.34 to 6.02 per week. In this study, a slight increase in the posterior mean of heritability was observed as the weighing age decreased due to the decreasing residual variance as the weighing age decreased. This happened even though genetic variance in general decreased as the weighing age decreased. In agreement with this, Kinney (1969) observed heritability estimates of BW in broiler chickens decreasing at later ages considering BW at 4, 8 and 12 weeks of ages. Chapuis et al. (1996) have reported considerable differences in heritability estimates and genetic parameters of BW due to age at recording in turkeys. The heritability estimates of BW in this study were found to be moderate ranging from 0.21 to 0.42 in males and 0.30 to 0.53 in females, which is in agreement with Buss (1990) who reported BW at different ages to have moderate to high heritability in the range from 0.23 to 0.71 . The observed fluctuations in the heritability estimates from one SR to another is mainly due to the fluctuation observed in the residual variance (Figure 3.5) since heritability is a function of phenotypic variance which includes the residual variance. 
The genetic correlation of BW between the three weighing ages were different from unity and decreased as the distance between weighing ages increased (Figures 6-8). I.e. Genetic correlations of BW between period one and two is higher than that of period one and three while genetic correlations of BW between period two and three is higher than that of period one and two. This is in agreement with Aslam et al. (2011) who noted the genetic correlation of BW in turkey birds decreasing as the distance between BW measurements increased. This might be related to change in the physiological system of birds as explained by Schaeffer (2011) which states that there might be genes that "turn on" and "turn off" as animal ages causing changes in physiology and performance. In general, the heritability and genetic variance of BW changed with weighing ages, genetic correlations of BW measured at different ages were lower than unity and decreased even further as the distance between the ages at weighing increased. Therefore, the genetic background of BW in the three ages is partly different and models for genetic evaluation of BW should take this in to account.

\subsubsection{The effect of selection on genetic parameters of BW}

The effect of selection on genetic parameters of BW can only be observed in the first period since the numbers of SRs in the two later periods with a reduced weighing age were too small to observe clear pattern in change in variance along the selection trajectory.

The observed increasing trend in genetic variance within the first period might partly be due to scale effect as the birds at the later SRs have higher mean BW than that of the earlier SRs at the same age. This is due to selection for growth rate, which results the physiological age of the birds to increase along the selection trajectory, which might release new genetic variation (Schaeffer, 2011). In addition, the increase in genetic variance along the selection trajectory might be due to change in genetic property of the trait as a result of mutation or other genetic effects which were not directly taken in to account in the model. This clearly shows that the genetic variance of BW has not been exhausted after several generations of selection. This might also indicate that BW in broilers is influenced by many genes that do not quickly go towards fixation even after several generations of selection.

The variance of genetic effects in the first period was modeled with a covariance function using linear splines so that each animal was modeled with two breeding values belonging to this period. The linear spline mixed model behaves similar to a multivariate model where traits are recorded on the knots (Misztal, 2006). Our model had knots at the start and end of the period and can show how the trait 
behaves at both ends of the period and models a gradual change of trait expression during the period. The model can be used to compute breeding values at any time during the period for each individual. Such gradual changes in breeding value expressed how birds would be ranked in the population at SR that can differ from the SR where it was hatched. Such changes in breeding value are due to change in genetic background of BW with SR.

The covariance function used in our study models the gradual change in genetic parameters over different SRs in period one. Such a model generally fits best at the knots, whereas fit between the knots can be less; it is mainly because the second derivatives of the covariance function based on splines is often positive (Misztal, 2006). However, our results clearly showed that all variance components increased over the selection trajectory. The genetic correlations of BW between early and late SRs within the first period were different from unity and the genetic correlation of BW between adjacent SRs were found to be high and close to one suggesting a gradual change in genetic variance of BW over the selection trajectory. Therefore, the genetic background of BW in early and late SRs was different (Figure 3.6). In agreement with this study, Sørensen (1986) reported that the genetic variance for growth rate in broiler chickens were not reduced significantly after several generations of selection which was explained to be due to generation of new genetic variation and epistatic effects. In a simulation study covering 25 generations of selection and using a finite locus model with no mutation, dominance and epistatic effects, Liu et al. (2014) observed a fast increase of genetic variance in the first generations of selection. Thereafter the genetic variance reached a higher peak before it decreased gradually. The increase in genetic variance was explained to be due to a rapid rise in frequency of favorable alleles and the higher peak was due to all quantitative trait loci reaching an intermediate allele frequency and finally the observed gradual decrease in genetic variance was explained to be due to fixation of favorable alleles.

The increased heritability of BW along the selection trajectory in the first period where weighing age was constant show that the increase in genetic variance of BW was not only due to scale effects. In addition, it illustrates that the genetic variance of BW has not been exhausted after many generations of selection, since heritability is not influenced by scale effect (Figure 3.5). In the second and third period, the heritability estimates did not show clear pattern along the selection trajectory due to the observed fluctuation in the residual variance. The observed pattern in the heritability estimates along the selection trajectory is an image of the residual variance, since in period two and three; the model assumes a constant genetic and maternal permanent environmental variance for BW in each sex (Figure 3.5). 
In this study, an increasing trend in the heritability estimates and genetic variance of BW along the selection trajectory was observed in the first period, which was long enough to be able to detect changes in genetic parameters. In addition, genetic correlation of BW between early and late SRs was found to be different from unity while genetic correlations of BW between adjacent SRs were found to be close to one. This illustrates the existence of considerable amount of genetic variance left in the population after several generations of selection and that BW in different SRs should not be considered as exactly same trait or completely different trait, rather a gradual change in the genetic background of the trait along the selection trajectory should be assumed. Such gradual change in genetic variance over time can be modeled using spline models. This result is in contrast to what is expected according to the previous knowledge of selection, which states an expected decrease in genetic variance as a result of selection (Falconer and Mackay, 1996). However, the same authors stated that the outcome of selection over a long period is difficult to predict due to the properties of individual genes contributing to the response and also due to mutation effects. The results of this study clearly illustrate that in a real population there might be an increase in genetic variance even after many generations of selection due to different factors which might partly be scaling effect in this case and/or due to changes in the genetic property of the trait as a result of mutation which were not directly taken in to account in the statistical model. These phenomena clearly contribute to the high amounts of genetic variance still existing in highly selected broiler populations.

\subsection{Conclusion}

In this study, random regression model using linear splines were used to study the effect of sex by genotype interaction, estimate genetic parameters of BW at three different ages and also to study the effect of selection on genetic parameters of the trait. The simulation study verified that a change in variance over time can be estimated using proper random regression models. There were clear sex by genotype interactions. Heritabilities of BW were different in males and females and males had higher residual variance than females at all weighing ages. Genetic correlations of BW between males and females were lower than unity and decreased further if weighing ages were increased. Therefore, BW in males and females should be considered as different but correlated traits. Genetic correlations between BW at different ages were lower than unity and the correlations further decreased as the distance between weighing ages increased. Thus, models for genetic evaluation of BW must take this effect in to account. The increasing trend in genetic variance and 
heritability estimates (with fluctuations) along the selection trajectory illustrated that the genetic variance of BW is not exhausted or diminished even after several generations of selection in this broiler population. There was a gradual change in genetic variance and the genetic correlations between BW measured in different SRs decreased as the distance between SRs involved in the correlation increased. Therefore, the effects of genes that are influencing BW changes with SR. This process contributes to the maintenance of large amounts of genetic variance in the population. The gradual change in genetic (co)variance along the selection trajectory should be modeled as a continuous process using linear splines. Furthermore, the results of this study illustrate that random regression models are appropriate for the genetic analysis of BW in broiler chickens to study the effect of selection on genetic parameters of the trait. Such models should be used if the effect of genes affecting BW is gradually changing along the selection trajectory.

\section{Acknowledgements}

The authors would like to thank Cobb-Vantress poultry Research Company for providing the data used in this study. We also thank European graduate school in animal breeding and genetics, which is funded by the European Union, for providing scholarship for the first Author.

\section{References}

Aslam ML, Bastiaansen JW, Crooijmans RP, Ducro BJ, Groenen MA, Vereijken A. 2011. Genetic variances, heritabilities and maternal effects on body weight, breast meat yield, meat quality traits and the shape of the growth curve in turkey birds. BMC Genet. 12: 14.

Begli HE, Torshizi RV, Masoudi AA, Ehsani A, Jensen J. 2016. Longitudinal analysis of body weight, feed intake and residual feed intake in F2 chickens. Livestock science.184: 28-34.

Bohmanova J, Misztal I and Bertrand JK. 2005. Studies on multiple traits and random regression models for genetic evaluation of beef cattle for growth. J. Anim. Sci. 500. 83: 62-67.

Buss EG. 1990. Genetics of growth and meat production in turkeys, in: CRAWFORD, R.D. (ED.) Poultry breeding and Genetics Amsterdam, Elsevier. 645-675.

Chapuis H, Delabrosse Y, Ducroc V, Tixer-Boichard M. 1996. Multivariate restricted maximum likelihood estimation of genetic parameters for production traits in three selected turkey strains. Genet. Sel. Evol. 28: 299-317. 
Falconer D, Mackay TF. 1996. Introduction to Quantitative Genetics, Fourth ed. Longman, U.K.

Iwaisaki H, Tsuruta S, Misztal I, Bertrand JK. 2005. Genetic parameters estimated with multi trait and linear spline-random regression models using Gelbvieh early growth data. J. Anim. Sci. 83: 757-763.

Jensen J. 2001. Genetic evaluation of dairy cattle using test day models. J. Dairy Sci. 84: 2803-2812.

Liu H, Sorensen AC, Meuwissen THE, Berg P. 2014. Allele frequency changes due to hitch- hiking in genomic selection programs. Genet. Sel. Evol, 46: 1-14.

Madsen P, Jensen J. 2013. A user's guide to DMU. A package for analyzing multivariate mixed models, Version 6, Release 5.2. (http://dmu.agrsci.dk/DMU/Doc/Current/dmuv6_guide.5.2.pdf)

Merritt ES. 1966. Estimates by sex of genetic parameters for body weight and skeletal dimensions in a random bred strain of meat type fowl. Poult Sci. 45: 118125.

Meyer K. 2004. Scope for a random regression model in genetic evaluation of beef cattle for growth. Livest. Prod. Sci. 86: 68-83.

Meyer K. 1998. Modelling 'repeated' records: covariance functions and random regression models to analyse animal breeding data. Proc. 6th World. Congr. Genet. Appl. Livest. Prod., Armidale, Australia. 25: 517-520.

Misztal I. 2006. Properties of random regression models using linear splines. J. Anim. Breed. Genet. 123: 74-80.

Misztal I, Strabel T, Mantysaari EA, Meuswissen THE and Jamrozik J. 2000. Strategies for estimating the parameters needed for different test-day models. J. Dairy Sci. 83: 1125-1134.

Morton J.R. 1973. Analysis of gene action in the control of body weight in the chicken. Heredity. 31: 165-180.

Nassar MK, Goraga ZS, Brockmann GA. 2012. Quantitative trait loci segregating in Crosses between New Hampshire and White Leghorn chicken lines: II. Muscle weight and carcass composition. Anim. Gen. 10: 1365-2052.

Nestor KE, Anderson JW, Patterson RA and Velleman SG. 2008. Genetics of growth and reproduction in the turkey. 17 . Changes in genetic parameters over forty generations of selection for increased sixteen-week body weight. Poult Sci. 87: 1971-1979.

Prado-González E A, Ramírez-Avila L and Segura-Correa JC. 2003: Genetic parameters for body weights of Creole chickens from Southeastern Mexico using an animal model. Livestock Research for Rural Development. Volume 15, Article 
\#6.

Retrieved

January

21,

2015,

from

http://www.Irrd.org//rrd15/1/prad151.htm

Robbins KR, Misztal I and Bertrand JK. 2005. A practical longitudinal model for evaluating growth in Gelbvieh cattle. J. Anim. Sci. 83: 29-33.

Schaeffer LR. 2004. Application of random regression models in animal breeding. Livest. Prod. Sci. 86: 35-45.

Schaeffer LR. 2011. Animal Breeding methods, Random regression models course notes. Access http://www.aps.uoguelph.ca/ Irs/ (Accessed 05.08.2015).

Smith BJ. 2007. Boa: An R Package for MCMC Output Convergence Assessment and Posterior Inference Journal of Statistical Software. 21(11): 1-37.

Szwaczkowski T, Grzech M, Borowska A, Wencek E and Wolc A. 2010. Maternal genetic effects on body weight and breast morphological traits in duck population under selection. Arch. Anim. Breed. 53: 600-608.

Towne B, Seirvogel RM and Blangero J. 1997. Effects of genotype by sex interaction on quantitative trait linkage analysis. Genet. Epidemiol. 14: 1053-1058. 



\section{4}

\section{Genetic parameters for body weight and different definitions of residual feed intake in broiler chickens}

W. Mebratie ${ }^{1,2}$, P. Madsen ${ }^{1}$, R. Hawken ${ }^{3}$, H. Romé ${ }^{1}$, D. Marois ${ }^{3}$, J. Henshall ${ }^{3}$, H. Bovenhuis ${ }^{2}$, and J. Jensen ${ }^{1}$.

${ }^{1}$ Center for Quantitative Genetics and Genomics, Department of Molecular Biology and Genetics, Aarhus University 8830 Tjele, Denmark. ${ }^{2}$ Animal Breeding and Genomics Centre, Wageningen University, P.O. Box 338, 6700 AH Wageningen, the Netherlands. ${ }^{3}$ Cobb-Vantress Inc. Siloam Springs, Arkansas, USA 72761-1030.

Submitted to GSE 


\section{Abstract}

Body weight (BW) and feed efficiency (FE) traits have received major consideration in the poultry industry due to their economic and environmental implications. The objectives of this study were 1 ) to simultaneously estimate genetic parameters for BW, feed intake (FI), and body weight gain (Gain) during FI test in broiler chickens using a multi-trait Bayesian analysis; 2) derive phenotypic and genetic residual feed intake (RFI) and estimate genetic parameters for the traits; and 3) compute Bayesian measure of direct and correlated superiority of a selected group on phenotypic and genetic residual feed intake. A total of 56,649 male and female broiler chickens were measured in one of two different ages ( $t$ or $t-6$ days of age). BW in males and females as well as BW in the two ages were considered as separate traits in each of the three traits. This resulted in a 12-trait model for BW, FI and Gain in the two sexes and two ages (periods). Phenotypic RFI ( $\mathrm{RFI}_{\mathrm{P}}$ ) was estimated from a conditional distribution of FI given BW and Gain using partial phenotypic regression coefficients. Similarly, genetic RFI ( $\mathrm{RFI}_{\mathrm{G}}$ ) was estimated from a conditional distribution of FI given BW and Gain using partial genetic regression coefficients. The Bayesian measure of direct and correlated superiority of a selected group was computed as the difference between the mean of the breeding values of the selected top individuals and the mean of the population after correcting for the genetic trend. Posterior means of heritability for BW, $\mathrm{FI}$ and Gain were moderate and estimates were significantly different in males and females at the same age for all the traits. In addition, the genetic correlation between males and females at the same age were significantly different from unity suggesting a sex by genotype interaction for BW and FE traits. Posterior means of heritability estimates for $\mathrm{RFI}_{P}$ were significantly higher than that of $\mathrm{RFI}_{\mathrm{G}}$ within sexes and ages. Moreover, the genetic correlations between $\mathrm{RFI}_{\mathrm{P}}$ and $\mathrm{RFI}_{\mathrm{G}}$ were significantly different from unity at $t$ days of age but not at $t-6$ days of age. Selecting the best $10 \%$ birds for $\mathrm{RFI}_{\mathrm{G}}$ at $t$ days of age yielded a genetic superiority of $-59.4 \mathrm{~g}$ on $\mathrm{RFI}_{\mathrm{G}}$ and a correlated superiority of $-58.2 \mathrm{~g}$ on $\mathrm{FI}$ at the same age in males with no significant change in production traits. The results of the multivariate Bayesian analysis in this study show that genetic evaluation for production traits (BW and Gain) and feed efficiency traits $\left(\mathrm{FI}, \mathrm{RFI}_{\mathrm{P}}\right.$ and $\mathrm{RFI}_{\mathrm{G}}$ ) should take sex and age differences in to account to increase accuracy of selection and genetic gain. Genetic $\mathrm{RFI}$, which is genetically independent of production traits, is easier to communicate with stakeholders than phenotypic RFI, which is not genetically independent of production traits.

Key words: Phenotypic residual feed intake; genetic residual feed intake; Bayesian analysis; genetic parameters; superiority of the selected group 


\subsection{Introduction}

Genetic improvement of body weight (BW) and feed efficiency (FE) traits has received major consideration in the poultry industry due to their economic and environmental implications. Body weight is the live weight of birds at a specific age while feed efficiency is the ability of birds to convert kg of feed in to kg of body weight. Among the different ways of measuring FE in poultry, residual feed intake (RFI) is a popular partial measure of FE due to its phenotypic independence from production traits, the presence of considerable variation in RFI among birds and moderate heritability of the trait (Willems et al. 2013). RFI is classically defined as the difference between actual feed intake and predicted feed intake based on energy requirements for production (e.g. body weight, body weight gain) and maintenance (Koch et al., 1963). Since RFI is phenotypically independent from production traits, variation in RFI explains differences in efficiency of birds to use feed for production and maintenance of BW, as well as errors in the prediction (Kennedy et al., 1993).

Prediction of RFI has been mostly based on phenotypic regression of feed intake on measures of production from a multiple regression analysis. This is called phenotypic RFI since direct consideration has not been given to underlying genetic regressions in the computation of RFI and it is not genetically independent of production traits. Kennedy et al. (1993) derived phenotypic RFI using phenotypic regression coefficients obtained from phenotypic co (variance) matrices of feed intake and production traits, that were assumed to be known without error and showed that phenotypic RFI is phenotypically independent from production traits but not genetically independent from production traits. In the same context, Kennedy et al. (1993) proposed the term genetic RFI to explain the component of feed intake, which is genetically independent of production traits derived using genetic regression coefficients obtained from genetic co (variance) matrices of feed intake and production traits that were assumed to be known. In this regard, direct consideration is not given to phenotypic regressions in the computation of genetic $R F I\left(R_{G} I_{G}\right)$, therefore, $\mathrm{RFI}_{\mathrm{G}}$ is not phenotypically independent of production traits (Kennedy et al., 1993).

Jensen et al. (2013) extended the definitions of phenotypic and genetic RFI by Kennedy et al. (1993) to a Bayesian framework, which estimates the co (variance) function for RFI, using proper distributions of feed intake conditional on production traits in a one-step procedure. This one-step procedure estimates the partial phenotypic and genetic regression coefficients from co (variance) matrices of feed intake and production traits resulting from a multiple regression analysis of feed 
intake and production traits and then it simultaneously derives phenotypic and genetic RFI inside the model. This one-step approach properly accounts for errors in estimating regression coefficients compared to the classical two-step approach by Kennedy et al. (1993) which assumes co (variance) matrices of component traits of RFI as known without error and the classical two-step approach. In the classical twostep procedure, first feed intake and production traits are analyzed together in a multiple regression analysis and regression coefficients are obtained from the resulting co (variance) matrices before the genetic analysis. Then RFI is computed using the regression coefficients for each animal and the genetic analysis is performed together with production or body composition traits. In this procedure, the resulting covariance functions of RFI and production traits are usually singular due to defining RFI before the genetic analysis as a linear combination of other traits (Jensen, 2013). However, the one-step procedure in the Bayesian analysis avoids singularity of the co (variance) matrices by simultaneously estimating the co (variance) functions of RFI based on the conditional distribution of $\mathrm{FI}$ given production traits and possibly body composition traits (Jensen, 2013). In addition, the Bayesian one-step procedure ensures that parameter estimation in the regression analysis is not biased by "fixed effects" in the model and by effects due to genetic trends for component traits in the population under study (Jensen et al., 2013).

Thus, the objectives of this study were 1) to simultaneously estimate genetic parameters for body weight, feed intake, and body weight gain in broiler chickens from a multi-trait Bayesian analysis; 2) derive phenotypic and genetic RFI and estimate genetic parameters for the traits; and 3) compute Bayesian measure of direct and correlated superiority of a selected group on phenotypic and genetic residual feed intake.

\subsection{Methods}

\subsubsection{Data}

Data from 16 selection rounds (SRs) for growth rate of broiler chickens, reared under strict bio-secure environmental conditions were collected using procedures by CobbVantress. The number of male and female broilers with phenotypic data were 56,649 . For the first $10 \mathrm{SRs}$, broilers were weighed at $t$ days of age in males $\left(\mathrm{BW}_{\mathrm{m}(\mathrm{t})}\right)$ and females $\left(\mathrm{BW}_{\mathrm{f}(\mathrm{t})}\right)$ however as selection continued the birds start to mature earlier and the weighing age was changed to 6 days earlier ( $t-6$ days) for the 
last $6 \mathrm{SRs}$ in males $\left(\mathrm{BW}_{\mathrm{m}(\mathrm{t}-6)}\right.$ and females $\left(\mathrm{BW}_{\mathrm{f}(\mathrm{t}-6)}\right)$. The heaviest 22,281 male and female birds in the two periods ( $t$ and $t-6$ days of age) entered the feed efficiency (FE) test and feed intake ( $\mathrm{FI})$ was recorded over the test period in males $\left(\mathrm{FI}_{\mathrm{m}(\mathrm{t})}\right.$ and females $\left(\mathrm{FI}_{\mathrm{f}(\mathrm{t})}\right)$ at $t$ days of age and males $\left(\mathrm{FI}_{\mathrm{m}(\mathrm{t}-6)}\right)$ and females $\left(\mathrm{FI}_{\mathrm{f}(\mathrm{t}-6)}\right)$ at $t-6$ days of age. The proportion of birds entering the FE test were the same for each selection round. Body weight gain (Gain) during the FE test in males $\left(\operatorname{Gain}_{m(t)}\right)$ and females $\left(\mathrm{Gain}_{\mathrm{f}(\mathrm{t})}\right)$ at $t$ days of age and body weight gain in males $\left(\mathrm{Gain}_{\mathrm{m}(\mathrm{t}-6)}\right)$ and females $\left(\right.$ Gain $\left._{\mathrm{f}(\mathrm{t}-6)}\right)$ at $t-6$ days of age were calculated as the difference between final body weight and body weight at the start of the FE test. Descriptive statistics of the data is presented in Table 4.1.

\subsubsection{Statistical model and estimation of parameters}

Preliminary univariate and bivariate restricted maximum likelihood estimation (REML) analysis was conducted to determine whether BW, FI and Gain in males and females at the two ages should be considered as same trait or separate traits. The REML results showed that genetic parameters are significantly different between sexes (males and females) and in the two ages ( $t$ and $t-6$ days) suggesting that records on, males and females, as well as the two ages should be considered as separate traits in the subsequent analysis. This resulted four different traits for each of the BW, FI and Gain traits. For example, BW in males at two different periods having different recording ages $\left(\mathrm{BW}_{\mathrm{m}(\mathrm{t})}\right), \mathrm{BW}_{\mathrm{m}(\mathrm{t}-6)}$ and $\mathrm{BW}$ in females at two different periods having different recording ages $\left(\mathrm{BW}_{\mathrm{f}(\mathrm{t})}, \mathrm{BW}_{\mathrm{f}(\mathrm{t}-6)}\right)$. Thus, the final model was analyzed in a Bayesian multivariate (12-trait) analysis using Gibbs sampling where the following model was specified for each of the BW, FI and Gain traits in males and females and the two ages ( $t$ and $t-6$ days).

$\mathrm{y}_{\mathrm{ijkl}}=\mathrm{SRH}_{\mathrm{j}}+$ Dage $_{\mathrm{k}}+\mathrm{a}_{\mathrm{i}}+\mathrm{pe}_{\mathrm{l}}+\mathrm{e}_{\mathrm{ijkl}}$

Where $y_{i j k l}$ is the $\mathrm{BW}_{\mathrm{m}(\mathrm{t})}, \mathrm{BW}_{\mathrm{f}(\mathrm{t})}, \mathrm{BW}_{\mathrm{m}(\mathrm{t}-6)}, \mathrm{BW}_{\mathrm{f}(\mathrm{t}-6)}, \mathrm{FI}_{\mathrm{m}(\mathrm{t})}, \mathrm{FI}_{\mathrm{f}(\mathrm{t})}, \mathrm{FI}_{\mathrm{m}(\mathrm{t}-6)}$, $\mathrm{FI}_{\mathrm{f}(\mathrm{t}-6)}, \operatorname{Gain}_{\mathrm{m}(\mathrm{t})}$, Gain $\mathrm{f}_{\mathrm{f}(\mathrm{t})}$, $\operatorname{Gain}_{\mathrm{m}(\mathrm{t}-6)}$, and $\operatorname{Gain}_{\mathrm{f}(\mathrm{t}-6)}$ observations of chicken $\mathrm{i}$ hatched in selection round and hatch batch $\mathrm{j}, \mathrm{SRH}$ is the interaction of selection round of the individual chicken and hatch batch of the individual chicken, Dage $\mathrm{e}_{\mathrm{k}}$ is the effect of $k^{\text {th }}$ age of dam with $\mathrm{k}$ having 32 levels, $a_{i}$ is the additive genetic effect of chicken $\mathrm{i}, \mathrm{pe}_{\mathrm{l}}$ is the maternal permanent environmental effect of dam I and e is the random residual effect of chicken $i$. 
Flat priors were used for all "fixed" location and dispersion parameters. Prior distributions for random vectors in the model were: $\mathbf{a} \sim \mathrm{N}\left(0, \mathbf{A} \otimes \mathbf{G}_{\mathbf{0}}\right), \mathbf{p e} \sim \mathrm{N}(0, \mathbf{I} \otimes$ $\left.\mathbf{K}_{\mathbf{0}}\right), \mathbf{e} \sim \mathrm{N}\left(0, \mathbf{I} \otimes \mathbf{R}_{\mathbf{0}}\right)$. Where $\mathbf{A}$ is the numerator relationship matrix, $\mathbf{G}_{\mathbf{0}}$ is the co (variance) matrix for direct additive genetic effects of dimension 12 (four variance components for each of the BW, FI and Gain traits), I is identity matrix, $\mathbf{K}_{\mathbf{0}}$ is the co (variance) matrix for maternal permanent environmental effect of dimension $12, \mathbf{R}_{\mathbf{0}}$ is the residual co (variance) matrix of dimension 12 which was assumed to be heterogeneous with different variance for each of the 12 traits. Symbol $\otimes$ denotes Kronecker (direct) product. The random effects a, pe, and e were considered independent of each other. The Gibbs sampler was used to obtain posterior distributions for all parameters included in the 12-trait model. The Gibbs sampler was run for 1,000,000 rounds; the first 250,000 rounds were discarded as burn-in and from the remaining samples, every $250^{\text {th }}$ sample was saved for post Gibbs analysis. The RJMC module in the DMU software package was used for analysis (Madsen and Jensen, 2014).

\subsubsection{Posterior distributions of parameters}

From the joint posterior distribution of all location and (co) variance parameters of the 12-trait model, 3000 samples were saved for post-Gibbs analysis. Posterior means of breeding values and co (variance) components were computed as average of samples after the burn-in period. The boa package in the R program was used to evaluate convergence of all co (variance) parameters (Smith et al., 2007).

Functions to specify the posterior distribution of genetic, maternal permanent and residual (co)variances for the 12 original traits $\left(\mathrm{BW}_{\mathrm{m}(\mathrm{t})}, \mathrm{BW}_{\mathrm{f}(\mathrm{t})}, \mathrm{BW}_{\mathrm{m}(\mathrm{t}-6)}, \mathrm{BW}_{\mathrm{f}(\mathrm{t}-6)}\right.$, $\mathrm{FI}_{\mathrm{m}(\mathrm{t})}, \mathrm{FI}_{\mathrm{f}(\mathrm{t})}, \mathrm{FI}_{\mathrm{m}(\mathrm{t}-6)}, \mathrm{FI}_{\mathrm{f}(\mathrm{t}-6)}, \operatorname{Gain}_{\mathrm{m}(\mathrm{t})}, \operatorname{Gain}_{\mathrm{f}(\mathrm{t})}, \operatorname{Gain}_{\mathrm{m}(\mathrm{t}-6)}, \operatorname{Gain}_{\mathrm{f}(\mathrm{t}-6)}$ and the 8 derived RFI traits namely, phenotypic RFI in males at $t$ days of age $\left(\mathrm{RFI}_{\mathrm{P}(\mathrm{m} \text { tdays })}\right)$, phenotypic $\mathrm{RFI}$ in females at $t$ days of age $\left(\mathrm{RFI}_{\mathrm{P}(\mathrm{f} \text { tdays })}\right)$, phenotypic $\mathrm{RFI}$ in males at $t-6$ days of age $\left(\mathrm{RFI}_{\mathrm{P}(\mathrm{mt}-6 \text { days })}\right)$, phenotypic $\mathrm{RFI}$ in females at $t-6$ days of age $\left(\mathrm{RFI}_{\mathrm{P}(\mathrm{ft}-6 \text { days })}\right)$, genetic $\mathrm{RFI}$ in males at $t$ days of age $\left(\mathrm{RFI}_{\mathrm{G}(\mathrm{m} \text { tdays })}\right)$, genetic $\mathrm{RFI}$ in females at $t$ days of age $\left(\mathrm{RFI}_{\mathrm{G} \text { (ftdays) }}\right)$, genetic $\mathrm{RFI}$ in males at $t-6$ days of age $\left(\mathrm{RFI}_{\mathrm{G}(\mathrm{m} \mathrm{t} \text {-6days })}\right)$, and genetic $\mathrm{RFI}$ in females at $t-6$ days of age $\left(\mathrm{RFI}_{\mathrm{G}(\mathrm{ft}-6 \text { days })}\right)$ were derived based on Shirali et al. (2018). 
Table 4.1. Descriptive statistics of the data

\begin{tabular}{cccccc}
\hline Trait & $\mathrm{N}$ & Mean $(\mathrm{g})$ & $\mathrm{SD}$ & Min & Max \\
\hline $\mathrm{BW}_{\mathrm{m}(\mathrm{t})}$ & 17270 & 2732.3 & 268.6 & 1776 & 3712 \\
$\mathrm{BW}_{\mathrm{f}(\mathrm{t})}$ & 18461 & 2303.3 & 221.9 & 221.9 & 1463 \\
$\mathrm{BW}_{\mathrm{m}(\mathrm{t}-6)}$ & 10117 & 2182.8 & 213.3 & 213.3 & 1319 \\
$\mathrm{BW}_{\mathrm{f}(\mathrm{t}-6)}$ & 10801 & 1882.4 & 180.2 & 1077 & 2449 \\
$\mathrm{FI}_{\mathrm{m}(\mathrm{t})}$ & 5065 & 2851.7 & 215.6 & 1919.0 & 3712.0 \\
$\mathrm{FI}_{\mathrm{f}(\mathrm{t})}$ & 10334 & 2355.1 & 185.2 & 1700.0 & 3045.0 \\
$\mathrm{FI}_{\mathrm{m}(\mathrm{t}-6)}$ & 2301 & 2311.3 & 163.1 & 1493.0 & 2890.0 \\
$\mathrm{FI}_{\mathrm{f}(\mathrm{t}-6)}$ & 4581 & 1954.3 & 141.3 & 1421.0 & 2449.0 \\
$\mathrm{Gain}_{\mathrm{m}(\mathrm{t})}$ & 5056 & 619.2 & 146.6 & 206.0 & 1161.0 \\
$\mathrm{Gain}_{\mathrm{f}(\mathrm{t})}$ & 10239 & 479.3 & 102.6 & 182.0 & 865.0 \\
$\operatorname{Gain}_{\mathrm{m}(\mathrm{t}-6)}$ & 2299 & 636.4 & 115.4 & 292.0 & 960.0 \\
Gain $_{\mathrm{f}(\mathrm{t}-6)}$ & 4533 & 469.2 & 91.3 & 211.0 & 725.0 \\
\hline
\end{tabular}

$\mathrm{BW}_{\mathrm{m}(\mathrm{t})}$ : Body weight in males at $t$ days of age; $\mathrm{BW}_{\mathrm{f}(\mathrm{t})}$ : Body weight in females at $t$ days of age;

$\mathrm{BW}_{\mathrm{m}(\mathrm{t}-6)}$ : : 0 ody weight in males at $t-6$ days of age; $\mathrm{BW}_{\mathrm{f}(\mathrm{t}-6)}$ : Body weight in females at $\mathrm{t}-6$ days of age; $\mathrm{FI}_{\mathrm{m}(\mathrm{t})}$ :Feed intake in males at $t$ days of age; $\mathrm{FI}_{\mathrm{f}(\mathrm{t})}$ : Feed intake in females at $t$ days of age; $\mathrm{FI}_{\mathrm{m}(\mathrm{t}-6)}$ : Feed intake in males at $t-6$ days of age; $\mathrm{FI}_{\mathrm{f}(\mathrm{t}-6)}$ :Feed intake in females at $t-6$ days of age; $\mathrm{Gain}_{\mathrm{m}(\mathrm{t})}$ : Body weight gain in males at $t$ days of age; $\operatorname{Gain}_{\mathrm{f}(\mathrm{t})}$ : Body weight gain in females at $t$ days of age; $\mathrm{Gain}_{\mathrm{m}(\mathrm{t}-6)}$ :Body weight gain in males at $t-6$ days of age; $\operatorname{Gain}_{\mathrm{f}(\mathrm{t}-6)}$ : Body weight gain in females at $t-6$ days of age.

Phenotypic RFI $\left(\mathrm{RFI}_{\mathrm{P}}\right)$ and genetic $\mathrm{RFI}\left(\mathrm{RFI}_{\mathrm{G}}\right)$ were derived using phenotypic partial regression coefficients and genetic partial regression coefficients, respectively for each sex and age sub class. This ensures that the phenotypic co (variances) between $\mathrm{RFI}_{\mathrm{P}}$ and production traits (BW and Gain) is zero and the genetic covariance between $\mathrm{RFI}_{\mathrm{G}}$ and production traits is zero. $\mathrm{RFI}_{\mathrm{P}}$ and $\mathrm{RFI}_{\mathrm{G}}$ are linear combinations of $\mathrm{BW}, \mathrm{FI}$ and Gain. For $\mathrm{RFI}_{\mathrm{P}}$, the partial phenotypic regression coefficients $\left(\mathbf{b}_{\mathrm{P}}\right)$ for $\mathrm{BW}$ and Gain were computed from the phenotypic (co)variance matrix while for $\mathrm{RFI}_{\mathrm{G}}$, the partial genetic regression coefficients $\left(\mathbf{b}_{\mathrm{G}}\right)$ for $\mathrm{BW}$ and Gain were computed from the genetic (co)variance matrix. In a given posterior sample, the two RFI definitions have conditional normal distributions and derived as follows: let $\mathbf{P}_{\mathbf{0}}=\mathbf{G}_{\mathbf{0}}+\mathbf{K}_{\mathbf{0}}+\mathbf{R}_{\mathbf{0}}$ be the phenotypic and $\mathbf{G}_{\mathbf{0}}$ the genetic (co)variance matrices, which were computed based on each sample from the posterior distribution of parameters. Where $\mathbf{P}_{\mathbf{0}}$ is $12 \times 12$ phenotypic co(variance) matrix, $\mathbf{K}_{\mathbf{0}}$ is $12 \times 12$ maternal permanent environmental co(variance) matrix, $\mathbf{R}_{\mathbf{0}}$ is $12 \times 12$ residual co (variance) matrix. The Bayesian estimation of partial phenotypic $\left(\mathbf{b}_{\mathrm{P}}\right)$ and genetic $\left(\mathbf{b}_{\mathrm{G}}\right)$ regression coefficients were computed as follows:

$\mathbf{b}_{\mathrm{P}}=\mathbf{P}_{\mathbf{P}}^{-1} \mathbf{P}_{\mathrm{P}, \mathrm{FI}} \quad$ and $\quad \mathbf{b}_{\mathrm{G}}=\mathbf{G}_{\mathrm{P}}^{-1} \mathbf{G}_{\mathrm{P}, \mathrm{FI}}$ 
Where $\mathbf{b}_{\mathrm{P}}$ and $\mathbf{b}_{\mathrm{G}}$ are $2 \times 1$ vectors obtained in each sample from the Gibbs output for each sex and age. $\mathbf{P}_{\mathbf{P}}$ and $\mathbf{G}_{\mathbf{P}}$ are $2 \times 2$ phenotypic and genetic (co)variance matrices for the production traits of BW and Gain from $\mathbf{P}_{\mathbf{0}}$ and $\mathbf{G}_{\mathbf{0}}$, respectively in each sex and age. $\mathbf{P}_{\mathrm{P}, \mathrm{FI}}$ and $\mathbf{G}_{\mathrm{P}, \mathrm{FI}}$ are phenotypic and genetic (co)variance matrices, respectively, between the production traits (BW and Gain) and FI in each sex and age. The breeding values for $\mathrm{RFI}_{P}$ can be computed for all animals by conditional distribution of breeding values for $\mathrm{FI}$, given breeding values of $\mathrm{BW}$ and Gain using $\mathbf{b}_{\mathbf{P}}$ and the breeding values for $\mathrm{RFI}_{\mathrm{G}}$ can be obtained for all animals by conditional distribution of breeding values for $\mathrm{FI}$, given breeding values of $\mathrm{BW}$ and Gain using $\mathrm{b}_{\mathrm{G}}$ (Shirali et al., 2018). For example, a given sample from the posterior distribution of breeding values for phenotypic $\left(\mathbf{a}_{\mathrm{RFIP}}\right)$ and genetic $\left(\mathbf{a}_{\mathrm{RFIG}}\right)$ can be computed as follows:

$$
\begin{aligned}
& \mathbf{a}_{\mathrm{RFIP}}=\mathbf{a}_{\mathrm{FI}}-\left[\begin{array}{ll}
\mathbf{a}_{\text {Gain }} & \mathbf{a}_{\mathrm{BW}}
\end{array}\right] \mathbf{b}_{\mathrm{P}} \\
& \mathbf{a}_{\mathrm{RFIG}}=\mathbf{a}_{\mathrm{FI}}-\left[\begin{array}{ll}
\mathbf{a}_{\text {Gain }} & \mathbf{a}_{\mathrm{BW}}
\end{array}\right] \mathbf{b}_{\mathrm{G}}
\end{aligned}
$$

The distribution of $\mathrm{RFI}_{\mathrm{P}}$ for a given sample were obtained as the distribution of $\mathrm{FI}$, conditional on BW and Gain. Similarly, the distribution of $\mathrm{RFI}_{\mathrm{G}}$ for a given sample were obtained as the distribution of $\mathrm{Fl}$, conditional on BW and Gain. The corresponding co (variances) can be computed as follows:

$\mathbf{P}_{\mathbf{1}}=\mathbf{B} * \mathbf{P}_{\mathbf{0}} * \mathbf{B}^{\prime} \quad$ and $\quad \mathbf{G}_{\mathbf{1}}=\mathbf{B} * \mathbf{G}_{\mathbf{0}} * \mathbf{B}^{\prime}$

Where $\mathbf{P}_{\mathbf{1}}$ is the new $20 \times 20$ phenotypic co (variance) matrix and $\mathbf{G}_{\mathbf{1}}$ is the new $20 \times$ 20 genetic co (variance) matrix that includes the 8 derived traits of RFI in addition to the original 12 traits included in the Bayesian multivariate model. $\mathbf{P}_{\mathbf{0}}$ and $\mathbf{G}_{\mathbf{0}}$ are $12 \times 12$ phenotypic and genetic co (variance) matrices of the original traits, respectively and $\mathbf{B}$ represents 20 linear functions used to derive the new set of traits. The first 12 are identity functions for the 12 original traits and the remaining 8 are functions for the 8 derived traits of RFI. Details can be found in Shirali et al. (2018).

\subsubsection{Superiority of the selected group}

The Bayesian measure of direct and correlated genetic superiority of a group of selected birds was calculated as the difference between the mean of the breeding values in the selected population and the mean of the population corrected for genetic trend. Unlike the classical selection index calculations, it is possible to make probability statements on the expected response to selection in the Bayesian analysis and their posterior standard deviations can be derived easily. This gives an 
expression of the superiority of the selected group in every sample from the posterior distribution. The mean of the selected group for trait $\mathrm{j}$ when selecting on trait j' was calculated based on the formula from Shirali et al. (2018).

$\mathbf{a}_{\mathrm{ji}^{\prime}}^{\mathrm{s}}=\frac{1}{\mathbf{n}_{\mathrm{s}}} \sum_{\mathrm{i}=1}^{\mathrm{n}} \mathbf{a}_{\mathrm{ij}} \mathbf{I}\left(\mathbf{a}_{\mathrm{ij}^{\prime}}>\mathbf{a}_{\mathbf{n}_{\mathbf{s}} \mathbf{j}^{\prime}}\right)$

Where

$a_{j j^{\prime}}^{s}$ is the mean of the selected group for trait $j$ when selection is on trait $j^{\prime}, a_{i j}$ is the additive breeding value for trait $j$ on animal $i$ conditional on the genetic trend; $n$ is the total number of animals, and $a_{n_{s} j}$ is the additive genetic value for a ranked individual $\left(n_{s}\right)$ when ordering animals based on breeding values for trait $j^{\prime}$. If $j=j^{\prime}$, the superiority is due to direct selection for the trait, and if $j \neq j^{\prime}$, the superiority is in trait $j$ due to selection of possible correlated trait $j^{\prime}$. In this study, there are 20 traits (12 original and 8 derived traits). Therefore, 20 scenarios were developed to compare the direct and correlated superiority of the selected group on production or feed efficiency traits. However, only the results of the 8 scenarios for the derived traits are presented. The number of individuals ranked for analysis was decided based on truncation selection by selecting the best 5, 10 and $20 \%$ of birds, however, only the results of truncation selection when selecting the best $10 \%$ are presented since the results are consistent across all selection percentages. Production traits (BW and Gain), were selected upwards and $\mathrm{FE}$ traits $\left(\mathrm{FI}, \mathrm{RFI}_{\mathrm{P}}\right.$ and $\mathrm{RFI}_{\mathrm{G}}$ ) were selected downwards.

\subsection{Results}

\subsubsection{Genetic parameters of production and feed efficiency traits}

Descriptive statistics of the data is presented in Table 4.1. Males have higher mean BW, FI and Gain than females in the two ages. The higher mean BW in males than females is consistent with previous studies (Mebratie et al., 2018; Begli et al., 2017). The posterior mean and posterior standard deviations (PSDs) of genetic variance, residual variance and heritability estimates for the 12 original traits and the 8 derived traits of RFI are presented in Table 4.2, where all trait abbreviations are also summarized. All the reported parameters are posterior means, which were computed as averages of 3000 samples. For ease of presentation and interpretation of the results, comparison of genetic parameters in males and females is limited to the same age and comparison of genetic parameters in the two ages is limited to the same sex in the results and discussion section. The genetic variance of BW in males and females was found to be significantly different, males having higher genetic 
variance than females in both ages. However, higher heritability estimates were observed in females than males at both ages. Similarly, the genetic variance of BW was significantly different in the two ages and it decreased as the weighing age decreased from $t$ to $t-6$ days. However, the heritability estimates of BW increased as weighing age decreased.

Unlike BW traits, the heritability estimates of $\mathrm{FI}, \mathrm{Gain}, \mathrm{RFI}_{\mathrm{P}}$ and $\mathrm{RFI}_{\mathrm{G}}$ were higher in males than females at both ages except for $\mathrm{RFI}_{\mathrm{G}}$ at $t$ days of age in which the heritability estimates were the same in males and females. The posterior means of the heritability estimates of $\mathrm{FI}$ and Gain were found to be low to moderate (0.190.38) in males and females at both ages with males having significantly higher estimates than females. Moreover, the genetic variance and heritability estimates of FI were significantly higher than that of Gain in males and females at the two ages (Table 4.2). The heritability estimates of the two RFI definitions were low (0.14-0.28); $\mathrm{RFI}_{\mathrm{P}}$ having significantly higher heritability estimates than $\mathrm{RFI}_{\mathrm{G}}$ in the two sexes and ages. This was followed by a slightly higher genetic variance in $\mathrm{RFI}_{\mathrm{P}}$ than $\mathrm{RFI}_{\mathrm{G}}$ and higher residual variance in $\mathrm{RFI}_{\mathrm{G}}$ than $\mathrm{RFI}_{\mathrm{P}}$ in both sexes and ages.

The posterior means of the genetic correlations between the 12 traits included in the multivariate model are presented in Table 4.3. PSDs of correlations are not shown to simplify presentation of the results; however, they were in the lower range (0.01-0.06). The posterior means of genetic correlation of BW (PSDs in parenthesis) between males and females at $t$ days was $0.90(0.02)$ and the genetic correlation of BW between males and females at $t-6$ days was $0.90(0.03)$. The genetic correlations of $\mathrm{FI}$ between males and females were $0.82(0.04)$ and $0.86(0.04)$ at $t$ and $t-6$ days of age, respectively. The genetic correlations of Gain between males and females were $0.75(0.06)$ and $0.81(0.06)$ at $t$ and $t-6$ days of age, respectively with genetic correlations significantly higher at early ages ( $t-6$ days) than later ages ( $t$ ) for both FI and Gain. 
Table 4.2. Posterior means of variance components and heritability of body weight (BW), feed intake (FI), body weight gain (Gain) and the two RFI definitions $\left(\mathrm{RFI}_{\mathrm{P}}\right.$ and $\left.\mathrm{RFI}_{\mathrm{G}}\right)$ with their posterior standard deviations (PSDs).

\begin{tabular}{ccccccccc}
\hline Traits & $\sigma_{\mathrm{a}}^{2}\left(\mathrm{~g}^{2}\right)$ & $\mathrm{PSD}$ & $\sigma_{\mathrm{e}}^{2}\left(\mathrm{~g}^{2}\right)$ & $\mathrm{PSD}$ & $\sigma_{\mathrm{pe}}^{2}\left(\mathrm{~g}^{2}\right)$ & $\mathrm{PSD}$ & $\mathrm{h}^{2}$ & PSD \\
\hline $\mathrm{BW}_{\mathrm{m}(\mathrm{t})}$ & 17865.5 & 1870.0 & 37592.8 & 1056.0 & 1868.5 & 391.4 & 0.31 & 0.03 \\
$\mathrm{BW}_{\mathrm{f}(\mathrm{t})}$ & 13339.2 & 1349.4 & 25141.9 & 747.1 & 1519.5 & 282.4 & 0.33 & 0.03 \\
$\mathrm{BW}_{\mathrm{m}(\mathrm{t}-6)}$ & 12277.1 & 1643.8 & 23589.6 & 902.1 & 1578.6 & 354.2 & 0.33 & 0.04 \\
$\mathrm{BW}_{\mathrm{f}(\mathrm{t}-6)}$ & 10228.5 & 1263.3 & 15983.8 & 680.3 & 1116.8 & 249.8 & 0.37 & 0.04 \\
$\mathrm{FI}_{\mathrm{m}(\mathrm{t})}$ & 8014.2 & 993.4 & 17993.3 & 647.0 & 976.5 & 280.0 & 0.30 & 0.03 \\
$\mathrm{FI}_{\mathrm{f}(\mathrm{t})}$ & 4926.2 & 535.9 & 13493.1 & 339.9 & 616.3 & 140.6 & 0.26 & 0.03 \\
$\mathrm{FI}_{\mathrm{m}(\mathrm{t}-6)}$ & 6981.7 & 1178.8 & 10445.3 & 706.1 & 971.7 & 312.9 & 0.38 & 0.05 \\
$\mathrm{FI}_{\mathrm{f}(\mathrm{t}-6)}$ & 4645.4 & 568.7 & 8343.7 & 350.6 & 447.1 & 144.0 & 0.35 & 0.04 \\
Gain $_{\mathrm{m}(\mathrm{t})}$ & 4053.8 & 576.9 & 13212.1 & 414.5 & 549.6 & 174.1 & 0.23 & 0.03 \\
Gain $_{\mathrm{f}(\mathrm{t})}$ & 1664.5 & 210.4 & 6841.4 & 147.9 & 231.8 & 58.3 & 0.19 & 0.02 \\
Gain $_{\mathrm{m}(\mathrm{t}-6)}$ & 4307.4 & 798.3 & 7686.0 & 490.6 & 607.0 & 203.2 & 0.34 & 0.05 \\
Gain $_{\mathrm{f}(\mathrm{t}-6)}$ & 2099.1 & 297.3 & 5124.7 & 195.6 & 239.9 & 76.7 & 0.28 & 0.04
\end{tabular}

$\mathrm{BW}_{\mathrm{m}(\mathrm{t})}$ : Body weight in males at $t$ days of age; $\mathrm{BW}_{\mathrm{f}(\mathrm{t})}$ :Body weight in females at $t$ days of age; $\mathrm{BW}\left(\mathrm{m}(\mathrm{t}-6)\right.$ :Body weight in males at $t-6$ days of age; $\mathrm{BW}_{\mathrm{f}(\mathrm{t}-6)}$ : $\mathrm{Body}$ weight in females at $t-6$ days of age; $\mathrm{FI}_{\mathrm{m}(\mathrm{t})}$ :Feed intake in males at $t$ days of age; $\mathrm{FI}_{\mathrm{f}(\mathrm{t})}$ : Feed intake in females at $t$ days of age; $\mathrm{FI}_{\mathrm{m}(\mathrm{t}-6)}$ : Feed intake in males at $t-6$ days of age; $\mathrm{FI}_{\mathrm{f}(\mathrm{t}-6)}$ :Feed intake in females at $t-6$ days of age; $\operatorname{Gain}_{\mathrm{m}(\mathrm{t})}$ : Body weight gain in males at $t$ days of age; $\mathrm{Gain}_{\mathrm{f}(\mathrm{t})}$ : Body weight gain in females at $t$ days of age; Gain $_{\mathrm{m}(\mathrm{t}-6)}$ : Body weight gain in males at $t-6$ days of age; $\operatorname{Gain}_{\mathrm{f}(\mathrm{t}-6)}$ : Body weight gain in females at $t-6$ days of age. 
Table 4.2. Continued

\begin{tabular}{ccccccccc}
\hline Traits & $\sigma_{\mathrm{a}}^{2}\left(\mathrm{~g}^{2}\right)$ & $\mathrm{PSD}$ & $\sigma_{\mathrm{e}}^{2}\left(\mathrm{~g}^{2}\right)$ & $\mathrm{PSD}$ & $\sigma_{\mathrm{pe}}^{2}\left(\mathrm{~g}^{2}\right)$ & $\mathrm{PSD}$ & $\mathrm{h}^{2}$ & $\mathrm{PSD}$ \\
\hline $\mathrm{RFI}_{\mathrm{P}(\mathrm{m} \text { tdays })}$ & 1431.2 & 247.1 & 6260.3 & 183.8 & 290.7 & 83.7 & 0.18 & 0.03 \\
$\mathrm{RFI}_{\mathrm{P}(\mathrm{f} \text { tdays })}$ & 961.1 & 143.0 & 4878.0 & 103.0 & 231.1 & 48.6 & 0.16 & 0.02 \\
$\mathrm{RFI}_{\mathrm{P}(\mathrm{m} \text { t-6days })}$ & 1443.0 & 295.7 & 3369.7 & 191.4 & 272.0 & 89.3 & 0.28 & 0.05 \\
$\mathrm{RFI}_{\mathrm{P}(\mathrm{ft} \text {-6days })}$ & 747.0 & 128.3 & 2243.2 & 83.0 & 117.8 & 35.4 & 0.24 & 0.04 \\
$\mathrm{RFI}_{\mathrm{G} \text { (m tdays })}$ & 1261.0 & 246.1 & 7171.2 & 537.7 & 299.5 & 90.7 & 0.14 & 0.03 \\
$\mathrm{RFI}_{\mathrm{G}(\mathrm{f} \text { tdays })}$ & 874.8 & 145.7 & 5241.3 & 537.7 & 256.9 & 54.3 & 0.14 & 0.02 \\
$\mathrm{RFI}_{\mathrm{G} \text { (m t-6days) }}$ & 1380.8 & 297.5 & 3660.2 & 207.1 & 287.9 & 96.9 & 0.26 & 0.05 \\
$\mathrm{RFI}_{\mathrm{G} \text { (f t-6days })}$ & 720.5 & 128.0 & 2357.2 & 365.5 & 128.3 & 40.6 & 0.22 & 0.04 \\
\hline
\end{tabular}

RFI: Residual feed intake; $\mathrm{RFI}_{\mathrm{P}(\mathrm{m} \text { tdays })}$ : Phenotypic $\mathrm{RFI}$ in males at $t$ days of age; $\mathrm{RFI}_{\mathrm{P}(\mathrm{ftdays})}$ : Phenotypic $\mathrm{RFI}$ in females at $t$ days of age; $\mathrm{RFI}_{\mathrm{P}(\mathrm{m} \mathrm{t}-6 \text { days })}$ : Phenotypic RFI in males at $t-6$ days of age; $\mathrm{RFI}_{\mathrm{P}(\mathrm{ft}-6 \text { days })}$ : Phenotypic $\mathrm{RFI}$ in females at $t-6$ days of age; $\mathrm{RFI}_{\mathrm{G}(\mathrm{m} \text { tdays })}$ : Genetic $\mathrm{RFI}$ in males at $t$ days of age; $\mathrm{RFI}_{\mathrm{G}(\mathrm{ftdays})}$ : Genetic $\mathrm{RFI}$ in females at $t$ days of age; $\mathrm{RFI}_{\mathrm{G}(\mathrm{m} \mathrm{t}-6 \text { days })}$ : Genetic $\mathrm{RFI}$ in males at $t-6$ days of age; $\mathrm{RFI}_{\mathrm{G}(\mathrm{ft}-6 \text { days) }}$ : Genetic $\mathrm{RFI}$ in females at $t-6$ days of age; $\mathrm{g}$ : Gram; PSD:Posterior standard deviation. 
The posterior means of genetic correlations between BW and FI were moderate (0.49-0.63) in males and females at both ages. The genetic correlations between BW and Gain were also moderate (0.30-0.50) in males and females along with the two ages except the low genetic correlation (0.25) between BW and Gain in males at $t$ days of age. The genetic correlations between FI and Gain were high (0.82-0.90) in males and females along the two ages (Table 4.3). The posterior means of the genetic correlations between the two RFI definitions are presented in Table 4.4. The genetic correlations between $\mathrm{RFI}_{\mathrm{P}}$ and $\mathrm{RFI}_{\mathrm{G}}$ at the same sex and age were high and significantly different from unity at $t$ days of age; however, at $t-6$ days of age the genetic correlations were not significantly different from unity (Table 4.4).

The genetic and phenotypic correlations between production traits and the two RFI definitions are presented in Table 4.5. $\mathrm{RFI}_{\mathrm{G}}$ was derived using genetic partial regression coefficients of $\mathrm{FI}$ on production traits. Therefore, the posterior mean of genetic correlations between $\mathrm{RFI}_{\mathrm{G}}$ and $\mathrm{BW}$ at the same sex and age were zero (results not shown) and the genetic correlations between $\mathrm{RFI}_{\mathrm{P}}$ and $\mathrm{BW}$ at the same sex and age were found to be low (0.04-0.24) but different from zero (Table 4.5). Similarly, $\mathrm{RFI}_{\mathrm{P}}$ was derived using phenotypic partial regression coefficients of $\mathrm{FI}$ on production traits, therefore the phenotypic correlations between $\mathrm{RFI}_{P}$ and $\mathrm{BW}$ at the same sex and age were zero (results not shown) and the phenotypic correlations between $\mathrm{RFI}_{\mathrm{G}}$ and $\mathrm{BW}$ at the same sex and age were low $(-0.002$ to -0.15$)$ but different from zero (Table 4.5)

The same holds true for genetic correlations and phenotypic correlations between the two RFI definitions and Gain. The posterior mean of genetic correlations between $\mathrm{RFI}_{\mathrm{G}}$ and Gain at the same sex and age were confirmed to be zero (results not shown) and the genetic correlations between $\mathrm{RFI}_{P}$ and Gain at the same sex and age were found to be low to moderate (0.11-0.32) (Table 4.5). Similarly, the phenotypic correlations between $\mathrm{RFI}_{\mathrm{P}}$ and Gain at the same sex and age were confirmed to be zero (results not shown) and the phenotypic correlations between $\mathrm{RFI}_{\mathrm{G}}$ and $\mathrm{Gain}$ at the same sex and age were found to be low (-0.09 to -0.27$)$ but non-zero (Table 4.5).

The genetic and phenotypic correlations between FI and the two RFI definitions are presented in Table 4.6. The correlations were moderate in males and females along with the two ages, with higher genetic correlations between $\mathrm{FI}$ and $\mathrm{RFI}_{P}$ (0.51-0.66) than between $\mathrm{FI}$ and $\mathrm{RFI}_{\mathrm{G}}$ (0.39-0.45). The phenotypic correlations between $\mathrm{FI}$ and $\mathrm{RFI}_{P}$ at the same sex and age were found to be (0.48-0.57) and the phenotypic correlations between $\mathrm{FI}$ and $\mathrm{RFI}_{\mathrm{G}}$ at the same sex and age were found to be (0.31- 
Table 4.3. Posterior means of genetic correlations between body weight (BW), feed intake (FI) and body weight gain (Gain).

\begin{tabular}{|c|c|c|c|c|c|c|c|c|c|c|c|}
\hline Trait & $\mathrm{BW}_{\mathrm{m}(\mathrm{t})}$ & $\mathrm{BW}_{\mathrm{f}(\mathrm{t})}$ & $\mathrm{BW}_{\mathrm{m}(\mathrm{t}-6)}$ & $\mathrm{BW}_{\mathrm{f}(\mathrm{t}-6)}$ & $\mathrm{FI}_{\mathrm{m}(\mathrm{t})}$ & $\mathrm{FI}_{\mathrm{f}(\mathrm{t})}$ & $\mathrm{FI}_{\mathrm{m}(\mathrm{t}-6)}$ & $\mathrm{FI}_{\mathrm{f}(\mathrm{t}-6)}$ & $\operatorname{Gain}_{\mathrm{m}(\mathrm{t})}$ & $\operatorname{Gain}_{\mathrm{f}(\mathrm{t})}$ & $\operatorname{Gain}_{\mathrm{m}(\mathrm{t}-6)}$ \\
\hline \multicolumn{12}{|l|}{$\mathrm{BW}_{\mathrm{m}(\mathrm{t})}$} \\
\hline $\mathrm{BW}_{\mathrm{f}(\mathrm{t})}$ & ${ }^{\mathrm{a}} 0.90$ & & & & & & & & & & \\
\hline $\mathrm{BW}_{\mathrm{m}(\mathrm{t}-6)}$ & $* 0.84$ & 0.82 & & & & & & & & & \\
\hline $\mathrm{BW}_{\mathrm{f}(\mathrm{t}-6)}$ & 0.78 & $* 0.87$ & b 0.90 & & & & & & & & \\
\hline $\mathrm{FI}_{\mathrm{m}(\mathrm{t})}$ & 0.49 & 0.41 & 0.44 & 0.37 & & & & & & & \\
\hline $\mathrm{FI}_{\mathrm{f}(\mathrm{t})}$ & 0.53 & 0.60 & 0.52 & 0.59 & ${ }^{\circ} 0.82$ & & & & & & \\
\hline $\mathrm{FI}_{\mathrm{m}(\mathrm{t}-6)}$ & 0.50 & 0.44 & 0.51 & 0.48 & ${ }^{*} 0.76$ & 0.75 & & & & & \\
\hline $\mathrm{FI}_{\mathrm{f}(\mathrm{t}-6)}$ & 0.60 & 0.57 & 0.55 & 0.63 & 0.77 & *0.88 & d 0.86 & & & & \\
\hline $\operatorname{Gain}_{\mathrm{m}(\mathrm{t})}$ & 0.25 & 0.20 & 0.25 & 0.16 & 0.87 & 0.64 & 0.59 & 0.55 & & & \\
\hline $\operatorname{Gain}_{\mathrm{f}(\mathrm{t})}$ & 0.21 & 0.30 & 0.24 & 0.29 & 0.69 & 0.82 & 0.60 & 0.68 & e 0.75 & & \\
\hline Gain $_{\mathrm{m}(\mathrm{t}-6)}$ & 0.46 & 0.42 & 0.45 & 0.42 & 0.67 & 0.68 & 0.88 & 0.73 & $* 0.64$ & 0.68 & \\
\hline $\operatorname{Gain}_{\mathrm{f}(\mathrm{t}-6)}$ & 0.49 & 0.47 & 0.47 & 0.50 & 0.73 & 0.79 & 0.82 & 0.89 & 0.67 & $* 0.78$ & $f^{\circ} 0.81$ \\
\hline
\end{tabular}

Trait descriptions can be referred in Table 4.2; numbers in bold are genetic correlations between traits at the same sex and age; a-f: genetic correlations of traits

between males and females within ages; *: Genetic correlations of traits between ages within sexes. 
0.43 ) but lower than the genetic correlations between $\mathrm{FI}$ and the two RFI definitions (Table 4.6).

\subsubsection{Superiority of the selected group}

Table 4.7 shows the posterior mean of direct and correlated genetic level of the selected groups under single trait selection against the two RFI definitions. Direct selection against $\mathrm{RFI}_{\mathrm{P}}$ in males at $t$ days of age resulted in a direct selection response of $-63.0 \mathrm{~g}$ and a correlated response of decreasing $\mathrm{RFI}_{\mathrm{G}}$ by $55.6 \mathrm{~g}$ at the same age in males. Similarly direct selection against $\mathrm{RFI}_{\mathrm{G}}$ in males at $t$ days of age resulted in a direct selection response of $-59.4 \mathrm{~g}$ and a correlated response of decreasing $\mathrm{RFI}_{\mathrm{P}}$ by $59.0 \mathrm{~g}$ at the same age in males. As shown in the table, the correlated response in $\mathrm{RFI}_{G}$ from direct selection on $\mathrm{RFI}_{\mathrm{P}}$ is slightly different from direct response in $\mathrm{RFI}_{\mathrm{P}}$ at $t$ day of age; however, correlated response in $\mathrm{RFI}_{\mathrm{P}}$ is the same as direct selection on $\mathrm{RFI}_{\mathrm{G}}$ in both ages. The slight differences in the correlated response at $t$ days of age might be due to the significantly different from unity genetic correlations between $\mathrm{RFI}_{\mathrm{P}}$ and $\mathrm{RFI}_{\mathrm{G}}$ at $t$ days of age.

Table 4.8 shows the posterior means of correlated genetic level of the selected groups under single trait selection against the two RFI definitions. Direct selection against $\mathrm{RFI}_{\mathrm{P}}$ at $t$ days of age in males has a correlated response of decreasing $\mathrm{FI}$ by $98.2 \mathrm{~g}$ while decreasing BW and Gain by $17.3 \mathrm{~g}$ and $33.8 \mathrm{~g}$, respectively at $t$ days of age in males. Thus, direct selection against $\mathrm{RFI}_{\mathrm{P}}$ has a favorable correlated response of decreasing $\mathrm{Fl}$ in a relatively higher amount than decreasing BW and Gain. Moreover, direct selection against $\mathrm{RFI}_{\mathrm{G}}$ in males at $t$ days of age resulted in a correlated response of decreasing $\mathrm{FI}$ by $58.2 \mathrm{~g}$ at the same age in males with no significant change on BW and Gain. Similarly direct selection against $\mathrm{RFI}_{\mathrm{G}}$ in females at $t-6$ days decreased the $\mathrm{FI}$ by $43.2 \mathrm{~g}$ with no significant change on BW and Gain at $t-6$ days of age in females (Table 4.8). As expected from the definition, direct selection on $\mathrm{RFI}_{\mathrm{G}}$ did not show considerable correlated response on BW and Gain at the same sex and age, however, it had a correlated response of decreasing FI (Table 4.8). 
Table 4.4. Posterior means of genetic correlations with PSDs in parenthesis between phenotypic and genetic residual feed intake $\left(\mathrm{RFI}_{\mathrm{P}}\right.$ and $\mathrm{RFI}_{\mathrm{G}}$, respectively).

\begin{tabular}{|c|c|c|c|c|c|c|c|}
\hline Trait & $\mathrm{RFI}_{\mathrm{P}(\mathrm{m} \text { tdays })}$ & $\mathrm{RFI}_{\mathrm{P}(\mathrm{f} \text { tdays })}$ & $\mathrm{RFI}_{\mathrm{P}(\mathrm{m} \mathrm{t}-6 \text { days })}$ & $\mathrm{RFI}_{\mathrm{P}(\mathrm{ft} \mathrm{t}-6 \text { days })}$ & $\mathrm{RFI}_{\mathrm{G}(\mathrm{m} \text { tdays })}$ & $\mathrm{RFI}_{\mathrm{G} \text { (f tdays) }}$ & $\mathrm{RFI}_{\mathrm{G}(\mathrm{m} \mathrm{t}-6 \mathrm{days})}$ \\
\hline \multicolumn{8}{|l|}{$\mathrm{RFI}_{\mathrm{P}(\mathrm{m} \text { tdays })}$} \\
\hline $\mathrm{RFI}_{\mathrm{P}(\mathrm{f} \text { tdays })}$ & a0.80(0.06) & & & & & & \\
\hline $\mathrm{RFI}_{\mathrm{P}(\mathrm{m} \mathrm{t}-6 \text { days })}$ & $* 0.68(0.11)$ & $0.63(0.14)$ & & & & & \\
\hline $\mathrm{RFI}_{\mathrm{P}(\mathrm{ft}-6 \text { days })}$ & $0.70(0.10)$ & *0.71 (0.09) & b0.70 (0.09) & & & & \\
\hline $\mathrm{RFI}_{\mathrm{G}(\mathrm{m} \text { tdays })}$ & $0.94(0.04)$ & $0.77(0.07)$ & $0.67(0.12)$ & $0.72(0.10)$ & & & \\
\hline $\mathrm{RFI}_{\mathrm{G}(\mathrm{f} \text { tdays })}$ & $0.78(0.07)$ & $0.95(0.02)$ & $0.64(0.16)$ & $0.71(0.10)$ & ${ }^{c} 0.80(0.07)$ & & \\
\hline $\mathrm{RFI}_{\mathrm{G}(\mathrm{m} \mathrm{t}-6 \text { days })}$ & $0.65(0.11)$ & $0.60(0.15)$ & $0.98(0.02)$ & $0.69(0.09)$ & $* 0.66(0.12)$ & $0.63(0.16)$ & \\
\hline $\mathrm{RFI}_{\mathrm{G}(\mathrm{ft}-6 \text { days })}$ & $0.67(0.10)$ & $0.67(0.10)$ & $0.67(0.09)$ & $0.98(0.02)$ & $0.71(0.11)$ & $* 0.69(0.11)$ & do.68 (0.09) \\
\hline
\end{tabular}

Description of abbreviations can be refered in Table 4.2; numbers in bold are genetic correlations between $\mathrm{RFI}_{\mathrm{P}}$ and $\mathrm{RFI}_{\mathrm{G}}$ at the same sex and age; a-d: genetic correlations of $\mathrm{RFI}_{P}$ and $\mathrm{RFI}_{G}$ between sexes within ages; ${ }^{*}$ Genetic correlations of $\mathrm{RFI}_{\mathrm{P}}$ and and $\mathrm{RFI}_{\mathrm{G}}$ between ages within sexes. 


\subsection{Discussion}

\subsubsection{Genetic parameters of production and feed efficiency traits}

Bayesian method of analysis was used to study genetic parameters for production and feed efficiency traits in male and female broiler chickens recorded at two different ages, derive phenotypic and genetic RFI and study Bayesian measure of direct and correlated superiority of a group selected on phenotypic and genetic RFI. The Bayesian method allows to simultaneously derive the two RFI definitions with their posterior standard deviations and it integrates over all unknown model parameters, including "fixed" and random effects.

\subsubsection{Genetic parameters for body weight, feed intake and body weight gain}

Different authors have estimated genetic parameters for BW in males and females at different ages of broiler chickens and reported the heritability estimates of BW in the range from 0.20 to 0.53 (Mebratie et al., 2017; Adeyinka et al., 2006; MignonGrasteau et al., 1999; Le Bihan-Duval et al., 1998). Our heritability estimates of BW in males and females were moderate (0.31-0.37) at both ages and in the range with previous studies. Moreover, our results showed that the genetic variance of BW is higher in males than females in both ages. The higher genetic variance in males than females might partly be due to scale effect since males have higher mean BW than females at a given age; however, the heritability estimates were significantly higher in females than males due to higher residual variance in males. The higher residual variance in males than females might be due to higher feed competition between males. The genetic correlation of BW between males and females in both ages were significantly different from unity, which is in agreement with Mebratie et al. (2017). The difference in heritability estimates between BW in males and females, and genetic correlations of BW between males and females that deviate from unity suggest that there is sex by genotype interaction for BW in broiler chickens. This implies that, genes may react differently in male and female "physiological environments" due to differences in hormonal regulations or growth metabolism in male and female broiler chickens (Towne et al. 1997). The proportion of the maternal permanent environmental variance to the total phenotypic variance was low in the current study but not negligible. This might be due to the relatively older age of birds in our study since maternal permanent environmental variance often influences birds at early age and diminishes as birds grow older which is also in line with previous studies in poultry (Mebratie et al., 2017; Begli et al., 2016; Aslam et al., 2011; Towne et al., 1997). 
Table 4.5. Posterior means of genetic and phenotypic correlations with PSDs between production traits (BW and Gain) and the two RFI definitions $\left(\mathrm{RFI}_{\mathrm{P}}\right.$ and $\left.\mathrm{RFI}_{\mathrm{G}}\right)$.

\begin{tabular}{|c|c|c|c|c|c|}
\hline $\begin{array}{l}\text { Production } \\
\text { traits }\end{array}$ & $\begin{array}{l}\text { The two RFI } \\
\text { definitions }\end{array}$ & Genetic correlation & Production traits & $\begin{array}{l}\text { The two RFI } \\
\text { definitions }\end{array}$ & $\begin{array}{l}\text { Phenotypic } \\
\text { correlation }\end{array}$ \\
\hline $\mathrm{BW}_{\mathrm{m}(\mathrm{t})}$ & $\mathrm{RFI}_{\mathrm{P}(\mathrm{m} \text { tdays })}$ & $0.09(0.09)$ & $\mathrm{BW}_{\mathrm{m}(\mathrm{t})}$ & $\mathrm{RFI}_{\mathrm{G}(\mathrm{m} \text { tdays })}$ & $-0.04(0.07)$ \\
\hline $\mathrm{BW}_{\mathrm{f}(\mathrm{t})}$ & $\mathrm{RFI}_{\mathrm{P}(\mathrm{f} \text { tdays })}$ & $0.24(0.08)$ & $\mathrm{BW}_{\mathrm{f}(\mathrm{t})}$ & $\mathrm{RFI}_{\mathrm{G}(\mathrm{f} \text { tdays })}$ & $-0.15(0.06)$ \\
\hline $\mathrm{BW}_{\mathrm{m}(\mathrm{t}-6)}$ & $\mathrm{RFI}_{\mathrm{P}(\mathrm{m} \mathrm{t}-6 \text { days })}$ & $0.04(0.11)$ & $\mathrm{BW}_{\mathrm{m}(\mathrm{t}-6)}$ & $\mathrm{RFI}_{\mathrm{G}(\mathrm{mt}-6 \text { days })}$ & $-0.002(0.12)$ \\
\hline $\mathrm{BW}_{\mathrm{f}(\mathrm{t}-6)}$ & $\mathrm{RFI}_{\mathrm{P}(\mathrm{ft} \mathrm{t}-6 \text { days })}$ & $0.10(0.09)$ & $\mathrm{BW}_{\mathrm{f}(\mathrm{t}-6)}$ & $\mathrm{RFI}_{\mathrm{G}(\mathrm{f} \mathrm{t}-6 \text { days })}$ & $-0.05(0.08)$ \\
\hline $\operatorname{Gain}_{\mathrm{m}(\mathrm{t})}$ & $\mathrm{RFI}_{\mathrm{P}(\mathrm{m} \text { tdays })}$ & $0.32(0.10)$ & $\operatorname{Gain}_{\mathrm{m}(\mathrm{t})}$ & $\mathrm{RFI}_{\mathrm{G}(\mathrm{m} \text { tdays })}$ & $-0.27(0.08)$ \\
\hline $\operatorname{Gain}_{\mathrm{f}(\mathrm{t})}$ & $\mathrm{RFI}_{\mathrm{P}(\mathrm{f} \text { tdays })}$ & $0.20(0.09)$ & $\operatorname{Gain}_{\mathrm{f}(\mathrm{t})}$ & $\mathrm{RFI}_{\mathrm{G}(\mathrm{f} \text { tdays })}$ & $-0.14(0.08)$ \\
\hline $\operatorname{Gain}_{\mathrm{m}(\mathrm{t}-6)}$ & $\mathrm{RFI}_{\mathrm{P}(\mathrm{m} \mathrm{t}-6 \text { days })}$ & $0.11(0.13)$ & Gain $_{m(t-6)}$ & $\mathrm{RFI}_{\mathrm{G}(\mathrm{mt}-6 \text { days })}$ & $-0.10(0.13)$ \\
\hline $\operatorname{Gain}_{\mathrm{f}(\mathrm{t}-6)}$ & $\mathrm{RFI}_{\mathrm{P}(\mathrm{f} \mathrm{t}-6 \text { days })}$ & $0.12(0.10)$ & $\operatorname{Gain}_{\mathrm{f}(\mathrm{t}-6)}$ & $\mathrm{RFI}_{\mathrm{G}(\mathrm{f} \mathrm{t}-6 \text { days })}$ & $-0.09(0.10)$ \\
\hline
\end{tabular}

Description of abbreviations can be referred in Table 4.2. 
Table 4.6. Posterior means of genetic and phenotypic correlations with PSDs between feed intake and the two $R F I$ definitions $\left(\mathrm{RFI}_{\mathrm{P}}\right.$ and $\left.\mathrm{RFI} \mathrm{I}_{\mathrm{G}}\right)$.

\begin{tabular}{|c|c|c|c|c|c|}
\hline Feed intake & $\begin{array}{l}\text { The two RFI } \\
\text { definitions }\end{array}$ & $\begin{array}{c}\text { Genetic } \\
\text { correlation }\end{array}$ & Feed intake & $\begin{array}{l}\text { The two RFI } \\
\text { definitions }\end{array}$ & $\begin{array}{l}\text { Phenotypic } \\
\text { correlation }\end{array}$ \\
\hline $\mathrm{FI}_{\mathrm{m}(\mathrm{t})}$ & $\mathrm{RFI}_{\mathrm{P}(\mathrm{m} \text { tdays })}$ & $0.66(0.06)$ & $\mathrm{FI}_{\mathrm{m}(\mathrm{t})}$ & $\mathrm{RFI}_{\mathrm{P}(\mathrm{m} \text { tdays })}$ & $0.54(0.01)$ \\
\hline $\mathrm{FI}_{\mathrm{f}(\mathrm{t})}$ & $\mathrm{RFI}_{\mathrm{P}(\mathrm{f} \text { tdays })}$ & $0.64(0.05)$ & $\mathrm{FI}_{\mathrm{f}(\mathrm{t})}$ & $\mathrm{RFI}_{\mathrm{P}(\mathrm{f} \text { tdays })}$ & $0.57(0.01)$ \\
\hline $\mathrm{FI}_{\mathrm{m}(\mathrm{t}-6)}$ & $\mathrm{RFI}_{\mathrm{P}(\mathrm{mt} \mathrm{t}-6 \text { days })}$ & $0.54(0.09)$ & $\mathrm{FI}_{\mathrm{m}(\mathrm{t}-6)}$ & $\mathrm{RFI}_{\mathrm{P}(\mathrm{m} t-6 \text { days })}$ & $0.53(0.01)$ \\
\hline $\mathrm{FI}_{\mathrm{f}(\mathrm{t}-6)}$ & $\mathrm{RFI}_{\mathrm{P}(\mathrm{ft}-6 \text { days })}$ & $0.51(0.07)$ & $\mathrm{FI}_{\mathrm{f}(\mathrm{t}-6)}$ & $\mathrm{RFI}_{\mathrm{P}(\mathrm{ft}-6 \text { days })}$ & $0.48(0.01)$ \\
\hline $\mathrm{FI}_{\mathrm{m}(\mathrm{t})}$ & $\mathrm{RFI}_{\mathrm{G}(\mathrm{m} \text { tdays })}$ & $0.40(0.04)$ & $\mathrm{FI}_{\mathrm{m}(\mathrm{t})}$ & $\mathrm{RFI}_{\mathrm{G}(\mathrm{m} \text { tdays })}$ & $0.31(0.08)$ \\
\hline $\mathrm{FI}_{\mathrm{f}(\mathrm{t})}$ & $\mathrm{RFI}_{\mathrm{G}(\mathrm{f} \text { tdays })}$ & $0.42(0.04)$ & $\mathrm{FI}_{\mathrm{f}(\mathrm{t})}$ & $\mathrm{RFI}_{\mathrm{G}(\mathrm{f} \text { tdays })}$ & $0.41(0.06)$ \\
\hline $\mathrm{FI}_{\mathrm{m}(\mathrm{t}-6)}$ & $\mathrm{RFI}_{\mathrm{G}(\mathrm{m} \mathrm{t}-6 \text { days })}$ & $0.45(0.06)$ & $\mathrm{FI}_{\mathrm{m}(\mathrm{t}-6)}$ & $\mathrm{RFI}_{\mathrm{G}(\mathrm{m} \mathrm{t}-6 \text { days })}$ & $0.43(0.11)$ \\
\hline $\mathrm{FI}_{\mathrm{f}(\mathrm{t}-6)}$ & $\mathrm{RFI}_{\mathrm{G}(\mathrm{ft}-6 \text { days })}$ & $0.39(0.04)$ & $\mathrm{FI}_{\mathrm{f}(\mathrm{t}-6)}$ & $\mathrm{RFI}_{\mathrm{G}(\mathrm{ft}-6 \text { days })}$ & $0.39(0.08)$ \\
\hline
\end{tabular}

Description of abbreviations can be referred in Table 4.2. 
The genetic variance and heritability estimates of BW was different in the two ages and the genetic correlation of BW between the two ages was significantly different from unity. This is consistent with Mebratie et al. (2017) who reported different heritability estimates for BW at three different ages and genetic correlations (standard errors in parenthesis) of BW between the three different ages in the range between 0.81 (0.05) - 0.97(0.01) in broiler chickens. Aslam et al. (2011) also reported genetic correlations between BW at six different ages in the range between 0.86 (0.06)-0.98 (0.01) in turkeys which significantly deviate from one. The differences in heritability estimates in the two ages and genetic correlations of BW between the two ages suggest that genes influencing BW might change with the age of broiler chickens. This confirms the statement from Schaeffer (2011) which highlights that there are genes, which "turns on" and "turns off" with the age of animals causing changes in physiology and performance.

In general, the different heritability estimates of BW in males and females and genetic correlations of BW between males and females in the two ages suggest that there is sex by genotype interaction for BW and the genetic background of BW might be partly different in male and female broiler chickens. Similarly, the heritability estimates of BW in the two ages and genetic correlations of BW in the two ages suggest that there is age by genotype interaction for BW and the genetic background of BW in broiler chickens might be partially different in the two ages. Therefore, models for genetic evaluation of BW in broiler chickens should take in to account sex and age differences. Otherwise, ignoring the differences and combining them may create bias in the prediction of breeding values and it in turn influences selection decision.

The heritability estimates of $\mathrm{FI}$ and Gain in males and females at the two ages of recording were found to be moderate $(0.26-0.38)$ but lower than the estimates from Aggrey et al. (2010) who reported heritability estimates of FI to be 0.46 and 0.48 at 5 and 6 weeks of age, respectively. The authors also reported heritability estimates for Gain to be 0.48 and 0.51 at 5 and 6 weeks of age, respectively in broiler chickens. 
Table 4.7. Posterior means of direct (bold numbers) and correlated (non-bold numbers in a row) additive genetic superiority when the best $10 \%$ population were selected against single traits of the two RFI definitions.

\begin{tabular}{|c|c|c|c|c|c|c|c|c|}
\hline Trait & $\mathrm{RFI}_{\mathrm{P}(\mathrm{m} \text { tdays })}$ & $\mathrm{RFI}_{\mathrm{P}(\mathrm{f} \text { tdays })}$ & $\mathrm{RFI}_{\mathrm{P}(\mathrm{m} \mathrm{t}-6 \text { days })}$ & $\mathrm{RFI}_{\mathrm{P}(\mathrm{ft} \mathrm{t}-6 \mathrm{days})}$ & $\mathrm{RFI}_{\mathrm{G}(\mathrm{m} \text { tdays })}$ & $\mathrm{RFI}_{\mathrm{G} \text { (f tdays) }}$ & $\mathrm{RFI}_{\mathrm{G}(\mathrm{m} \mathrm{t}-6 \text { days })}$ & $\mathrm{RFI}_{\mathrm{G}(\mathrm{ft} t-6 \text { days })}$ \\
\hline $\mathrm{RFI}_{\mathrm{P}(\mathrm{m} \text { tdays })}$ & -63.0 & -40.7 & -42.5 & -31.8 & -55.6 & -37.8 & -39.8 & -29.8 \\
\hline $\mathrm{RFI}_{\mathrm{P}(\mathrm{f} \text { tdays })}$ & -49.7 & -51.7 & -39.0 & -32.5 & -45.2 & -47.2 & -36.7 & -30.0 \\
\hline $\mathrm{RFI}_{\mathrm{P}(\mathrm{m} t-6 \text { days })}$ & -42.0 & -31.7 & -63.5 & -31.5 & -38.8 & -30.7 & -60.8 & -29.8 \\
\hline $\mathrm{RFI}_{\mathrm{P}(\mathrm{ft}-6 \text { days })}$ & -43.5 & -36.5 & -43.6 & -45.9 & -42.2 & -34.5 & -42.4 & -44.4 \\
\hline $\mathrm{RFI}_{\mathrm{G}(\mathrm{m} \text { t days })}$ & -59.0 & -39.4 & -41.6 & -32.8 & -59.4 & -39.2 & -40.5 & -31.8 \\
\hline $\mathrm{RFI}_{\mathrm{G}(\mathrm{f} \mathrm{t} \text { days })}$ & -48.3 & -49.4 & -39.7 & -32.2 & -47.1 & -49.4 & -38.5 & -31.1 \\
\hline $\mathrm{RFI}_{\mathrm{G}(\mathrm{ft}-6 \text { days })}$ & -41.3 & -34.2 & -41.8 & -45.0 & -41.5 & -33.8 & -41.5 & -45.3 \\
\hline
\end{tabular}

Please refer Table 4.2 for description of abbreviations. 
However, our estimates are slightly higher than that of Begli et al. (2016) who reported cumulative heritability estimates for $\mathrm{Fl}$ in chickens from weeks 2-10 to be 0.24 and Case et al. (2012) who reported heritability estimates of FI to be 0.25 in turkeys. Similar to the observed sex and age differences in genetic parameters for BW, the different heritability estimates in FI and Gain between males and females and the genetic correlations between them that is significantly different from unity suggest that there is sex by genotype interaction for $\mathrm{Fl}$ and Gain. Moreover, the higher genetic correlations in FI and Gain between males and females at early age ( $t$ 6) than later age $(t)$ suggest that there is sex by age interaction for $\mathrm{FI}$ and Gain showing that sex by genotype interaction increases with age as broilers start to attain sexual maturity. The significantly different heritability estimates of FI and Gain in males and females and the genetic correlations between sexes, which were significantly different from unity, suggest that the genetic background of these traits might be partly different in males and females. Similarly, the significantly different heritability estimates for $\mathrm{Fl}$ and Gain in the two ages and the genetic correlations of the traits between the two ages, which is significantly different from one, suggest that there is age by genotype interaction for the traits. Moreover, it suggests that the genetic background of $\mathrm{FI}$ and Gain might partly be different in the two ages. Therefore, models for genetic analysis of the two traits should consider the sex and age differences to increase accuracy of selection and genetic gain. The moderate genetic correlation (0.30-0.50) within production traits (BW and Gain) and between BW and FI (0.49-0.63) as well as the high genetic correlation between FI and Gain (0.82-0.89) in the current study is not surprising since higher BW and Gain might require higher feed intake and vice versa. Case et al. (2012) reported a genetic correlation 0.67 between $\mathrm{BW}$ and $\mathrm{FI}$ and a genetic correlation of 0.41 between BW and Gain in turkeys.

\subsubsection{Genetic parameters for the two RFI definitions}

Previous studies have reported low to moderate heritability estimates $(0.10-0.49)$ for phenotypic RFI in male and female broiler chickens at different ages (Begli et al., 2016; Aggrey et al., 2010; Pakdel et al., 2005). In pigs, Shirali et al. (2018) reported low heritability estimate for $\operatorname{RFI}_{P}(0.20(0.03))$ and $\mathrm{RFI}_{G}(0.15(0.03))$, respectively. Our heritability estimates of $\mathrm{RFI}_{P}(0.18-0.28)$ were in the range with previous studies in chickens while heritability estimates of $\mathrm{RFI}_{\mathrm{G}}$ is scant in literature; however, our estimates (0.14-0.26) were in the range with previous estimates of $\mathrm{RFI}_{P}$ in broiler chickens. In addition, the genetic variance and heritability estimates of $\mathrm{RFI}_{\mathrm{P}}$ was higher than $\mathrm{RFI}_{\mathrm{G}}(0.14-0.26)$ which is expected because the genetic variance of 
Table 4.8. Posterior means of correlated (numbers in a row) additive genetic superiority of the selected group when the best $10 \%$ population were selected against single traits of the two RFI definitions.

\begin{tabular}{|c|c|c|c|c|c|c|c|c|c|c|c|c|}
\hline Trait & $\mathrm{BW}_{\mathrm{m}(\mathrm{t})}$ & $\mathrm{BW}_{\mathrm{f}(\mathrm{t})}$ & $\mathrm{BW}_{\mathrm{m}(\mathrm{t}-6)}$ & $\mathrm{BW}_{\mathrm{f}(\mathrm{t}-6)}$ & $\mathrm{FI}_{\mathrm{m}(\mathrm{t})}$ & $\mathrm{FI}_{\mathrm{f}(\mathrm{t})}$ & $\mathrm{FI}_{\mathrm{m}(\mathrm{t}-6}$ & $\mathrm{FI}_{\mathrm{f}(\mathrm{t}-6)}$ & $\operatorname{Gain}_{\mathrm{m}(\mathrm{t})}$ & $\operatorname{Gain}_{\mathrm{f}(\mathrm{t})}$ & Gain $_{m(t-6)}$ & $\operatorname{Gain}_{\mathrm{f}(\mathrm{t}-6)}$ \\
\hline $\mathrm{RFI}_{\mathrm{P}(\mathrm{m} \text { tdays })}$ & -17.3 & -5.2 & -12.9 & -15.7 & -98.2 & -65.9 & -71.6 & -62.2 & -33.8 & -21.8 & -28.1 & -25.7 \\
\hline $\mathrm{RFI}_{\mathrm{P}(\mathrm{f} \text { tdays })}$ & -63.7 & -47.6 & -50.1 & -54.5 & -79.6 & -74.4 & -69.7 & -67.7 & -19.0 & -12.5 & -25.6 & -24.8 \\
\hline $\mathrm{RFI}_{\mathrm{P}(\mathrm{m} \mathrm{t}-6 \text { days })}$ & -10.8 & 1.1 & -6.4 & -10.6 & -58.0 & -39.4 & -76.3 & -56.2 & -14.8 & -7.2 & -12.1 & -21.1 \\
\hline $\mathrm{RFI}_{\mathrm{P}(\mathrm{f} t-6 \text { days })}$ & -38.1 & -20.0 & -3.6 & -17.8 & -54.3 & -46.9 & -51.1 & -56.2 & -3.8 & -6.0 & -7.2 & -7.0 \\
\hline $\mathrm{RFI}_{\mathrm{G}(\mathrm{m} \text { tdays })}$ & -0.4 & 6.90 & 0.52 & -8.8 & -58.2 & -43.6 & -46.2 & -43.6 & 1.0 & -4.9 & -4.6 & -8.7 \\
\hline $\mathrm{RFI}_{\mathrm{G}(\mathrm{f} \text { tdays })}$ & -20.6 & -3.3 & -16.5 & -21.0 & -56.1 & -49.0 & -48.6 & -46.6 & -4.1 & 0.8 & -7.1 & -10.3 \\
\hline $\mathrm{RFI}_{\mathrm{G}(\mathrm{mt} \text { t-6days })}$ & -3.1 & 6.9 & -0.5 & -5.8 & -47.4 & -31.0 & -62.3 & -47.4 & -7.0 & -1.7 & -0.3 & -13.9 \\
\hline $\mathrm{RFI}_{\mathrm{G}(\mathrm{ft}-6 \text { days })}$ & -20.8 & -4.5 & 11.6 & -2.7 & -42.0 & -35.1 & -37.0 & -43.2 & 3.5 & -0.03 & 3.6 & 2.0 \\
\hline
\end{tabular}

Trait descriptions can be referred in Table 4.2; numbers in Bold are correlated responses within sexes and ages. 
$\mathrm{RFI}_{\mathrm{P}}$ is influenced by residual covariance between the component traits of feed intake and production traits whereas genetic variance of $\mathrm{RFI}_{\mathrm{G}}$ is not influenced by residual covariance between feed intake and production traits (Kennedy et al., 1993). The heritability estimates of $\mathrm{RFI}_{P}$ and $\mathrm{RFI}_{G}$ were significantly different in males and females at the same age and the estimates differed significantly between the two ages at the same sex. The genetic correlations of the two RFI definitions between males and females at the same sex, which was found to be significantly different from unity, suggest that there is sex by genotype interaction for the traits. Similarly, the genetic correlations for the two RFI definitions between $t$ and $t-6$ days at the same sex that significantly deviate from one suggest that there is age by genotype interaction for the traits. In agreement with our findings, Aggrey et al. (2010) noted moderate and significantly different from one genetic correlation (0.59) between phenotypic RFI in broiler chickens measured at two different periods (28-35 and 35-42 days of age). In our study, the genetic correlations between $\mathrm{RFI}_{\mathrm{P}}$ and $\mathrm{RFI}_{\mathrm{G}}$ was found to be high but significantly different from unity at $t$ days of age in both sexes, however at $t-6$ days of age the genetic correlations were high and not significantly different from unity. This suggests that selection for FE using either of them in breeding programs will yield the same genetic response at $t-6$ days but may not result the same response at $t$ days of age. Shirali et al. (2018) conditioned FI on average daily gain (ADG) and body composition trait (lean meat percentage) and reported a genetic correlation of $0.92(0.04)$ between $R_{F} I_{P}$ and $R_{F I}$ in pigs which is high but significantly different from unity.

The low to moderate genetic correlations (0.04-0.32) between $\mathrm{RFI}_{\mathrm{P}}$ and production traits ( $B W$ and Gain) in the current study is expected from the definition of $\mathrm{RFI}_{\mathrm{P}}$ since it is a component of $\mathrm{FI}$ that is phenotypically, but not genetically, independent of production traits. Genetic correlations between $\mathrm{RFI}_{\mathrm{P}}$ and production traits should not necessarily be zero but might vary considerably in sign and magnitude depending on the genetic and phenotypic parameters of its component traits (Kennedy et al., 1993). Moreover, the genetic covariance between $\mathrm{RFI}_{P}$ and production traits involves the environmental covariance between feed intake and production traits therefore the partial phenotypic regression coefficients of $\mathrm{RFI}_{\mathrm{P}}$ and production traits do not ensure that $\mathrm{RFI}_{\mathrm{P}}$ is genetically independent of production traits (Kennedy et al., 1993). According to the authors, $\mathrm{RFI}_{P}$ will only be genetically independent of production traits if the heritability of $\mathrm{FI}$ and production traits is equal and the genetic correlations between them is equal to the corresponding environmental correlations. In the same context, the phenotypic correlation between $\mathrm{RFI}_{\mathrm{G}}$ and production traits is not necessarily zero except in situations where the heritability of 
$\mathrm{FI}$ and production traits is zero and the genetic correlations of $\mathrm{FI}$ and production traits is equal to their corresponding environmental correlations (Kennedy et al., 1993). This is well confirmed in our study that the phenotypic correlations between $\mathrm{RFI}_{\mathrm{G}}$ and production traits were low $(-0.002$ to -0.27$)$ whereas the phenotypic correlations between $\mathrm{RFI}_{\mathrm{P}}$ and production traits were zero. Aggrey et al. (2010) reported low (-0.05 to 0.06) genetic correlation between $\mathrm{RFI}_{P}$ and average daily gain (ADG) and moderate genetic correlation (0.31-0.45) between $\mathrm{RFI}_{P}$ and metabolic BW in broiler chickens. In pigs, Shirali et al. (2018) reported moderate genetic correlation (0.35) between $\mathrm{RFI}_{P}$ and $\mathrm{ADG}$ and phenotypic correlations of -0.30 between $\mathrm{RFI}_{\mathrm{G}}$ and $\mathrm{ADG}$.

The genetic variance of $\mathrm{FI}$ was considerably and significantly higher than both $\mathrm{RFI}_{\mathrm{P}}$ and $\mathrm{RFI}_{\mathrm{G}}$ in males and females at the two ages showing that most of the variation in $\mathrm{Fl}$ is determined by production traits (BW and Gain). For example, at $t$ days of age in males, $83.3 \%$ of the variation in $\mathrm{Fl}$ is determined by production traits and at $t$ days of age in females, $82.2 \%$ of the variation in $\mathrm{Fl}$ is determined by production traits. Moreover, the heritability estimates of $\mathrm{RFI}_{\mathrm{P}}$ and $\mathrm{RFI}_{\mathrm{G}}$ were considerably lower than that of $\mathrm{Fl}$ in both ages. This might be due to the higher genetic correlations between $\mathrm{FI}$ and production traits than environmental correlations between the traits. Kennedy et al. (1993) reported that variability in $\mathrm{RFI}_{\mathrm{P}}$ relative to feed intake is dependent on the phenotypic correlation between $\mathrm{FI}$ and production traits (BW and Gain) which is a function of heritability of $\mathrm{FI}$, heritability of production traits, genetic correlation between $\mathrm{FI}$ and production traits as well as environmental correlation between $\mathrm{Fl}$ and production traits. Heritability of $\mathrm{RFI}_{\mathrm{P}}$ increases as the genetic covariance between $\mathrm{FI}$ and production traits decreases and the environmental correlation between feed intake and production traits increases (Kennedy et al., 1993). Genetic correlations between $\mathrm{FI}$ and $\mathrm{RFI}_{\mathrm{P}}$ was noted to be in the range 0.51-0.66 which is in line with Kennedy et al. (1993) who stated that genetic correlations between $\mathrm{FI}$ and $\mathrm{RFI}_{\mathrm{P}}$ are highly positive except in some situations where the heritability of $\mathrm{Fl}$ is low compared to production traits and their genetic and environmental correlations are both high. In such situations, the genetic correlation between $\mathrm{FI}$ and $\mathrm{RFI}_{\mathrm{P}}$ can even be negative (Kennedy et al., 1993). Higher genetic correlations between $\mathrm{FI}$ and $\mathrm{RFI}_{\mathrm{P}}$ than $\mathrm{FI}$ and $\mathrm{RFI}_{\mathrm{G}}$ in the current study is because the genetic correlation between $\mathrm{FI}$ and $\mathrm{RFI}_{\mathrm{P}}$ involves the environmental covariance between $\mathrm{Fl}$ and production traits whereas the genetic correlation between $\mathrm{FI}$ and $\mathrm{RFI}_{\mathrm{G}}$ does not involve the environmental covariance between $\mathrm{Fl}$ and production traits. In addition, lower phenotypic correlations than genetic correlations between $\mathrm{FI}$ and the two RFI definitions might indicate lower 
environmental covariance between $\mathrm{Fl}$ and production traits than their corresponding genetic covariance. Pym and Nichols (1979) noted that phenotypic correlations among traits such as BW, Gain, $\mathrm{FI}$ and feed conversion ratio are generally lower than their corresponding genetic correlations. Aggrey et al. (2010) reported genetic correlations between $\mathrm{FI}$ and $\mathrm{RFI}_{\mathrm{P}}$ in broiler chickens to be 0.51 and 0.56 in the periods, 35-42 days and 28-35 days, respectively, which are in line with our estimates at $t-6$ days of age.

\subsubsection{Superiority of the selected group}

The results of the current study showed that, direct selection on one of the 12 traits included in the model results in a positive correlated response on the other traits, which also means correlated positive response in $\mathrm{Fl}$, which is not advantageous (Results not shown). The observed positive correlated response between the traits in this study is a reflection of the moderate to high genetic correlations between them. The Bayesian analysis in our study suggests that direct selection against $\mathrm{RFI}_{\mathrm{G}}$ does not have a correlated response on production traits since the model ensures that genetic correlations between $\mathrm{RFI}_{\mathrm{G}}$ and production traits is zero. However, direct selection against $\mathrm{RFI}_{\mathrm{P}}$ results in a correlated response on production traits since $\mathrm{RFI}_{\mathrm{P}}$ is derived using phenotypic partial regression coefficients, which ensure that phenotypic correlations between phenotypic RFI and production traits are zero while genetic correlations between the traits are not necessarily zero. The correlated response in $\mathrm{FI}$ from selection against $\mathrm{RFI}_{\mathrm{G}}$ was found to be very similar to the direct response to selection against $\mathrm{RFI}_{G}$ at the same sex and age. This is in agreement with Kennedy et al. (1993) who noted that when selection is on genetic RFI direct response in genetic $\mathrm{RFI}$ is expected to be equal to the correlated response in $\mathrm{FI}$ because there is no change in $\mathrm{FI}$ due to $\mathrm{BW}$ and production. However, direct genetic response in $\mathrm{RFI}_{\mathrm{P}}$ and correlated response in $\mathrm{FI}$ will only be equal when there is no correlated response in production. Otherwise, correlated response in $\mathrm{FI}$ on direct selection of $\mathrm{RFI}_{\mathrm{P}}$ partly depends on correlated response in production traits. If the correlated response on production is positive, there will be less reduction in FI which also means positive response in $\mathrm{Fl}$ which is not favorable and vice versa.

Superiority of the selected group on $\mathrm{RFI}_{\mathrm{G}}$ was slightly but not significantly lower than $\mathrm{RFI}_{\mathrm{P}}$ in the current study. This is in agreement with Kennedy et al. (1993) who reported that response to selection against $\mathrm{RFI}_{\mathrm{G}}$ is less than or equal to the response to selection against $\mathrm{RFI}_{\mathrm{P}}$ because selection against $\mathrm{RFI}_{\mathrm{P}}$ results in a reduction of the proportion of feed intake used for production. Moreover, Kennedy et al. (1993) 
noted that response to selection on genetic RFI increases if the genetic correlation between feed intake and production traits is low or the heritability of feed intake is higher than the heritability of production traits. In our study, the heritability of FI is greater than production traits; however, the genetic correlation between $\mathrm{FI}$ and production traits is moderate to high.

The results of this study showed that selection for $\mathrm{FE}$ based on $\mathrm{RFI}_{\mathrm{P}}$ or $\mathrm{RFI}_{\mathrm{G}}$ gives the same genetic response at $t-6$ days but might result different response at $t$ days of age in both sexes. Since, $\mathrm{RFI}_{\mathrm{G}}$ explains the efficiency of birds in nutrient utilization irrespective of energy requirements for production and maintenance, it is easier to interpret the results to relevant stakeholders than $\mathrm{FI}$ and $\mathrm{RFI}_{\mathrm{P}}$ which is not genetically independent of production traits.

\subsection{Conclusions}

Genetic parameters were simultaneously estimated for feed intake, body weight and body weight gain from a multi-trait Bayesian analysis. The heritability estimates of the traits were moderate and significantly different in males and females at the same age. Moreover, the genetic correlations of BW, FI and Gain between males and females at the same age were significantly different from unity suggesting that BW, $\mathrm{FI}$ and Gain traits are influenced by sex by genotype interaction in addition to direct genetic and maternal permanent environmental effects. Similarly, the different heritability estimates of BW, $\mathrm{FI}$ and Gain in the two ages within sexes and the genetic correlations of BW, FI and Gain between the two ages within sexes shows that there is age by genotype interaction for the traits. In our study, heritability estimates of $\mathrm{RFI}_{\mathrm{P}}$ and $\mathrm{RFI}_{\mathrm{G}}$ were significantly different in both sexes and ages. Furthermore, the genetic correlations between the two RFI definitions were significantly different from unity at $t$ days of age and not significantly different from one at $t-6$ days of age. Direct selection against phenotypic RFI resulted in a decrease in FI with a decrease in production traits while direct selection against genetic RFI resulted in a correlated response of decreasing $\mathrm{FI}$ with no significant change in production traits. 


\section{References}

Adeyinka IA, Oni OO, Nwagu BI, and Adeyinka FD. 2006. Genetic parameters estimate of body weight of nacked neck broiler chickens. International journal of poultry science 5(6): 589-592.

Aggrey SE, Karnuah AB, Sebastian B, Anthony NB. 2010. Genetic properties of feed efficiency parameters in meat-type chickens. Genet. Sel. Evol. 42: 25.

Aslam ML, Bastiaansen JW, Crooijmans RP, Ducro BJ, Groenen MA, Vereijken A. 2011. Genetic variances, heritabilities and maternal effects on body weight, breast meat yield, meat quality traits and the shape of the growth curve in turkey birds. BMC. Genet. 12: 14.

Begli EH, Vaez Torshizi R, Masoudi AA, Ehsani A. 2016. Longitudinal analysis of body weight, feed intake and residual feed intake in F2 chickens. Livest. Sci. 184: 28-34.

Case LA, Wood BJ, Miller SP. 2012. The genetic parameters of feed efficiency and its component traits in the turkey (Meleagris gallopavo). Genet. Sel. Evol. 44: 2.

Jensen J. Joint estimation for curves for weight, feed intake, rate of gain, and residual feed intake. 601, 2013. EAAP 64th Meeting. Book of abstracts, 531.

Kennedy BW, van der Werf JH, Meuwissen TH. 1993. Genetic and statistical properties of residual feed intake. Journal of Animal Science. 71:3239-3250.

Koch RM, Swiger LA, Chambers D, Gregory KE. 1963. Efficiency of Feed Use in Beef Cattle. Journal of Animal Science. 1963: 22:486-494.

Le Bihan-Duval E, Mignon-Grasteau S, Millet N. and Beaumont C. 1998. Genetic analysis of a selection experiment on increased body weight and breast muscle weight as well as on limited abdominal fat weight. British Poultry Science. 39: 346-353.

Madsen P and Jensen J. 2014. A User's guide to DMU: a package for analyzing multivariate mixed models. Version 6, release 5.2. Aarhus University, Foulum, Denmark.

Mebratie W, Shirali M, Sapp RL, Madsen P, Hawken R, Jensen J. 2017. The effect of selection and sex on genetic parameters of body weight in a commercial broiler chicken population. Livestock science. 204: 78-87.

Mignon-Grasteau S, Beaumont C, Le Bihan-Duval E, Poivey JP, Rochambeau H and Ricard FH. 1999. Genetic parameters of growth curve parameters in male and female chickens. British Poultry Science. 40: 44-51. 
Pakdel A, van Arendonk JAM, Vereijken AL, Bovenhuis H. 2005. Genetic parameters of ascites-related traits in broilers: correlations with feed efficiency and carcass traits. Br. Poult.Sci. 46: 43-53.

Pym RAE and Nicholls PJ. 1979. Selection for food conversion in broilers: Direct and correlated responses to selection for body weight gain, food consumption, and food conversion ratio. Br. Poult. Sci. 20:73-86.

Schaeffer LR. 2011. Animal breeding methods, Random regression models. Course notes. Access http://www.aps.uoguelph.ca/ Irs/ (Accessed 15.10.2016).

Shirali M, Varley PF, Jensen J. 2018. Bayesian estimation of direct and correlated response to genetic selection on linear or ratio expressions of feed efficiency in pigs. Genet Sel. Evol. 50:33.

Smith BJ. 2007. Boa: An R Package for MCMC Output Convergence Assessment and Posterior Inference Journal of Statistical Software. 21(11): 1-37.

Towne B, Seirvogel RM, Blangero J. 1997. Effects of genotype by sex interaction on quantitative trait linkage analysis. Genet. Epidemiol. 14: 1053- 1058.

Willems OW, Miller SP, Wood BJ. 2013. Aspects of selection for feed efficiency in meat producing poultry. World's Poultry Science Journal. 69: 77-87.

\section{Acknowledgements}

The European Graduate School in Animal Breeding and Genetics (EGS-ABG), which is funded by the European Union, is acknowledged for providing scholarship for the first Author. Cobb-Vantress poultry Research Company is acknowledged for providing the data used in this study. 



\begin{abstract}
5
Genome wide association study of body weight and feed efficiency traits in a commercial broiler chicken population, a re-visitation.
\end{abstract}

\begin{abstract}
W. Mebratie ${ }^{1,2}$, H. Reyer ${ }^{3}$, K.Wimmers ${ }^{3}$, H. Bovenhuis ${ }^{2}$, J. Jensen ${ }^{1}$
${ }^{1}$ Center for Quantitative Genetics and Genomics, Department of Molecular Biology and Genetics, Aarhus University 8830 Tjele, Denmark. ${ }^{2}$ Animal Breeding and Genomics Centre, Wageningen University, P.O. Box 338, $6700 \mathrm{AH}$ Wageningen, the Netherlands. ${ }^{3}$ Leibniz Institute for Farm Animal Biology, Institute for Genome Biology, Wilhelm-Stahl-Allee 2, 18196 Dummerstorf, Germany.
\end{abstract}

Scientific reports (2019) 9: 922. Doi: 10.1038/s41598-018-37216-z 


\begin{abstract}
Genome wide association study was conducted using a mixed linear model (MLM) approach that accounted for family structure to identify single nucleotide polymorphisms (SNPs) and candidate genes associated with body weight (BW) and feed efficiency (FE) traits in a broiler chicken population. The results of the MLM approach were compared with the results of a general linear model approach that does not take family structure in to account. In total, 11 quantitative trait loci (QTL) and 21 SNPs, were identified to be significantly associated with BW traits and 5 QTL and 5 SNPs were found associated with FE traits using MLM approach. Besides some overlaps between the results of the two GWAS approaches, there are considerable differences in the detected QTL regions. Even though the genomic inflation factor $(\lambda)$ values indicate that there is no strong family structure in this population, using models that account for the existing family structure may reduce bias and increase accuracy of the estimated SNP effects in the association analysis. The SNPs and candidate genes identified in this study provide information on the genetic background of BW and FE traits in broiler chickens and might be used as prior information for genomic selection.
\end{abstract}

Key words: Genome wide association study; Body weight; Feed efficiency; Mixed linear model; General linear model 


\subsection{Introduction}

Genome wide association studies (GWAS) are commonly used to identify single nucleotide polymorphisms (SNPs) and candidate genes associated with quantitative traits. GWAS have revealed important regions associated with production, reproduction and disease resistance traits in chickens (Fan et al., 2017; Wang et al., 2016; Jin et al., 2015; Zhang et al., 2015; Reyer et al., 2015; Xu et al., 2013; Yuan et al., 2010).

One of the essential elements in GWAS is a powerful statistical method that can be employed to identify genetic associations in unbiased fashion (Cantor et al., 2010). Methods that model population structure by estimating the covariance due to genetic relatedness between individuals has been reported to perform better in terms of detecting true associations than models that ignore population structure (Gianola et al., 2016; Eu-ahsunthornwattana et al., 2014; Kang et al., 2010; Yu et al., 2006).

Kennedy et al. (1992) reported that using general linear model (GLM) analysis when relations between animals exist, results in an inflated F-test. Consequently it is likely to find an excess of spurious genotype effects when actually no genotype effect exists (Kennedy et al., 1992). In this situation, the use of mixed-model procedures under an animal model treating single-gene effects as fixed effect and accounting for family relations can provide an exact F-test of associated hypotheses and unbiased estimates of genotype effects (Ekine et al., 2014; Kennedy et al., 1992).

Population structure mainly refers to population stratification and cryptic relatedness (Zhang et al., 2010). Population stratification is the presence of systematic differences in allele frequencies between subpopulations in a population due to different ancestry between study subjects (Li et al., 2010). Unidentified population stratification can result both false positive and false negative associations and can hide the true association signals if not properly corrected (Sillanpää et al., 2011; Voight et al., 2005).

Cryptic relatedness refers to the phenomenon that some members of a study sample (population) might be related beyond what can be inferred from the pedigree, in which case their genotypes are not independent of the population frequencies (Price et al., 2010). Because population based association studies assume individual independence of study samples, cryptic relatedness may make these statistical tests less reliable and reduce the robustness and efficiencies of the studies (Sillanpää et al., 2011; Zhang et al., 2010). 
Methods modeling population structure, family structure and cryptic relatedness are expected to be better than models that ignore these complexities (Sillanpää et al., 2011; Kang et al., 2010). Mixed models provide a practical and extensive approach to simultaneously address confounding due to population stratification, family structure and cryptic relatedness (Gianola et al., 2016; Eu-ahsunthornwattana et al., 2014; Price et al., 2014 ).

This study aims to identify potential loci and candidate genes associated with body weight (BW) and feed efficiency (FE) traits in a commercial broiler line genotyped with 60k SNP chip using mixed linear model (MLM) approach that accounts for family structure and compare the results with general linear model (GLM) approach that does not take family structure in to account.

\subsection{Material and Methods}

Ethical statement. Samples were collected from a commercial flock under the guidance of the local committees for the care and use of animals following the CobbVantress Inc. Animal Welfare Policy. In addition, the experimental protocol was carried out in accordance with the approved guidelines for safeguarding good scientific practice at the institutions in the Leibniz Association.

Birds and phenotypic data. Phenotypic data were obtained from Cobb-Vantress broiler breeding company. A total of 5000 male broilers fed standard commercial broiler chicken diet based mainly on maize were raised from hatch to five weeks of age. Only males were studied in this experiment since selection intensity in males is considerably higher than that of females in broiler breeding programs. At the age of 36 days (BW36), birds were weighed and the heaviest 1000 birds were selected for feed efficiency (FE) experiment and put in individual cages. At the age of 39 days (BW39), birds entered to a 7 day FE experiment and final body weight (BW46) were recorded at the end of the experiment. Total feed intake (FI) was recorded from individually caged birds during the experiment. Body weight gain (Gain) was calculated as the difference between final body weight (BW49) and start weight (BW39). Feed conversion ratio (FCR) was calculated as the ratio of feed intake to body weight gain. After data cleaning, $848 \mathrm{BW}$ and FE records were used for further analysis.

Genotyping and quality control. Blood samples from the branchial vein were collected in anticoagulant tubes for DNA extraction. Extraction of genomic DNA was performed using Qiagen 96-well extraction kit (Qiagen, Hilden, Germany). DNA from a total of 864 samples were genotyped using the Illumina 60K SNP chip (Illumina, San 
Diego, CA, USA). The Illumina 60K SNP chip contains 57636 SNPs that are distributed across 29 autosomes (chromosome 1 to 28 and chromosome 32), two linkage groups (LGE 64 and LGE 22 C19 W28_E50C23), and two sex chromosomes (Z and W) using chicken genome assembly Galgal4. In this study only male broilers were examined so only genotypes from the $Z$ sex chromosome were included. Plink software was used for quality control of the genotypic data (Purcell et al., 2007). SNPs with low call rates $(<95 \%)$, minor allele frequency $(\mathrm{MAF}<0.03)$ and Hardy Weinberg equilibrium (HWE) P-value (<0.0001) were excluded. After quality control a total of 43914 SNPs were retained for GWAS analysis.

Genome wide association analysis. Genome wide association analysis was performed for BW traits (BW36, BW39, BW46) and for traits from the FE test (FI, Gain and FCR) using GCTA (Yang et al., 2011). The genomic relationship matrix (GRM) was constructed using methods from Yang et al. (2010). The P-values were adjusted by Bonferroni correction based on linkage disequilibrium (Duggal et al., 2008). The effective number of independent SNPs of autosomes were defined by the independent pairwise option in plink (Purcell et al., 2007). A total of 19416 independent SNPs were identified and the $5 \%$ genome wide significance threshold was adjusted to $-\log 10(\mathrm{P}$-value $)=5.60$. The threshold $\mathrm{P}$-value for suggestive significant association that allows one false positive association per GWAS was adjusted to $-\log 10$ (P-value) $=4$.3. Genomic inflation factor $(\lambda)$, was calculated using the R package GenABEL with “median” option (Aulchenko et al., 2014).

Manhattan plots of genome wide association analysis and quantile-quantile (QQ) plots were created using the qqman package in R software (Turner et al., 2014). The annotated genes that were closest to the top SNPs were identified using Ensembl and NCBI. The reported top SNPs or "lead SNPs" are SNPs which have the highest log 10 (P-value) among the significant SNPs which are in linkage disequilibrium (LD) with each other in $1 \mathrm{Mb}$ windows. Base pair positions of SNP markers were updated to the latest version of the chicken genome assembly Gallus-gallus-5 (Galgal5).

For FI and Gain, the following linear mixed model was used:

$$
y=\mu+\beta m_{i}+\beta_{1} x+Z u+e
$$

For FCR and BW traits the following linear mixed model was used:

$$
y=\mu+\beta m_{i}+Z u+e
$$


Where, $\mathrm{y}$ is a vector of BW or FE observations, $\mu$ is the mean term, $\beta$ is the SNP effect for marker $i, m$ is a vector of SNPs for the $i^{\text {th }}$ SNP genotype indicator variable coded as 0,1 or 2, $\beta_{1}$ is the regression coefficient (the effect of start weight on $\mathrm{FI}$ and Gain that accounts for differences in start weight), $\mathrm{x}$ is a vector of start weights (BW39), $u$ is a vector of random polygenic effects i.e. The effect of all QTL except those on the chromosome where the candidate SNP is located, e is a vector of random residuals. The variance of $u$ was re-estimated each time when a chromosome was excluded from calculating the genetic relationship matrix. $Z$ is the incidence matrix for the random effect. The variance co-variance structure for random effects were assumed to be normally distributed with mean 0 and variance; $\operatorname{var}(\mathrm{u})=\mathbf{G} \sigma_{\mathrm{g}}^{2}$ and $\operatorname{var}(\mathrm{e})=\mathbf{I} \sigma_{\mathrm{e}}^{2}$. Start weight was included in the model as covariate for Fl and Gain in order to account for differences in start weight for these traits. The genomic relationship matrix of this broiler population indicated that there are only small number of half sibs and full sibs in the data (Mebratie et al., 2018), therefore maternal effects were not included in the model.

Comparison of MLM and GLM approaches. The results of the present study were compared with the results of the GLM analysis by Reyer et al. (2015) which does not take family structure in to account, using the following model.

$$
y=\mu+\beta m_{i}+\beta_{1} x+e
$$

Where, $\mathrm{y}$ is the BW or FE observations, $\mu$ is the mean term, $\beta$ is the SNP effect for marker $\mathrm{i}, \mathrm{m}$ is vector of markers for the $\mathrm{i}^{\text {th }}$ SNP genotype indicator variable coded as 0,1 or $2, \beta_{1}$ is the regression coefficient (the effect of start weight on FI and Gain) that accounts for differences in start weight, $\mathrm{x}$ is a vector of start weights (BW39) for $\mathrm{FI}$ and Gain, and, $\mathrm{e}$ is the random residual. The variance of e is $\mathrm{I} \sigma_{\mathrm{e}}^{2}$. Base pair positions of SNP markers in Reyer et al. (2015) were updated to the latest version of the chicken genome assembly, Gallus-gallus-5 (Galgal5) for easy comparison of the results with the current study.

\subsection{Results}

GWAS results for body weight traits. Using MLM approach, the present study revealed 3 QTL which have suggestive significance association with BW36, 6 QTL with BW39 and 2 QTL with BW46 (Table 5.1). A total of 11 QTL and 21 SNPs reached the suggestive significance level with BW traits. The top SNPs and candidate genes associated with BW36 are located on chromosome 12, 14, and 8 while the top SNPs 
associated with BW39 are located on chromosome 12, 14, 1 and 23. The top SNPs associated with BW 46 are located on chromosome 6 and 1 (Table 5.1). Manhattan plots and $\mathrm{QQ}$ plots of body weight traits are shown in Fig. 5.1 and Fig. 5.2, respectively. All the reported QTL in Table 5.1 are suggestive, no SNP reached the genome-wide significance level for BW and FE traits in the present study, which suggests that BW and FE traits are controlled by many genes, each having small effect. All of the reported top SNPs were found inside the candidate genes in an intronic region except SNP rs15652523 associated with BW39, which is located $2.52 \mathrm{~Kb}$ upstream of the candidate gene LOC107054392 (Table 5.1).

SNP, rs14042911 is one of the top SNPs (-log 10 (P-value) $=5.15)$ associated with BW36 which is located on chromosome 12. Due to the proximal position to the top SNP, PTPRG (protein tyrosine phosphatase receptor type $\mathrm{G}$ ) is proposed as candidate gene associated with BW36 (Table 5.1). PTPRG is a protein coding gene which is a member of the protein tyrosine phosphatase (PTP) family. In humans members of the PTP gene family are known to be signaling molecules that regulate a variety of cellular processes including cell growth and differentiation, mitotic cycle, and oncogenic transformation (GeneCards, 2018). Moreover, SNPs, rs14073523 and rs16617885, located on chromosome 14 and 8, are top SNPs associated with BW36. CACNA1H (calcium voltage-gated channel subunit alpha1 $\mathrm{H}$ ); a protein coding gene and LOC107053920 (uncharacterized gene) are the proximal genes to the top SNPs, rs14073523 and rs16617885, respectively. Wang et al. (2016) identified QTL located on chromosome 14 associated with abdominal fat weight in chickens. The detected QTL for BW traits in the current study suggest that the genetic variance of BW was not exhausted after the pre-selection rather there are many genes with small effects left in the population. This is a remarkable finding relative to our expectation given the fact that this broiler line has been pre-selected for BW. Mebratie et al. (2017) also noted an increase in genetic variance of BW after several generations of selection in a commercial broiler chicken population.

This study also revealed 6 QTL located on chromosome 12, 14, 1 and 23, to have suggestive significance association with BW39, 3 of them located on chromosome 12. SNP, rs10723005 is one of the top SNPs, associated with BW39 found on chromosome 12 which is located in an intron region of CCDC71 (coiled-coil domain containing 71 recombinant protein). SNPs, rs316610173, and, rs15652523, which are located on chromosome 12 and SNPs, rs14073523, rs13880135, and, rs16190017 located on chromosome 14, 1 and 23, respectively, are also found associated with BW 39 (Table 5.1). PTPRG, LOC107054435 (uncharacterized gene), CACNA1H, SOX5 
(transcription factor SOX-5) and RSPO1 (R-spondin 1) are candidate genes, with putative contribution to the variation in BW39. They are found proximal to SNPS, rs316610173, rs14073523, rs13880135 and rs16190017, respectively (Table 5.1). In humans, SOX5 is involved in the regulation of embryonic development and in the determination of the cell fate (Genecards, 2018) while RSPO1 gene in mice is involved in the rapid onset of crypt cell proliferation (Genecards, 2018).

Two QTL located on chromosome 6 and 1, showing suggestive significance association with BW46 were identified with MLM approach. SNP,rs315083186, located on chromosome 6 and, SNP, rs314956606, located on chromosome 1 were found significantly associated with BW46 (Table 5.1). The candidate genes associated with BW46 are LOC101748440 (uncharacterized gene) and ADIPOR2 (adiponectin receptor 2), which is a protein coding gene involved in fatty acid oxidation and glucose uptake in humans (Genecards, 2018). In the chicken QTL database (https://www.animalgenome.org/cgi-bin/QTLdb/GG/index), 3 QTL located on chromosome 12 and 2 QTL located on chromosome 12 are reported to be associated with BW36 and BW46, respectively. One of the 3 QTL reported in the chicken QTL database for BW36 by Reyer et al. (2015) is overlapping with the identified QTL in the current study. However, the others are different QTL on the same chromosome, suggesting that chromosome 12 is potential chromosome for QTL associated with BW traits. 
Table 5.1. Top SNPs associated with body weight and feed efficiency traits using mixed linear model approach.

\begin{tabular}{|c|c|c|c|c|c|c|c|c|}
\hline Trait & $\begin{array}{l}\text { Chrom } \\
\text { osome }\end{array}$ & $\begin{array}{c}\text { Number of } \\
\text { significant } \\
\text { SNPs }\end{array}$ & $\begin{array}{c}\text { Top SNP in } 1 \mathrm{MB} \\
\text { window }\end{array}$ & $\begin{array}{c}\text { Galgal5 } \\
\text { position (bp) }\end{array}$ & $\begin{array}{c}\text {-log10 } \\
\text { (P-value) }\end{array}$ & $\begin{array}{l}\text { SNP } \\
\text { effect } \\
\text { (SE) }\end{array}$ & Proximal gene & $\begin{array}{l}\text { Distance } \\
\text { from gene }\end{array}$ \\
\hline Body weight ( 36 days) & 12 & 8 & rs13612706 & 12867052 & 5.03 & $\begin{array}{l}-0.039 \\
(0.009)\end{array}$ & PTPRG & Within \\
\hline Body weight ( 36 days) & 14 & 1 & rs14073523 & 5337950 & 4.89 & $\begin{array}{c}0.036 \\
(0.008)\end{array}$ & CACNA1H & Within \\
\hline Body weight ( 36 days) & 8 & 1 & rs16617885 & 1883743 & 4.79 & $\begin{array}{l}-0.051 \\
(0.012)\end{array}$ & LOC107053920 & Within \\
\hline Body weight (39 days) & 12 & 1 & rs10723005 & 11570033 & 4.89 & $\begin{array}{l}-0.054 \\
(0.012)\end{array}$ & CCDC71 & Within \\
\hline Body weight (39 days) & 12 & 3 & rs316610173 & 12931647 & 4.74 & $\begin{array}{l}-0.047 \\
(0.011)\end{array}$ & PTPRG & Within \\
\hline Body weight (39 days) & 12 & 2 & rs15652523 & 10278318 & 4.72 & $\begin{array}{l}-0.043 \\
(0.010)\end{array}$ & LOC107054392 & $\begin{array}{c}2.52 \mathrm{~Kb} \\
\text { upstream }\end{array}$ \\
\hline Body weight (39 days) & 14 & 1 & rs14073523 & 5337950 & 4.67 & $\begin{array}{c}0.041 \\
(0.010)\end{array}$ & CACNA1H & Within \\
\hline Body weight (39 days) & 1 & 1 & rs13880135 & 66076666 & 4.44 & $\begin{array}{c}0.040 \\
(0.010)\end{array}$ & SOX5 & Within \\
\hline Body weight (39 days) & 23 & 1 & rs16190017 & 3741996 & 4.38 & $\begin{array}{c}0.043 \\
(0.011)\end{array}$ & RSPO1 & Within \\
\hline
\end{tabular}


Table 5.1. Continued

\begin{tabular}{|c|c|c|c|c|c|c|c|c|}
\hline Body weight (46 days) & 6 & 1 & rs315083186 & 7305184 & 4.94 & $\begin{array}{l}-0.118 \\
(0.027)\end{array}$ & LOC101748440 & Within \\
\hline Body weight (46 days) & 1 & 1 & rs314956606 & 61033904 & 4.39 & $\begin{array}{l}-0.095 \\
(0.023)\end{array}$ & ADIPOR2 & Within \\
\hline Feed intake & 1 & 1 & rs15384287 & 110928416 & 4.96 & $\begin{array}{l}-0.111 \\
(0.021)\end{array}$ & KDM6A & Within \\
\hline Body weight gain & 8 & 1 & rs16617885 & 1883743 & 4.43 & $\begin{array}{l}-0.058 \\
(0.013)\end{array}$ & LOC107053920 & Within \\
\hline Body weight gain & 17 & 1 & rs14098962 & 7902999 & 4.32 & $\begin{array}{l}-0.054 \\
(0.012)\end{array}$ & LOC107052218 & Within \\
\hline Feed conversion ratio & 17 & 1 & rs14098962 & 7902999 & 4.78 & $\begin{array}{l}0.082 \\
(0.019)\end{array}$ & LOC107052218 & Within \\
\hline Feed conversion ratio & 6 & 1 & rs14568465 & 6730175 & 4.30 & $\begin{array}{l}0.073 \\
(0.018)\end{array}$ & CTNNA3 & Within \\
\hline
\end{tabular}




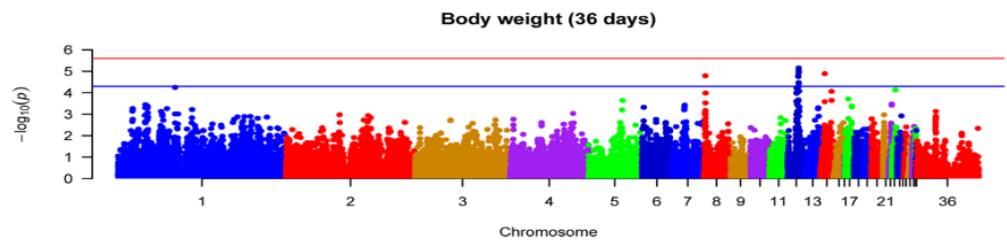

Body weight ( 39 days)

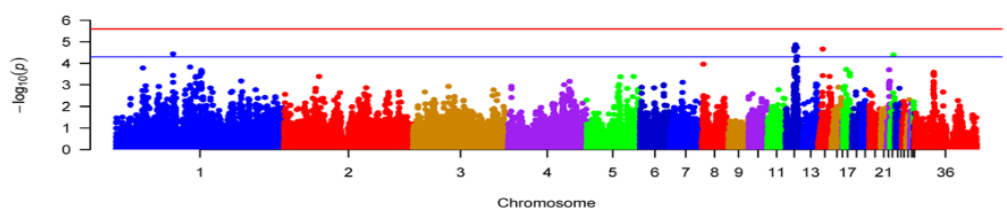

Body weight (46 days)

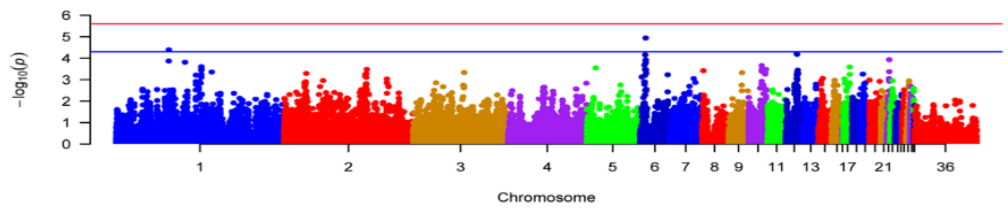

Figure 5.1. Manhattan plots of genome wide association results for body weight traits using linear mixed model analysis. Chromosomes 29, 30 and 36 represent linkage groups LGE22C19W28_E50C23, LGE64, and chromosome Z respectively. Red and blue lines indicate genome wide and suggestive significance thresholds respectively.
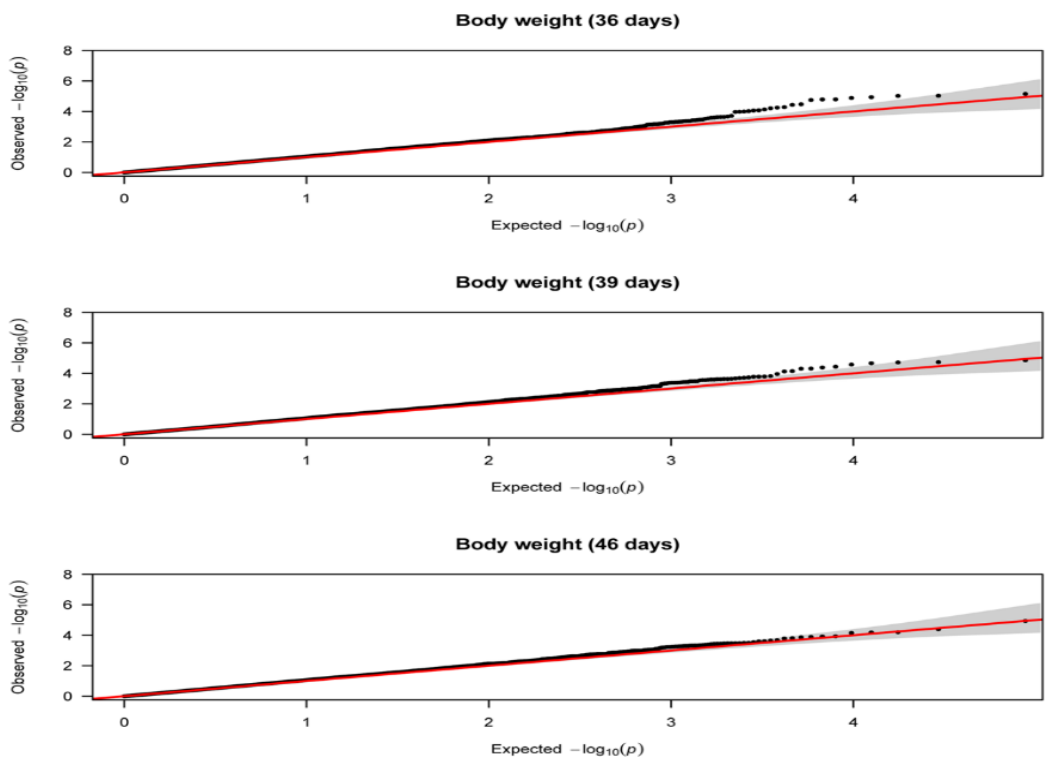

Figure 5.2. Quantile-quantile plots of body weight traits using linear mixed model approach. 
GWAS results for Feed efficiency traits. In this study a total of 5 QTL and 5 SNPs that showed suggestive significance association with FE traits were identified using MLM approach. QTL located on chromosome 1 is found associated with feed intake while 2 QTL located on chromosome 8 and 17 are found associated with body weight gain. Two QTL located on chromosome 17 and 6 are found significantly associated with FCR. The top SNPs and proximal genes associated with FI, Gain and FCR are reported in Table 5.1. Manhattan plots and QQ plots of feed efficiency traits are shown in Fig. 5.3 and Fig. 5.4, respectively.

QTL that contain SNP, rs15384287 located on chromosome 1 is found to be associated with feed intake (Table 5.1). The candidate gene associated with feed intake is KDM6A (lysine demethylase 6A). In line with this study, Yuan et al. (2010) reported a region on chromosome 1 that contains 8 SNPs which are significantly associated with feed intake in laying hens. Similarly, Mignon-Grasteau et al. (2015) reported four QTL associated with feed intake on chromosome 1 in chickens. Gao et al. (2009) and Tran et al. (2014) also reported QTL located on chromosome 1 to be associated with Gizzard weight in chickens which might have positive correlation with feed intake.

Two QTL located on chromosome 8 and 17 reached the suggestive significance level with body weight gain. SNP, rs16617885, located on chromosome 8 and SNP, rs14098962, located on chromosome 17 are found associated with body weight gain (Table 5.1). LOC107053920 and LOC107052218 are uncharacterized candidate genes associated with the trait which are found proximal to the significant SNPS rs16617885 and rs14098962, respectively. SNP, rs16617885, located on chromosome 8 is also found associated with BW36 with overlapping uncharacterized candidate gene, LOC107053920 (Table 5.1).

Two QTL located on chromosome 17 and 6 showed suggestive significance association with FCR. SNPs, rs14098962 and rs14568465 located on chromosome 17 and 6, respectively are found associated with FCR (Table 5.1). CTNNA3 (catenin alpha 3 ) and LOC107052218 (uncharacterized gene) are candidate genes found proximal to SNPs, rs14098962 and rs14568465, respectively. SNP, rs14098962 located on chromosome 17 and candidate gene LOC107052218 are also found associated with body weight gain (Table 5.1). Yuan et al. (2010) reported a region on chromosome 17 which is significantly associated with residual feed intake (RFI) in laying hens. In the chicken QTL database (https://www.animalgenome.org/cgibin/QTLdb/GG/index) different authors have reported different QTL on chromosome 1 to be associated with FI. Similarly QTL on chromosomes 6 and 17 were reported to be associated with FCR in the QTL database. The reported chromosomes are overlapping with the chromosomes associated with FI and FCR in 
the current study. However the QTL regions are different except the QTL reported by Reyer et al. (2015) for FCR located on chromosome 6 which were identified using Bayesian method of analysis for the same broiler line.

Comparison of results in MLM and GLM approach. The results of the MLM analysis in this study were compared with the results of the GLM analysis by Reyer et al. (2015) (Table 5.2). There were some overlaps between the identified QTL and candidate genes for BW36 and FCR. However, for most of the BW and FE traits, the identified QTL and candidate genes were different suggesting that the two methods do not necessarily give similar results. Table 5.3 shows comparison of genomic inflation factor $(\lambda)$ between MLM and GLM analysis. The $\lambda$ values in both approaches are "benign" and not significantly different from each other suggesting that population stratification is not a strong concern in our data.

Reyer et al. (2015) have reported GWAS results for two BW traits (BW36 and BW46) and three FE traits (FI, Gain and FCR) using the same data. Table 5.2 shows the reported GWAS results of the BW and FE traits derived from a general linear model (GLM) by Reyer et al. (2015). The GLM analysis was replicated in this study to compute the $\lambda$ values reported in Table 5.3 and we found similar significant SNPs and - $\log 10$ (P-values) for all of the BW and FE traits as reported by Reyer et al. (2015) (Table 5.2). BW39 was not considered in the analysis of Reyer et al. (2015) but considered both in the replicated GLM analysis and the MLM analysis in this study. 

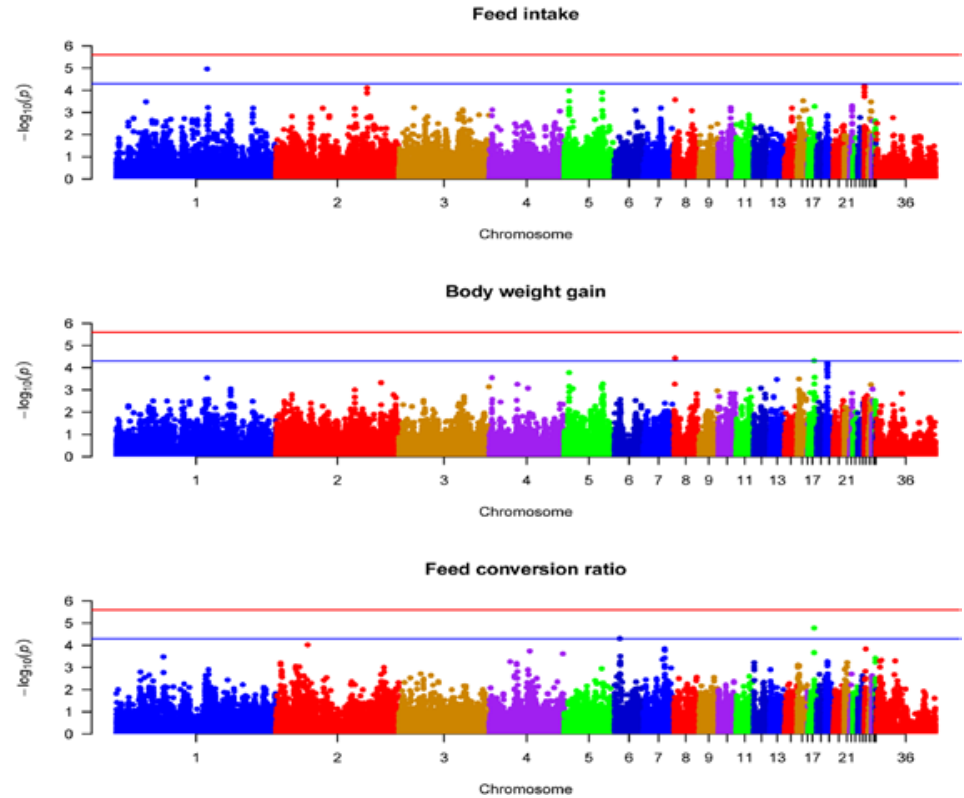

Figure 5.3. Manhattan plots of genome wide association results for feed efficiency traits using linear mixed model analysis. Chromosomes 29, 30 and 36 represent linkage groups LGE22C19W28_E50C23, LGE64, and chromosome Z respectively. Red and blue lines indicate genome wide and suggestive significance thresholds respectively.
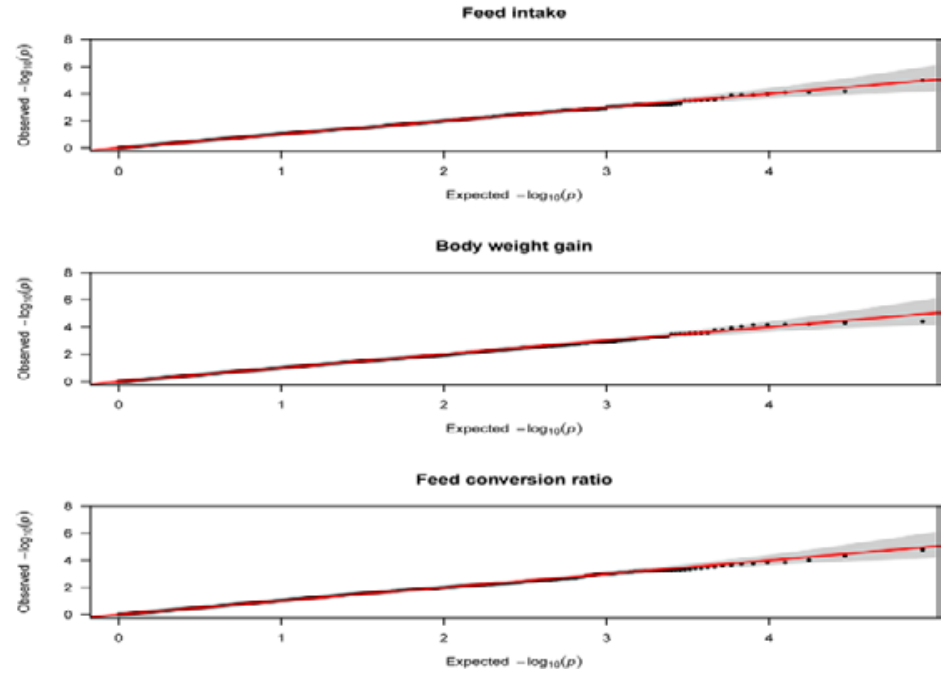

Figure 5.4. Quantile-quantile plots of feed efficiency traits using linear mixed model approach. 
Using the GLM approach, Reyer et al. (2015) reported 2 QTL and 9 SNPs that reached the suggestive significance level, located on chromosome 12 and 14 which were associated with BW36. The reported top SNPs, rs13612706, rs14073523, and proximal candidate genes associated with BW 36 are consistent with the present study (Table 5.1 and 5.2). SNP, rs13612706 showed higher -log 10 (P-value) in the GLM analysis compared to the MLM approach, whereas SNP, rs14073523 was indicated by a higher - $\log 10$ (P-value) in the MLM approach than the GLM approach (Table 5.1 and 5.2).

Reyer et al. (2015) also reported 2 QTL and 2 SNPs associated with BW46 located on chromosome 8 and Z, 1 QTL and a single SNP associated with body weight gain located on chromosome 17, 1 QTL and 3 SNPs associated with feed intake located on chromosome 5, 19 and 26, which are not consistent with the present study (Table 5.2). Moreover, Reyer et al. (2015) reported 4 QTL and 5 SNPs which have significant association with FCR, 2 of them located on chromosome 17, 1 located on chromosome 4 and the remaining QTL located on chromosome 22 (Table 5.2). Among the reported top SNPs associated with FCR, SNP rs4098962, located on chromosome 17 was found overlapping with the present study with higher -log 10 (P-value) in the GLM approach compared to the MLM approach. However, the reported candidate genes are different (Table 5.1 and 5.2).

For most of the BW and FE traits, the reported QTL in this study are not consistent with the reported QTL by Reyer et al. (2015). A total of 12 QTL and 20 SNPs associated with two BW (4 QTL and 11 SNPs) and three FE traits (8 QTL and 9 SNPs), were reported by Reyer et al. (2015) using the GLM approach (Table 5.2). By applying the MLM approach, the present study identified a total of 10 QTL and 17 SNPs, associated with the same BW (5 QTL and 12 SNPS) and FE (5 QTL and 5 SNPs) traits (Table 5.1). Among the identified 10 QTL in the MLM approach only 2 QTL associated with BW36 and 1 QTL associated with FCR were found overlapping with the GLM approach while the 7 identified QTL were different from the ones reported in Reyer et al. (2015) for the same BW and FE traits. 
Table 5.2. Top SNPs associated with body weight and feed efficiency traits using general linear model approach by Reyer et al. (2015). The position of SNPs is updated to the latest chicken genome assembly (Galgal5).

\begin{tabular}{|c|c|c|c|c|c|c|}
\hline Trait & $\begin{array}{l}\text { Chrom } \\
\text { osome }\end{array}$ & $\begin{array}{l}\text { Number of } \\
\text { significant } \\
\text { SNPs }\end{array}$ & $\begin{array}{c}\text { Top SNP in } 1 M B \\
\text { window }\end{array}$ & $\begin{array}{l}\text { Galgal5 position } \\
\text { (bp) }\end{array}$ & $\begin{array}{c}-\log 10 \\
\text { (P-value) }\end{array}$ & Candidate gene \\
\hline Body weight (36 days) & 12 & 8 & rs13612706 & 12867052 & 5.31 & PTPRG \\
\hline Body weight (36 days) & 14 & 1 & rs14073523 & 5337950 & 4.42 & CACNA1H \\
\hline Body weight (46 days) & 8 & 1 & rs16617885 & 1883740 & 5.21 & PTPRC,NR5A2 \\
\hline Body weight (46 days) & Z & 1 & rs14753816 & 19805476 & 4.89 & HTR1A \\
\hline Feed intake & 5 & 1 & rs16266739 & 6549732 & 4.38 & SPON1 \\
\hline Feed intake & 19 & 1 & $\begin{array}{c}\text { GGaluGA001282 } \\
\text { ( rs313913143) }\end{array}$ & 1878406 & 4.61 & ENSGALG0000002830 \\
\hline Feed intake & 26 & 1 & rs15467593 & 539371 & 4.50 & KDM5b \\
\hline Body weight gain & 17 & 1 & $\begin{array}{c}\text { GGaluGA117403 } \\
\text { ( rs312843163) }\end{array}$ & 9904101 & 5.29 & GPR144,NR5A1,NR6A1 \\
\hline Feed conversion ratio & 4 & 2 & rs14445503 & 31108872 & 5.04 & HHIP \\
\hline Feed conversion ratio & 17 & 1 & $\begin{array}{c}\text { GGaluGA117403 } \\
\text { (rs312843163) }\end{array}$ & 9904101 & 6.57 & NR5A1, NR6A1 \\
\hline
\end{tabular}


Table 5.2. Continued

\begin{tabular}{|c|c|c|c|c|c|c|}
\hline \multirow{2}{*}{$\begin{array}{l}\text { Feed conversion ratio } \\
\text { Feed conversion ratio }\end{array}$} & 17 & 1 & rs14098962 & 7902999 & 4.86 & RXRA \\
\hline & 22 & 1 & GGaluGA186837 & 4533949 & 5.07 & ADRA1A \\
\hline & & & ( rs312757200 & & & \\
\hline
\end{tabular}

Table 5.3. Comparison of lambda values with standard errors in general linear model (GLM) and mixed linear model (MLM) analysis.

\begin{tabular}{ccccc}
\hline Trait & Lambda GLM & SE & Lambda MLM & SE \\
\hline Body weight (36 days) & 1.0812 & $9.921616 \mathrm{e}-05$ & 1.0532 & 0.0001531706 \\
Body weight (39 days) & 1.0925 & $8.277596 \mathrm{e}-05$ & 1.0423 & $8.860991 \mathrm{e}-05$ \\
Body weight (46 days) & 1.0592 & 0.002739952 & 1.0057 & 0.0001031297 \\
Feed intake & 1.0429 & $8.538701 \mathrm{e}-05$ & 1.0242 & 0.0001203372 \\
Body weight gain & 1.0022 & $6.283618 \mathrm{e}-05$ & 0.9955 & $9.700197 \mathrm{e}-05$ \\
Feed conversion ratio & 1.0513 & 0.0002345801 & 1.0258 & 0.0001107539 \\
\hline
\end{tabular}




\subsection{Discussion}

Body weight and feed efficiency traits are the most important economic traits in the poultry industry. Body weight is the live weight of birds at a given age and feed efficiency (FE) is the ability of birds to convert a certain input to a certain output (e.g. $\mathrm{Kg}$ of feed in to Kg of meat) (Willems et al., 2010). Among the number of way to asses feed efficiency, the most widely used are feed conversion ratio (FCR) and residual feed intake (Willems et al., 2010). We have performed GWAS for body weight and feed efficiency traits in a commercial broiler chicken population using a MLM approach, taking family structure into account. The results were compared with the results of a GLM approach, which does not take family structure into account. Reyer et al. (2015) also used Bayesian (Multi-marker) approach, which is more robust to population stratification (Kärkkäinen et al., 2012) and reported more significant SNPs associated with BW and FE traits than the GLM approach. However, in this paper the results were only compared with the single marker GLM approach which is comparable to the single marker MLM approach in the present study.

Xu et al. (2013) reported that chromosome 1 and 4 are the two critical chromosomes influencing growth traits particularly body weight in chickens. In this study, SNPs on chromosome 1 were found to be associated with BW39 and BW46 while no significant SNP were found on chromosome 4 for any of the BW traits under study. Podisi et al. (2013) also reported two significant QTL for body weight at 12 weeks of age on chromosome 1 in broiler-layer cross female chickens.

Some of the BW and FE traits share consistent QTL and candidate genes. BW36 and BW39 share consistent region on chromosome 14 and candidate genes, PTPRG and CACNA1H, while BW46 does not share those candidate genes with BW36 and BW39. The effects of the lead SNPs with standard errors in parenthesis for BW36 and BW39 were found to be $0.036(0.008)$ and $0.041(0.010)$, respectively. This might indicate that the effects of these genes are smaller on BW46 due to increasing importance of other genes for the trait, suggesting that the identified genes are age dependent and the two traits (BW36 and BW39) might be genetically correlated. Mebratie et al. (2017) have reported that the genetic correlation between BW at different ages increased as the distance between BW measurements decreased. This might be due to changes in the physiological system of the chickens with age. Indeed, Schaeffer et al. (2011) states that there might be genes that "switch on" and "off" at a certain age of an animal which could lead to changes in physiology and performance. Similarly, Carlborg et al. (2004) concluded that there are different genes and gene actions involved in growth at different developmental stages. 
BW36 and body weight gain share an overlapping region on chromosome 8 and consistent candidate gene, LOC107053920 with SNP effects -0.051 (0.012) and 0.058 (0.013), respectively (Table 5.1 ). This might suggest high positive genetic correlation between BW36 and body weight gain which is not surprising since body weight gain is a component of body weight. Furthermore, body weight gain and FCR share consistent QTL on chromosome 17 and candidate gene LOC107052218 (Table 5.1) with SNP effects -0.054 (0.012) and 0.082 (0.019), respectively.

This broiler line is pre-selected for BW (only heaviest birds were entered to the FE experiment) and undergone several generations of selection for feed efficiency. This phenomenon might affect the detection power of our GWAS and estimated SNP effect sizes since the genetic variance of BW and FE traits might be reduced due to pre-selection and several generations of intense selection. Mebratie et al. (2018) have reported that the SNP based estimated genetic variance of BW $(0-0.006 \mathrm{~kg} 2)$ and FE traits $(0.001-0.006 \mathrm{~kg} 2)$ in this broiler population is very small with high standard error and among others, one of the reasons for the reported very small estimates of genetic variance was pre-selection of the broiler line for BW.

We have conducted GWAS using MLM approach, which takes in to account family structure and compared the results with the GLM approach by Reyer et al. (2015) which does not take family structure in to account. A number of studies (Fang et al., 2010; Kang et al., 2010) have shown that methods that model family structure perform better than models that ignore family structure. A widely used approach to evaluate whether confounding due to population stratification, family structure and cryptic relatedness exist is to compute the genomic inflation factor $(\lambda)$, which is computed as the median $\chi 2$ ( 1 degree of freedom) association statistic across SNPs divided by its theoretical median under the null distribution (Reich et al., 2001). Values of genomic inflation factor $(\lambda)>1$ generally suggest population stratification or other confounders, such as family structure or/and cryptic relatedness (Price et al., 2010). Values of $\lambda<1.05$ are considered "benign" regarding power and type I error (Price et al., 2010), although inflation in $\lambda$ is proportional to sample size.

Table 5.3 shows the $\lambda$ values of BW and FE traits using the MLM approach in the present study and the GLM approach by Reyer et al. (2015). The genomic inflation factor values suggest that population structure is not a strong concern in our data and the values are not significantly different from each other in the two methods. Moreover, the genomic relationship matrix of individuals shows that there are only few half sib and full sib relations in the current data (Mebratie et al., 2018) suggesting that family structure is not a strong concern in this study. However, there is a slightly higher inflation of $\lambda$ values in the results of Reyer et al. (2015) compared to the 
results of the present study. This may suggest that although there is no strong family structure in the population, using MLM analysis that takes in to account the existing family structure may increase power to detect true associations than ignoring this kind of sample structure which may result spurious associations.

In a simulation study, Thornton et al. (2010) have noted that using the genomic relationship matrix that accounts for family and population structure can successfully control spurious associations under different settings. Price et al. (2010) have also suggested that in studies where population stratification is not a very serious concern, an appealing and simple approach is to use mixed models.

For the commercial broiler chicken data used in this study, family structure is not a strong concern. However, as suggested by different authors (Ekine et al., 2014; Price et al., 2010; Thornton et al., 2010), we have used a MLM approach that takes in to account the existing family structure and revealed differences in the identified top SNPs and candidate genes associated with BW and FE traits compared with the GLM approach by Reyer et al. (2015). This strengthens the suggestion that, even though there is no strong family structure in the data, MLM approach that uses the genomic relationship matrix to account for the existing family structure may decrease bias and improve accuracy of the association analysis.

The results of this study might provide insight about the genetic background of body weight and feed efficiency traits. Furthermore, the study emphasizes that GWAS using the two approaches (GLM and MLM) does not necessarily give similar results even with the absence of strong family structure in the data.

\subsection{Conclusions}

GWAS for BW and FE traits was performed in a commercial broiler chicken population. The present study has identified 11 QTL and 21 SNPs associated with BW traits and 5 QTL and 5 SNPs associated with FE traits. The results of this study provide insight on QTL and genes that are involved in the genetics of BW and FE traits in broiler chickens and can be used as fundamental information for genomic selection. Moreover, the results of the study showed that the MLM approach, which takes in to account the existing family structure by using the genomic relationship matrix results in different QTL and SNPs for most of the analyzed BW and FE traits compared to the GLM approach that ignored the existing family structure. Although, there is no strong family structure in this population, the use of MLM approach may increase power to detect true associations compared to the GLM approach that does not take family structure into account as suggested by previous studies. 


\section{References}

Aulchenko YS, Ripke S, Isaacs A and van Duijn CM. 2007. GenABEL: an R library for genome-wide association analysis. Bioinformatics. 23: 1294-1296 .

Cantor RM, Lange K. \& Sinsheimer JS. 2010. Prioritizing GWAS results: A review of statistical methods and recommendations for their application. Am. J. Hum. Genet. 86: 6-22.

Carlborg O, Hocking PM, Burt DW \& Haley CS. 2004. Simultaneous mapping of epistatic QTL in chickens reveals clusters of QTL pairs with similar genetic effects on growth. Genet. Res. 83: 197-209.

Chicken QTL database. https://www.animalgenome.org/cgi bin/QTLdb/GG/index. Accessed 05 March 2018.

Duggal P, Gillanders EM, Holmes TN \& Bailey-Wilson JE. 2008. Establishing an adjusted $\mathrm{p}$-value threshold to control the family-wide type 1 error in genome wide association studies. BMC Genomics. 9: 516; Doi: 10.1186/1471-2164-9-516.

Ekine CC, Rowe SJ, Bishop SC. \& de Koning DJ. 2014. Why breeding values estimated using familial data should not be used for Genome-Wide Association Studies. G3 (Bethesda). 4: 341-347.

Eu-ahsunthornwattana J, Miller EN, Fakiola M, Wellcome Trust Case Control Consortium 2, Jeronimo SMB, Blackwell JM, et al. 2014. Comparison of Methods to Account for Relatedness in Genome-Wide Association Studies with FamilyBased Data. PLoS Genet 10(7): e1004445. https://doi.org/10.1371/journal.pgen.1004445

Fan QC, Wu PF, Dai GJ, Zhang GX, Zhang T, Xue Q, Shi HQ and Wang JY. 2017. Identification of 19 loci for reproductive traits in a local Chinese chicken by genome-wide study. Genet. Mol. Res. 16, 1; Doi: 10.4238/gmr16019431.

Fang M, Nie Q, Luo C, Zhang D, \& Zhang X. 2010. Associations of GHSR gene polymorphisms with chicken growth and carcass traits. Mol. Biol. Rep. 37: 423428.

Gao Y, Du ZQ, Wei WH, Yu XJ, Deng XM, Feng CG, Fei J, Feng JD, Li N and Hu XX. 2009. Mapping quantitative trait loci regulating chicken body composition traits. Anim. Genet. 40: 952-954.

GeneCards. 2018. Human Gene Database. https://www.genecards.org/. Accessed on 04 April 2018.

Gianola D, Fariello MI, Naya H \& Schön C. 2016. Genome-Wide Association Studies with a Genomic Relationship Matrix: A Case Study with Wheat and Arabidopsis. G3 (Bethesda). 6: 3241-3256. 
Gross A, Tönjes A, \& Scholz M. 2017. On the impact of relatedness on SNP association analysis. BMC Genet. 18,104; Doi:10.1186/s12863-017-0571-x.

Jin CF, Chen YJ, Yang ZQ, Shi KA \& Chen CK. 2015. Genome wide association study for growth trait related single nucleotide polymorphisms in Chinese Yancheng chickens. Genet. Mol. Res. 14: 15783-15792.

Kang HM. et al. 2010. Variance component model to account for sample structure in genome-wide association studies. Nat. Genet. 42: 348-354.

Kärkkäinen HP \& Sillanpää MJ. 2012. Back to Basics for Bayesian Model Building in Genomic Selection. Genetics. 191: 969-987.

Kennedy BW, Quinton M \& van Arendonk JAM. 1992. Estimation of effects of single genes on quantitative traits. J. Anim. Sci. 70: 2000-2012.

Li M, Reilly MP, Rader DJ \& Wang L. 2010. Correcting population stratification in genetic association studies using a phylogenetic approach. Bioinformatics. 26: 798-806.

Mebratie W, Shirali M, Sapp RL, Madsen P. Hawken R, Jensen J. 2017. The effect of selection and sex on genetic parameters of body weight in a commercial broiler chicken population. Livestock scie. 204: 78-87.

Mebratie W, Bovenhuis H \& Jensen J. 2018. Estimation of genetic parameters for body weight and feed efficiency traits in a broiler chicken population using genomic information. Proceedings of the World Congress on Genetics Applied to Livestock Production. 11: 819.

Mignon-Grasteau S, Rideau N, Gabriel I, Chantry-Darmon C, Boscher M, Sellier N, Chabault M, Le Bihan-Duva E and Narcy A. 2015. Detection of QTL controlling feed efficiency and excretion in chickens fed a wheat-based diet Genet. Sel. Evol. 47: 74; Doi: 10.1186/s12711-015-0156-y.

Podisi BK, Knott SA, Burt DW \& Hocking PM. 2013. Comparative analysis of quantitative trait loci for body weight, growth rate and growth curve parameters from 3 to 72 weeks of age in female chickens of a broiler layer cross. BMC Genet. 14: 22; Doi: 10.1186/1471-2156-14-22.

Price AL, Zaitlen NA, Reich D \& Patterson N. 2010. New approaches to population stratification in genome-wide association studies. Nat. Rev. Genet. 11: 459-463.

Purcell S. et al. 2007. Plink: a tool set for whole genome association and populationbased linkage analyses. AM. J. Hum. Genet. 81: 559-575.

Reich DE \& Goldstein DB. 2001. Detecting association in a case-control study while correcting for population stratification. Genet. Epidemiol. 20: 4-16.

Reyer H, Hawken R, Murani E, Ponsuksili S \& Wimmers K. 2015. The genetics of feed conversion efficiency traits in a commercial broiler line. Sci. Rep. 5: 16387; Doi: $10.1038 /$ srep 16387. 
Schaeffer LR. 2011. Animal breeding methods, Random regression models. course notes. 1-9; http://www.aps.uoguelph.ca/ /rs/.

Sillanpää MJ. 2011. Overview of techniques to account for confounding due to population stratification and cryptic relatedness in genomic data association analyses. Heredity. 106: 511-519.

Thornton T \& McPeek MS. 2010. ROADTRIPS: case-control association testing with partially or completely unknown population and pedigree structure. Am. J. Hum. Genet. 86: 172-184.

Tran T-S, Narcy A, Gabriel I, Rideau N, Gilbert H. et al. 2014. Detection of QTL controlling digestive efficiency and anatomy of the digestive tract in chicken fed a wheat-based diet. Genet. Select. Evol. 46: 25; Doi: 10.1186/1297-9686-46-25.

Turner SD. 2014. qqman: an R package for visualizing GWAS results using Q-Q and manhattan plots. Doi: 10.1101/005165.

Voight BF \& Pritchard JK. 2005. Confounding from cryptic relatedness in case-control association studies. PLoS Genet. 1, 3; e32.

Wang W, Zhang T, Wang J, Zhang G, Wang Y, Zhang Y, Zhang J, et al. 2016. Genomewide association study of 8 carcass traits in Jinghai Yellow chickens using specificlocus amplified fragment sequencing technology. Poult. Sci. 95: 500-506.

Willems OW, Miller SP \& Wood BJ. 2013. Aspects of selection for feed efficiency in meat producing poultry. Worlds Poult. Sci. J. 69: 77-88.

Xu Z, Nie Q \& Zhang X. 2013. Overview of Genomic Insights into Chicken Growth Traits Based on Genome-Wide Association Study and microRNA Regulation. Curr. Genomics. 14: 137-146.

Yang J, Benyamin B, McEvoy BP, Gordon S, Henders AK, Nyholt DR. et al. 2010. Common SNPs explain a large proportion of the heritability for human height. Nat. Genet. 42: 565-569.

Yang J, Lee SH, Goddard ME \& Visscher PM. 2011. GCTA: a tool for genome-wide complex trait analysis. Am. J. Hum. Genet. 88: 76-82.

Yu J, Pressoir G, Briggs WH, Vroh Bi, Yamasaki M, Doebely JG. et al. 2006. A unified mixed-model method for association mapping that accounts for multiple levels of relatedness. Nat. Genet. 38: 203-208.

Yuan J, Wang K, Yi G, Ma M, Dou T, Sun C. et al. 2010. Genome wide association analysis for feed intake and efficiency in two laying periods of chickens. Genet. Sel. Evol. 47: 82; Doi 10.1186/s12711-015-0161-1.

Zhang F \& Deng H. 2010. Correcting for cryptic Relatedness in population-Based association studies of continuous traits. Hum. Hered. 69: 28-33 (2010). 
Zhang T, Fan QC, Wang JY, Zhang GX, Gu YP and Tang Y. 2015. Genome-wide association study of meat quality traits in chicken. Genet. Mol. Res. 14: 1045210460.

\section{Acknowledgements}

The presented work was done as part of the ECO-FCE project. ECO-FCE is funded by the European Union Seventh Framework Programme (FP7/2007-2013) under grant agreement number 311794 . We would also like to thank Cobb-Vantress for providing the data. The first author benefited from the Erasmus-Mundus Fellowship under the European Graduate School of Animal Breeding and Genetics program. 


\section{6}

General discussion 



\subsection{Introduction}

Improvement of growth rate and feed efficiency is the primary breeding goal in most broiler breeding programs. Growth rate and feed efficiency are not only economically important traits in the broiler industry but also have environmental implications, which increasingly become a global issue. Aggrey et al. (2010) quantified feed cost to account for about $70 \%$ of the total cost of poultry production attesting the significance of improving feed efficiency on the profitability of the broiler industry. It is known that body weight or growth rate and feed efficiency are highly correlated (Emmerson, 1997). Thus, other than direct selection, improvement in feed efficiency of broilers can be achieved through improvement in growth rate of broilers since the time required in achieving a specific weight for age decreases with increased growth rate, which in turn improves feed efficiency due to lower needs for maintenance of body mass. Although poultry production accounts the least of the global emissions relative to other livestock sectors such as beef, sheep and pigs, the continuous development of the sector makes reduction in emission intensity necessary (MacLeod et al., 2013). Feed production is the activity that produces the highest emission in the poultry sector, which makes feed efficiency a major determinant for reduction in emission intensity (MacLeod et al., 2013). The world population is predicted to reach 9.6 billion in 2050 (UN, 2015) and the global demand for chicken meat is forecasted to grow by 61\% between 2005 and 2030 (MacLeod et al., 2013). Thus, there is no doubt about the need to further improve growth rate (body weight) and feed efficiency of broiler chickens.

In order to further improve body weight at a certain age and feed efficiency, unravelling the genetic background of the traits is essential. The main objective of this thesis is to understand the genetic background of body weight and feed efficiency using different statistical models and methods. In chapter 2, genetic parameters of body weight were estimated using multi-trait REML analysis, hence, sex by genotype interaction as well as age by genotype interaction for BW was investigated. Chapter 3 confirmed the results of chapter 2 using Bayesian bivariate random regression model with an additional objective of investigating the effect of selection on body weight along a selection trajectory of 39 selection rounds. In chapter 4 genetic parameters for body weight, feed intake and body weight gain were estimated simultaneously using a multi-trait Bayesian model. Moreover, the relationship between production and feed efficiency traits were investigated. The two RFI definitions were derived inside the model; genetic parameters were 
estimated for the traits, and the relationship between the two RFI definitions were investigated. Furthermore, direct and correlated superiority of a group selected on phenotypic and genetic RFI were investigated. In chapter 5 GWAS was conducted to identify QTL and candidate genes associated with BW and FE traits using mixed linear model approach that takes in to account family structure and the results were compared with a general linear model approach that does not take family structure in to account. By doing so, we investigated several new loci associated with BW and FE traits and showed that GWAS using the two approaches does not necessarily give similar results, even in the absence of strong family structure.

In this chapter, the main findings of the four papers of this thesis are summarized and integrated with each other and the different statistical models and methods employed in the papers are discussed relative to other possible models and methods. Moreover, available information on literature about unintended consequences of improved growth rate and feed efficiency of broiler chickens are discussed. Finally, areas that could be exploited to enhance further improvement in body weight and feed efficiency as well as to alleviate unintended consequences of improved growth rate and feed efficiency are explored.

\subsection{Genetic variability in body weight and feed efficiency}

In animal breeding knowledge of variance components of traits of interest is a primary pre-requisite to establish a selection program. In an infinitesimal additive model estimation of genetic parameters is often synonyms to estimation of variance components (Thompson et al., 2005). Reliable estimates of genetic parameters such as genetic variance, heritabilities, genetic correlations etc. are essential to properly exploit the properties of best linear unbiased predictions (BLUP) of breeding values (Chapuis et al., 1996). Genetic parameters enable animal breeders to understand the genetic background of traits of interest. Moreover, genetic parameters are essential for prediction of breeding values and expected response to selection in breeding programs.

In chapter 2, 3 and 4 of this thesis genetic parameters of BW and FE traits were estimated in commercial broiler chicken populations. Furthermore, sex by genotype interaction for BW and FE traits, age by genotype interaction for BW and FE traits, the effect of selection on genetic parameters of BW, phenotypic and genetic definitions of RFI and relationship between production and feed efficiency traits were investigated. The results showed that heritability estimates of BW and FE traits are moderate and thus could be modified by genetic manipulation or selection. Moreover genetic parameters of BW and FE traits were found to differ between 
males and females as well as between the different recording ages suggesting sex by genotype and age by genotype interaction, respectively for BW and FE traits. In addition to the heritability estimates, the genetic correlations of BW and FE traits between males and females as well as the genetic correlations of BW and FE traits between the different recording ages were found to be different from unity. Therefore, it was concluded that BW in males and females as well as BW in the different recording ages are not the same traits. Furthermore, the moderate heritability estimates of BW and FE traits indicate that despite the intense selection carried out in BW and FE traits, there is still possibility to further improve the traits through selective breeding.

\subsubsection{Sex by genotype interaction}

Sex by genotype interaction refers to the interaction of genes with male or female physiological "environments" (Towne et al., 1997). To understand the genetic basis of sex differences in economically important traits, it is necessary to consider differential effects of genes on a trait in males and females (Towne et al., 1997).

In quantitative genetics research there is an implicit, or sometimes, explicit assumption that genetic control of metric traits is similar in males and females, sex differences being caused by a simple proportional effect of sex on otherwise identical genetic effects (Morton, 1973). However, recent studies have consistently reported higher BW in males than females at the same age (Begli et al., 2017; Mebratie et al., 2017) and accelerated growth rate in male birds compared to females (Tagirov and Rutkowska, 2015). The main source of this sexual dimorphism is considered to be of epigenetic origin, probably due to the availability and dosage of active sex chromosomes (Gutierrez-Adan et al., 2006). The proportion of genes which are over expressed is larger in avian males which are homogametic (Zhang et al., 2010). In male embryos, those genes which are expressed at a higher dose are involved in fatty acid and carbohydrate metabolisms as well as mitochondrial and cell cycle processes starting from the primitive streak-stage (Zhang et al., 2010). Hence, it is suggested that the faster growth rate of males than females is associated with the overexpression of growth hormone receptors and other genes that regulate the cell cycle and metabolism (Tagirov and Rutkowska, 2015).

In humans, sexual dimorphism in disease susceptibility is reported to be due to sex chromosomes and gonadal sex hormone effects. The latter is more prominent at sexual maturity where as difference in sex chromosomes is a result of evolution of $X Y$ testis determination. i.e Females carry two copies of the $X$ chromosome which contains relatively higher dosage of genes, whereas males carry a single copy of the 
$X$ chromosome and a $Y$ chromosome which relatively contains lower dosage of genes. Thus, there are differences in gene expression between males and females since the sex chromosomes $(X-Y)$ gene pairs are functionally diverged contributing to sexual dimorphism (Snell and Turner, 2018 ).

On the other hand, Mignon-grasteau et al. (1999) reported that sexual dimorphism of body weight at 8 weeks of age is lowly heritable (0.05) where as it is moderately heritable (0.21) at 36 weeks of age suggesting that selection on growth curve parameters might modify the difference between sexes in body weight at a given age particularly at later age when the birds attain sexual maturity.

The results of chapter 2 (Mebratie et al., 2018), 3 (Mebratie et al., 2017) and 4 of this thesis showed that the genetic background of BW and FE traits is different in males and females. The different heritability estimates of BW and FE traits in the two sexes and the genetic correlations of BW and FE traits between males and females which were significantly different from unity suggest that the traits are influenced by sex by genotype interaction. The genetic correlations between sexes is lower at later ages than early ages suggesting that hormonal differences become more distinct at later ages. In such cases, treating male and female records of BW and FE traits as different traits in broiler breeding programs is important since it may result in reranking of selection candidates. In this regard, Falconer and Mackay (1996) noted that cross-sex genetic correlations are population-specific like all other genetic parameters due to differences in allele frequencies. In addition to being populationspecific, genetic correlation estimates between male and female traits are expected to be environment specific due to genotype by environment interactions particulary for fitness traits like longevity (Falconer and Mackay, 1996; Simons and Roff, 1994) suggesting that genetic correlation estimates obtained in a single environment or averaged across environments may not be sufficient to fully understand the evolutionary dynamics of sexual dimorphism when environmental conditions are heterogeneous (Poissant et al., 2009). Hence, the effect of sex by genotype interaction should be considered in genetic evaluation models for BW and FE traits as well as other economically important traits in different broiler populations rather than assuming a genetic correlation of unity between males and females and average heritability estimates across sexes.

\subsubsection{Age by genotype interaction}

Body weight and feed efficiency traits are quantitative traits which could be recorded at a continuous range of points in the life of a bird in which case genes may react differently or different genes may be involved at different ages (range of points) of 
the bird which is termed as age by genotype interaction ( $A x G)$. Variation in quantitative traits is assumed to be caused by many loci of small effects. In the absence of $A x G$, breeding values may be constant across ages in which the individual is expected to express the same value for the traits recorded at different ages. However, when AxG is present, the magnitude of the effects of loci on the trait may change with the age of the animal. Some loci which did not have an effect earlier may be "turned on" and others which had an effect may be "turned off", or the same genes may increase or decrease in their effect. Thus, the presence of $A x G$ is assumed to indicate a change in the genetic basis of the trait with age (Brommer and Class, 2015) suggesting that accounting for AxG in genetic evaluation of broiler chickens is important in order to fully exploit the sources of variation in BW and FE traits of broiler chickens.

Chapter 2, 3 and chapter 4 of this thesis investigated AxG for BW and FE traits in broiler chickens. In chapter 2 (Mebratie et al., 2018) and 3 (Mebratie et al., 2017), it is shown that the heritability estimates of BW were significantly different at the three different recording ages. In chapter 4 , the heritability estimates of FE traits were significantly different at the two weighing ages. Moreover genetic correlations of BW at the three ages in chapter 2 (Mebratie et al., 2018) and 3 (Mebratie et al., 2017) and genetic correlations of FE traits at the two recording ages in chapter 4 were significantly different from unity suggesting significance of AxG for BW and FE traits in broiler chickens. The genetic correlations of BW between different ages is also shown to decrease as the distance between BW measurements increased suggesting that BW at "early age" and "late age" is partly controlled by different genes which might be related to change in the physiological system of birds with age as explained by Schaeffer (2011) stating that there could be genes that "turn on" and "turn off" as an animal ages causing changes in physiology and performance. This is consistent with our results in chapter 5 (Mebratie et al., 2019) where we have identified age specific Quantitative trait locus (QTL) regions; different QTLs and candidate genes were identified to be associated with BW at three different ages with only a little overlap between the identified QTL regions and candidate genes across the three ages. The reported overlap in QTL and candidate genes were for BW measurements that were taken closer together than those recorded far apart. Ovelapping QTLS were identified for BW at 36 days and BW at 39 days where as no overlapping QTL was reported between BW at 46 days with BW36 and BW39. In general, our results suggest that that the genetic background of BW and FE traits are not the same across ages indicating that BW and FE traits should be selected at the target age to maximize genetic gain. Furthermore our results suggest that genetic evaluation models for BW 
and FE traits in broiler chickens should take in to account AxG instead of assuming a genetic correlation of unity and average heritability across ages.

Genetic improvement of growth rate in broilers has long been accomplished mainly by selection for BW at a specific age (Siegel and Dunnington, 1987) which may result in differences in body weight between birds at a common age (Liu et al., 1988b). Growth curve parameters describe the growth process by summarizing the information provided by all weights in to only a few parameters (Mignon-Grasteau etal., 1999). The Gompertz curve is one of the most popular growth curve in poultry (Laird, 1966). Mignon-Grasteau et al. (1999) used the Gompertz curve in chickens which included 8-10 weights per animal from 0 to 20 weeks of age and estimated genetic parameters for the growth curve parameters. They reported different heritability estimates for the growth curve parameters in the range between 0.25 0.48 in males and $0.43-0.54$ in females. Moreover the reported genetic correlations between the different growth curve parameters range from low and negative to positive and high (-0.02 to 0.98 ) but significantly different from unity suggesting that growth curve parameters are partly controlled by different genes. Furthermore, it suggests that specific breeding programs for different growth curve parameters could alter the growth trajectory for example to maintain optimal growth at early age and protein accretion while reducing fat deposition. Genetic manipulation of growth curve parameters could be an alternative to decrease unintended consequences of intense selection for BW at a specific age on fitness traits in modern broilers by independently selecting the heritable part of the curve or selecting based on genetic correlations.

\subsubsection{Maternal effects on body weight}

Body weight in broilers is not only influenced by direct genetic effects but also by maternal genetic and maternal environmental effects (Liu et al., 1993). Females vary in their ability to provide suitable environment to their offspring to survive and grow in terms of protection and nourishment. This ability has both genetic and nongenetic basis, which are called maternal genetic and maternal environmental effects, respectively. Maternal effects are mainly exhibited in mammals and related to prenatal and post-natal nutrition (Falckoner and Mackay, 1996).

Maternal environment influences the growth of birds in two ways which are known as pre-ovipositional maternal effects and post-ovipositional maternal effects (Aggrey and Cheng, 1993). The pre-ovipositional maternal effects are common oviductal factors expressed by the characteristics of the egg (Aggrey and Cheng, 1993). The post-ovipositional effects can be divided into pre-hatch (incubation) and post-hatch 
effects (Aggrey and Cheng, 1993). Pre-hatch and post-hatch maternal effects are not important in growth of commercial broilers where chicks are incubated and raised independet from hens. Thus, the common environmental effects that could possibly affect chick growth are pre-ovipositional maternal components, such as egg weight, egg size, yolk composition and shell quality (Aggrey and Cheng, 1993).

In poultry maternal environmental effects are mainly due to egg weight/size which is influenced by the age of the hens (Shalev and Pasternak, 1993) and the size of the hens (Mignon-Grasteau et al., 1999). Schmidt et al. (2003) noted that 62 to $78 \%$ of chick weight is determined by egg weight while Koerhuis et al. (1997) reported that a difference in 1 gram egg weight is reflected in about 10 gram gain of body weight of juvenile broilers. In a different study, Schmidt et al. (2009a) reported an increase in 0.71 gram and 0.68 gram chick weight for selected line for growth rate and control lines, respectively, which result from an increase in 1.0 gram egg weight. Maternal effects are shown to be sensitive to effects such as hatch, age, year etc. (Koerhuis and Thompson, 1997; Robinson, 1996; Robinson, 1994). If such sources of variations are not taken in to account in the model, they could affect estimates of maternal effects.

In chapter 2, 3, and chapter 4 of this thesis, maternal genetic effect was not significant for BW at different ages in the studied broiler population, hence, it was not included in the models while maternal permanent environmental effect was significant and included in the statistical models. In all our studies, the maternal environmental effect accounted for a relatively small proportion of the total phenotypic variance, decreased with age and were smaller in males than in females. This is in agreement with literature. For example, Aslam et al. (2011) reported the proportion of variance explained by common (maternal) environment in turkeys to be 0.43 for body weight at day 1 , however it reduced quickly to 0.11 at day 17 and became negligible after 60 days. Similarly, Koerhuis and Thompson (1997) reported a relatively low maternal environmental variance as a proportion of phenotypic variance in chickens. They also reported low maternal heritability in the range 0.010.17 in broiler chickens. In contrast, Mignon-Grasteau et al. (1999) reported a relatively higher maternal heritability; 0.21 in females and 0.24 in males at 8 weeks of age and 0.08 in females and 0.11 in males at 36 weeks of age in chickens. In the same study, they observed maternal effects on growth curve parameters and reported that maternal effects were higher for the juvenile traits (BW at hatch and initial specific growth rate) relative to other growth curve parameters. Indeed, maternal effects are more pronounced at earlier age of birds and diminish with age. Higher maternal effects in males than females is also observed in turkey birds (Chapuis et al., 1996) and was explained by females being precocius (appearing more 
mature at a given age) than males (Mignon-Grasteau et al., 1999; Chapuis et al., 1996). Morover, the differences in maternal effects between males and females is suggested to be due to differences in growth metabolisms and other causes such as incidences of leg disorders (Chapuis et al., 1996). In turkeys, Chapuis et al. (1996) compared six different animal models for BW which ranges from a simple model with animals as the only random effects to the most comphrensive model which includes both genetic and maternal environmental effects as well as a genetic covariance between direct and maternal effects and noted that the most comphrensive model resulted in the highest log likelihood value. However, increase in computation time and convergence problems may be an issue in using such complex models.

Maternal effects on feed efficiency traits did not receive much attention in poultry. In chapter 4, we have observed that the maternal environmental effect is significant for FE traits, although it accounts only small proportion of the total phenotypic variance, the effect is not negligible. It seems that the effect of the dam on the variation of FE of its offspring needs further investigation.

In general maternal effects (genetic and environmental) should receive due consideration in genetic evaluation models since ignoring these effects while statistically significant may result inflation of the genetic variance and in turn inflation of the direct heritability estimates. Roehe and Kennedy (1993) evaluated the loss of selection response due to a model that ignored maternal effects while statistically significant versus a model that included maternal effects and reported that ignoring maternal effects slightly decreased the accuracy of estimating direct effects and caused an increased overestimation of genetic trend over 10 years for the direct effect. As a result, younger animals were more frequently selected than older animals. When generations are not overlapping, this kind of bias does not affect selection decisions dramatically. However, in commercial broiler breeding schemes generations are mostly overlapping thus ignoring maternal effects may highly influence selection decisions.

\subsection{Effects of selection on body weight and feed efficiency}

The aim of a selection program in animal breeding is to select individuals having high additive genetic merit to be parents of the next generation. On average, half of the genes of a parent and thus random half of its additive genetic merit is transmitted to the offspring. While selecting parents based on their additive genetic merit any parallel merit for additive by additive epistatic effects is also transmitted. The additive genetic merit or the breeding value of an individual is defined as the sum of 
the additive effects of its genes, which mainly determines response to selection (Falconer and Mackay, 1996).

In chapter 3 (Mebratie et al., 2017), the effect of selection on genetic parameters of $\mathrm{BW}$ is investigated by studying the development in genetic variance of BW across a selection trajectory of 39 selection rounds. It is shown that the genetic variance of BW did not diminish or exhaust after several generations of selection suggesting that there is still genetic variance avilable for selection and considerable genetic gain can be obtained by selective breeding. Theoretically, it is known that long term selection reduces the genetic variability of a trait which also reduces the heritability and inturn diminishes the response to selection. However, our results indicate that this is not always the case. We have clearly shown that the genetic variance and the heritability estimates of BW increased across the selection trajectory. It can be argued that the increased genetic variance is partly due to scale effect since the weight of the birds is expected to increase due to the increase in their "physiological age" along the selection trajectory. However, heritability estimates cannot be influenced by scale effects since they are ratios of two variances. Hence, the increase in the heritability estimates across the selection trajectory attest the increase in genetic variance is not only due to scale effects rather it may be attributed to accumulation of new mutuations or other genetic effects that are not properly accounted in the statistical model. This is consistent with the reported results in chapter 5 (Mebratie et al., 2019) in which we have detected a number of QTL regions and candidate genes associated with BW and FE traits even though birds were pre-selected for BW and undergone several generations of selection for FE. In fact, the increase in genetic variance of quantitative traits from the accumulation of new mutations has been known for quite some time (Hill, 2000; Falconer and Mackay, 1996). After 50 generations of selection for body weight in an inbred mice line, Keightley (1998) reported an increase of $0.23-0.57 \%$ in heritability of body weight per generation and the author suggested that the increase in heritability is due to new mutations.

Despite the intense selection carried out on growth rate of broiler chickens for the last several decades, there is considerable genetic variation for BW; heritability of body weight at different ages in males and females is reported to be in the range from 0.20-0.64 (Mebratie et al., 2017; Begli et al., 2016; Adeyinka et al., 2006; PradoGonzalez et al., 2003; Mignon-Grasteau et al., 1999; Le Bihan-Duval et al., 1998). Moreover tody's broilers have about four fold higher body weight at the same age than broilers at the 1950s (Havestein et al., 2003a). It is not likely that this is only due 
to random mutuations that occured in all commercial broilers rather it is likely that selection increased the frequency of new combinations of rare alleles and genes, which gave rise to higher performing genotypes (Deeb and Lamont, 2002).

Selection results changes in allele frequency of a gene. The effect of selection on gene frequency not only depends on the intensity of selection but also on the actual frequency of the gene at the time of selection. It is noted that the rate of change increases dramatically for intermediate initial gene frequencies and declines rapidly for small and large initial gene frequencies. However, if the favourable gene is rare, the variance can increase by selection until intermidiate gene frequency is reached in the absence of dominance (Falconer and Mackay, 1996). The consequence of selection over a long period is, however, unpredictable. It depends on the individual genes contributing to the response and the presence/absence of mutation, which can produce new variation that is hard to predict (Falconer and Mackay, 1996). On the other hand, Bulmer (1971) noted that in artificial selection experiments, it is more likely that the effects of linkage disequilibrium are more important than the effects of gene frequiencies which are slower and less rapid. Under the infinitesimal model, selection-induced changes in gametic-phase disequilibrium can cause rapid and significant changes in the additive genetic variance. Directional and stabilizing selection induces negative covariances (negative disequilibrum) among loci affecting a trait, which reduces the genetic variance and inturn reduces the phenotypic variance (Bulmer, 1971). However, the reduction in genetic variance does not continue indefinitely rather it is balaced when the increase in disequilibrum is balanced by the loss in disequilibrum due to recombination. In the absence of linkage about four generations are enough to bring the popultion near to balance (Falconer and Mackay, 1996).

In a simulation study, Liu et al. (2014) noted that genetic variance across 25 generations of selection was influenced by the number of QTL controlling a trait. The authors compared different selection criteria and different numbers of QTL (4, 40 and 100) controlling a trait and reported that the change in genetic variance is more prounounced for a trait controlled by smaller number of QTL (4 QTL). In this regard, all selection criteria have shown a faster initial increase in genetic variance followed by a higher peak and finally a faster reduction in genetic variance. The faster initial increase in genetic variance was attributed to a rapid rise in allele frequency due to easier identification of animals with favourable alleles when the number of QTL was smaller. While the higher peak was attributed to all QTL reaching intermidiate allele 
frequencies at the same time because of the small number of QTL. Finally the reduction in genetic variance was attributed to the rapid fixation of favourable alleles (Liu et al., 2014).

The effect of selection that can be observed and of interest to animal breeders is ,however, restricted mainly to changes in population mean since changes in individual gene frequencies are hidden as most genes are effectively unknown (Falconer and Mackay, 1996). This is known as response to selection which is computed as the difference between mean phenotypic value of progeny of selected parents and the mean of the parental generation before selection (Falconer and Mackay, 1996). Response to selection depends on the accuracy of selection, which inturn depends on the heritability of the trait and the amount of information available for estimating breeding values, the intensity of selection and the genetic variance in the population of individuals being selected (Falconer and Mackay, 1996). The moderate heritability of BW and FE traits reported in chapter 2, 3, and 4 suggest that further improvement/response can be achieved through direct selection on these traits.

It may sometimes be advantageous to improve a trait using indirect selection through its correlated response to another trait than direct selection if the trait is lowly heritable, difficult or/and expensive to measure with precision, or/and if it is expressed in only one sex (Falconer and Mackay, 1996). The response of a correlated trait can be predicted if the genetic correlation between the traits and the heritabilities for the traits are known (Falconer and Mackay, 1996). If trait 1 is the trait of interest, the gain in trait 1 through indirect selection relative to the gain from direct selection is calculated as the genetic correlation between the traits multiplied by the the ratio of heritability of trait 2 to trait 1 (Falconer and Mackay, 1996). Hence, indirect selection is better than direct selection, if trait 2 has considerably higher heritability than trait 1 and the genetic correlation between the traits is high.

The moderate heritability estimates of production traits (body weight and body weight gain) and feed efficiency traits (feed intake and the two RFI definitions) as well as the moderate to high genetic correlations between production and feed efficiency traits reported in chapter 4 suggest that selection on production traits will result a considerable correlated response on feed efficiency traits and vice versa. Indeed improvement in feed efficiency of broilers has long been achieved through indirect selection of growth rate and still broilers with highest body weight are pre- 
selected before they start feed efficiency test in most commercial breeding programs.

\subsection{Different measures of feed efficiency}

In chapter 4 two RFI definitions (phenotypic and genetic RFI) were derived from a joint Bayesian analysis of body weight, feed intake and body weight gain. Phenotypic RFI was derived using partial phenotypic regression coefficients and genetic RFI were derived using partial genetic regression coefficients. The advantage of the Bayesian analysis over the conventional methods is that it minimizes error in the estimation of regression coefficients by estimating the partial phenotypic and genetic regression coefficients from co (variance) matrices of feed intake and production traits simultaneously compared to the assumption of known co (variance) matrices of component traits of RFI in Kennedy et al. (1993) and the classical two-step approach (Koch et al., 1963). In the classical two step approach, feed intake and production traits are analyzed together in a multiple regression analysis and regression coefficients are obtained from the resulting co (variance) matrices before the genetic analysis. Then RFI is computed using the regression coefficients for each animal and the genetic analysis is performed. In this procedure, the resulting covariance matrices of RFI and production traits are usually singular due to problems related to defining the traits before the genetic analysis (Jensen, 2013).

The genetic correlation between phenotypic and genetic RFI were high and not significantly different from unity at $t-6$ days of age suggesting that selection for FE based on either phenotypic or genetic RFI will result similar genetic response at this specific age. However, genetic RFI is easier to communicate to stakeholders since it is a part of Fl which is not genetically correlated with production traits. In a recent study in pigs, body composition trait was included as production trait other than average daily gain and a genetic correlation between phenotypic and genetic RFI which is significantly different from unity was reported (Shirali et al., 2018).

Feed conversion ratio (FCR) which is calculated as the ratio of feed intake to body weight gain is also a popular measure of feed efficiency in poultry. The trait is moderately heritable, hence, improvement of FE using FCR as selection criterion is possible. However, it is well known that selection for FE based on FCR has an inherent problem which is related to ratio traits. Mainly, as selection intensity increases, direct selection for FCR causes selection to be focused primarily on the information in the numerator regardless of the distributional properties of the component traits (Gunsett, 1984) which leads to selection pressure being placed 
non-linearly on feed intake and body weight gain (Willems et al., 2013). This problem may be circumvented by using the Bayesian method applied in chapte 4 which accounts for the non-normal distribution of ratio traits. The Bayesian method enables the amount of genetic variance and covariance available for selection to be derived from the results of the Gibbs sampler without enforcing approximations due to the unknown distributional properties of a ratio trait and its component traits (Shirali et al., 2018).

Other measures of FE such as Residual gain (RG) and Residual feed intake and Gain (RIG) were suggested in literature as alternative measures of FE in poultry. Residual gain $(R G)$ is defined as the residuals from the linear regression of average daily gain $(A D G)$ on both $\mathrm{FI}$ and $\mathrm{BW}$. It is calculated as: RG $=$ ADG $-\left[\mu+\left(\mathrm{b} 1^{*} \mathrm{FI}\right)+(\mathrm{b} 2 * \mathrm{BW})\right]$. Where, ADG represents the average daily gain over a defined period, $\mu$ represents the average ADG, b1 and b2 represent the partial regression coefficients on $\mathrm{Fl}$ and BW, respectively (Berry and Crowley, 2012; Romero et al., 2009b). In this regard, birds having high RG, have higher growth rate but not higher feed intake (Berry and Crowley, 2012). Our Bayesian analysis presented in chapter 4 can be easily extended to include RG without resorting to the two step procedure assumed in the definition of RG. Using the Bayesian analysis it is possible to simultaneously estimate regression coefficients and perform genetic analysis for RG rather than the two step procedure. In the two step procedure, first RG is computed using regression coefficients obtained from joint analysis of ADG, FI and Gain and then genetic analysis of RG is conducted with FI and ADG. However, the Bayesian one step procedure minimizes error in the estimation of regression coefficients by estimating the regression coefficients and conducting the genetic analysis simultaneously.

Residual feed intake and Gain (RIG) which integrates the beneficial characteristics of both RFI and RG was also suggested as an alternative measure of FE. RIG which is calculated as, $\mathrm{RIG}=\left[\left(-1^{*} \mathrm{RFI}\right)+\mathrm{RG}\right]$ is independent of $\mathrm{BW}$, but when used for selection it can increase body weight gain and reduce feed intake, simultaneously. Both RFI and RG are standardised to a variance of one and multiplying RFI by a negative value accounts for the fact that birds with a negative RFI have better feed efficiency, whereas the opposite is true with RG; a positive number corresponds to having greater feed efficiency (Berry and Crowley, 2012). The above alternative measures of FE are not commonly used in poultry, hence, the impact of using these alternative measures should be further investigated.

One of the challenges in using the different measures of FE is to find optimal ways of measuring feed intake. In this regard, all the available measures of FE require the measurement of individual feed intake, which can be difficult to measure in practice. The commonly used way to measure individual Fl is using individually caged birds 
and record aggregate feed intake over a test period. This method is cheap and simple, but requires a significant amount of barn space, doesn't account for social interactions and feed intake measurements can only be taken on a limited number of birds. Moreover, it does not represent the real situation in which parents are selected in individual cages while their progeny's are expected to perform in a group housed enviroment. Therefore, the FI measured in this way might be a genetically different trait compared to that of the FI measured from commercial birds which are housed in groups. To this end, an automated electronic feeding system that enables to take feed intake measurements on specific individuals in a group-house setting was proposed as an alternative (Howie et al., 2011; Tu et al., 2011). This system enables feed intake measurements to be taken on larger number of birds, and because of the group-housed environment, it takes in to account social interactions between birds. However it is expensive to implement except in large scale industries. In fact, large global breeding companies have started to replace single bird cage selection with selection of individual birds from group floor housing, using transponders on the birds and feeding stations with sensors to record feed intake (Pym, 2008). This way of measuring FI should be developed to a cheaper version to fully exploit the system.

Other than feed intake and energy use of birds, feed efficiency of broilers also depend on the digestion ability (digestibility) of birds (Fairfull and Chambers, 1984). Mignon-Grasteau et al. (2004) reported variation in digestibility of birds that were fed a wheat based diet while birds fed a corn-based diet were reported to have homogenous digestibility. The authors reported moderate heritability (0.37) of digestibility for birds fed wheat based diet and low heritability of digestibility for birds fed corn based diet. This suggests that selection for FE based on digestibility could be possible. However, the type of feed that is fed to broilers is important to select on digestibility since there is considerable variability of birds in digestibilty depending on the type of feed. Until recently, there was no evidence for genetic improvement of digestive efficiency in broilers (Tallentire et al., 2016). However, considering the variation in digestibility among birds and its moderate heritability, it seems that genetic selection for improved digestibility is worth trying to further improve feed efficiency.

Another possibility for improvement in FE could be exploring the gut microbiota of broilers. Host genotype may influence the gut microbiota composition either directly through secretions into the gut, control of gut motility and modification of epithelial cell surfaces, or indirectly, through feed and other husbandry practices (Zhao et al., 2013). Zhao et al. (2013) compared gut microbiota composition of two chicken lines which are selected for high and low BW for more than 50 generations, fed the same 
diet and reared in the same environment. The authors reported that the composition of the gut microbiota were different in the two lines as well as in males and females suggesting that the composition of gut microbiota is influenced by host genotype and sex. They reported 190 microbiome species and of which 68 were influenced by genotype, sex, and sex by genotype interactions, among which the most prominent microbiome is Lactobacillus, which is reported to be associated with variations in BW. In dairy cows, Difford et al. (2018) reported associations between rumen bacteria abundance and methane emissions and suggested that unlocking the genetic potential of the host through strategies which may result required changes in the rumen microbiota through selective breeding may reduce methane emissions. Likewise, exploring the gut microbiota of broilers if there is significant association between specific microbiota and FE and selection of birds with the desired microbiota after quantifying their associations with FE may complement the currently avilable strategy of selection for FE.

It is known that improvement of FE reduces the enviromental impact of poultry production. However other than indirect selection, direct selection against emission related traits could also be a possibility to reduce the environmental impact of poultry production. The most significant emissions from poultry production include carbon dioxide (CO2), ammonia (NH3), nitrous oxide (N2O) and methane ( $\mathrm{CH} 4)$ that are considered to be components of global warming that result from feed production, energy use, transport, manure storage and processing and directly from the live animal (MacLeod et al., 2013; Williams et al., 2006). Despite the difficulty to measure these traits, estimation of genetic parameters for emission related traits and quantify genetic correlations with FE traits may help to understand the genetic background of the traits and explore possibilities of direct selection or/and including them in a multi trait selection index with FE traits may be an area that needs to be further explored.

\subsection{Identification of $Q T L$}

Most economically important traits in livestock are highly polygenic, and are controlled by many genes spread throughout the genome, environmental factors, as well as genotype by environment interactions (Gao et al., 2007; Zhu and Zhao, 2007). Body weight and feed efficiency traits are quantitaive traits which are controlled by many genes, each having small effects. In chapter 5 (Mebratie et al., 2019), a number of QTL regions have been reported to be associated with BW and FE traits. This is a remarkable finding, given the fact that the broiler population were pre-selected for 
body weight and undergone several generations of selection for feed efficiency, one may not expect to detect a considerable number of QTL. In fact, this is consistent with our investigation in chapter 3 (Mebratie et al., 2017) in which we reported that the genetic variance of BW were not exhausted after several generations of selection. Although there were an overlap of QTL regions for BW at the three different ages a number of age specific QTL were identified which supports our investigations in chapter 2, 3 and 4 suggesting that genes affecting BW is partially changing with age. Moreover, an overlap of QTL regions and candidate genes were observed for BW measurements taken closer together than far apart which is also in line with our investigations in chapter 2 (Mebratie et al., 2018) and chapter 3 (Mebratie et al., 2017) in which genetic correlations were higher between BW measurements taken closer together than far apart. In this regard, it would be interesting to investigate if there is sex specific QTL for the traits. Unfortunately we had only access to male broilers in our GWAS and we, therefore, could not investigate this.

Inspite of the many success stories of GWAS, one of the challenges in GWA studies is inconsistencies among the results of GWAS reports for the same trait, which may be mainly attributed to aspects such as population size, density of the markers (SNPs), accounting/not accounting for population genetic structure, as well as choice of statistical models and methods (Sharma et al., 2015; Zhang et al., 2012). A number of studies have shown that methods that model family structure, population structure and cryptic relatedness are better interms of reducing type I error than methods that ignore these complexities (Kang et al., 2010; Zhang et al., 2010). Mixed models offer a practical and comprehensive approach for simultaneously addressing confounding due to population stratification, family structure and cryptic relatedness (Gialona et al., 2018; EU-ahsunthornwattana et al., 2014; Price et al., 2010).

In chapter 5 (Mebratie et al., 2019), we have conducted GWAS using a statistical model (Mixed linear model) that takes in to account family structure by using the genomic relationship matrix and compared the results with a general linear model (GLM) which does not take family structure in to account. Although there were overlaps in the detected QTL regions in the two methods, most of the identified QTL regions for BW and FE traits were different suggesting that careful consideration of statistical models in GWAS is important. Moreover, the slightly lower genomic inflation factor values in our analysis than the GLM analysis may suggest that using mixed linear models that takes in to account the existing sample structure may help to reduce type I error and reduce spurious associations than the GLM analysis even if family structure is not a strong concern in the data. 


\subsection{Methods and models for estimation of variance components}

In animal breeding, estimation of variance components is a primary pre-requisite to establish a selection program. One of the problems involved in the application of quantitative genetic theories is accurate statistical estimation of genetic parameters (variance and covariance components). There are different methods of variance component estimation and there is no one method that is uniformly best for all situations (Mašata and Rasch, 2006) because different methods have different statistical properties. The choice of methods depend on the data available for analysis, the objective of the study, the availability of computing resources, and property of the statistical model to be used for analysis. Different methods can be applied in combination with different statistical models. Models are simple approximations to how factors influence a trait. The goal is to find the best practical model that leads to the most accurate inference (Schaeffer, 2011). In chapters 2, 3, and 4 we have used different statistical models and methods for estimation of variance components. Below, the different statistical models and methods used in this thesis are discussed relative to other possible models and methods.

In chapter 2 (Mebratie et al., 2018), our objective was to study genetic parameters for BW in males and females recorded at three different ages considering BW in males and females as well as BW at the three different ages as different traits. Hence, we have used multivariate model which enables estimation of genetic correlations of BW between sexes and ages. Multivariate models (MTMs) are essential for estimation of genetic and phenotypic correlations between traits. Moreover, joint analyses of correlated traits yields more accurate results for a trait of interest by utilizing information from all other traits. One of the advantages of multivariate models is that information on each trait contributes to the accuracy of breeding value prediction in other traits because utilization of the available information increases accuracy and decreases systematic biases in genetic parameters and breeding values. For example accuracy of predicting breeding value for trait 3 might increase when including information on traits 1 and 2 . This is more important when data are not a random sample, i.e. when records for some traits are missing due to selection which is often practical in animal breeding where data is obtained from selection experiments or field records (Meyer, 1991). However, multivariate models have limitations such as being computationally expensive and require more memory and disc space than univariate models. Moreover, MTMs do not increase accuracy if 
heritability of traits are similar in magnitude; genetic and residual correlations are relatively the same in magnitude or sign and when each animal is recorded for all traits (Schaeffer, 2011). Another problem in MTMs is that the number of (co) variance parameters to estimate grows proportional to the square of the number of traits included in the analysis. This increases computation time and for small data sets accurate estimation of parameters will be even more difficult. Hence, joint estimation of many parameters may lead to models with low predictive ability than simpler univariate models.

One can use univariate models to estimate genetic parameters and reduce the computation time, however such models do not enable estimation of genetic correlations between traits rather they implicitly assume that all correlations are 0 or 1 . In addition, the accuracy of estimation may decrease due to the fact that the available information is not utilized. In chapter 2 (Mebratie et al., 2018), we have used multivariate analysis and shown that the heritability estimates of BW are different in males and females as well as the three ages. Furthermore, every animal is not measured for each of the traits because of selection. i.e. the time required for market age reduced due to selection for growth rate, and the weighing age was reduced from $t$ to $t-4$ and $t-7$ days. Thus, birds measured at $t$ days of age did not have records at $t-4$ and $t-7$ days and birds measured at $t-4$ days did not have records at $t$ and $t-7$ days, etc. Therefore, using multivariate models in such cases increases accuracy of estimation due to the arguments justified above.

Nevertheless, MTMs are not optimal for traits that are measured over a trajectory (longitudinal data). For traits that are recorded repeatedly and may change, gradually and continually, as time progresses like growth (body weight), individual records can be considered as points on a trajectory (Meyer, 2004). Thus, an appropriate way of modelling such traits is to fit a set of random coefficients of time or weight for each animal to allow for individual variation across the trajectory (Meyer, 1998). Since using each record at the "age" it was taken is more appropriate than a repeatability model that assumes homogeneous variance and treat records at different "ages" as same traits or multivariate models that assumes hetrogeneous variance and treat records at different "ages" as different traits (Meyer, 2000). In chapter 3 (Mebratie et al., 2017), we have used bivariate random regression model via Gibbs sampling to study the development in genetic variance of BW over a selection trajectory of 39 selection rounds in males and females. To model such kind of data random regression models (RRMs) are more appropriate because they assume the correct variance for each BW records at each selection round whereas MTMs treat all BW records at each SR as if they had variances and genetic parameters equal to that of the target age ( $t$ days of age) (Meyer, 2004). Thus, using 
RRMs increase accuracy compared to MTMs when records occur outside non standard points (target ages) (Bohmanova et al., 2005; Meyer, 2004).

RRMs are commonly used with LeGendre polynomials (LPs) and splines. However, differenet studies have shown than splines have better numerical properties than LPs particularly at the extremes of the trajectory where the number of records is small (Meyer, 2005a; Misztal et al., 2000). In chapter 3 (Mebratie et al., 2017), we have used RRMs with splines and investigated the development in genetic variance of BW over the selection trajectory and showed that the gradual change in genetic variance of BW along a selection trajectory should be modelled as a continuous process using RRMs. Such models are important to investigate the effect of selection on genetic parameters of traits of interest.

In chapter 4, we have employed a multivariate (12-trait) Bayesian analysis to analyse body weight, feed intake and body weight gain in males and females at two different ages simultaneously and derive the two RFI definitions inside the model. The Bayesian analysis used in our study enables estimation of the co (variance) function for phenotypic and genetic RFI using proper distributions of feed intake conditional on production traits in a one-step procedure. This minimizes error in the estimation of regression coefficients compared to the assumption of known co (variance) matrices of component traits in Kennedy et al. (1993). Moreover, the Bayesian onestep procedure ensures that parameter estimation in the regression analysis is not biased by "fixed effects" in the model and by effects due to genetic trends for component traits in the population under investigation (Jensen et al., 2013) compared to the two-step procedure (Koch et al., 1963) where RFI is estimated before the genetic analysis. However, both genetic and phenotypic RFI can be estimated in a standard multivariate REML analysis as well. Nevertheless, such analysis cannot be extended to ratio traits like FCR due to distributional properties of ratio traits.

Methods of estimation of genetic parameters in animal breeding have changed considerably over the last decade. Increasing application of mixed model methodology in genetic evaluation (BLUP) has been followed by progressive use of efficient procedures to estimate variance components. In particular, the animal model has influenced the use of mixed model methodology in the statistical analysis of animal breeding data considerably. The animal model includes a random effect for the additive genetic merit of each animal incorporating all known relationship information in the analysis via the additive genetic relationship matrix. This is important to obtain more accurate predictors and to take in to account effects of selection on prediction and estimation of genetic parameters (Sorensen et al., 1994). In chapter 2, 3 and 4 we have used pedigree based BLUP animal model under 
different settings. In chapter 2 (Mebratie et al., 2018), we have used REML analysis to estimate genetic parameters for BW where as in chapter 3 (Mebratie et al., 2017) and 4 we have used Bayesian analysis via Gibbs sampling to estimate genetic parameters for BW and FE traits. Estimation of genetic parameters needed for BLUP has been largely based on REML analysis using an animal model (Gianola et al., 2018). REML estimators of variance components maximizes the part of the likelihood function, which is independent of fixed effects (Corbeil and Searle, 1976; Patterson and Thompson, 1971) by replacing the data by linear functions also called 'error contrasts', with an expectation of zero (Meyer, 1991). However, the REML analysis does not lead to exact inferences about genetic change when variances are unknown (Sorensen et al., 1994). In contrast the Bayesian analysis makes inferences about breeding values (or functions thereof such as selection response) irrespective of whether variances are unknown, using the marginal posterior distribution of the vector of breeding values or from the marginal posterior distribution of selection response. In the Bayesian analysis, all other unknown parameters, such as 'fixed effects' and variance components or heritability, are considered as nuisance parameters and must be integrated out of the joint posterior distribution (Gianola et al., 1986).

The Bayesian analysis yields a Monte-Carlo estimate of the full marginal posterior distribution of a parameter of interest, from which probabilities that the parameter lies between specified values can be computed. This is particularly relevant in the case where the asymptotic normality of posterior distributions is difficult to justify, which can often be the case in selection experiments (Sorensen et al., 1994). Nevertheless, the Bayesian approach is computationally demanding in terms of computation time and the rate of convergence can be extremely slow, especially when there is high correlation between random effects, which is often the case in animal models. However, the cost of the additional computation time needed to conduct the Bayesian analysis is negligible relative to the total cost of the selection experiment (Sorensen et al., 1994).

\subsection{Correlated effects of improved growth rate and feed efficiency}

Genetic selection for improved growth rate, feed efficiency, and carcass yields have considerably changed the morphology and physiology of broiler chickens. In just 6 weeks, modern broilers undergo a 50-fold multiplication in body weight from hatching to slaughter weight (Tickle et al., 2014). Growth rates in commercial broiler 
chickens have consistently increased such that a $300 \%$ increase has been acheived in the past 60 years, from $25 \mathrm{~g}$ per day in the 1950's to $100 \mathrm{~g}$ per day in the modern broiler (Knowles et al., 2008). However, selection for rapid growth and improved feed efficiency is associated with unintended consequences resulting from disruption of physiological equilibria (Chambers, 1990). This may compromise the welfare of broilers and could limit further improvement in growth rate and feed efficiency (Tickle et al., 2014). The major unintended consequences of selection for growth rate and feed efficiency in broiler chickens that can reduce performance and compromise their welfare can be classified as physiological, skeletal, reproductive and immunological consequences. Each of them are discussed below.

Physiological consequences: One of the physiological consequences of increased growth rate is pulmonary hypertension that leads to ascites, which is accumulation of fluid in the abdomen (water belly). Pulmonary hypertension is characterized by increased blood flow, hypertrophy of the right ventricle, valvular insufficiency, increased venous pressure which leads to ascites (Julian, 1993). Pulmonary hypertension syndrome (PHS) is related to increased metabolic oxygen requirement due to insufficient oxygen supply to the tissues of the rapidly growing broilers, i.e. any factor that increases oxygen requirement increases ascites incidence caused by PHS (Julian et al., 1989; Julian et al., 1987). Rapid growth has been signalled as a cause for increased ascites due to increased metabolic oxygen requirement related to it (Pakdel et al., 2005; Currie, 1999; Julian, 1993; Scheele et al., 1992; Scheele et al., 1991). Large and heavy breast of modern broilers together with the pressure of abdominal contents on air sacs are reported to be involved in the development of PHS that leads to ascites (Julian, 1998). Furthermore, broilers selected for high BW and lower FCR are less flexible in metabolic adaptation to a changing environment (e.g. low temperature, high altitude) which could be a cause for ascites (Julian, 2000; Scheele, 1996; Scheele et al., 1991). Genetic selection for growth rate in broilers has not only led to higher BW but resulted in allometric changes; decreased heart and lung size relative to the rest of the body (Ducuypere et al., 2000; Julian, 1998) which causes inability of the heart and lungs to deliver sufficient oxygen to tissues and inturn makes the birds susceptible to ascites.

Improved feed efficiency results in decreased metabolic rate, which inturn leads to low oxygen consumption (Decuypere et al., 2000). Broilers which are selected for low oxygen consumption has been reported to show high feed efficiency (Steward et al., 1980) and low thyroid gland activity (Buys et al., 1999) which is associated with regulation of metabolic rate. Thus improved feed efficiency in broilers is associated with low oxygen consumption leading to ascites (Luger et al., 2001; Decuypere et al., 2000). Ascites mortality is late occurring, after a significant amount of feed and 
labour has been committed (Anthony, 1998), hence, it has has a great economic impact in the broiler industry. It has been reported that ascites results $25 \%$ of broiler losses and an economic loss of about 1 billion US dollar annually worldwide (Navarro et al., 2002; Maxwell and Robertson, 1997).

Considerable genetic variation exists between and within broiler lines in susceptibility of ascites (Deeb et al., 2002). To this end, breeding companies are working to reduce these physiological limitations through selection. A number of breeding programs have included ascites in the breeding objective and remarkable success has been acheived in reducing the incidence of ascites. Hence, levels of ascites in the field are now greatly decreased, even at high altitudes (Pym, 2008). Nevertheless, breeding companies need to give further emphasis in reducing ascites and other physiological problems related to higher growth rate and improved feed efficiency.

Together with increased body weight, an increase in fat deposition is also reported which influences carcass composition (Havenstein et al., 2003a ; Havenstein et al., 1994b) and slightly reducing feed efficiency due to higher energetic cost of synthesizing adipose tissue. This fat deposition could be a consequence of increased concentrations of insulin and glucagon in plasma (Sinsigalli et al., 1987). Abdominal fat is highly heritable (Siegel, 1959), and breeding programs have been selecting against it for quite some time (Laughlin, 2007; Muir and Aggrey, 2003). Hence, significant improvement is achieved due to commercial selection pressures on reducing fatness (Zuidhof et al., 2014; Fleming et al., 2007). The decrease in fat composition was also attributed to improved feed efficiency and improved diet (Tallentire et al., 2016). Due to genetic and nutritional improvements, it is reported that tody's broilers have leaner body composition by the time they reach slaughter weight than broilers in the recent decades (Tallentire et al., 2016; Fleming et al., 2007; Havenstein et al., 2003a).

Immunological consequences: Selection for increased growth rate and feed efficiency is also reported to have consequences on the immune response. Havenstein (1994a, 1994b) compared the immune response of Ross 308 which is a representative of modern broiler line and a random bred ACRBC line which is representative of broilers from 1950s. Results showed higher Immunoglobulin G (IgG) and Immunoglobulin M (IgM) antibody production in the ACRBC line. Similar results were also reported due to genetic selection for growth rate in turkeys (Nestor et al., 1996). In comparing mortality of a random bred line and three commercial lines of turkeys selected for growth rate, Nestor et al. (1996) reported $26 \%$ mortality in the random bred control line while the mortality of the commercial lines ranged from 54 to $65 \%$. Causes of mortality associated with fast growth are mainly related 
to ascites (Maxwell and Robertson, 1997) and sudden death syndrome (SDS) (Gardiner et al., 1988). Regarding SDS male broilers are generally more susceptible than female broilers (Grashorn et al., 1998) probably due to higher growth rate of males than females. Although the physiological mechanisms causing SDS are not quite clear, growth rate is believed to be the primary cause. Birds with the syndrome die within a short period of time; the first sign of unrest until death reported to be from 37 to 69 seconds (Newberry et al., 1987).

Skeletal problems: Various skeletal disorders have been reported to be related to rapid growth of broiler chickens (Julian, 1998; Lilburn, 1994). Rapid growth may be the main factor in defects occurring up to about 4 weeks of age, after which high body weight produces more stress on the bones, tendons and ligaments (Thiruvenkadan et al., 2011). Among the skeletal problems, tibial dyschondroplasia, spondylolisthesis, osteodystrophy, epiphyseal ischaemic necrosis, epiphyseal separation, skeletal fracture, gastrocnemius tendon rupture, valgus and varus deformities (twisted leg) are the most common disorders (Bessie et al., 2006). Most of them are found in the locomotor system (Bessie et al., 2006). For example, tibial dyschondroplasia (TD) is growth-related abnormality that occurs when transitional chondrocytes accumulate, forming a mass of a vascular cartilage underlying the layer of proliferative chondrocytes, often in the proximal tibia (Eu-ahsunthornwattana et al., 2011). Havenstein et al. (1994b) compared the incidence of TD in a 1991 strain which is a representative of modern broilers with a 1957 strain and reported that the incidence of TD in 1991 and 1957 strains was $47.5 \%$ and 1.2\%, respectively. Different studies (Kuhlers and Mcdaniel, 1996; Ducro and Sorensen, 1992) have reported moderate heritability for TD, Valgus and Varus deformities (Le Bihan-Duval et al., 1996) suggesting possibility of genetic improvement of the traits through genetic selection. Indeed, selection based on gait, morphology and X-ray imaging has done much to reduce the expression of conditions such as TD, spondylolisthesis and valgus and varus deformities in most commercial strains of broilers, but skeletal abnormalities still continue to be a major focus in most broiler breeding programs (Pym, 2008).

Reproductive consequences: Selection for high juvenile body weight is reported to influence reproductive traits in males and females. Marks (1985) reported that high juvenile BW is negatively correlated to spermatozoa motility. In comparing, broilers with high and low body weight lines the authors reported that the high body weight line had more dead and abnormal spermatozoa with a lower concentration of spermatozoa in semen than the low body weight line. Increased growth rate has also consequence on breeders such that breeders rapidly become obese (Dunnington \& Siegel, 1985); the males have reduced fertility (McGary et al., 2002), poor libido 
(Bilcik \& Estevez, 2005) and lower mating frequencies (Schmidt et al., 1994) while the females have multiple ovulation (Hocking et al., 1987) and decreased egg production (Robinson et al., 1991) as well as reduced fertility and hatchability (Schmidt et al., 1998).

In general, breeding companies have become successful in reducing some of these unintended consequences of growth rate and feed efficiency such as ascites and carcass fatness, however, there are still reports of higher mortality and suceptability to suboptimal management of nutrition and environment in highly selected commercial broilers than those that are less selected for growth rate and feed efficiency. Thus, further work needs to be done on reducing these negative consequences by including those traits in the selection goal. Otherwise, the disruption of physiological homeostasis might ultimately result in economic and genetic barriers in further improving growth rate and feed efficiency. Moreover, these negative consequences are increasingly raising serious animal welfare issues and become concerns of considerable consumer segments. Thus, further understanding of the biological basis of these consequences is essential to design breeding programs that aim to reduce unintended consequences or prevent them from progressing further. In such cases, genomics could play a role to unravel the biological mechanisms and support breeders in selection programs.

\subsection{Has genetic level reached a plateau?}

It has been speculated that genetic progress at the present rate and for the current main traits like growth rate and feed efficiency in broiler chickens will only be possible for a limited period of less than two decades (Albers, 1998). Even though the speculated period is over and broilers continue to show genetic progress a number of scientists in the area still seem to agree that a plateau will be reached soon and broilers are near to their physiological limits especially in terms of the main breeding goal traits in the industry such as growth rate and feed efficiency. I do not have strong argument on the speculation, however, in this section areas that seem promising to further exploit the genetic potential of broilers which are directly or indirectly related to growth rate and FE are discussed.

In theory, intense selection of traits having moderate to high heritabilities such as growth rate and feed efficiency is expected to narrow the genetic variation, and a close to zero value of genetic variance would be approached. As a result, the heritability estimates and response to selection are also expected to diminish (Falconer and Mackay, 1996). In chapter 3 (Mebratie et al., 2017), we have shown that the genetic variance of BW did not exhausted after several generations of 
selection for growth rate, rather an increase in genetic variance across the selection trajectory was observed. Moreover the heritability estimates of BW found in our study and reported in several other studies suggest that further improvement in growth rate and feed efficiency can be achieved through selective breeding. The increase in genetic variance for BW after several generations of selection may be attributed to accumulation of new mutations and also epistatic effects. In fact, results from long term selection experiments provide little evidence of long term genetic plateaus, and suggest that plateaus are only temporary when they do occur (Marks, 1991). This is also in line with our results in chapter 5 (Mebratie et al., 2019) where we have identified several loci and candidate genes associated with BW and FE traits, even though birds were pre-selected for BW and undergone several generations of selection for FE. Indeed, BW and FE traits are quantitative traits influenced by many genes which therefore do not go to fixation quickly.

To further improve BW and FE traits as well as to address related welfare issues, the unintended negative consequences of high growth rate and feed efficiency should be alleviated. For this, genomics could play a great role in understanding the biological basis and alleviating the negative consequences of improved growth rate and feed efficiency. In this regard, It might also be important to detect linkages between DNA markers and QTL associated with growth rate and FE as well as fitness traits such as metabolic disorders, skeletal problems and disease susceptibility to improve animals simultaneously in both categories of traits. In this way sustainability of broiler production can also be achieved.

In addition to genomic selection, the negative consequences of increased growth rate such as disease susceptibility may be solved by the availability of precision genome engineering tools such as genome editing. Using genome editing, SNPs or gene variants associated with a specific disease, can be introduced into a desired line of genetics in a single step rather than waiting several reproductive rounds (Doran et al., 2016). This reduces the time taken to introduce resilience to specific diseases that may threaten the poultry industry (Doran et al., 2016). However, there might be ethical concerns and public acceptance issues which should be properly dealt and communicated. If desired SNPs or variants already exist within the species, introduction of genes within the species rather than exogenous genes could be one way of challenging the public concern.

Furthermore, gene editing could also contribute in sex determination of broilers before hatching unlike the conventional way of sex determination such as manual sexing or colour feather identification after hatching. It is reported that male broilers have higher BW (growth rate) than females at a given age. For example, Emmerson (1997) reported that male broiler lines are 30-40\% heavier than female broiler lines 
while Singh (1989) reported male chickens to be $15-20 \%$ heavier than females at the same age. Therefore, gene-editing technology could help to selectively hatch male broiler chicks thereof increase the profitability of the industry. For example in the layer industry, Doran et al. (2016) suggested a possibility of editing the Z chromosome in females so that males can be identified and excluded before hatching to mainly address ethical issue in which males are culled after hatching (Doran et al., 2016). In poultry, males are homogametic (ZZ) and females are heterogametic (ZW). According to Doran et al. (2016), if a marker gene (e.g. with coloured flourecent protein) can be sited specifically engineered in to the $Z$ chromosome in the female, then males (ZZ) crossed with females (WZ*) would yield offsprings, $Z Z^{*}, Z Z^{*}, Z W$, and $Z W$, hence, all male embryos will carry the marker gene and female embryos will be free of the marker gene. This could be detected easily in a freshly laid egg using lighting. In this way, it is possible to exclude male broilers in the layer industry before hatching. Thus, there might be a possibility to modify this technology a little bit and extend to the broiler industry.

Furthermore, combined crossbred and purebred selection (CCPS) is an area that could be exploited in broilers. It is suggested that including the information recorded on purebreds as well as crossbreds in selection programs might help in improving the response to selection in crossbreds (Bijma et al., 1998; Wei and van der Werf, 1994). Bijma et al. (1998) reported that including information of crossbred halfsibs while estimating breeding values for the purebred selection candidates increases accuracy of selection. In fact, the superiority of CCPS over purebred or crossbred selection is determined by the genetic correlation between purebreds with combined purebred and crossbred performance (rpc) as well as the heritability of the crossbreds (Wei and van der Werf, 1994). Superiority of CCPS over purebred selection increases with decreasing rpc while superiority of CCPS over crossbred selection decreases with decreasing rpc (Wei and van der Werf, 1994). Moreover response of CCPS and crossbreds is reported to increase with increasing heritability of crossbreds relative to purebreds (Wei and van der Werf, 1994). However for very large values of $\mathrm{rpc}(>0.8)$, CCPS is reported to be worse than purebred selection (Wei and van der Werf, 1994). Thus, CCPS could be a strategy that could help to further exploit the genetic potential of broiler chickens.

Finally there is an issue of maintaining genetic diversity. The majority of breeding populations in broilers are controlled by a limited number of breeding companies, thus genetic diversity may be a concern in the future. As the genetic relatedness between parents increases, the probability that pairs of alleles in an offspring are copies of a single allele in a common ancestor increases (Koenig and Simianer, 2006). Those alleles which are identical by descent have negative effects such as loss in 
genetic variability, higher chance of appearance of detrimental recessive genes in the homozygous state, and inbreeding depression (Falconer and Mackay, 1989). It is reported that $50 \%$ or more of the genetic diversity in ancestoral breeds is lost in commercial pure lines (Muir et al., 2008), suggesting that looking for genotypes outside the current commercial stock could be important. In this regard, breeding companies should keep utilizing tools to recapture variation such as outcrossing, importing genetic material from a relatively unrelated stock, optimum contribution selection and development of synthetic lines in addition to utilizing large population size so as to avoid inbreeding and maintain genetic diversity.

\subsection{Conclusions}

This thesis has explored the genetics of BW and FE traits using different statistical models and methods. It is shown that, in addition to direct genetic effect, maternal environmental effect and other environmental effects, BW and FE traits in broiler chickens are influenced by sex by genotype interaction as well as age by genotype interaction. Furthermore, we have shown that the genetic variance of BW did not exhaust after several generations of selection rather an increase in genetic variance has been observed along the selection trajectory. This was also supported by our GWAS results in which we have identified several QTL regions and candidate genes associated with BW and FE traits using a broiler population that has been preselected for BW and undergone several generations of selection for FE. This suggests that BW and FE traits are influenced by many genes, which do not go to fixation quickly. Hence, we have shown that inspite of the long history of selection for BW and FE traits, there is still available genetic variation for these traits which enables further improvement of the traits through selective breeding. However, further improvement should be implemented considering sustainability of the industry in away that reduces the conflict between high production efficiency and welfare of broilers. In this regard further investigations using tools such as genomics may help to understand the biological basis of the consequences thereby alleviate the unintended negative consequences of improved growth rate and feed efficiency. 


\section{References}

Adeyinka IA, Oni OO, Nwagu BI, and Adeyinka FD. 2006. Genetic Parameter Estimates of Body Weights of Naked Neck Broiler Chickens. International Journal of Poultry Science. 5 (6): 589-592.

Aggrey SE and Cheng KM. 1993. Genetic and posthatch parental influences on growth of pigeons squabs. Journal of Heredity. 84: 184-187.

Aggrey SE, Karnuah AB, Sebastian B, Anthony NB. 2010. Genetic properties of feed efficiency parameters in meat-type chickens. Genet. Sel. Evol. 42: 25.

Albers GAA. 1998. Future trends in poultry breeding. In: 10th European Poultry Conference, Jerusalem, June 21-26: Proceedings Volume I. World's Poultry Science Associa- tion, Israel Branch, pp. 16-20.

Anthony NB. 1998. A review of genetic practices in poultry: efforts to improve meat quality. Journal of Muscle Foods. 9:25-33.

Aslam ML, Bastiaansen JW, Crooijmans RP, Ducro BJ, Groenen MA, Vereijken A. 2011. Genetic variances, heritabilities aAnd maternal effects on body weight, breast meat yield, meat quality traits and the shape of the growth curve in turkey birds. BMC Genet. 12:14.

Begli H, Vaez Torshizi R, Masoudi AA, Ehsani A. 2016. Longitudinal analysis of body weight, feed intake and residual feed intake in F2 chickens. Livest. Sci. 184: 28-34.

Berry D. and Crowley J. 2012. Residual intake and body weight gain: A new measure of efficiency in growing cattle. Journal of Animal Science. 90: 109-115.

Bessie W. 2006. Welfare of broilers, a review. World's Poultry Science Journal 62(03):455-466.

Bijma P, Arendonk JAM. 1998. Maximizing genetic gain for the sire line of a crossbreeding scheme utilizing both purebred and crossbred information. Animal Science. 66:529-542.

Bilcik B and Estevez I. 2005. Impact of male-male competition and morphological traits on mating strategies and reproductive success in broiler breeders. Applied Animal Behaviour Science. 92:307-323.

Bohmanova J, Misztal I, Bertrand JK. 2005. Studies on multiple traits and random regression models for genetic evaluation of beef cattle for growth. J. Anim. Sci. 500 (83): 62-67.

Brommer JE and Class B. 2015. The importance of genotype-by-age interactions for the development of repeatable behavior and correlated behaviors over lifetime. Frontiers in Zoology. 12(Suppl 1):S2 
Bulmer MG. 1971. The Effect of Selection on Genetic Variability. The American Naturalist. 943:201-211.

Buys N, Scheele CW, Kwakernak C and Decuypere E. 1999. Performance and physiological variables in broiler chicken lines differing in susceptibility to the ascites syndrome: 2. Effect of ambient temperatures on partial efficiencies of protein and fat retention and plasma hormone concentration. British Poultry Science. 40: 140-144.

Chambers JR. 1990. Genetics of growth and meat production in chickens. Pages 599643 in: Poultry Breeding and Genetics. R. D. Crawford, ed. Elsevier Science Publishing Co., New York, NY.

Chapuis H, Delabrosse Y, Ducroc V, Tixer-Boichard M. 1996. Multivariate restricted maximum likelihood estimation of genetic parameters for production traits in three selected turkey strains. Genet. Sel. Evol. 28: 299-317.

Corbeil RR and Searle SR. 1976. Restricted Maximum Likelihood (REML) Estimation of Variance components in the Mixed Model. 18: 31-38.

Currie RJW. 1999. Ascites in poultry: recent investigations. Avian Pathol. 28:313 326.

Decuypere E, Buyse J and Buys N. 2000. Ascites in broiler chickens: exogenous and endogenous structural and functional causal factors. World's Poultry Science Journal. 56: 367-377.

Deeb N and Lamont SJ. 2002. Genetic Architecture of Growth and Body Composition in Unique Chicken Populations. The American Genetic Association. 93:107-118.

Deeb N, Shlosberg A and Cahaner A. 2002. Genotype-by-environment interaction with broiler genotypes differing in growth rate. 4. Association between responses to heat stress and to cold-induced ascites. Poultry Science. 81: 1454-1462.

Difford GF, Plichta DR, Løvendahl P, Lassen J, Noel SJ, Højberg O, et al. 2018. Host genetics and the rumen microbiome jointly associate with methane emissions in dairy cows. PLoS Genet 14(10): e1007580.

Doran T, Challagulla A, Cooper C, Tizard M, and Jenkins K. 2016. Genome Editing and the Future of Farming. National Institutes of Bioscience Journal. Vol. 1. http://www.nibjournal.ed.ac.uk/article/view/1742.

Ducro BJ and Sorenson P. 1992. Evaluation of a selection experiment on tibial dyschondroplasia in broiler chickens. Proc. XIX World's Poultry Congress, Dutch Branch of the WPSA, Amsterdam. 2:386-389.

Dunnington EA and Siegel PB. 1985. Long-term selection for eight-week body weight in chickens: direct and correlated responses. Theoretical Applied Genetics. 71: 305-313. 
Emmerson, DA. 1997. Commercial Approaches to Genetic Selection for Growth and Feed Conversion in Domestic Poultry. Poultry Science. 76:1121-1125.

Thiruvenkadan AK, Prabakaran R and Panneerselvam S. 2011. Broiler breeding strategies over the decades: an overview. World's Poultry Science Journal. 67: 309-336.

Eu-ahsunthornwattana J, Miller EN, Fakiola M, Wellcome Trust Case Control Consortium 2, Jeronimo SMB, Blackwell JM, et al. 2014. Comparison of Methods to Account for Relatedness in Genome-Wide Association Studies with Family-Based Data. PLoS Genet 10(7): e1004445. https://doi.org/10.1371/journal.pgen.1004445.

Fairfull RW and Chambers RJ. 1984. Breeding for feed efficiency: poultry. Can. J. Anim. Sci. 64:513-527.

Falconer DS \& Mackay TFC. 1996. Introduction to quantitative genetics. Harlow: Longman.

Fleming EC, Fisher C, McAdam J. 2007. Genetic progress in broiler traits implications for body composition In: Proceedings of the British Society of Animal Science, Southport, UK p 67.

Gao Y, Hu XX, Du ZQ, Deng XM, Huang YH, Fei J, Feng JD, Liu ZL, Da Y and Li N. 2006. A genome scan for quantitative trait loci associated with body weight at different developmental stages in chickens. Animal Genetics. 37: 276-278.

Gardiner EE, Hunt JR and Newberry RC. 1988. Relationship between age, body weight and season of the year and the incidence of sudden death syndrome in male broiler chickens. Poultry Science. 67:1243-1249.

Gianola D, Fernando RL. 1986. Bayesian methods in animal breeding. J Anim. Sci. 63: 217-244.

Gianola D, Cecchinato A, Naya H and Schön C-C. 2018. Prediction of Complex Traits: Robust Alternatives to Best Linear Unbiased Prediction. Front. Genet. 9:195.

Grashorn M, Bessei W, Thiele HA and Seemann G. 1998. Inheritance of Troponin T levels in meat-type chicken. Archiv für Geflügelkunde 62: 283-286.

Gunsett F. 1984. Linear index selection to improve traits defined as ratios. Journal of Animal Science. 59: 1185-1193.

Gutierrez-Adan A, Perez-Crespo M, Fernandez- Gonzalez R, Ramirez M, Moreira P, Pintado B, Lonergan P, Rizos D. 2006. Developmental consequences of sexual dimorphism during pre-implantation embryonic development. Reprod. Domest. Anim. 41:54-62. 
Havenstein GB, Ferket PR, Scheideler SE and Larson BT. 1994a. Growth, livability, and feed conversion of 1957 vs 1991 broilers when fed "typical" 1957 and 1991 broiler diets. Poult. Sci. 73:1785-1794.

Havenstein GB, Ferket PR, Scheideler SE and Rives DV. 1994b. Carcass composition and yield of 1991 vs 1957 broilers when fed "typical" 1957 and 1991 broiler diets. Poult. Sci. 73:1795-1804.

Havenstein GB, Ferket PR, and Qureshi MA. 2003a. Carcass composition and yield of 1957 versus 2001 broilers when fed representative 1957 and 2001 broiler diets. Poult. Sci. 82:1509.

Hill GW. 2000. Maintenance of quantitative genetic variation in animal breeding programmes. Livestock Prod Sci . 63:99-109.

Hocking PM, Gilbert AB, Walker M and Waddington D. 1987. Ovarian follicular structure of white leghorns fed ad libitum and dwarf and normal broiler breeders fed ad libitum or restricted until point of lay. Poultry Science. 28: 493-506.

Howie J, Avendano S, Tolkamp B and Kyriazakis, I. 2011. Genetic parameters of feeding behavior traits and their relationship with live performance traits in modern broiler lines. Poultry Science. 90: 1197.

Jensen J. 2013. Joint estimation for curves for weight, feed intake, rate of gain, and residual feed intake. 601. EAAP $64^{\text {th }}$ Meeting. Book of abstracts, 531.

Julian R, Friars G, French H, Quinton M. 1987. The relationship of right ventricular hypertrophy, right ventricular failure, and ascites to weight gain in broiler and roaster chickens. Avian Dis. 31:130-135.

Julian RJ, McMillan I, and Quinton M. 1989. The effect of cold and dietary energy on right ventricular hypertrophy, right ventricular failure and ascites in meattype chickens. Avian Pathol. 18: 675-684.

Julian RJ. 1993. Ascites in poultry. Avian Pathol. 22:419-454.

Julian R. 1998. Rapid growth problems: ascites and skeletal deformities in broilers. Poult. Sci. 77:1773-1780.

Julian, RJ. 2000. Physiological, management and environmental triggers of the ascites syndrome: A review. Avian Pathology. 22: 519-527.

Kang HM, Sul JH, Service SK, Zaitlen NA, Kong S, Friemer NB, Sabatti C and Eskin E. et al. 2010. Variance component model to account for sample structure in genome wide association studies. Nat. Genet. 42: 348-354.

Katanbaf MN, Siegel PB, Dunnington EA. 1988b. Organ growth of selected lines of chickens and their $F$ crosses to a common body weight or age. Theor. Appl. Genet. 76: 540-544. 
Keightley PD. 1998. Genetic Basis of Response to 50 Generations of Selection on Body Weight in Inbred Mice. Genetics. 148: 1931-1939.

Kennedy BW, van der Werf JH, Meuwissen TH. 1993. Genetic and statistical properties of residual feed intake. Journal of Animal Science. 71:32393250.

Knowles TG, Kestin SC, Haslam SM, Brown SN, Green LE, Butterworth A, Pope SJ, Pfeiffer D, and Nicol CJ. 2008. Leg disorders in broiler chickens: prevalence, risk factors and prevention. PLoS ONE 3:e1545.

Koch RM, Swiger LA, Chambers D, Gregory KE. 1963. Efficiency of Feed Use in Beef Cattle. Journal of Animal Science. 22: 486-494.

Koenig S and Simianer H. 2006. Approaches to the management of inbreeding and relationship in the German Holstein dairy cattle population. Livestock Science. 103: 40-53

Koerhuis ANM and Thompson R. 1997. Models to estimate maternal effects for juvenile body weight in broiler chickens. Genet. Sel. Evol. 29: 225-249.

Koerhuis ANM, McKay JC, Hill WG and Thompson R. 1997. A genetic analysis of egg quality traits and their maternal influence on offspring-parental regressions of juvenile body weight performance in broiler chickens. Genet. Sel. Evol. 49: 203-215.

Kuhlers DL and Mcdaniel GR. 1996. Estimates of heritabilities and genetic correlations between tibial dyschondroplasia expression and body weight at two ages in broilers. Poultry Science. 75: 959-961.

Laird AK. 1966. Postnatal growth of birds and mammals. Growth 30:349-363.

Laughlin K. 2007. The evolution of genetics, breeding and production. Harper Adams University College, Newport, Shropshire, TF10 8NB.

Le Bihan-duval E, Beaumont C and Colleau JJ. 1996. Genetic parameters of twisted legs syndrome in broiler chickens. Genetics Selection and Evolution. 28: 177-195.

Le Bihan-duval E, Mignon-grasteau S, Millet N \& Beaumont C. 1998. Genetic analysis of a selection experiment on increased body weight and breast muscle weight as well as on limited abdominal fat weight, British Poultry Science, 39 (3): 346-353. DOI: 10.1080/00071669888881.

Lilburn MS. 1994. Skeletal growth of commercial poultry species. Poult. Sci. 73: 897903.

Liu G, Dunnington EA and Siegiel PB. 1993. Maternal effects and heterosis for growth in reciprocal cross populations of chickens. Journal of Animal Breeding and Genetics. 110: 423-428. 
Liu H, Sorensen AC, Meuwissen THE, Berg P. 2014. Allele frequency changes due to hitch- hiking in genomic selection programs. Genet. Sel. Evol. 46: 1-14.

Luger D, Shinder D., Rzepakovsky V, Rusal M and Yadav S. 2001. Association between weight gain, blood parameters and thyroid hormones and development of ascites syndrome in broiler chickens. Poultry Science. 80: 965-971.

MacLeod M, Gerber P, Mottet A, Tempio G, Falcucci A, Opio C, Vellinga T, Henderson B \& Steinfeld H. 2013. Greenhouse gas emissions from pig and chicken supply chains - A global life cycle assessment. Food and Agriculture Organization of the United Nations (FAO), Rome.

Mašata $O$ and Rasch D. 2006. Methods of variance component estimation. Czech J. Anim. Sci. 51 (6): 227-235.

Marks H. 1985. Direct and correlated responses to selection for growth. Poultry Genetics and Breeding.

Marks HL. 1991. Eight-five generations of selection for high four-week body weight in Japanese quail. Pages 113-132 in: Proceedings of the Fortieth Annual National Poultry Breeders Roundtable. St. Louis, MO.

Maxwell MH and Robertson GW. 1997. World Broiler Ascites Survey. 1996. Poultry International 36: 16-30.

McGary S, Estevez I, Bakst MR and Pollock DL. 2002. Phenotypic traits as reliable indicators of fertility in male broiler breeders. Poultry Science 81: 102-111.

Mebratie W, Shirali M, Sapp RL, Madsen P, Hawken R, Jensen J. 2017. The effect of selection and sex on genetic parameters of body weight in a commercial broiler chicken population. Livestock scie. 204: 78-87.

Mebratie W, Madsen P, Hawken R, Jensen J. 2018. Short communication: Multi-trait estimation of genetic parameters for body weight in a commercial broiler chicken population. Livestock Science 217:15-18.

Mebratie W, Reyer H, Wimmers K, Bovenhuis H, Jensen J. 2019. Genome wide association of body weight and feed efficiency traits in a commercial broiler population, a re-visitation. 9: 922. Doi: 10.1038/s41598-018-37216-z.

Meyer K. 1991. Estimating variances and covariances for multivariate animal models by restricted maximum likelihood. 1991. Gen. Sel. Evol. 23: 67-83.

Meyer K. 1998. Modelling 'repeated' records: covariance functions and random regression models to analyse animal breeding data. In: Proceedings of the $6^{\text {th }}$ World Congress Genetics Applied Livestock Production, vol. 25. Armidale, Australia, pp. 517-520.

Meyer K. 2000. Random regressions to model phenotypic variation in monthly weights of Australian beef cows. Livestock Production Science. 65: 19-38. 
Meyer K. 2004. Scope for a random regression model in genetic evaluation of beef cattle for growth. Livest. Prod. Sci. 86: 68-83.

Meyer K. 2005a. Estimates of genetic covariance functions for growth of Angus cattle. J. Anim. Breed. Genet. 122: 73-85.

Misztal I, Strabel T, Mantysaari EA, Meuswissen THE, Jamrozik J. 2000. Strategies for estimating the parameters needed for different test-day models. J. Dairy Sci. 83: $1125-1134$.

Mignon-Grasteau S, Beaumont C, Le Bihan-Duval E, Poivey JP, Rochambeau H and Ricard FH. 1999. Genetic parameters of growth curve parameters in male and female chickens. British Poultry Science. 40: 44-51.

Mignon-Grasteau S, Muley N, Bastianelli D, Gomez J, Peron A, Sellier N, Millet N, Besnard J, Hallouis J and Carre B. 2004. Heritability of divergent selection and digestibilities for digestion ability in growing chicks fed a wheat diet. Poult. Sci. 83:860-867.

Morton JR. 1973. Analysis of gene action in the control of body weight in the chicken. Heredity. 31(2): 165-180.

Muir WM, Aggrey SE, eds. 2003. Poultry Genetics, Breeding and Biotechnology. Oxfordshire, UK: CABI. 706 pp.

Muir WM, Wong GK, Zhang Y, Wang J, Groenen MAM, Crooijmans RPMA, et al. 2008. Genome wide assessment of worldwide chicken SNP genetic diversity indicates significant absence of rare alleles in commercial breeds. Proceedings of the National Academy of Sciences USA 105: 17312-17317.

Navarro P, Koerhuis ANM, Chatziplis D, Vissche PM and Haley CS. 2002. Genetic studies of ascites in a broiler population. Proc. $7^{\text {th }}$ World Congress on Genetics Applied to Livestock Production, Montpellier, France, August 1923, 2002.

Nestor K, Saif Y, Zhu J, and Noble D. 1996. Influence of growth selection in turkeys on resistance to Pasteurella multocida. Poult. Sci. 75:1161-1163.

Newberry RG, Gardiner EE and Hunt JR. 1987. Behaviour of chickens prior to death from sudden death syndrome. Poultry Science 66: 1446 -1450.

Poissant J, Wilson AJ, Coltman DW. 2009. Sex-specific genetic variance and the evolution of sexual dimorphism: a systematic review of cross-sex genetic correlations. Evolution 64-1: 97-107.

Patterson HD and Thompson R. 1971. Recovery of Inter-Block Information when Block Sizes Are Unequal. Biometrika. 58: 545-54.

Prado-Gonzalez EA, Ramirez-Avila L, Segura-Correa JC, 2003. Genetic parameters for body weights of Creole chickens from Southeastern Mexicou singan animal model. Livest. Res. Rural. Dev. 15: 1-7. 
Price AL, Zaitlen NA, Reich D \& Patterson N. 2010. New approaches to population stratification in genome-wide association studies. Nat. Rev. Genet. 11, 459463.

Pym R. 2008. Poultry genetics and breeding in developing countries. http://www.fao.org/3/a-al726e.pdf.

Robinson FE, Robinson NA and Scott TA. 1991. Reproductive performance, growth and body composition of full-fed versus feed restricted broiler breeder hens. Canadian Journal of Animal Science. 71: 549-556.

Robinson DL. 1994. Models which might explain negative correlations between direct and maternal genetic effects. In: Proc 5th World Congr Genet Appl Livest Prod Guelph Canada.

Robinson DL. 1996. Estimation and interpretation of direct and maternal genetic parameters for weights of Australian Angus cattle. Livest. Prod. Sci. 45:1-11.

Roehe R and Kennedy W. 1993. The influence of maternal effects on accuracy of evaluation of litter size in swine. J Anim Sci. 71: 2353-2364.

Romero LF, Zuidhof MJ, Renema RA, Naeima AN and Robinson FE. 2009b. Effects of maternal energetic efficiency on egg traits, chick traits, broiler growth, yield, and meat quality. Poultry Science. 88: 236 -245.

Schaeffer L. 2011. Animal models. Random regression models. Course notes. http://animalbiosciences.uoguelph.ca/ /rs/ABModels/notesx.html Accessed on 12-11- 2018.

Scheele C, De-Wit W, Frankenhuis M and Vereijken P. 1991. Ascites in Broilers. Poult. Sci. 70:1069-1083.

Scheele C, Decuypere E, Vereiken P, and Schreurs F. 1992. Ascites in Broilers. Poult. Sci. 71:1971-1984.

Schmidt GS, Figueiredo EAP, Ledur MC and Fairfull RW. 1994. Selection for reproductive traits in a white egg stock breeding programme. Proc. $5^{\text {th }}$ World Congress on Genetics Applied to Livestock Production, University of Gulph, August 7-12, 1994.

Schmidt GS, Figueiredo EAP, Ledur MC and Munari DP. 1998. Correlated response on reproductive traits when broiler lines are selected for body weight. Proc. $6^{\text {th }}$ World Congress on Genetics. Applied to Livestock production, Armidale, Australia, January 11-16, 1998.

Schmidt GS, Figueiredo EAP, Ledur MC and Alves HJ. 2003. Effect of selection for productive traits in broiler maternal lines on embryo development. Brazilian Journal of Poultry Science. 5:125-129. 
Schmidt GS and Figueiredo EAP. 2009a. Effect of selection for productive traits in broiler male lines on embryo development. Brazilian Journal of Poultry Science. 11:17-20.

Shalev BA and Pasternak H. 1993. Increment of egg weight with hen age in various commercial avian species. Br. Poult. Sci. 34: 915-924.

Sharma A, Leea JS, Dang CG, Sudrajad P, Kim HC, Yeon SH, Kang HS and Lee S. 2015. Genome Wide Association Studies in Livestock - A Review. Asian Australas. J. Anim. Sci. 28(10): 1371-1379.

Shirali M, Varley PF, Jensen J. 2018. Bayesian estimation of direct and correlated response to genetic selection on linear or ratio expressions of feed efficiency in pigs. Genet Sel. Evol. 50:33. https://doi.org/10.1186/s12711018-0403-0.

Siegel PB and Dunnington EA. 1987. Selection for growth in chick- ens. CRC Crit Rev Poult. Biol. 1:1-24.

Simons AM and Roff DA. 1994. The effect of environmental variability on the heritabilities of traits of a field cricket. Evolution 48:1637-1649.

Singh SS, Verma SK, Khan AG, Shrivastava AK. 1989. Studies in genetic variability in juvenile body weight and sexual dimorphism in layer type chickens, Indian J. Poult. Scie.24 (4): 308-310.

Sinsigalli NA, McMurtry JP, Cherry JA and Siegel PB. 1987. Glucose tolerance, plasma insulin and immunoreactive glucagon in chickens selected for high and low body weight. J. Nutr. 117: 941-947.

Sorensen D, Wang CS, Jensen J, Gianola D. 1994. Bayesian analysis of genetic change due to selection using Gibbs sampling. Genetic Selection Evolution. 26:333360.

Tagirov M and Golovan S. 2015. Sexual Dimorphism in the Early Embryogenesis of the Chicken (Gallus Gallus domesticus). Molecular Reproduction \& Development. 82: 332-343.

Tallentire CW, Leinonen I and Kyriazakis I. 2016. Breeding for efficiency in the broiler chicken: A review. Agron. Sustain. Dev. 36:66. DOI 10.1007/s13593-0160398-2.

Thiruvenkadan AK, Prabakaran R, Panneerselvam S. 2011. Broiler breeding strategies over the decades: an overview. World's Poultry Science Journal. 67: 309336.

Thompson R, Brotherstone S, White IMS. 2005. Estimation of quantitative genetic parameters. Phil. Trans. R. Soc. B. 360:1469-1477.

Tickle PG, Paxton H., Rankin JW, Hutchinson JR, Codd JR. 2014. Anatomical and biomechanical traits of broiler chickens across ontogeny. Part I. Anatomy of 
the musculoskeletal respiratory apparatus and changes in organ size. PeerJ 2:e432 https://doi.org/10.7717/peerj.432.

Towne B, Seirvogel RM, and Blangero J. 1997. Effects of genotype by sex interaction on quantitative trait linkage analysis. Genet.Epidemiol. 14: 1053- 1058.

Tu X, Du S, Tang L, Xin H and Wood B. 2011. A real-time automated system for monitoring individual feed intake and body weight of group housed turkeys. Computers and Electronics in Agriculture. 75: 313-320.

UN (United Nations). 2015. World population projected to reach 9.7 billion by 2050 http://www.un.org/en/development/desa/news/population/2015 report.html. Accessed on 28-11-2018

Snell DM and Turner JMA. 2018. Chromosome Effects on Male-Female Differences in Mammals. Current Biology. 28: R1313-R1324.

Wei M, Van der Werf JHJ. 1994. Maximizing genetic response in crossbreds using both purebred and crossbred information. Animal Production. 59: 401-413.

Williams AG, Audsley E \& Sandars DL. 2006. Determining the environmental burdens and resource use in the production of agricultural and horticultural commodities. Main Report, Defra Research Project ISO205, Bedford, Cranfield University and Defra, available on www.silsoe.cranfield.ac.uk, and www.defra.gov.uk.

Willems OW, Miller SP, Wood BJ. 2013. Aspects of selection for feed efficiency in meat producing poultry. World's Poultry Science Journal. 69: 77-88.

Zhang H, Wang Z, Wang S, Li H. 2012. Progress of genome wide association study in domestic animals. J Anim. Sci. Biotechnol. 3:26.

Zhang SO, Mathur S, Hattem G, Tassy O, Pourquie O. 2010. Sex-dimorphic gene expression and ineffective dosage compensation of Z-linked genes in gastrulating chicken embryos. BMC Genomics. 11:13.

Zhao L, Wang G, Siegel P, He C, Wang H, et al. 2013. Quantitative genetic background of the host influences gut microbiomes in chickens. Scientific Reports. 1163. DOI: $10.1038 /$ srep01163.

Zuidhof MJ, Schneider BL, Carney VL, Korver DR, Robinson FE. 2014. Growth, efficiency, and yield of commercial broilers from 1957, 1978, and 2005. Poult. Sci. 93(12):2970-2982. 

Summary

\&

Sammendrag 



\section{Summary}

Growth rate (body weight) and feed efficiency have received greatest attention in the broiler industry due to their economic and environmental implications. Among the different strategies of improving growth rate and feed efficiency, selective breeding is optimal since its effect is cumulative and persistent over generations. Genetic selection has improved the growth rate and feed efficiency of broiler chickens in the last five or more decades. However, further genetic improvement in growth rate (body weight) and feed efficiency is essential due to the increasing human population, increasing global demand for cheap source of animal protein, increase in feed price and continued global environmental issue. In order to further improve the traits unravelling the genetic background of BW and FE traits in today's broilers is essential. Thus, the main objective of this thesis is to study the genetic background of BW and FE traits in broiler chickens using different statistical models and methods.

In chapter 2, multivariate REML analysis was employed to study genetic parameters of BW in male and female broiler chickens measured at three different ages. We have shown that in addition to direct genetic effects, maternal permanent environmental effects and residual environmental effects, BW in broiler chickens is influenced by sex by genotype interaction as well as age by genotype interaction. In chapter 3, Bayesian bivariate random regression model were used to study the effect of selection on genetic parameters of BW. It is shown that the genetic variance and heritability estimates of BW increased along a selection trajectory of 39 selection rounds, which is a remarkable finding relative to the animal breeding theory, which is known for quite some time stating a reduction in genetic variance as a result of long term selection. Moreover, the multivariate REML results obtained in chapter 2 were confirmed using the bivariate random regression model. In chapter $\mathbf{4}$, body weight, feed intake and body weight gain in males and females at two different ages were simultaneously analyzed in a multivariate Bayesian analysis and genetic parameters were estimated for the traits. Moreover, phenotypic RFI were derived using partial phenotypic regression coefficients while genetic RFI were derived using partial genetic regression coefficients in a one-step procedure inside the model. It is shown that FE traits are influenced by sex by genotype as well as age by genotype interaction in addition to other genetic and non-genetic effects. Genetic correlations between phenotypic and genetic RFI were high and close to unity at a younger age suggesting that selection using either of them in breeding programs will result the same genetic response at that specific age. In chapter $\mathbf{5}$, genome wide association study (GWAS) was conducted to identify quantitative trait locus (QTL) and candidate 
genes associated with BW and FE traits. Moreover, GWAS using mixed linear model (MLM) approach that takes in to account family structure and general linear model (GLM) approach that does not take family structure in to account were compared. As a result, several QTL regions and candidate genes associated with BW and FE traits were identified even if the broiler population were pre-selected for BW before the FE test and undergone several generations of selection for FE. Although there were overlaps, most of the identified QTLs for BW and FE traits were different in the MLM and GLM approaches, suggesting that statistical models in GWAS should be carefully chosen. Overall, the moderate heritability of BW and FE traits, the increase in genetic variance and heritability of BW along the selection trajectory and the identified QTLS and candidate genes associated with BW and FE traits after pre-selection and several generations of selection, respectively suggest that further improvement of the traits is possible through genetic selection. In chapter 6 (General discussion), the core findings of the four chapters of this thesis are summarized and integrated and the different statistical models and methods employed in the papers are discussed relative to other possible models and methods. Furthermore, the available information on literature about the major unintended consequences of improved growth rate and feed efficiency that can reduce performance and compromise animal welfare such as physiological, skeletal, reproductive, and immunological consequences are discussed. Finally, areas that can possibly be exploited to enhance further improvement in growth rate and feed efficiency of broiler chickens along with alleviating the unintended consequences of improved growth rate and feed efficiency are discussed. The knowledge gained in this thesis will contribute to the understanding of the genetic background of BW and FE traits in broiler chickens. Moreover, the results found and the statistical models employed in this thesis can be expanded to other poultry species with little modification. 


\section{Sammendrag}

Egenskaber som tilvækst (vægt) og foderudnyttelse har gennem mange år været de primære fokusområder for forbedring i fjerkræproduktionen på grund af den store $\emptyset$ konomiske og miljømæssige betydning af disse egenskaber. Mellem forskellige strategier til forbedring af tilvækst og foderudnyttelse er genetiske forbedringer optimale, da genetiske forbedringer er kumulative og bevares over generationer. Genetisk selektion har været anvendt til forbedring af tilvækst og foderudnyttelse gennem de sidste mere end 50 år. En fortsat genetisk forbedring af tilvækst og foderudnyttelse er dog stadig nødvendig på grund af den globalt stigende befolkning, stigende globalt behov for billig adgang til protein af animalsk oprindelse, stigende foderpriser, samt problemer med emission fra miljøskadelige stoffer fra produktionen. For at sikre en fortsat genetisk forbedring af disse egenskaber er det derfor af afgørende betydning at udvikle en bedre forståelse af den genetiske baggrund for tilvækst og foderudnyttelse i moderne kyllinger, der er specialiseret til $k \varnothing$ dproduktion. Derfor er hovedformålet med denne afhandling at studere den genetiske baggrund for tilvækst, vægt og foderudnyttelse i kyllinger ved anvendelse af forskellige statistiske modeller og metoder.

I kapitel II blev multivariate REML analyser anvendt til at studere genetiske parametre for vægt i kok- og hønekyllinger, som var vejet ved tre forskellige aldre. Analyserne viste at, ud over direkte genetiske effekter ved de tre vejealdre, var egenskaberne også påvirker af permanente maternelle miljømæssige effekter samt vekselvirkninger mellem genotype og $k \varnothing n$ og vekselvirkninger mellem alder og genotype. I kapitel III, blev en bivariat regressions model med tilfældige effekter anvendt til at studere effekten af genetiske selektion på kyllingers vægt. Analyserne viste at genetisk variation og heritabilitet for vægt steg i løbet af 39 selektionsrunder. Dette er særligt bemærkelsesværdigt da den genetisk teori siger at der skulle forventes en reduktion af den genetiske variation som følge af konstant genetisk selektion over lang tid. Derudover blev de resultater der blev fundet med den multivariate model bekræftet ved anvendelse af den bivariate regresionsmodel med tilfældige effekter.

I kapitel IV blev vægt, foderoptagelse og tilvækst i kok- og hønekyllinger analyseret i en såkaldt multivariat Bayesiansk analyse og genetiske varianser og ko-varianser blev estimeret for alle egenskaber. Testperioden for de analyserede kyllinger involverede to forskellige aldre da sluttidspunktet for testen var blevet nedsat på grund af den fortsatte genetiske forbedring i populationen. Den udviklede model blev anvendt til at udvikle genetiske parametre og avlsværdital for foderudnyttelse i form af residualfoderoptagelse. Residualfoderoptagelse blev defineret såvel fænotypisk som genetisk. Analyserne viste at foderudnyttelse, ud over direkte genetisk effekter, er påvirket af vekselvirkninger mellem $k \emptyset n$ og genotype og vekselvirkninger mellem alder og genotype og andre genetiske og ikke-genetiske 
effekter. Den genetisk korrelation mellem fænotypisk og genetisk residualfoderoptagelse var $h \emptyset j$ og tæt på 1.0 specielt når målingerne blev foretaget ved en yngre alder. Uanset hvilken af de undersøgte definitioner af residualfoderoptagelse, der anvendes i et avlsprogram så forventes der den samme effekt i form af genetisk fremgang.

I kapitel V blev hel-genom studier (GWAS) anvendt til at identificere gener eller kandidatgener med effekt på vægt og foderudnyttelse hos kyllinger. I analysen blev to forskellige statistiske metoder anvendt, en stokastisk model versus en generaliseret lineær model. Den stokastiske model tager hensyn til familiestrukturen i data, hvorimod dette ikke sker i den almindeligt anvendte generaliserede lineære model. Resultatet af analyserne var at flere gener eller kandidatgener, der var associeret med vægt og foderudnyttelse, blev identificeret selv om de anvendte kyllinger kom fra en avlslinje, som var selekteret for disse egenskaber gennem mange generationer. Der var et vist overlap mellem de gener der blev identificeret med de to metoder men fleste identificerede gener var forskellige afhængig af den anvendte statistiske metode. Dette viser at statistisk model og metode skal udvælges og testes omhyggeligt i studier hvor man søger at identificere individuelle gener.

Generelt så viser den moderate heritabilitet for tilvækst og foderudnyttelse, stigningen i genetisk variation som følge af selektion og de identificerede gener associeret med tilvækst og foderudnyttelse, at en fortsat genetisk forbedring af tilvækst og foderudnyttelse hos kyllinger i høj grad er mulig.

I kapitel VI (Generel Diskussion), bliver de vigtigste resultater fra de fire kapitler i denne afhandling opsummeret og diskuteret og de forskellige statistiske modeller og metoder, som er anvendt i de enkelte kapitler bliver også diskuteret i forhold til andre mulige modeller og metoder. De fundne resultater bliver sammenlignet med resultater fra litteraturen og sidstnævnte bliver yderligere anvendt til at diskutere mulige uønskede konsekvenser af øget tilvækst of foderudnyttelse der kan reducere frugtbarhed eller påvirke dyrevelfærd såsom fysiologiske, skeletale, reproduktive, og immunologiske $f \varnothing$ lgevirkninger. Dette følges af en diskussion af mulige tiltag, der kan implementeres for at undgå sådanne uønskede konsekvenser af genetisk forbedret tilvækst og foderudnyttelse.

Den viden som er opnået i denne afhandling vil bidrage til en bedre forståelse af den genetiske baggrund for tilvækst og foderudnyttelse i voksende kyllinger. De fundne resultater og de udviklede statistiske modeller og metoder kan let videreudvikles til anvendelse i andre fjerkræarter. 
Acknowledgement 



\section{Acknowledgement}

Above all, I would like to thank the Almighty God for blessing me in all aspects of my life and giving me the strength and courage to finish my PhD study. This PhD would not be possible without the help of a number of people and I would like to take this opportunity to thank them.

Just Jensen, I feel very fortunate to have you as my supervisor. You always had time to help me throughout my PhD no matter your tight schedule. Other than the weekly meetings, I knocked at your office whenever I had questions and you said "sure" and answered my questions. You make sure to give your comments/suggestions on my manuscripts on time, and if there were a little delay, you would tell me when you would expect to give me back. I am equally amazed with your professional ethics as much as I did on your academic skills. I learned a lot from you. Thank you so much. Henk Bovenhuis thanks a lot for arranging my stay in Wageningen and the enthusiastic discussions we have had during our meetings. Thank you so much for your very thoughtful comments/suggestions on my manuscripts. Per Madsen, you were not officially my supervisor, however, you contributed to my PhD no less than a supervisor. I run in to your office whenever I had difficulty in DMU, and you always had solution for my problems. Besides, you have been there whenever I needed your help in the discussions regarding my results. Thank you so much.

I would like to thank all of my co-authors for their contributions on my papers and researchers from Cobb-Vantress for their data and discussions we have had during our monthly meetings. I would like to thank all QGG friends and colleagues for the very good friendship and work environment. Particularly I would like to thank the late Karin, Louise and Elise who have helped me a lot at the start of my PhD and Hanne for all the help at all stages of my PhD. I would also like to thank former/current secretaries at QGG and Wageningen for all their help; Cindie, Tina, Birgit and Birgitte from QGG and Ada, Lisette and Monique from Wageningen, thanks a lot. I have shared office with a number of nice people at different times of my PhD in QGG and Wageningen. From QGG, Nuzul, Jane, Lise, Qianqian, Hadi and Thinh, thanks a lot for being such nice officemates. Special thanks goes to Hélène who had my back during my thesis writing. Thanks a lot Hélène, it was a pleasure sharing all those emotions with you. I have also shared a big office with many people in Wageningen which I cannot mention the long list here, but I would like to thank all, particularly Mandy for the very good time and the nice discussions we have had about science and life.

Back home, many people have helped me throughout my academic journey. I would like to thank my teachers and mentors at all levels of my education who have been helping me, encouraging me and believed in me. Particularly I would like to thank Azage Tegegne and Tadelle Dessie from ILRI for encouraging me, believing in me and 
helping me a lot at the start of my PhD. I would also like to thank friends I met in Wageningen, Alemye, Banchi, Engu, Kali, Mahi, Mahdi, Mikinay, Netsi, Sabi, Tigi, Tsiye, Yenu and many others for the very good time we have had; especially for taking care of me and my family during my maternity. Thank you so much ladies, you have no idea how you made my early weeks of maternity easier. My good friends, Takele and Gudetu, thank you so much for all the kindness you have shown me and my family, it really means a lot. My parents (the late Shibabaw Mebratie and Yeshihareg Alemu), sisters and brothers, thanks a lot for your unconditional love and encouragement. Last but foremost; I would like to thank my husband and best friend Alehegn ( $P_{b} \square-P_{-}$) for the love, care, patience, and encouragement throughout my $\mathrm{PhD}$ and most importantly for being a wonderful dad to our Daughter. My dear, I know that there is no "thank you" between us but I have to say it here; Thank you so much, I love you. My daughter Johannan ( $\mathrm{P}_{b} \mathrm{~d} \mathrm{~d}_{\mathrm{d}}$ ) ), You have been my energy for the last two years of my PhD. God has blessed me a lot in my life but the greatest blessing is you. I love you my precious. 
Curriculum vitae 



\section{About the author}

Wossenie Shibabaw Mebratie was born on 29 August 1983 in Bahirdar, Ethiopia. She completed her Bachelor of Science degree in Animal, Rangeland and Wildlife science in 2005 from Mekelle University, Ethiopia. Thereafter, Wossenie was employed by agriculture and rural development office as animal and forage production expert in district and provincial offices in Ethiopia, and worked mainly on training development agents and farmers about scientific animal husbandry and forage production practices that includes field demonstrations. In 2010, she received a scholarship funded by Swedish international development agency (SIDA) and joined Haramaya University, Ethiopia to study a Master of Science degree in Animal Breeding and Genetics. Her master's thesis entitled "Phenotypic Characterization of Harerghe highland Sheep and Production system in Eastern Harerghe Zone, Ethiopia" mainly focused on morphological characterization of indigenous sheep type and explored production and breeding practices, as well as production constraints in the study area. After receiving her master's degree in 2012, Wossenie was employed by International livestock research organization (ILRI), Ethiopia as an assistant researcher and worked mainly on compiling and organizing information on farm animal genetic resources in Africa. In 2013, Wossenie was awarded an Erasmus Mundus joint PhD scholarship under European Graduate School in Animal Breeding and Genetics ("EGS-ABG") program between Aarhus University, Denmark and Wageningen University, the Netherlands, which resulted this thesis. 


\section{Peer reviewed Publications}

1. Mebratie W, Reyer H, Wimmers k, Bovenhuis H, Jensen J. 2019. Genome wide association study of body weight and feed efficiency traits in a commercial broiler chicken population, a re-visitation. Sci. Rep. 9:922. Doi: 10.1038/s41598-018-37216-z

2. Mebratie W, Madsen P, Hawken R, Jensen J. 2018. Short communication: Multi-trait estimation of genetic parameters for body weight in a commercial chicken population. Livestock Science. 217, 15-18.

3. Mebratie W, Shirali M, Madsen P, Sapp RL, Hawken R, and Jensen J. 2017. The effect of selection and sex on genetic parameters of body weight in a commercial broiler chicken population. Livestock Science. 204, 78-87.

\section{Conference proceedings, abstracts and presentations}

1. Mebratie W, Bovenhuis $H$ and Jensen J. 2018. Estimation of genetic parameters for body weight and feed efficiency traits in a broiler chicken population using genomic information. Proceedings of the World Congress on Genetics Applied to Livestock Production, 11 (819).

2. Mebratie W, Madsen P, Shirali M, Hawken R, Jensen J. 2015. Genetic parameters of body weight at different stages of growth in male and female broiler chicken. Proceedings of the $66^{\text {th }}$ Annual Meeting of the European Federation of Animal Science, Warsaw, Poland.

3. Mebratie W, Shirali M, Madsen P, Hawken R, Jensen J. 2015. Genetic parameters of body weight in male and female broiler chicken at different stages of growth over time. Proceedings of the $9^{\text {th }}$ European symposium on poultry genetics, Tussula, Finland.

4. Romé H, Mebratie W, Hawken R, Henshall J, Jensen J. 2018. Choice of statistical model highly affects QTL detection in a commercial broiler line. $69^{\text {th }}$ Annual Meeting of the European Federation of Animal Science (EAAP). Dubrovnik, Croatia. 


\section{Individual Training Plan (ITP)}

\begin{tabular}{lcr}
\hline Mandatory courses (7 ECTS) & Place & Year \\
\hline Welcome to EGS-ABG & Addis Ababa & 2013 \\
EGS-ABG summer research school & Addis Ababa & 2013 \\
EGS-ABG summer research school & Wageningen & 2017 \\
Ethics in Animal Science & Wageninegn & 2019
\end{tabular}

Advanced Scientific courses (19 ECTS)

Introduction to statistical methods

SLU

2014

Introduction to genomic selection

Helsinki

2014

Advanced quantitative genetics

Helsinki

2014

Design of breeding programs with genomic selection

lowa

2015

Genomic prediction in livestock

lowa

2015

Professional Skills support courses (9.3 ECTS)

Academic English for PhD students

Foulum

2014

QGG Research skills

Foulum

2015

Introduction to ASReml

Wageningen

2017

Essentials of scientific writing and presenting

Wageningen

Knowledge dissemination

Teaching

Teaching assistance in Genetics course

$\mathrm{AU}$

2015

\section{International conferences}

The $11^{\text {th }}$ world conference on Genetics applied

Auckland

to Livestock production (WCGALP)

$66^{\text {th }}$ European society of animal science (EAAP)

Warsaw

2015

European poultry genetics symposium (EPGS)

Tussula

Seminars and workshops

MBG PhD conference

Denmark

2017

ECO-FCE meeting

Austria

2015

$2^{\text {nd }}$ GenSAP annual meeting

Denmark

2014

MBG annual meeting

Denmark

2013 



\section{Colophon}

The research described in this thesis was financially supported by the European commission within the framework of the Erasmus-Mundus joint doctorate program "EGS-ABG" and the ECO-FCE project funded by European Union Seventh Framework Program (FP7 2007/2013) under grant agreement No. 311794.

The data used in this study was obtained from Cobb-Vantress, USA, which is a poultry research company, engaged in the development, production and sale of broiler breeding stock.

This thesis was printed by Digisource, Viborg, Denmark. 
